\title{
PERSONAL, PROFESSIONAL, POLITICAL: AN EXPLORATION OF SCIENCE TEACHER IDENTITY DEVELOPMENT FOR TEACHING CLIMATE CHANGE
}

by

Andrea Drewes

A dissertation submitted to the Faculty of the University of Delaware in partial fulfillment of the requirements for the degree of Doctor of Philosophy in Education

Summer 2018

(C) 2018 Andrea Drewes

All Rights Reserved 


\title{
PERSONAL, PROFESSIONAL, POLITICAL: AN EXPLORATION OF SCIENCE TEACHER IDENTITY DEVELOPMENT FOR TEACHING CLIMATE CHANGE
}

\author{
by \\ Andrea Drewes
}

Approved:

Chrystalla Mouza, Ed.D.

Interim Director of the School of Education

Approved:

Carol Vukelich, Ph.D.

Dean of the College of Education and Human Development

Approved:

Douglas J. Doren, Ph.D.

Interim Vice Provost for the Office of Graduate and Professional Education 
I certify that I have read this dissertation and that in my opinion it meets the academic and professional standard required by the University as a dissertation for the degree of Doctor of Philosophy.

Signed:

Danielle Ford, Ph.D.

Professor in charge of dissertation

I certify that I have read this dissertation and that in my opinion it meets the academic and professional standard required by the University as a dissertation for the degree of Doctor of Philosophy.

Signed:

Zoubeida Dagher, Ph.D.

Member of dissertation committee

I certify that I have read this dissertation and that in my opinion it meets the academic and professional standard required by the University as a dissertation for the degree of Doctor of Philosophy.

Signed:

Chrystalla Mouza, Ed.D.

Member of dissertation committee

I certify that I have read this dissertation and that in my opinion it meets the academic and professional standard required by the University as a dissertation for the degree of Doctor of Philosophy.

Signed:

Kathryn Scantlebury, Ph.D.

Member of dissertation committee 


\section{ACKNOWLEDGMENTS}

This dissertation study was supported in part by a grant from the National Science Foundation Climate Change Education Partnership Program (NSF CCEP \#1239758). The MADE CLEAR (Maryland and Delaware Climate Change Education, Assessment, and Research) program sought to encourage climate scientists, teacher educators, learning scientists, science educators, and students to develop more comprehensive climate change education plans for our region. However, this study is not intended to be an evaluation of these efforts. I would like to thank the NSF and coprincipal investigator, Dr. Chrystalla Mouza, along with Dr. Jen Merrill and Pat Harcourt for their leadership and support to pursue this research study and to Dr. Nancy Brickhouse, Dr. Nicole Shea, and Dr. Joe Henderson for their expertise throughout the MADE CLEAR project. I also would like to express my appreciation to my MADE CLEAR colleagues on the Learning Sciences research team and K-12 professional development team for their collective guidance and moral support: Dr. Asli Sezen-Barrie, Dr. Randy McGinnis, Dr. Wayne Breslyn, Dr. Emily Hestness, Melissa Rogers, and Chris Petrone.

My doctoral program advisor, Dr. Danielle Ford, has generously shared her time and wisdom with me over the past few years, for which I am extremely grateful. I would also like to thank Dr. Zoubeida Dagher, Dr. Chrystalla Mouza, and Dr. Kate Scantlebury as members of my doctoral dissertation committee for their thoughtful guidance and meaningful feedback provided to me. The completion of this dissertation 
research was also supported through the generosity of the University of Delaware in the form of a dissertation fellowship award, for which I am extremely appreciative.

I am also grateful to the 15 science teacher participants who shared their time and genuine reflections on their climate change teaching experiences. I have learned so much from all these stories - thank you for trusting me with them.

Finally, a truly heartfelt thank you to my husband, Eric, for his extraordinary support and love throughout the challenges and successes we've experienced over the past few years. I would also like to especially thank my parents for their constant encouragement during the stressful times and the celebratory moments, as well as my extended family for the support that inspired me to preserve on this pathway. I am also eternally grateful to my sister-in-law Heidi, my parents, and my parents-in-law for their gifts of time, energy, and support to watch my son to enable me to have dedicated research and writing time. Lastly, thank you to my son, Tanner, who turned two years old only three days after the defense of this dissertation. Even though you are blissfully unaware of the crazy and exciting Ph.D. journey our family has been on, your enthusiastic joy and pure love have provided a respite and welcome distraction many times throughout this process. Thank you, I love you all! 


\section{TABLE OF CONTENTS}

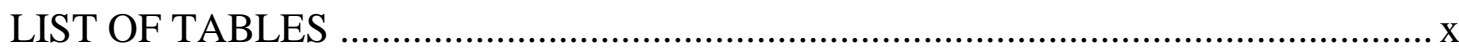

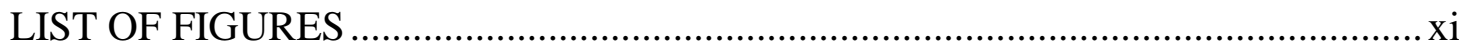

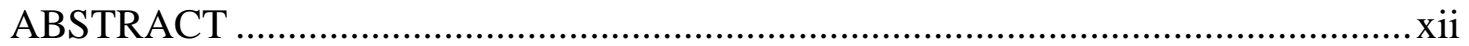

Chapter

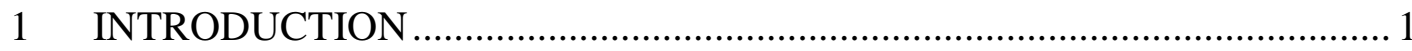

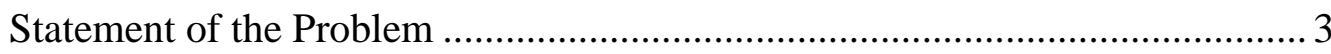

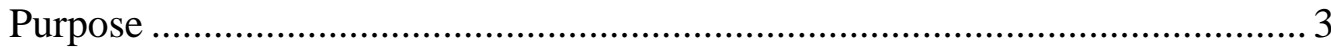

Theoretical Perspective ……………………………................................ 4

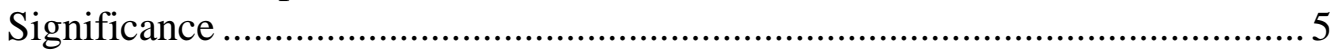

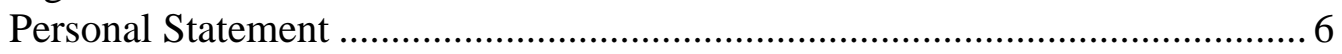

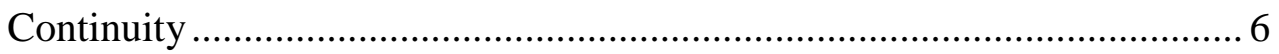

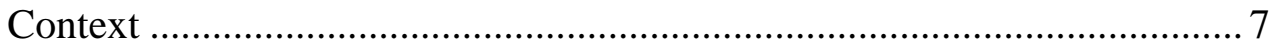

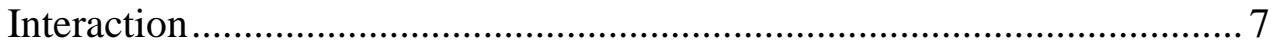

2 LITERATURE REVIEW AND THEORETICAL FRAMEWORK................... 9

Climate Change as a Pressing Environmental and Educational Topic.............. 12

Socioscientific Issues Based Education.............................................................. 17

Educational movements for scientific literacy ………………………....... 17

Socioscientific issues .......................................................................... 18

Benefits of SSI based education ........................................................... 18

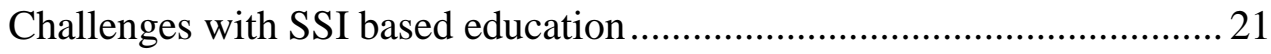

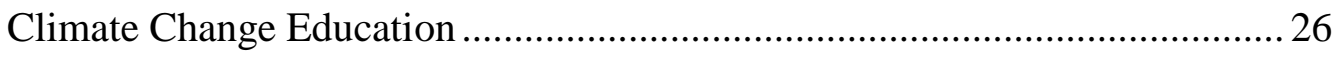

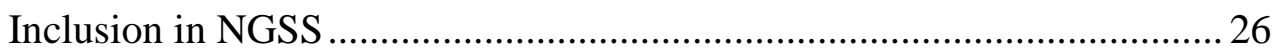

Educational benefits of climate change instruction .....................................22

Challenges with teaching climate change ...................................................2 27

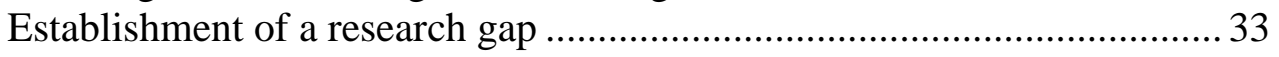

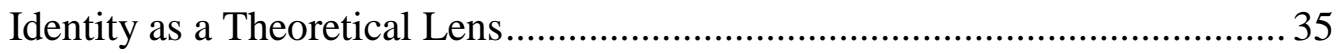

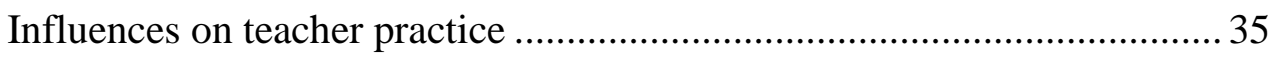


Identity models for educational research........................................... 37

Aspects of teacher identity .............................................................. 38

Studies of science teachers and professional identity...............................4 42

Specific types of science teacher identities .......................................... 48

Approaches for identity study ......................................................... 53

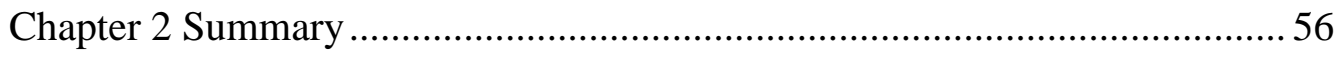

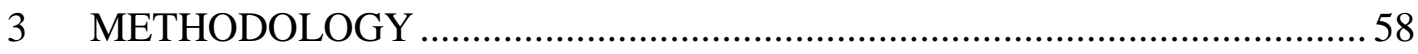

Justification for the Use of Qualitative Approach and Narrative Inquiry ........59

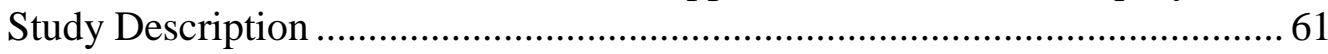

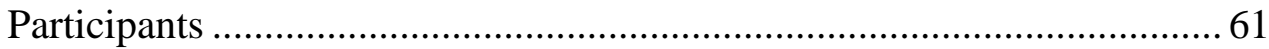

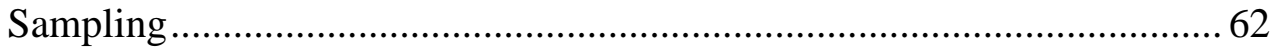

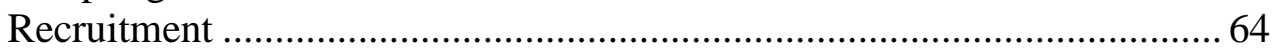

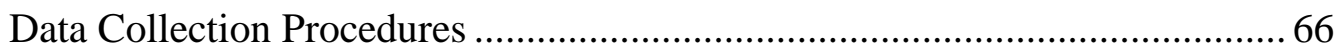

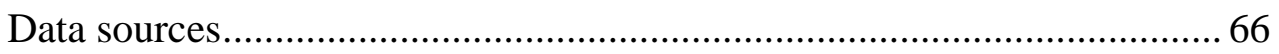

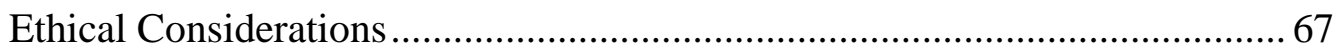

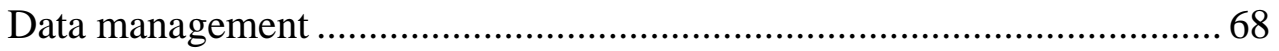

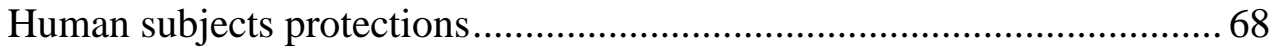

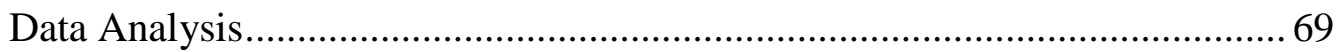

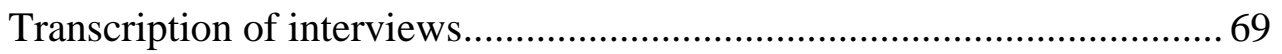

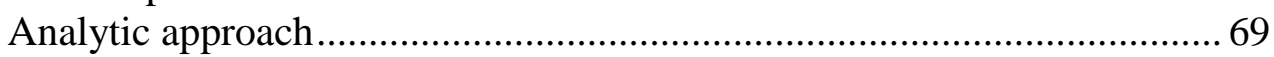

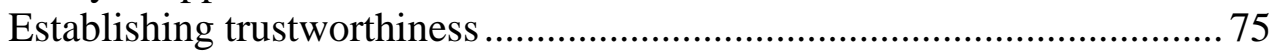

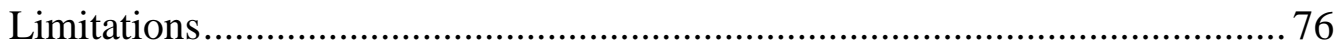

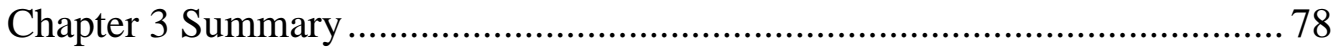

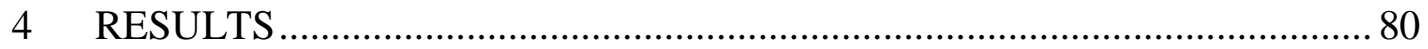

Section 1: Participant Characteristics ................................................... 80

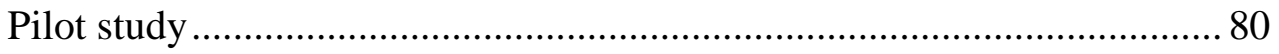

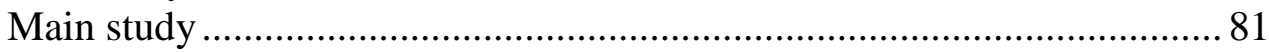

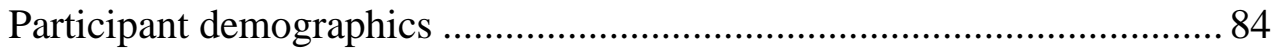

Section 2: Teacher Narrative Profiles............................................................. 85 
Amanda Kerry narrative profile ............................................................ 86

Barbara Pender narrative profile …………………………………….... 88

Beverley Sanders narrative profile ....................................................... 91

Connie Stevens narrative profile ……………………………………..... 93

Emily Skand narrative profile …………………………......................... 97

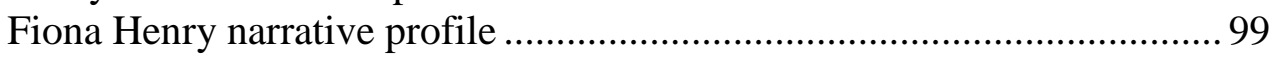

Fred Robbins narrative profile................................................................ 102

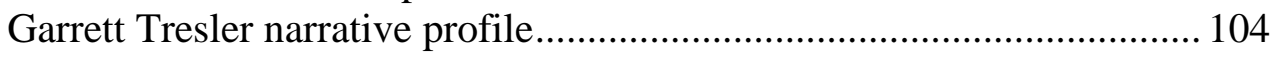

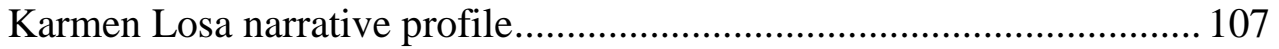

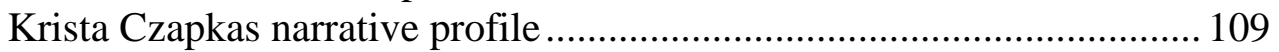

Mary Jenkins narrative profile.............................................................. 112

Melissa Eckerds narrative profile ........................................................ 115

Tara Thorpe narrative profile .............................................................. 118

Veronica Acker narrative profile......................................................... 122

Wanda Katz narrative profile ............................................................... 125

Section 3: Differences Within Teachers' Climate Change Experiences ........ 128

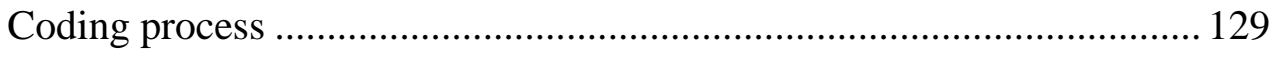

Section 4: Similarities Across Climate Change Teaching Experiences ......... 132

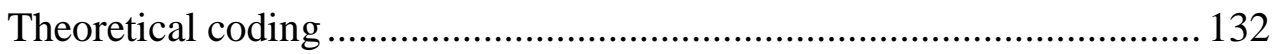

Process for code-weaving .................................................................... 133

Conceptual Model for Climate Change Teaching Identity....................... 134

Trend 1: Personal Valuation of Nature...................................................... 136

Trend 2: Experiences in Science Teaching and Learning ........................ 138

Trend 3: Teacher Instructional Agency .................................................. 141

Trend 4: Epistemic Evidence-Based Instruction ........................................ 141

Trend 5: Civic and Social Awareness via Socioscientific Literacy .......... 143

Section 5: Multifaceted Constructions of Teacher Identity for Climate

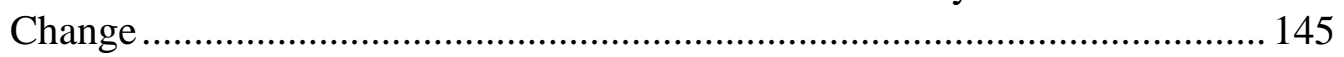

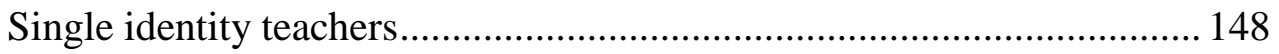

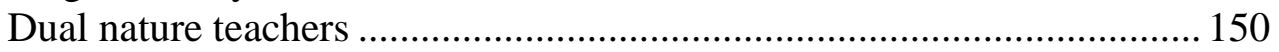

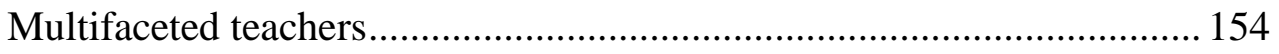

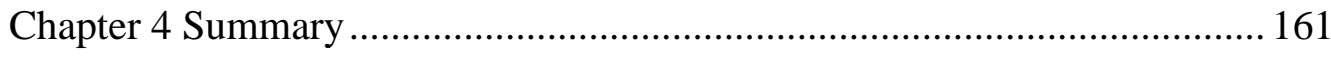

5 DISCUSSION AND IMPLICATIONS ...................................................... 162

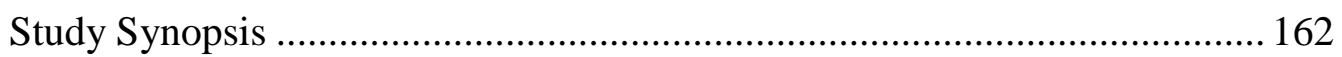

Discussion of the Main Research Findings .................................................... 164 
Modifications to an identity theoretical framework ............................. 166

Conflicting versus cohesive constructions of identity.......................... 172

Vital nature of instructional agency .................................................. 174

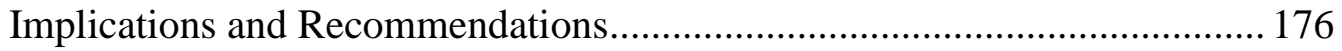

Climate change as SSI instructional approaches ................................... 176

Supporting CC as SSI instruction ......................................................... 180

Prioritization of climate change by educational policy ........................ 181

Educational research...................................................................... 182

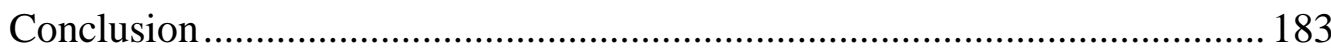

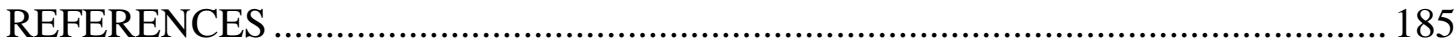

A INTERVIEW PROTOCOLS \& INSTRUMENTATION .............................. 208

B INSTITUTIONAL REVIEW BOARD DOCUMENTS ................................2 215

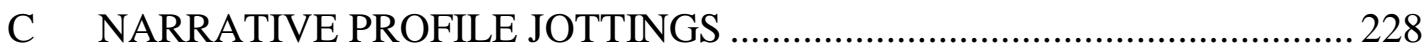

D CODING MANUAL - DESCRIPTIVE CODES …...................................2.258

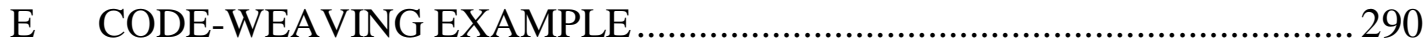




\section{LIST OF TABLES}

Table 1 Overview of Key Ideas Related to the Study ……………....................... 10

Table 2 Summary of Prior Studies on Perceptions of Teaching Climate Change .............................................................................................. 32

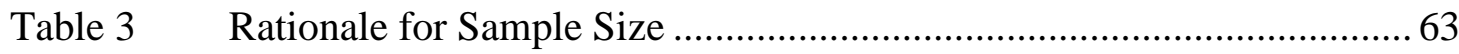

Table $4 \quad$ State Representation of Participants ........................................................ 82

Table $5 \quad$ Gender Representation of Participants ...................................................... 82

Table $6 \quad$ School Types of Participants ………………....................................... 83

Table $7 \quad$ Charter School Representation of Participants..........................................83

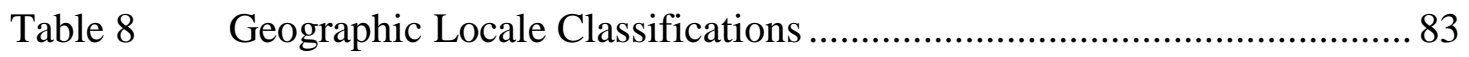

Table 9 Student Population Characteristics ........................................................... 84

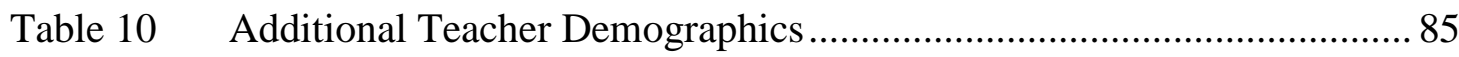

Table 11 Structural Codes and Code Frequency ………....................................... 129

Table 12 Emergent Codes and Code Frequency ………........................................ 131

Table 13 Personal, Professional, and Political Categorization of Descriptive

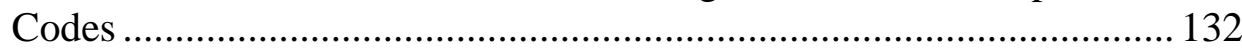

Table 14 Alignment of Elements, Predominant Trends, and Identity

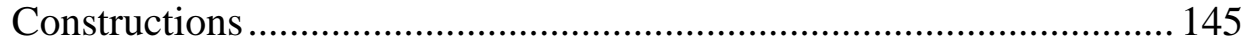

Table 15 Comparison of Identity Theoretical Frameworks.................................. 165 


\section{LIST OF FIGURES}

Figure 1 Conceptual Model for Climate Change Teaching .............................. 134

Figure 2 Conceptual Model Classified by Trend ............................................ 136

Figure 3 Trend 1: Personal Valuation of Nature............................................ 137

Figure 4 Trend 2: Experiences in Science Teaching and Learning .................... 139

Figure 5 Trend 3: Teacher Instructional Agency ..................................... 141

Figure 6 Trend 4: Epistemic, Evidence-Based Instruction ............................... 142

Figure 7 Trend 5: Civic and Social Awareness via Socioscientific Literacy ...... 144

Figure 8 Integrated Diagram of Identity Constructions ................................... 146

Figure 9 Combinations of Identity Constructions by Teacher .......................... 147

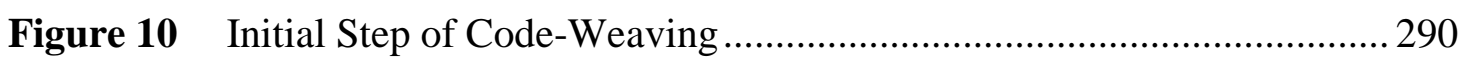

Figure 11 Final Step of Code-Weaving for Personal Elements .......................... 292 


\begin{abstract}
The purpose of this study is to investigate science teacher identity development as climate change educators. In applying the theoretical construct of identity as narrative to investigate the climate change related instructional experiences, I posed the overarching question: How do teachers' lived experiences shape their science teacher identity development as a 'teacher of climate change'?

I used qualitative narrative inquiry methods to examine professional and personal stories of science teachers and their descriptions of instructional enactment of climate change lessons. I described the ways in which teachers draw on aspects of their teaching identity to navigate the opportunities and challenges encountered while teaching this controversial and complex, yet critically important science topic. I collected empirical data to form insights regarding how teachers negotiate competing demands while planning, implementing, and reflecting on their instruction. Data sources included multiple interviews with each teacher and teacher reflections.

In analyzing the collected data, I determined how the identity narratives play a role in their enactment of climate change instruction. Results demonstrate how identity development for teaching climate change is embedded in one's personal histories, professional teaching and learning experiences, and the political context. Through this process, I developed a conceptual model to show how these lived experiences influence patterns of identity development through five trends: Personal Valuation of Nature; Experiences in Science Teaching and Learning; Teacher Instructional Support and Agency; Epistemic Evidence-based Instruction; and Civic and Social
\end{abstract}


Awareness via Socioscientific Literacy. The strength of enactment of these five trends leads to four possible constructions of identity. These four identities are: Passionate Environmentalist, Student Interest Engager, Content First Educator, and Civic \& Epistemic Skills Promoter.

The findings suggest that teacher identities for climate change are frequently multifaceted and these various identities are usually cohesive within an individual, but at times, they may present competing tensions for enactment. Additionally, this study demonstrates the critical need to support educators to strengthen their perceptions of instructional agency to effectively overcome challenges to the enactment of climate change lessons. Implications for teaching, teacher education, educational policy, and educational research related to climate change education and science teacher identity development are also presented. 


\section{Chapter 1 INTRODUCTION}

Climate change is an environmental issue that is a "defining challenge of our time" and a "common concern of humankind" as described by the United Nations (UN, 2014; 2015). Not only is it a challenging problem to address via individual and societal actions (IPCC, 2014) but quite simply it is a challenge even to understand the phenomenon at work and the far-ranging impacts on natural and human systems (IPCC, 2014).

Compounding the complexity of the climate change phenomenon, the scientific facts are too often twisted in political debate (Nisbet \& Mooney, 2007) leading to an even grander social controversy. Often referred to as climate change skeptics, the forces behind the manufactured misinformation and doubt (Oreskes \& Conway, 2010) are more accurately labeled as climate change denialists (Union of Concerned Scientists, 2007). These climate change deniers take advantage of the public's naïve understandings (Inman, 2012) and media sources' desire to discuss the phenomenon like an election with the false perception of balance from both supposed sides of the debate (Boykoff \& Boykoff, 2004) to create an air of uncertainty around scientific predictions and recommendations for climate change.

However, climate change has recently been included in the Next Generation Science Standards (NGSS, NGSS Lead States, 2013; Wysession, 2013) although educational researchers have studied student and teacher understanding of this topic for quite some time. Their conclusions are clear: developing a deep understanding of 
the causes and impacts of climate change is very difficult for students (Boyes \& Stanisstreet, 1993; 1997; Shepardson, Choi, Niyogi, \& Charusombat, 2011a) and their teachers (Boon, 2010; Herman, Feldman, \& Vernaza-Hernandez, 2015). Some of the obstacles for teaching and learning about climate change deal with its surrounding controversy (Andersson \& Wallin, 2000; Fortner, 2001), its abstract underlying phenomena (Koulaidis \& Christidou, 1999; Shepardson, Niyogi, Choi, \& Charusombat, 2011b), and its misconception-laden nature (Choi, Niyogi, Shepardson, \& Charusombat, 2010; Rye, Rubba, \& Wiesenmayer, 1997).

One approach to teaching climate change is to utilize a socioscientific issues based perspective which aims to consider the scientific and the moral or social aspects of the topic (Lester, Ma, Lee, \& Lambert, 2006; Zeidler, Sadler, Simmons, \& Howe, 2005) to develop content understanding in meaningful contexts (Bossér, Lundin, Lindahl, \& Linder, 2015; Mansour, 2010) and to improve critical thinking and scientific decision-making skills (Kolstø, 2001; Lee, Abd-El-Khalick, \& Choi, 2006) as teachers work to encourage scientific literacy in their students (Roberts, 2007). However, teaching in this manner has its own inherent complexities (Barrett \& Nieswandt, 2010; Wise, 2010) which challenge teachers to address the topic appropriately bracketed from their own bias (Kilinc et al., 2017; Sadler, Amirshokoohi, Kazempour, \& Allspaw, 2006). Teacher knowledge and teacher beliefs related to climate change vary broadly (Herman et al., 2017; Liu, Roehrig, Bhattacharya, \& Varma, 2015) and these constructs have frequently been used by science education researchers to describe and explain teaching practice (Kagan, 1992; Pajares, 1992). 
Yet these lines of research fail to address the whole teacher when studying attributes such as orientations, beliefs, attitudes or knowledge (Cooper \& Olson, 1996; Enyedy, Goldberg, Welsh, 2006; Friedrichsen, Van Driel, \& Abell, 2011; Mansour, 2013). Science teacher identity (Avraamidou, 2014a; Enyedy et al., 2006; Luehmann, 2007), is a theoretical perspective that can be employed to more adequately describe and understand teachers' experiences while enacting climate change instruction, and the personal, professional, social, political, and contextual factors which influence their pedagogical choices.

\section{Statement of the Problem}

Researchers' use of the constructs of teacher knowledge and teacher beliefs to examine instructional practice related to the socioscientific topic of climate change have identified many challenges in the implementation of climate change curricula. However, there is a need for greater insight into the successful enactment of climate change instruction and the teachers responsible for this enactment. Therefore, this study will examine the professional identities (composed of professional knowledge, personal narratives, and lived experiences) of science teachers who may identify as 'teachers of climate change'. Specifically, this study seeks to describe not only the lived experiences of climate change instruction, but also examine how components of their science teacher identity motivate them to include this topic and how they draw on their professional and personal resources to overcome challenges to enactment.

\section{Purpose}

The purpose of this study is to investigate and report on science teacher identity development as teachers of climate change. In applying the theoretical 
construct of identity as narrative to investigate the climate change related instructional experiences, I posed the overarching question: How do teachers' lived experiences shape their science teacher identity development as a 'teacher of climate change'? I use qualitative narrative inquiry methods to examine professional and personal stories of science teachers and descriptions of their instructional enactment of climate change lessons. I describe the ways in which teachers draw on aspects of their teaching identity to navigate the opportunities and challenges encountered while teaching this controversial and complex, yet critically important science topic.

I collected empirical data to form insights regarding how teachers negotiate the competing demands while planning, implementing, and reflecting on their instruction. Data sources include multiple interviews with each teacher and teacher reflections. My analysis focused on the interviews and reflections generated by the teachers and utilized the lens of narrative inquiry. In analyzing the collected data, I determined how the identity narratives of each teacher play a role in their enactment of climate change instruction realized through the narrative structure components of continuity, context, and interaction (Clandinin \& Connelly, 2000) and the contextual, relational, dynamic, and storied aspects of identity (Rodgers \& Scott, 2008).

\section{Theoretical Perspective}

The teacher identity as narrative framework allows the researcher to look beyond only knowledge and beliefs and more deeply into the dynamic, contextual, relational, and storied components of the lived experiences of teachers (Avraamidou, 2014b; Drake, Spillane, and Hufferd-Ackles, 2001; Rodgers \& Scott, 2008). Science teacher identity has been studied previously with an attentive eye to specific types of teachers (e.g., "reform-minded" - Luehmann, 2007; "science teacher leader" - 
Hanuscin, Cheng, Rebello, Sinha, \& Muslu, 2014) and I contend that this theoretical perspective is fruitful for the examination of the professional identities of teachers as 'teachers of climate change'. Specifically, I employed the Three-Dimensional Narrative structure (Clandinin \& Connelly, 2000) to explore the multifaceted dimensions of teacher identity.

\section{Significance}

This study provides insights into the instruction of climate change as a critically urgent environmental issue for our global society. There is a great need for timely educational action to prepare current and future citizens to combat and mitigate the harmful outcomes the world is already experiencing from climate change. Meaningful and effective climate change instruction is necessary to better educate and inspire a population to take this threat more seriously. Educators must be better prepared to teach this topic and to navigate the challenges and opportunities presented by this socioscientific issue in the classroom.

But first, we need to understand what teachers are already teaching, and why they currently implement such instruction based on their personal experiences and professional identities. This study sought a deeper understanding of how teachers are successfully integrating this topic, which has been labeled controversial in public discourse around science and education. The contribution of this research is to highlight the personal, professional, and pedagogical aspects that should be encouraged through teacher education efforts to enhance future implementation of climate change education. 


\section{Personal Statement}

I undertake this study while acknowledging my own lived experiences and those influences on my personal and professional identity. My "story to live by" has undoubtedly affected my approach and perspective on this topic. Much like in this study, for this section I find utility in Clandinin and Connelly's Three-Dimensional Narrative Space (2000) to examine my own positionality through Continuity (past, present, future), Interaction (relational and personal) and Context.

Continuity: Past - From my prior formal education I would describe myself as a multidisciplinary learner with an undergraduate chemistry education major, a biology minor, and a passion for environmental studies. This content knowledge training helped to demonstrate the interconnected nature of the broad field of science and encourages me to always look to understand and address science phenomenon through big picture approaches. Additionally, as a middle school science teacher, I saw firsthand the push and pull of the competing interests of the curriculum, administration, my students, and my own goals for teaching. More recently, as a professional development provider at the Bronx Zoo/Wildlife Conservation Society, I worked to advocate for important environmental issues of conservation, wildlife protection, and climate change and have personal experience in the difficult nature of this task.

Present - As a recent graduate research assistant for MADE CLEAR (Maryland and Delaware Climate Education, Assessment, and Research grant from the National Science Foundation), I have been heavily involved with former and current research efforts focused on climate change professional development. I have led teacher professional development sessions on climate change learning activities, NGSS and its three-dimensional science instruction and assessment, formative 
assessment techniques, and ocean connections to climate change. Additionally, I have worked closely with several climate professional development academy teachers to conduct classroom-based research on climate instruction and student learning outcomes. In conjunction with these research efforts, I assisted with the design and led the validation efforts on a climate change content assessment instrument. These research experiences have helped to fine-tune my eye to interesting climate change educational phenomena to observe and investigate.

Future - My future self and envisioned pathway is still yet to be written but I aim to be a reflective researcher in science education to better prepare teachers to meet the evolving challenges of practice. Keeping these professional goals in mind undoubtedly played a role in my methodological and analytic choices. Also, I continually reflected on my strong personal moral warrant related to the imperative need for society to do more to combat and mitigate the negative impacts of climate change. I hope for a future tomorrow in which I had some positive influence on education related to this pressing societal challenge.

Context - I highlight the context in which I conduct this work. I am currently positioned within the MADE CLEAR grant and my familiarity with the project and the participating teachers from professional development and prior research efforts influenced the choices I made. My comfort with this context also allowed me to take advantage of situational opportunities to engage more fully with participant teachers across multiple settings.

Interaction: Personal - Additionally, I recognize my personal experience of feeling like I have valuable experiences and stories to share of my time as an educator. I believe that too often teachers are shut out from the research process and their 
inherent expertise is ignored at best but disregarded at worst. I admit my own goal is to rectify this issue through a narrative focus on the lived experiences of the teachers in my study.

Social - Lastly, the relational and social aspects of my research context are especially important. Reifying the perspectives and intentions behind teachers' public practice through meaningful conversations with others drives my own research passion. Developing those relationships and experiencing the stories of others is both exciting and important to me professionally and for these research goals. 


\section{Chapter 2}

\section{LITERATURE REVIEW AND THEORETICAL FRAMEWORK}

In my study, I explore how science teachers' lived experiences influence their identity development as a 'teacher of climate change'. I preface this work with a review of related literature divided into four sections. First, I briefly introduce climate change as an imperative environmental problem, as well as a pressing educational issue. In the second section, I review the science education literature on socioscientific issues (SSI) based education. I describe the benefits and challenges that teachers report related to the enactment of this instructional approach to science. In the third section, I dive more deeply into socioscientific issues education to specifically explore the topic of climate change as a socioscientific issue topic for instruction. I describe the outcomes from the body of work related to teachers' perceptions, beliefs, and reflections regarding teaching climate change. While there are numerous studies investigating the beliefs of science teachers, exceptionally few have employed the theoretical lens of identity. Therefore, in section 4 , I turn to an examination of the educational research literature on the development of professional teaching identities, science teacher identities, and specific types of science teacher identities. In this section, I show the inadequacy of a beliefs or a knowledge perspective and justify my theoretical choice of an identity framework. In concluding this chapter, I review the literature related to the most prevalent methodological choices employed to examine teacher identity and the storied experiences of teachers: narrative research. I highlight the connections between this methodological approach and the prior literature 
reviewed to justify the need for my research study. In the following chapter, this attention to methodology will continue as I present my current study and its inquiry into the development of science teacher identities as 'teachers of climate change'. Table 1 below provides a summary of the key ideas presented from the research literature.

Table 1 Overview of Key Ideas Related to the Study

\begin{tabular}{|c|l|}
\hline Section 1 - I will: & \\
\hline $\begin{array}{l}\text { Introduce climate change as a } \\
\text { pressing, global environmental } \\
\text { issue }\end{array}$ & $\begin{array}{l}\text { Key Idea: Climate change is a } \\
\text { phenomenon that is negatively influencing } \\
\text { Earth currently and will continue to do so } \\
\text { with greater impact in the near future. } \\
\text { While this issue is conceptually complex, } \\
\text { the scientific evidence is clear on the } \\
\text { harmful role of humans despite a } \\
\text { perceived controversy. Science education } \\
\text { offers a possible pathway for better } \\
\text { engaging learners to combat this pressing } \\
\text { environmental issue. }\end{array}$ \\
\hline $\begin{array}{l}\text { Describe the instructional } \\
\text { approach of socioscientific issues } \\
\text { (SSI) based instruction }\end{array}$ & $\begin{array}{l}\text { Key Idea: SSI offer a specific instructional } \\
\text { style that encourages teachers to take on } \\
\text { the ethical as well as the scientific aspects } \\
\text { of issues facing society, such as nuclear } \\
\text { energy or genetic testing. }\end{array}$ \\
\hline $\begin{array}{l}\text { Examine how the science } \\
\text { education research community } \\
\text { has explored the perceptions of } \\
\text { science teachers who enact SSI } \\
\text { based education }\end{array}$ & $\begin{array}{l}\text { Key Idea: } \text { Prior research shows that SSI } \\
\text { based education offers a meaningful and } \\
\text { relevant context for learning and } \\
\text { developing decision-making skills through } \\
\text { scientific literacy. Yet it also presents } \\
\text { challenges for teachers who are hesitant to } \\
\text { engage their students in topics that may be } \\
\text { politically, religiously, or socially charged } \\
\text { i.e. cloning or genetically modified } \\
\text { organisms). }\end{array}$ \\
\hline
\end{tabular}




\begin{tabular}{|c|c|}
\hline \multicolumn{2}{|l|}{ Section 3 - I will: } \\
\hline $\begin{array}{l}\text { Provide an overview of the need } \\
\text { to address climate change in } \\
\text { science instruction }\end{array}$ & $\begin{array}{l}\text { Key Idea: Climate change is often used as } \\
\text { relevant SSI for instruction, but frequently } \\
\text { it is presented without the ethical } \\
\text { considerations typified by true SSI based } \\
\text { approaches. Climate change is } \\
\text { experiencing wide recognition as a } \\
\text { pertinent concept for science instruction } \\
\text { due to its new inclusion in the Next } \\
\text { Generation Science Standards and as a } \\
\text { popular topic in media and society. }\end{array}$ \\
\hline $\begin{array}{l}\text { Review the prior work regarding } \\
\text { how teachers perceive, prepare, } \\
\text { experience, and reflect on climate } \\
\text { change instructional enactment in } \\
\text { a variety of settings and through } \\
\text { diverse research methods }\end{array}$ & $\begin{array}{l}\text { Key Idea: Research on teachers' } \\
\text { knowledge and instructional beliefs on } \\
\text { climate change show varied perspectives } \\
\text { of the opportunities and hazards presented } \\
\text { by the inclusion of this topic in their } \\
\text { teaching. Many science teachers do teach } \\
\text { the topic but show concerns regarding the } \\
\text { controversial nature, feelings of low self- } \\
\text { efficacy and confidence to teach this } \\
\text { topic. Internationally, research efforts } \\
\text { have frequently employed qualitative } \\
\text { methods, but domestically the } \\
\text { predominant approach has been } \\
\text { quantitatively driven, large-scale surveys } \\
\text { and self-reports of teacher beliefs and } \\
\text { instructional enactments. }\end{array}$ \\
\hline \multicolumn{2}{|l|}{ Section 4 - I will: } \\
\hline $\begin{array}{l}\text { Highlight the previous research } \\
\text { efforts to describe influences on } \\
\text { teaching practice through teacher } \\
\text { knowledge, beliefs, emphases, } \\
\text { orientations, and attitudes }\end{array}$ & $\begin{array}{l}\text { Key Idea: Past efforts clearly show that } \\
\text { many factors influence teaching practice } \\
\text { (such as knowledge, beliefs, and teaching } \\
\text { orientations). However, these approaches } \\
\text { are limiting in the overwhelming focus on } \\
\text { either what a teacher does with their } \\
\text { knowledge and skills, or the resiliency of } \\
\text { teacher beliefs even counter to } \\
\text { development efforts. }\end{array}$ \\
\hline $\begin{array}{l}\text { Introduce the theoretical } \\
\text { perspective of professional } \\
\text { identity }\end{array}$ & $\begin{array}{l}\text { Key Idea: Identity is a multifaceted } \\
\text { construct that more readily encompasses } \\
\text { not only the thoughts and actions of the } \\
\text { teacher, but also the complexity of } \\
\text { teachers' lived experiences both } \\
\text { professionally and personally. }\end{array}$ \\
\hline
\end{tabular}




\begin{tabular}{|l|l|}
\hline $\begin{array}{l}\text { Review the recent literature to } \\
\text { describe both the theoretical and } \\
\text { empirical work completed to } \\
\text { explore the development of a } \\
\text { science teacher identity in } \\
\text { preservice and in-service teachers }\end{array}$ & $\begin{array}{l}\text { Key Idea: A number of science education } \\
\text { researchers have adopted science teacher } \\
\text { identity as a lens for their work to better } \\
\text { understand the many influences on teacher } \\
\text { development and teacher practice. }\end{array}$ \\
\hline $\begin{array}{l}\text { Describe the prior applications of } \\
\text { the science teacher identity lens } \\
\text { towards specific types of science } \\
\text { teachers }\end{array}$ & $\begin{array}{l}\text { Key Idea: More recently, science } \\
\text { education researchers have begun to } \\
\text { classify more specific types of identity in } \\
\text { science education (e.g., reform-minded or } \\
\text { teacher leaders) to examine novel } \\
\text { instructional practices. }\end{array}$ \\
\hline $\begin{array}{l}\text { Present a synopsis of the } \\
\text { methodological approaches that } \\
\text { are often utilized to study science } \\
\text { teacher identity }\end{array}$ & $\begin{array}{l}\text { Key Idea: Most researchers find merit in } \\
\text { qualitative research methods with a } \\
\text { specific focus on narrative inquiry, life } \\
\text { history, or storied experiences through } \\
\text { interviews to study identity. }\end{array}$ \\
\hline $\begin{array}{l}\text { Argue the appropriateness of } \\
\text { using narrative methods to study } \\
\text { the relationship between science } \\
\text { teacher identity and the } \\
\text { experiences of climate change } \\
\text { instructional enactment }\end{array}$ & $\begin{array}{l}\text { Key Idea: Science teachers may be shaped } \\
\text { by components of their identity long } \\
\text { before entering the classroom. This } \\
\text { identity may continue to influence and be } \\
\text { influenced by their lived experiences of } \\
\text { climate change instruction. Better } \\
\text { understanding this relationship could } \\
\text { positively influence the preparation of } \\
\text { science teachers and future enactment of } \\
\text { climate change instruction. }\end{array}$ \\
\hline
\end{tabular}

\section{Climate Change as a Pressing Environmental and Educational Topic}

Climate change is already impacting human and ecological systems globally (U.S. Global Change Research Program, USGCRP, 2014) and the 5th IPCC (Intergovernmental Panel on Climate Change) report is clear in attributing these changes to anthropogenic emissions of greenhouse gases (2014). The global warming of our natural systems is "unequivocal" and "many of the observed changes are 
unprecedented over decades to millennia" (IPCC, 2014, p. 18). Researchers and scientists are hardly mincing words over the seriousness of the situation when describing this environmental issue as "a key problem of our epoch" (Klafki, 2000 in Feierabend, Jokmin, \& Eilks, 2011, p. 85), “a pressing concern” and a "grand challenge" (Crowley, 2000 in Liu et al., 2015, p. 1) and an urgent, scientifically complex, and socially challenging environmental issue (IPCC, 2014; USGCRP, 2014).

Research scientists state that humans and our greenhouse gas emissions are "extremely likely" to be the dominant cause of the rise in temperature (IPCC, 2014, p. 20). The controversy in the science is no longer whether climate change is happening, nor even if humans are causing it. Instead, the focus now is what can, and should humans do to mitigate the impacts of anthropogenic climate change.

While the scientific community is more resolute in the attribution of global temperature rises to anthropogenic causes and has reached an all-time high of $97 \%$ agreement (Cook et al., 2016), the general public unfortunately remains doubtful at times (Ding, Maibach, Zhao, Roser-Renouf, \& Leiserowitz, 2011; Leiserowitz, Maibach, Roser-Renouf, Rosenthal, \& Cutler, 2017). Despite the confident conclusions produced by climate scientists (IPCC, 2014) climate change looms large as a disputed partisan issue through intentional deception (Oreskes \& Conway, 2010) and manufactured skepticism of the evidence for anthropogenic climate change (Van Rensburg, 2015). "The politics has gotten worse, even as the body of knowledge has expanded and improved" (Sarewitz, 2011, p. 7). The pervasive and contentious nature of the debate on the causes and predicted outcomes of climate change has brought discord along partisan and ideological lines and apathy towards the issue (Dunlap \& McCright, 2011; Kahan et al., 2012; Nisbet, 2009; Stevenson, Peterson, Bondell, 
Moore, \& Carrier, 2014). These cultural and political debates have entangled science educators working to address this pressing issue (Kunkle \& Monroe, 2018) leaving many teachers and students questioning what is truly known.

This confusion and uncertainty are partially understandable due to the manufactured misinformation campaign (McCright \& Dunlap, 2011; Oreskes \& Conway, 2010) on top of the incredible complexity of the scientific phenomenon in its causes and impacts, and in how to mitigate or adapt to an already changing planet. Developing a climate understanding, or a climate literacy, encompasses having a working knowledge of the basics of these concepts (USGCRP, 2009). Working from an earlier version of the IPCC report (2007) and the USGCRP document (2009), Wise (2010) describes climate literacy as "understanding how people influence climate and in turn how the climate influences people.” This simple sentence masks the inherently complicated nature of the relationship between humans and climate systems (Wise, 2010).

Learning about climate change is cognitively challenging due to the abstract and highly interconnected earth systems involved. But what makes this topic even more confounding is the purposeful efforts of some to disparage and deny the scientific consensus, including parents and school community members (Colston \& Ivey, 2015). Additionally, the National Center for Science Education (NCSE) reports on the deliberate efforts of anti-science and climate denial campaigns to artificially create a perception of controversy and doubt surrounding the scientific evidence supporting anthropogenic climate change (NCSE, 2012). The presence of such antiscience campaigns positions the science classroom as a battleground and raises important questions about how to approach this topic in the midst of the controversy 
(Colston \& Ivey, 2015). The widespread influence of the anti-science climate denial efforts can be plainly seen in the opinions and pedagogical practices of some science educators (Meehan, 2012; Plutzer et al., 2016) to teach 'both sides' of the issue. But other more covert impacts from the climate change denial and misinformation campaigns are found in numerous science textbooks where climate change messages "more closely match the public discourse of doubt about climate change rather than the scientific discourse” (Román \& Busch, 2016, p. 1175).

The issue of misrepresentation to build up the claims of controversy deepens the complex nature of the topic and creates an uneasy educational experience. Yet it also could offer opportunities to discuss accurate interpretations of evidence and to appropriately apply a skeptical science mindset (Lambert \& Bleicher, 2014). Another possible opportunity is that while many American adults are culturally polarized by their political ideologies (Kahan et al., 2012), a recent study has shown that adolescents may be less susceptible to these partisan worldviews and are learning climate change information from reliable, scientifically accurate sources (Stevenson et al., 2014). These realities leave teachers positioned on the precarious, yet critical, leading edge of the efforts to build climate literacy in students (Boon, 2010).

Sullivan, Ledley, Lynds, and Gold (2014) describe classrooms as "a microcosm of society" (p. 550) and the same obstacles and uncertainties that are faced by research scientists towards educating the general citizenry are also experienced by climate change educators. The same misconceptions found in the public are found inside the science classroom - both in the minds of the students and the teachers (Monroe, Oxarart, \& Plate, 2013). Some climate change educational efforts have attempted to use these pseudo-scientific claims as agnotological tools to study how 
and why people should be wary of climate change denialist arguments (Bedford, 2010; Sezen-Barrie, Shea, \& Borman, 2017). Yet these approaches are uncommon and the pervasiveness of the uncertain or skeptical arguments presented by popular media, along with the partisan and ideological debates (Wibeck, 2014) have profound impacts on how learners interact with the climate change phenomenon.

Because many of these issues, climate change education is "currently not as successful as it needs to be" (Rickinson, 2001 as cited in Feierabend et al., 2011, p. 86). But still, science education remains a critical component in developing a knowledgeable society that is prepared to deal with the consequences and to determine solutions within this global climate change era (Sharma, 2012; Sullivan et al., 2014).

Research is needed to better understand this vital responsibility placed on teachers regarding their instruction and their perspectives towards this important and timely issue (Liu et al., 2015). This research study aims to gather these perspectives and to meet Colston and Ivey's call for more research into the lived experiences of science educators as they "understand, incorporate, and negotiate the implementation of climate change education in the face of such public controversy about climate change" (2015, p. 774).

This section reviewed the current literature on climate change as a critically important environmental issue that requires our attention both as a politicized societal problem and as an educational opportunity. In the next section, I introduce one pedagogical strategy that science teachers may employ to address climate change: socioscientific issues-based instructional approach which incorporates socially relevant, science focused concepts into the classrooms by considering both the scientific phenomenon and the ethical aspects of the topic. 


\section{Socioscientific Issues Based Education}

The phenomenon of climate change could be taught as a purely factual topic with little recognition of the roles that humans have played in the creation of this issue, no acknowledgment of the deleterious impacts on humans around the world, and no discussion of how humans could create innovative solutions to mitigate or adapt to this issue. It could be taught in an exceedingly straightforward manner like a traditional lecture devoid of the social implications. But it shouldn't be. To fully understand this environmental issue, teachers need to demonstrate how humans are unquestioningly connected to climate change causes, impacts, and hopeful solutions (Drewes, Henderson, \& Mouza, 2018). The social human aspects must be incorporated alongside the scientific components. Within climate change instruction, the integration of both is critical when examining climate change as an educational socioscientific issue.

Educational movements for scientific literacy. Socioscientific issues education is the reinterpretation of earlier Science-Technology-Society (STS) and Science, Technology, Society, Environment (STSE) approaches to developing more than just science literacy (vision I), but also scientific literacy (Roberts, 2007). By integrating societal connections to science topics, STS made science instruction more interesting and relevant (Zeidler et al., 2005). However, when also bringing in a consideration of the ethical aspects to a science concept found in society, socioscientific issues education aims to develop students' scientific decision-making skills that include a judgment of morality as well (Zeidler et al., 2005). When teachers avoid addressing the ethics of socioscientific issues, they miss opportunities for their students to develop an awareness of the connections between science and society (Ekborg, Ottander, Silfver, \& Simon, 2013; Zeidler et al., 2005). While I do not 
disagree that there is a critical distinction between SSI and STS/STSE, in the following literature review, I group these approaches together for clarity's sake.

Socioscientific issues. Socioscientific issues have a conceptual connection to science, are socially significant, and typically are contentious in nature without a simple solution (Forbes \& Davis, 2008; Sadler, 2004). When learning about a socioscientific issue, students need to examine their own content understandings and personal ethics to deal with the moral consideration as well as the ambiguous nature of the issue (Sadler et al., 2006; Sadler \& Zeidler, 2005).

Socioscientific issues teaching requires a pedagogical approach that is quite different from traditional science instruction, and even from reform-oriented inquiry perspectives as well (Zeidler \& Nichols, 2009). But research has demonstrated that socioscientific issues education can offer gains in content knowledge; serve as an effective context for learning; are a way to develop citizenship and scientific literacy; enthuse students to be motivated to learn about personally relevant science ideas; and empower student decision making in everyday life (Evagorou, Guven, \& Mugaloglu, 2014).

Benefits of SSI based education. Teachers and researchers recognize the value of socioscientific issues instruction for the development of today's students and tomorrow's citizens who need to learn how to evaluate their own values and personal philosophies in the context of science issues through a reform-oriented, humanistic approach (Cross \& Price, 1996; Lee \& Witz, 2009). This coherence between teacher's goals and reform efforts allows for the enhancement of student learning in several specific outcomes: creating a meaningful context for science learning and nurturing the development of scientific decision-making skills. 
Meaningful contexts. Most notably, socioscientific issues education offers a personally relevant and societally meaningful context for science teaching and learning. Socioscientific issues education requires students to make explicit connections between their lives outside of school and the science content under examination within the classroom (Barrett, 2008; Mansour, 2010). They have the "potential to build a bridge between school science and the students' lifeworlds" (Bossér et al., 2015, p. 160).

Some teachers are still uncertain how to develop this hybrid context for learning in an appropriate manner, and others often pay lip service to this benefit of socioscientific issues without following through to enact instruction that fully engages the controversial and ethical components (Barrett, 2008; Bryce \& Gray, 2004; Forbes \& Davis, 2008; Van Rooy, 1999). These challenges to socioscientific issues instruction will be addressed more fully in the next subsection.

Decision-making skills. Teachers readily acknowledge the value of this approach for the development of student critical thinking and decision-making skills. Socioscientific issues education allows students to evaluate their own positions while interacting with other learners to critique the evidence and arguments connected to dissimilar views (Bossér et al., 2015; Lee et al., 2006). Through the experience of socioscientific issues driven instruction, students can engage with the uncertainty and complexity of the topic while also being open-minded to consider multiple approaches and various possible solutions (Zeidler \& Keefer, 2003). Building decision making skills through civic participation in education is intertwined with values, action, and an inherent politicization (Pedretti, Bencze, Hewitt, Romkey, \& Jivraj, 2008), though at 
times (e.g. Barrett, 2008; Lee \& Witz, 2009) there is not always alignment between these aims of socioscientific issues instruction.

Teachers' goals for socioscientific issues instruction don't always align with the goals that reformers and researchers have for these pedagogical methods. Lee and Witz (2009) developed detailed case studies of four science teachers regarding their connections to teaching socioscientific issues. They found that these teachers began teaching socioscientific issues because of their own personal beliefs, commitments, and motivations as opposed to teaching socioscientific issues as a response to science education reform movements. The teachers reported that they were personally committed to teaching these controversial topics and to incorporating the ethical and social nature of science. One drawback of this personal motivation instead of curricular mandate is that "they all developed their own teaching goals for socioscientific issues, not limited to learning scientific knowledge on the issues; they formed their own ideal pictures of their students' overall growth, including their intellectual competency, decision-making skills, attitudes as democratic citizens, and to some degree, proactivity and political actions, and self-reflection" (Lee \& Witz, 2009, p. 956).

Gardner and Jones similarly explored how the framings utilized by university teaching assistants varied even in spite of the identical nature of the available teaching resources during an undergraduate course (2011). Furthermore, upon interviewing the instructors it became clear to Gardner and Jones that these various framings diverged greatly from the collectively espoused beliefs related to the importance of socioscientific issues and the values of individuals as agents of change. This disconnect was clear between the instructors' perceptions and pedagogical practice. 
This lingering disconnect begins to demonstrate the challenging nature of socioscientific issues education in several studies (Gardner \& Jones, 2011; Levinson, 2006). These studies highlight the critical need for research attention and curricular reform efforts to more fully consider teacher perspectives and their values, beliefs, and goals for controversial science education approaches.

Challenges with SSI based education. Obstacles are usually expected in new science curriculum efforts and socioscientific issues-based approaches offer no exception with a broad range of factors that may impede the translation from curriculum into practice (Lee et al., 2006). Even when teachers are highly motivated to incorporate these approaches, challenges can be numerous (Reis, 2014). They include: the multi- and interdisciplinary nature of the topics which may 'dilute' the 'true' science content; concerns about personal influences and 'indoctrination' of the students; a lack of professional development on guiding ethical and moral discourse; and minimal curriculum options and science standards that explicitly include socioscientific issues along with the difficulty of adding more to an already full curriculum. In the next subsections, I will review the research related to teachers' perceptions of these difficulties in more detail.

Multifaceted nature. Socioscientific issues do not just present a simple twosided debate. Instead, they are composed of a diverse grouping of perspectives from which to address the issue, including political, cultural, ethical, and economic factors (Gayford, 1998). Frequently teachers express concern towards the need to 'teach both sides' but this is a drastic simplification of the ambiguous and multifaceted perspectives found within socioscientific issues (Cross \& Price, 1996; Oulton, Day, Dillon, \& Grace, 2004; Sadler et al., 2006). 
Because there are numerous angles to consider in socioscientific issues instruction, some teachers view these approaches as a dilution of the discipline specific content in which they hold dear. Mitchener and Anderson (1989) investigated teacher beliefs on their curriculum and the reasons behind different enactment strategies. They identified several groups of teachers according to their approaches towards an adopted STS curriculum: those who accept, those who alter, and those who reject. Many teachers felt a strong reliance on their role as an expert information provider and may hesitate to incorporate a student-driven curriculum where student interest and questions could derail or undermine the teachers' traditional lectures or content knowledge focused instruction. The authors conclude that without consideration of teachers' beliefs, value systems, and perceptions, any reform efforts to integrate theory into practice "are in vain" (Mitchener \& Anderson, 1989, p. 358) and ought to better incorporate teachers' beliefs. A similar idea is found whereby the teachers report concerns that the interdisciplinary and wide-ranging socioscientific issues approaches devalue the traditional science curriculum (Hughes, 2000) and are less content focused in a high-stakes testing world (Pedretti et al., 2008).

Concerns of indoctrination. Before exploring the need for professional development, I turn first to the perceived obstacle of wanting to avoid indoctrination or undue influence on students to adopt specific views on socioscientific issues. This concern shows up frequently in studies of teachers' perceptions of socioscientific issues teaching (Barrue \& Albe, 2013; Cotton, 2006; Gayford, 2002; Van der Zande, Akkerman, Brekelmans, Waarlo, \& Vermunt, 2012). These studies found repeated examples of teachers hesitant to engage in value transfer of their own personal beliefs on socioscientific issues onto their students' values so instead sought to offer "neutral" 
learning experiences to explore students' own values systems. There are also fears of cultural indoctrination where teachers felt especially concerned about unduly influencing students' beliefs in light of the high-stakes context of competitive university entrance examinations and strong desires of students to seek the 'right' answer to please their teachers and parents.

Socioscientific issues instruction still has a lingering connotation of environmental or science advocacy in which teachers may unduly influence their students in a perceived effort to promote a personal agenda (Forbes \& Davis, 2008; Sadler et al., 2006; Waldron, Ruane, Obeman, \& Morris, 2016). In some cases, that perception rings true. Barrett and Nieswandt (2010) and Kilinc et al. (2017) both classified preservice teachers by their beliefs on the role of personal ethics in a teacher's instruction. Both studies found a broad spectrum of thinking on the roles and responsibilities of teachers to avoid, acknowledge, or advocate their personal perspectives (Barrett \& Nieswandt, 2010; Kilinc et al., 2017). Barrett and Nieswandt (2010) suggest that findings like these can help teacher educators to more fully understand teacher roles and perspectives towards socioscientific issues and will create more effective professional development training with these belief categories in mind.

Lack of pedagogical training. The roles that teachers take on during socioscientific issues instruction are critically important for the overall progress towards the learning goals for their students. But in the majority of studies on socioscientific issues instruction, teachers report a clear need for training to understand how to address socioscientific issues education and the connected controversies (Mitchener \& Anderson, 1989) and on how to critically examine 
knowledge and evidence in socioscientific issues (Levinson, 2006). Numerous studies also stress the need to support teachers who may be feeling underprepared to use controversial socioscientific issue topics in classroom discussions (Oulton et al., 2004; Van der Zande et al., 2012) and also feeling de-professionalized as a result of the lack of appropriate resources (Mansour, 2010; Sadler et al., 2006).

These needs may be addressed if teacher educators can provide firsthand experiences to participate in quality socioscientific issues education as learners (Ekborg et al., 2013; Evagorou et al., 2014). Evagorou et al. (2014) designed a framework for teaching socioscientific issues content and pedagogical approaches to pre-service teachers. Through engagement and reflection on the socioscientific issue topic itself along with curricular design efforts, Evagorou and colleagues contend that pre-service teachers will be able to engage with the content and the pedagogy and then translate these ideas into their own teaching practice. The findings highlight the need to support teachers with resources for instruction and time for reflection on their professional role during their efforts to transform pedagogy to incorporate socioscientific issue specific practices and to deal with this specialized discussion format.

Lee and colleagues (2006) go further to emphasize that teachers need to be able to participate in effective socioscientific issues instruction as learners because none of the study participants had ever experienced that type of instruction prior to being expected to implement it themselves. The authors suggest that teachers should engage as science learners to experience the "full package that integrates the content knowledge, the pedagogical approaches, the habits of mind, and the interaction of values centered on socioscientific issues and then be provided with structured 
opportunities to reflect on these experiences from the perspective of science teachers." (Lee et al., 2006, p. 114). Only after these personal learning experiences should then the teachers switch gears to reflect on those experiences from a pedagogical perspective as a science teacher (Lee et al., 2006).

Socioscientific issues curriculum and standards. In addition to establishing a need for professional development related to socioscientific issues, research has often found that teachers have trouble finding or developing appropriate curricular resources due to limited guidance from science standards (Lee et al., 2006; Levinson, 2006). Another curricular challenge is that teachers may quickly insert distinct activities but not in a truly meaningful manner that builds connections to the science curriculum. Van Rooy (1999) examined how one science teacher was successful in including controversial science topics but even with pedagogical proficiency, controversial issues only served as short activities instead of in-depth learning experiences infused over time.

In the near future, to overcome this obstacle, there is a necessity to develop a broader educative curriculum to address the need for professional development and for socioscientific issues specific curriculum resources (Lee et al., 2006), as well as expectations that this content is mandatory to teach. Until the assessment structure and curricular learning goals change, there is little institutional incentive to incorporate these topics into an already overcrowded science curriculum (Lee et al., 2006).

These choices demonstrate that it is only within the capacity of individual teachers to make or break the success of socioscientific issues curriculum enactments. Reis (2014) describes teachers who have a strong motivation and willingness to overcome the numerous obstacles to include socioscientific issues instruction and 
"empower both themselves and students as active citizens and agents of change in society" (p. 554). Importantly, Reis finds that successful teachers interpret curriculum in a novel approach: "these teachers assume a role of active curriculum constructors" (2014, p. 570) and highlights the role of teachers' conceptions about the curriculum, and not the curriculum itself, play a crucial role in the success of their instructional enactments. This re-envisioning of their own teaching identity and agency provides a critical impetus for their action on socioscientific based instruction.

These studies showcase the value in gaining an understanding of teachers' perceptions of socioscientific issues education as it relates to their practice and underscores the need for further research along this line of inquiry.

\section{Climate Change Education}

While there are numerous examples of socioscientific issues (e.g. nuclear energy, cloning, fracking), one popular socioscientific issue topic often incorporated into teaching is climate change, or global warming. Climate change is a current and relevant topic for students both in and out of school as it is a common focus of discussion in media and society. New research from the Yale Program on Climate Change Communication and George Mason University Center for Climate Change Communication show that Americans agree by a 3 to 1 margin (76\% agree vs. $24 \%$ disagree) that climate change should be taught to school children to educate them on the causes, consequences, and possible solutions (Leiserowitz et al., 2017).

Inclusion in NGSS. The Next Generation Science Standards (NGSS) offers revised science standards that seek to intertwine content knowledge (disciplinary core ideas) and scientific skills (science practices) with big pictures of patterns of science phenomenon (cross cutting concepts) (NGSS Lead States, 2013). Introduced in 2013, 
the NGSS are the first national science standards to explicitly include climate change (Wysession, 2013). This inclusion has been portrayed as controversial in some communities, and anti-science groups are working to link climate change with other volatile topics like evolution in an effort to exclude them from instruction (NCSE, 2012). Yet, the NGSS may serve as a new conduit for climate change concepts to be included in socioscientific issues instruction.

Educational benefits of climate change instruction. Building connections between socioscientific issues instruction and the accountability that comes with the adoption of the NGSS may offer new benefits while teaching and learning about climate change. Climate change is an important topic to teach as a socioscientific issue because it prepares learners to deal with global and local aspects of climate change that will impact them and others in the future (Seow \& Ho, 2016) and it educates students on how to engage with uncertainty and manage conflicts in situations inside and outside of the classroom (Baker \& Loxton, 2013). Like other socioscientific issue instructional topics, climate change education is perceived as valuable by teachers because of its goal of a more informed citizenry that understands the interwoven relationship between ourselves, our society, and our environment (Kirk et al., 2014). The benefits of appreciating and understanding climate change are straightforward enough, but due to the immense complexity of climate change as an overarching phenomenon, there are many challenges to negotiate as well.

Challenges with teaching climate change. The obstacles impeding the integration of climate change education have been documented by several researchers and include: the misconception-laden scientific phenomenon of climate change; the lack of teachers' content knowledge preparation; the lack of effective training for 
dealing with a controversial topic; and the sparseness of vetted and aligned climate change curriculum.

Complex content with prolific misconceptions. Recently the scientific evidence that supports the human role in global climate change has become even more resolute and more highly accepted by scientists as demonstrated in the 2014 U.S. National Climate Assessment (Melillo, Richmond, \& Yohe, 2014). But still very few people (15\%) are aware of the level of scientific consensus on this topic (Leiserowitz et al., 2017). This lack of awareness connects to the low general content knowledge understanding that the public holds. For many people, climate change seems "overly complex, controversial, and political” (Baker \& Loxton, 2013). Multiple studies have shown that like the American public (Kempton, 1991; Leiserowitz et al., 2017), science teachers also believe many of the misconceptions related to climate change (e.g. Boon, 2010; Liu et al., 2015) such as a connection between climate change and the ozone hole or directly to nuclear energy sources (Choi et al., 2010; Leiserowitz \& Smith, 2010).

Numerous studies show that teachers' climate change content knowledge is sparse (Boon, 2010; Herman et al., 2017). Only 16-26\% of secondary science teachers reported having any prior instruction (i.e. college or graduate level courses) on this topic throughout their formal schooling (Wise, 2010). This uncertainty in the content to be learned and taught is also impacted by the evolving aspects of the knowledge base as climate scientists themselves continue to learn more about this topic.

Sensitive emotional components. The ambiguity of the 'solutions' of climate change puts teachers in a position of not knowing all the answers, which for many can be quite disconcerting and uncomfortable. The future that we will experience two 
days, two years, two decades, or two centuries from now is far from guaranteed to be viewed as positive or negative. This uncertainty brings forth sensitive emotional components that teachers and students need to confront in the classroom.

Lombardi and Sinatra (2013) tackle the important role of teachers' emotions for learning climate change because conflicting emotions about the topic can contribute to misconceptions on the science content and problematic pedagogy for this controversial topic. Negative emotions including fear, hopelessness, anger, and anxiety can be experienced (Lombardi \& Sinatra, 2013) and some teachers purposefully avoid these discussions as a way to reduce the emotional components of the controversy (Griffith \& Brem, 2004). Teachers' emotions, like anger and hopelessness, can interfere with their ability to provide meaningful climate change instruction (Lombardi \& Sinatra, 2013). Additionally, if negative emotions of students are left unconfronted, this can lead to further de-motivation and disengagement in learning (Griffith \& Brem, 2004). Teachers need to walk a fine line when dealing with their own emotions and those of their students to allow the feelings to surface, but not to be overwhelmed by these emotions and the connections, or disconnections, to climate change (Hufnagel, 2015).

Preparation for pedagogy in controversy. The pedagogical methods that can and should be utilized to appropriately engage those powerful emotions and volatile perspectives are often not a part of science teacher preparation programs. In other words, most teachers are ill-prepared to handle the controversial nature of socioscientific issues, and this is especially problematic for learning about the controversy surrounding climate change (Lambert \& Bleicher, 2014). The instructional framing that teachers employ is crucial alongside an understanding of the 
learners' prior emotions, beliefs, and knowledge to challenge naïve understandings that are rooted in the social climate denial controversy (Lambert \& Bleicher, 2014).

Yet some science educators might not perceive these climate change educational efforts to be encompassed by their science educator role and instead that this topic should be reserved for environmental education programs (Stevenson, 2007) which can focus on more than just factual information to also incorporate more progressive environmental action. This dividing line "may highlight the point at which educators believe a fundamental science topic becomes political, and therefore too close to advocacy for classroom educators to address" (Monroe, Oxarart, Plate, Bowers, \& Chaves, 2017, p. 2). Waldron and colleagues (2016) also found clear discrepancies between how traditional classroom teachers and environmental education specialists approached teaching climate change. Specialists more easily introduced the idea of climate justice as a social justice, human rights issue that demanded action, while teachers positioned the topic within its scientific and geographic aspects of the phenomenon but with little readiness to engage students beyond general stewardship for the earth (Waldron et al., 2016).

Walsh and Tsurusaki (2018) have suggested that educational training workshops could, and should, be designed to assist teachers to approach controversial topics, infuse diverse worldviews, and prepare students to actively take on these societal challenges. However, this type of pedagogical framework and professional development is far from widespread or freely available to teachers currently.

No curriculum available. Envisioning all the appropriate pedagogical components and necessary content learning experiences together in a meaningful instructional unit can be quite challenging when there currently is no widely accepted, 
nor NGSS aligned climate change curriculum available to guide teachers. When climate change is present in their assigned science standards, teachers are more readily able to incorporate climate change into their classroom teaching (Sullivan et al., 2014). While not the most important factor, the presence of climate change in the curriculum is quite salient in the beliefs of many teachers regarding what should be taught in their classrooms.

Even when it is not present in their curriculum, many teachers still work to include climate change either through informal discussions or formal lesson plans (Baker \& Loxton, 2013) even in the face of direct opposition from anti-climate change efforts of state authorities (Colston \& Ivey, 2015). Wise (2010) reports that this type of direct administrative interference was actually quite infrequent, and the more common situation was that teachers excluded climate change because they personally felt it did not 'fit' into their curriculum. Finding time for climate change remains a challenge when attempting to insert it into an overcrowded curriculum especially because of the specialized instructional attention needed to address climate change with meaningful and appropriate methods. Often teachers instead may hesitate to attempt to overcome these challenges to integration (Hestness, McGinnis, Riedinger, \& Marbach-Ad, 2011).

Overall, these studies demonstrate the benefits and many challenges teachers perceive as related to their climate change instruction. I have synthesized these findings on teachers' perceptions of climate change teaching across international and domestic settings and through varied research methodologies. When examined and compared as individual studies, I believe that several gaps in this body of literature become clear. Table 2 presents these research efforts to understand teacher beliefs, 
knowledge, and perceptions of climate change education while also comparing their methods, sample type and size, research location, and general theoretical lens utilized. The table is organized so that the studies with a quantitative focus are listed first (and in chronological order), then the qualitative approaches, and lastly studies employing a mixture of methods.

Table 2 Summary of Prior Studies on Perceptions of Teaching Climate Change

\begin{tabular}{|c|c|c|c|c|c|c|}
\hline Study & Year & Location & TF employed & Sample & Size & Methods \\
\hline Wise & 2010 & USA & $\begin{array}{l}\text { Beliefs and } \\
\text { Practice }\end{array}$ & $\begin{array}{l}\text { In-Service } \\
\text { Teachers }\end{array}$ & 628 & Survey \\
\hline Boon & 2010 & Australia & Knowledge & $\begin{array}{l}\text { Pre-Service } \\
\text { Teachers }\end{array}$ & 107 & Survey \\
\hline $\begin{array}{l}\text { Hestness } \\
\text { et al. }\end{array}$ & 2011 & USA & $\begin{array}{l}\text { Knowledge, } \\
\text { Beliefs and } \\
\text { Practice }\end{array}$ & $\begin{array}{l}\text { Pre-Service } \\
\text { Teachers }\end{array}$ & 63 & $\begin{array}{l}\text { Survey; } \\
\text { Written } \\
\text { Artifacts }\end{array}$ \\
\hline $\begin{array}{l}\text { Baker \& } \\
\text { Loxton }\end{array}$ & 2013 & Canada & $\begin{array}{l}\text { Knowledge, } \\
\text { Beliefs and } \\
\text { Practice }\end{array}$ & $\begin{array}{l}\text { In-Service } \\
\text { Teachers }\end{array}$ & 188 & Survey \\
\hline $\begin{array}{l}\text { Monroe et } \\
\text { al. }\end{array}$ & 2013 & USA & $\begin{array}{l}\text { Beliefs and } \\
\text { Practice }\end{array}$ & $\begin{array}{l}\text { In-Service } \\
\text { Teachers }\end{array}$ & 746 & Survey \\
\hline $\begin{array}{l}\text { Lambert \& } \\
\text { Bleicher }\end{array}$ & 2014 & USA & $\begin{array}{l}\text { Knowledge, } \\
\text { Beliefs and } \\
\text { Practice }\end{array}$ & $\begin{array}{l}\text { Pre-Service } \\
\text { Teachers }\end{array}$ & 154 & Survey \\
\hline Kirk et al. & 2014 & USA & $\begin{array}{l}\text { Beliefs and } \\
\text { Practice }\end{array}$ & $\begin{array}{l}\text { College } \\
\text { Faculty }\end{array}$ & 83 & Survey \\
\hline $\begin{array}{l}\text { McNeal et } \\
\text { al. }\end{array}$ & 2014 & USA & $\begin{array}{l}\text { Knowledge } \\
\text { and Beliefs }\end{array}$ & $\begin{array}{l}\text { In-Service } \\
\text { Teachers }\end{array}$ & 420 & Survey \\
\hline $\begin{array}{l}\text { Sullivan et } \\
\text { al. }\end{array}$ & 2014 & USA & $\begin{array}{l}\text { Beliefs and } \\
\text { Practice }\end{array}$ & $\begin{array}{l}\text { In-Service } \\
\text { Teachers }\end{array}$ & 877 & Survey \\
\hline $\begin{array}{l}\text { Colston \& } \\
\text { Ivey }\end{array}$ & 2015 & USA & $\begin{array}{l}\text { Educational } \\
\text { Policy }\end{array}$ & $\begin{array}{l}\text { In-Service } \\
\text { Teachers }\end{array}$ & 115 & $\begin{array}{l}\text { Surveys and } \\
\text { Interviews }\end{array}$ \\
\hline $\begin{array}{l}\text { Herman et } \\
\text { al. }\end{array}$ & 2017 & USA & $\begin{array}{l}\text { Knowledge } \\
\text { and Practice }\end{array}$ & $\begin{array}{l}\text { In-Service } \\
\text { Teachers }\end{array}$ & 116 & Survey \\
\hline
\end{tabular}




\begin{tabular}{|l|l|l|l|l|l|l|}
\hline $\begin{array}{l}\text { Plutzer et } \\
\text { al. }\end{array}$ & 2016 & USA & $\begin{array}{l}\text { Beliefs and } \\
\text { Practice }\end{array}$ & $\begin{array}{l}\text { In-Service } \\
\text { Teachers }\end{array}$ & 1500 & Survey \\
\hline $\begin{array}{l}\text { Stevenson } \\
\text { et al. }\end{array}$ & 2016 & USA & $\begin{array}{l}\text { Beliefs, } \\
\text { Practice and } \\
\text { Student } \\
\text { Learning }\end{array}$ & $\begin{array}{l}\text { In-Service } \\
\text { Teachers }\end{array}$ & 369 & Surveys \\
\hline Gayford & 2002 & England & $\begin{array}{l}\text { Beliefs and } \\
\text { Practice }\end{array}$ & $\begin{array}{l}\text { In-Service } \\
\text { Teachers }\end{array}$ & 18 & $\begin{array}{l}\text { Focus Group } \\
\text { Interviews }\end{array}$ \\
\hline $\begin{array}{l}\text { Feierabend } \\
\text { et al. }\end{array}$ & 2011 & Germany & $\begin{array}{l}\text { Beliefs and } \\
\text { Practice }\end{array}$ & $\begin{array}{l}\text { In-Service } \\
\text { Teachers }\end{array}$ & 20 & Interviews \\
\hline $\begin{array}{l}\text { Hufnagel } \\
\text { Tuace }\end{array}$ & 2015 & USA & $\begin{array}{l}\text { Emotions and } \\
\text { Practice }\end{array}$ & $\begin{array}{l}\text { Pre-Service } \\
\text { Teachers }\end{array}$ & 30 & $\begin{array}{l}\text { Coursework } \\
\text { artifacts }\end{array}$ \\
\hline $\begin{array}{l}\text { Seow \& } \\
\text { Ho }\end{array}$ & 2016 & Singapore & $\begin{array}{l}\text { Beliefs and } \\
\text { Practice }\end{array}$ & $\begin{array}{l}\text { Pre- and } \\
\text { In-Service } \\
\text { Teachers }\end{array}$ & 10 & $\begin{array}{l}\text { Qualitative } \\
\text { Case studies }\end{array}$ \\
\hline $\begin{array}{l}\text { Lombardi } \\
\text { \& Sinatra }\end{array}$ & 2013 & USA & $\begin{array}{l}\text { Emotions and } \\
\text { Practice }\end{array}$ & $\begin{array}{l}\text { Pre- and } \\
\text { In-Service } \\
\text { Teachers }\end{array}$ & 85 & $\begin{array}{l}\text { Mixed - } \\
\text { measures and } \\
\text { interviews }\end{array}$ \\
\hline Liu et al. & 2015 & USA & $\begin{array}{l}\text { Knowledge, } \\
\text { Beliefs and } \\
\text { Practice }\end{array}$ & $\begin{array}{l}\text { In-Service } \\
\text { Teachers }\end{array}$ & 19 & $\begin{array}{l}\text { Mixed - } \\
\text { measures and } \\
\text { interviews }\end{array}$ \\
\hline
\end{tabular}

Establishment of a research gap. From this review of the literature on climate change related perceptions of teachers, the clear majority of studies focused on the constructs of teacher beliefs and teacher knowledge and the influence on practice. Only two studies employed an alternate theoretical framework for exploring the emotional perspectives of teachers as they relate to climate change. This summary also shows there were two main groupings of studies - international and qualitatively focused or USA based and quantitively driven. Through my study, I aim to consider and address these gaps in the research literature.

Research gap \#1. There are very few qualitative studies on teachers' perceptions of climate change and of the four studies described, three of them are 
internationally based. While this usually helps to broaden our understanding of a research topic, in this case, I contend that it shows a deficit in our knowledge that the science education community has not examined American teachers in depth. International settings don't seem to be experiencing the same contentiousness around the controversy and climate change denialism (Pew Research Center, 2015). Also, international settings would not be subject to any possible influence from the NGSS and its recent inclusion of climate change within the standards. Lastly, the one USA based study (Hufnagel, 2015) takes the novel approach of emotions to describe teacher thinking. Therefore, I conclude there is currently a research gap of USA based, qualitatively driven studies on teachers' perceptions of climate change education. Research gap \#2. Table 2 shows a near total reliance on the theoretical constructs of teacher beliefs and teacher knowledge to study the perceptions and experiences of teachers related to climate change education. There are no studies that employ a theoretical framework of teacher identity and also exclusively focus on climate change. I acknowledge that some of the other reviewed literature that focused on socioscientific issues instruction generally did take an identity perspective (e.g. Pedretti et al., 2008 on the topic of STSE approaches, Barrett \& Nieswandt, 2010 on socioscientific issue topics in general, and Goldston \& Kyzer, 2009 on teaching evolution). However, no studies were found to specifically focus on identities for teaching climate change, and thus this is where my study is situated.

To begin to address these research gaps, I now turn to an examination of the theoretical framework of teacher identity, and more specifically, science teacher identity. 


\section{Identity as a Theoretical Lens}

Influences on teacher practice - Knowledge. Content knowledge expertise has long been a key component of educational research to better understand teaching practice (Cochran-Smith \& Lytle, 1999). Undoubtedly, a teacher must be knowledgeable in the subject matter in which she aims to teach, demonstrate this knowledge to her students, and share this expertise with them through meaningful pedagogical approaches (e.g. Cochran-Smith \& Lytle, 1999). The depth of a teacher's preparation has been linked to her success in the classroom time and time again (Cochran-Smith \& Lytle, 1999; Gess-Newsome \& Lederman, 1999; Loughran, Mulhall, \& Berry, 2004). The components of this knowledge preparation have classically been divided into content knowledge, pedagogical knowledge, and pedagogical content knowledge in science education (Shulman, 1986). Knowing about a topic deeply, especially a complex science phenomenon, is a critical component of any teacher's development (Loughran et al., 2004).

As seen in the prior literature review, educational research on climate change and socioscientific issues related instruction has often relied on a knowledge-oriented framework and the effects that teacher knowledge has on pedagogical practice both positively (McNeal et al., 2014) and negatively (Stevenson et al., 2016b). Also, these studies have demonstrated a consistent lack of in-depth knowledge related to socioscientific issue topics like climate change (Boon, 2010; Herman et al., 2017). Specific knowledge on socioscientific issues, and especially on climate change, is important, albeit insufficient to understand why and how teachers integrate these topics into their teaching

Influence of beliefs on teaching practice. Another vastly popular aspect of educational research has been the effort to establish the link between teachers' beliefs 
and their teaching practice. Nearly every study reviewed in the earlier section on teacher perceptions of socioscientific issues and climate change teaching took this beliefs-driven approach to research. This line of investigation into teachers' beliefs and the impact on teaching practice has dominated the research field for quite some time (Brickhouse, 1990; Kagan, 1992; Pajares, 1992). Nespor put forth a model of teacher beliefs that shows how teacher belief systems are influenced by past experiences, which then also influence current practice (1987). This model has found utility in the work of many subsequent researchers as they empirically seek to confirm the relationship between teacher beliefs and their influences on teacher practice (Roehrig, Kruse, \& Kern, 2007; Waters-Adams, 2006). As with any popular theory, there are a number of detractors (e.g. Mansour, 2013; Wallace \& Kang, 2004) that have been able to demonstrate a frequent disconnect between the espoused beliefs and the beliefs actually activated during practice. Teacher beliefs have also been shown to be exceptionally resistant to change, even when these beliefs are incongruent with the learning goals (Cronin-Jones, 1991).

Orientations towards teaching goals. This small sector of research has begun to unravel some of the inherent complexity of teaching and learning socioscientific issues, but little attention has been paid to orientations towards teaching climate change. The teacher orientations framework was introduced by Magnusson, Krajcik, and Borko (1999) as a component of PCK but others have taken this concept to mean more broadly a perspective towards teaching, learning and curricular goals (e.g. curriculum emphases - Roberts, 1982). Orientations focused research efforts have shown that value orientations can motivate teachers and should be considered when planning curriculum (Witz \& Lee, 2009). The curriculum emphases approach was 
proposed as a possible theoretical avenue for future socioscientific issues education research by Zeidler (2014) but the fruitfulness of this perspective to understanding and describing teaching practice has yet to be determined. Critics of these perspectives have also argued that orientations perspectives can involve unclear interpretations and fuzzy or absent relationships between the different components (Friedrichsen et al., 2011).

Identity models for educational research. In light of the highlighted failings of the common theoretical frameworks of beliefs, knowledge, and orientations, I contend that teacher identity serves as a better theoretical framework to understand and describe the overall phenomenon of teaching climate change. This perspective pushes educational researchers to move away from questions like "What do I know and believe in this teaching moment?" to questions of identity like "Who am I in this teaching moment?" (Connelly \& Clandinin, 1999). Identity, I argue alongside with researchers before me, is an immensely useful and "valuable lens" to employ in educational research to examine and describe teacher practice (Enyedy et al., 2006; Gee, 2000-2001; Luehmann, 2007; Madden \& Wiebe, 2015). Luehmann (2007) offers that identity as a theoretical framework which better incorporates "the importance of overlooked elements such as the unique challenges and personal risks involved in taking on a new professional identity that runs counter to the norm..." (p. 837). Identity offers researchers an explanatory variable not previously considered by knowledge-only, beliefs-only, or practice-only approaches to investigating teaching and learning, especially in educational settings deemed novel or with an untraditional focus. Enyedy et al. (2006) puts forth another model that incorporates teacher identity as an important part of the decision-making process in 
which teachers engage to meet their instructional goals. Previously these components of personal stories and cultural history had not been considered as influential on practice. But Enyedy and colleagues (2006) argue that identity lies at the intersection of these ideas and is shaped in a number of directions by these and other political, historical, and social forces (Rodgers \& Scott, 2008). Due to these promising new directions for insight, researchers have suggested that identity and its formation "take center stage" as it encompasses the concepts of self, knowledge, beliefs, attitudes, dispositions, interests and orientations (Drake et al., 2001; Rodgers \& Scott, 2008).

Aspects of teacher identity. Often, identity is loosely defined and rarely agreed upon in research literature. Identity is multifaceted in nature and can be viewed from a wide range of perspectives which does little to give this concept a clear research focus. By highlighting the frequently described components and aspects of identity, the utility of identity as a theoretical lens can be more clearly seen. Clandinin and Connelly's Three-Dimensional Narrative Framework (2000) provides an organizational tool that can help to explore more of the nuanced aspects of identity and specifically here I focus on teacher identity. This framework is comprised of the three main dimensions of interaction, context, and continuity. Each of these areas will be described in more detail in the following paragraphs.

Interaction refers to both personal interactions within oneself and social relationships with others. Focusing first on personal aspects, researchers have described professional or teacher identity as centered in one's values and beliefs (Helms, 1998) and how the diversity of one's experiences influence those commitments (Luehmann, 2007). Gee introduces Nature Identity to describe the nature of a person as a key dimension of identity - both the physical or genetic 
attributes and the developed characteristics of the person (2000-2001). These individual characteristics are intensely personal and may also include more than just what a teacher thinks and believes, but also what they value and want to become (Helms, 1998). Gee (2000-2001) also described an Affinity Identity that bridges these personal interests to the affiliations we make with others based on those similarities in values. These interpersonal connections are important as well and will be addressed next, but we are reminded of the critical nature of the internal interactions by Helms: "While teachers' thoughts and actions are conditioned by the social and cultural context..., their search for meaning came from their sense of themselves as individuals in the larger world" (1998, p. 831, emphasis added).

Extending out from intra-personal interactions (i.e. one's thoughts, values, knowledge, and beliefs), we look to how relationships with others impact teacher identity as the second half of Clandinin and Connelly's Interaction dimension. Rodgers and Scott introduce this idea simply by explaining that "within multiple contexts, one forms multiple relationships and brings forth multiple aspects of oneself" (2008, p. 735). These relationships are essential to one's identity because they allow for a public recognition as a particular "kind of person" (Gee, 2000-2001) by other educators. As teachers, people develop professional relationships with students, their classroom community, and the school administration, and "such institutional relationships open the door to multiple areas of control or power that shape a person's identity and practice (Enyedy et al., 2006, p. 72). Teachers' relationships also inherently incorporate the social expectations of others which Helms (1998) includes as an impact on one's teacher identity. The recognizable collection of social expectations on how a teacher speaks, acts, and utilizes symbols or tools is described 
by Gee as the "big D" Discourses of being a science teacher (2005). Sachs also describes these expectations as "ideas of 'how to be', 'how to act', and 'how to understand' their work and their place in society (2001, p. 15). The acknowledgment of one's participation in particular Discourses or holding certain mindsets or perspectives are important within the relational aspect of teacher identity.

The second dimension of Clandinin and Connelly's Three-Dimensional Narrative Framework is situation or context. Numerous researchers describe the contextual elements of one's identity. Gee refers to it as Institutional Identity and examines how one interprets their role, duties, or position within an institution. Madden and Wiebe (2015) note that teachers' institutional identities are most often influenced by school-based factors like standards and curricula and to that list, I would add the availability of resources (or lack thereof), a school's geographic location, and even the political climate in which a teacher works. Enyedy and colleagues describe these contextual influences as the "everyday activities" through which teachers negotiate their identities (2006). Describing these everyday activities with more specificity, Rodgers and Scott highlight that "identity is dependent upon and formed within multiple contexts which bring social, cultural, political, and historical forces to bear upon that formation" (2008, p. 733). Similarly, Olsen (2008) incorporates the "intertwined influences" from a given context and the connected human relationships present at any given moment in his description of teacher identity. In short, the contexts in which teachers work are ever changing, and as such teacher identity is also ever-evolving and highly dependent on changing school situations.

The last dimension of Clandinin and Connelly's Three-Dimension Narrative Framework is Continuity. I interpret continuity in two ways: the dynamic nature of 
identity and the storied aspects. Volkmann and Anderson described professional identity development as "a complex and dynamic equilibrium where professional selfimage is balanced with a variety of roles teachers feel they have to play" (1998, p. 296). The balancing of this equilibrium is always underway and related to the diverse contexts in which teachers work (Enyedy et al., 2006). The ongoing process of identity construction is dynamic and allows for sensemaking and "(re)interpretation of one's own values and experiences" (Flores \& Day, 2006). Beijaard and colleagues attribute this shifting to its relational nature in which one is constantly in "the process of becoming" (Beijaard, Meijer, \& Verloop, 2004, p. 121). The identity that is presented at any one time is described as a deck of cards by Rodgers and Scott where "any [card] might be turned up at any time depending on the who, what, and where of circumstance" (2008, p. 736).

Based on these multifaceted descriptions of identity, it may be challenging to see identity as a useful organization framework. Rogers and Scott go on to describe how "the most widely embraced way of making sense is through the practice of narrative, or the telling of stories" (2008, p. 736). The sharing of stories is the discussion of experiences and how a teacher makes sense of these experiences (Sachs, 2001) which can illuminate noteworthy components of a teacher identity. Drake and colleagues describe this phenomenon as "stories, complete with themes, plots and characters reveal the ways in which individuals know themselves and their lives" - in essence, their identity (2001, p. 2). Several researchers go further to describe the narrative stories along with the construction and re-construction of meaning via these stories as one's identity (e.g. Rodgers \& Scott, 2008; Sfard \& Prusak, 2005). Sfard and Prusak (2005) divide the narrative construction of identity into the present tense, 
current state of affairs (actual identity) and the future oriented goals and idealized roles one intends to enact (designated identity). Both of these identity classifications are best shared through the selection of and characterizations of the stories that are shared.

In summary, teacher identity can be described employing the ThreeDimensional Narrative Framework (Clandinin \& Connelly, 2000). Interaction refers to the relational aspects of identity. This includes personal components and relations to oneself such as one's values, beliefs, and knowledge regarding teaching and learning. It also incorporates the social relationships that teachers form with students, colleagues, administrators, and parents, and the social expectations of these people for what makes a good or an effective teacher. Teacher identity is also contextually based on the various situations teachers encounter daily. In short, place also matters to teacher identity as it influences who one is at any particular time and how prepared a teacher is to handle educational challenges or cultural differences. The third dimension is continuity and it refers to both the dynamic and storied nature of identity. Identity itself is dynamic with a history of past experiences and future goals for one's own teaching practice and hopes for one's students. Additionally, identity is best expressed through narrative constructions to make sense of and give meaning to teaching and learning experiences. Next, I turn to examples of how researchers have examined these relational, contextual, dynamic, and storied aspects of teacher identity within the realm of science education.

Studies of science teachers and professional identity. In this section, I present a chronological review of studies related to the development of professional teacher identity specifically in science teachers. This section is intended to 
demonstrate how research on identity has evolved over time to be more subject specific from the initial conceptualization of the term 'science teacher identity'.

Spillane (2000) is a study that while not science specific, showed the important role of subject matter on teacher's identity and as a result the differences in the success of reform efforts on instruction. Spurred on by reform efforts in math and literacy, Spillane describes teacher identity as "who they are, their sense of self, and their habits of mind" (2000, p. 308) in addition to their knowledge and beliefs. He continues that it also "encompassed dispositions, interests, sense of efficacy, locus of control, and orientations towards work and change" which all have been influenced by one's experiences as a learner and as a teacher, and that are all subject-matter sensitive. There was a distinct difference in the subject matter disposition of the teacher in his study and her commitments to reform-based change - both of which had an influence on her teaching identity and as a learner about instruction. This study highlights the differences of subject specific teacher identity even within one teacher.

Finding similar subject-specific results in a larger sample of teachers, Helms (1998) is an early example of the recognition of how deeply the subject matter a teacher teaches impacts their practice and their teacher identity. Helms believes that "dimensions of [teachers"] identities, are to greater or lesser degrees, defined by [their subject matter]" (1998, p. 831). She describes a model of teacher identity that incorporates four major components: actions, the institutional, cultural, or social expectations of others, one's values and beliefs, and how one views an imagined future self. She contends that while science subject matter is not the "sole determinant" in one's teaching identity, it is a critical component that has often been ignored by contemporary educational research. 
Related findings were described by Volkmann and Anderson (1998) and cemented the important influence that subject matter can have on teachers, their practice, and their overall identity in the classroom. Volkmann and Anderson investigated the reflections of a novice chemistry teacher as she navigated various dilemmas in identity throughout her first year. These included experiences of varied expectations to act like an adult or like a student, the depth of her content knowledge expertise, and struggles with classroom management styles of being a friend or being an authority in her classroom. The analysis demonstrated how "professional identity is constituted by every aspect of teaching" and "connected to her history, the expectations of the school, her content knowledge, and her own vision of what it means to be a teacher" (1998, p. 307). Volkmann and Anderson conclude that while preparing, mentoring, and reforming teachers, it is important to attend to the complexity of science teacher identity (1998).

While not specifically on teacher identity, Carlone \& Johnson (2007) put forth a model of science identity that is still valuable to consider. It consists of three interrelated dimensions: performance, competency and recognition: "One cannot pull off being a particular kind of person (enacting a particular identity) unless one makes visible to (performs for) others one's competence in relevant practices, and, in response, others recognize one's performance as credible" (Carlone \& Johnson, 2007, p. 1190, emphasis in original). The authors continue to elaborate the component of recognition and its vital nature in identity development and the complex ways in which race and gender impact the recognition one receives.

This complexity is also described by Varelas, House, and Wenzel (2005) while utilizing a multidimensional lens for professional identity as scientists and as science 
teachers. Through an apprenticeship experience, beginning teachers were able to consider the development of their varying identities and the collisions between those perceived roles. "The beginning teachers were living interesting contradictions, a roller coaster of meanings and feelings, alternating emphases and roles" (Varelas et al., 2005, p. 513). This study demonstrates that while the subject matter is important to science teacher identity, it can also be a conflicting component between the practice of science and how that differs from the practice of science teaching.

Positionality, or positional identity, was the research focus of Moore's (2008a) analysis of three African American high school science teachers and this concept was operationalized as race, ethnicity, class, gender, age, and religion, and the intersections of these sociocultural elements. Employing a narrative, life history approach demonstrated the influential nature of their personal histories on their science teaching identities. While also showcasing the similarities and differences in their identities and orientations to science teaching and professional development, this study demonstrates how "positional identity simultaneously influences how we teach, how others perceive us, and how we plan our futures" (p. 704). Moore (2008a) concludes by putting forth a model of professional development that connects identity to personal experiences, professional learning, and student achievement.

During the process of identity development as learners, teachers will draw upon various identity resources. Synthesized first by Luehmann (2007) and summarized by Hanuscin et al. (2014), these resources are described as: "(a) multiple ways in which to display one's competence, (b) opportunities to exercise agency, (c) access to feedback from others, (d) the opportunity to be held accountable, (e) central positioning as the lead "actor," (f) a high-degree of support, and (g) flexible 
scaffolding that adapts to meet changing needs over time." (Hanuscin, 2014, p. 208).

Concluding her review of learning as identity development, Luehmann puts forth two design principles to assist with this process. Emphasizing multiple and meaningful participation in science as learners and as teachers, she first establishes a need for supported experiences in and out of traditional classroom environments. Second, Luehmann notes that during the process of identifying as a certain kind of science teacher, teachers benefit from repeated opportunities to have their participation be interpreted and recognized by themselves and by others through various forms of structure reflection (2007).

Similar to some of the earlier dilemmas discussed by Volkmann and Anderson, Mensah (2012) highlighted identity as a lens to describe the multidimensional nature of how teachers view how they should interact with students, how they portray themselves in the classroom, and how they view themselves as science teachers. Specifically, Mensah (2012) also employed positionality to describe how specific components of one's identity play a role in the teaching of science and the development of relationships with students in urban classrooms.

Through an in-depth study of one teacher's identity development, Avraamidou (2014b) described the teacher's identity trajectory throughout the early experiences in university, as a student teacher, and as an in-service teacher. Avraamidou offers a combined theoretical framework that integrates identity as described by Gee (20002001) and the Three-Dimensional Narrative inquiry space developed by Clandinin and Connelly (2000). By combining a framework of identity with the narrative structure, Avraamidou was able to more clearly describe not only the what (aspects of science teacher identity) but also the how (the development process of identity over time). A 
narrative approach allowed a combination of personal and social, the interaction of past, present, and future, with both of those situated alongside the context of place to be examined together which provided a "tool to think about teacher identity over both time and space" and "to capture the complex nature of a teacher's identity and trace its development" (Avraamidou, 2014b, p. 237). Avraamidou used the attributes of knowledge, beliefs, views, orientations, and actions to describe and characterize the science teacher identity(ies) held by the teacher. The analysis explored how identity is context specific and how its development often relies on various situations and experiences that teachers encounter while teaching science and also learning science themselves.

In Avraamidou 2016a and 2016b, the researcher employed a broader view of identity instead of only Gee's conceptualization (2000-2001). Avraamidou describes identity as "the ways in which a teacher represents herself/himself through her/his views, orientations, attitudes, knowledge, and beliefs about science teaching, the kind of science teacher she/he envisions to be, and the ways in which she/he is recognized by others" (2016a, p. 863). Avraamidou framed this research around the intersection of life histories and science teacher identity. "The stories we make throughout our everyday lives essentially make us who we are - they capture our identities" (2016b, p. 153, emphasis in original). The analysis demonstrates that "to become a science teacher is a distinctly personal and intimate affair influenced by myriads of interactions, events, and experiences that cause shifts in beliefs, values, emotions, knowledge, and understandings - essentially on identity development for science teaching (Avraamidou, 2016b, p. 172). A life history narrative approach allows 
researchers to identify critical experiences and gather insights that may not have been otherwise accessible.

In closing, Avraamidou (2014a) sought to summarize the body of literature specifically related to science teacher identity. She synthesized the various perspectives from which teacher identity has been studied and found some consensus amongst the collective findings. The theoretical lens of teacher identity is a powerful, multifaceted, and flexible perspective to study science teacher development. She concludes with three arguments related to the utility of this theoretical framework: "First, it pushes our boundaries and extends our definitions of science teacher learning and development as it proposes new ways of viewing the process of teacher learning and development. Second, it emphasizes the role of the context on science teacher learning and development and pays attention to the interactions that teachers have as members of various communities. Third, it allows us to examine science teachers' personal histories in relation to science. (Avraamidou, 2014a, p. 164-165)

Specific types of science teacher identities. A unique direction that some researchers are moving into is the exploration of teacher identity as a specific type of science teacher. Broadly understanding how teachers come to know themselves is still vitally important. Yet as today's teachers are repeatedly pulled in new directions for reform efforts, science education researchers must also strive to understand how these new challenges, situations, and requirements influence teachers' perceptions of their roles and their identities within an evolving classroom situation. This section will review the various research efforts to study specific "types" of science teachers. Instead of drawing broad connections between these studies, I present summaries of the studies to better examine how researchers have begun to further specify and hone 
in on more detailed and novel descriptions of how science teachers portray themselves as specific "types" of science teachers.

Teachers of the nature of science. Using Beijaard et al.'s (2004) definition of teacher identity, Akerson and colleagues have compared the identities of elementary pre-service and in-service teachers (Akerson, Pongsanon, Weiland, \& Nargund-Joshi, 2014). They especially highlighted the critical role of agency as a personal characteristic (Akerson, Carter, \& Elcan, 2016) when teachers are able to enact nature of science (NOS) related instruction even in the face of obstacles to its inclusion. In their work, Akerson and colleagues found that teachers who have developed identities as teachers of NOS have: mindsets to include NOS in their science instruction; a repertoire of strategies; proficiency in inquiry science teaching; and a collection of strategies for assessments aligned to NOS instruction (2016). They describe the development process as guided by teachers conceptualizing NOS and interacting with others who either have developed or are also developing NOS teacher identities. This then enables the teachers to overcome barriers that make NOS instruction difficult such as contextual challenges and personal struggles (Akerson et al., 2014).

Inquiry minded teachers. Eick and Reed (2002) examined how preservice teachers' personal histories affected the development of an initial identity as an inquiry-oriented science teacher. Eick and Reed employed the TPPI (Teachers' Pedagogical Philosophy Instrument) to “clarify the student teachers' pedagogical philosophy or reasoning behind their practice, and the values, beliefs, and contexts informing that philosophy" (2002, p. 404). Additionally, they utilized written reflections following their implementation and email follow as needed. Overall, they found that "it is not teacher education alone that makes an inquiry-oriented teacher, 
but that a preservice teacher predisposed to inquiry-oriented teaching benefits most from science teacher education" (Eick \& Reed, 2002, p. 412). This study recognized the lingering and predisposing influence of teachers' beliefs and personal experiences while learning, teaching, and doing science. This can play a role in the strength of one's identity and the ability of teachers to effectively integrate inquiry into their classrooms.

Initially, Danielsson and Warwick (2014a; 2014b) sought to examine the development of student teachers "content knowledge and pedagogical content knowledge but the authors found that these concepts were insufficient to explain the multitude of affordances and constraints that act upon teacher development" (2014a, p. 106). Instead, they utilized Gee's theory of Discourses (2005) and related the concept of identity and personal histories can affect engagement with the various Discourses. Through in-depth interviews with preservice teachers, they identified five Discourses that can consider the often competing tensions related to elementary science teaching: traditional science teaching; teaching science through inquiry; traditional primary school teacher; teacher as classroom authority; teacher as role model (2014a). Additionally, the authors explored (2014a) these perspectives and intersections of the challenges and experienced while constructing an inquiry-oriented science teacher identity.

Reform-minded teachers. Luehmann (2007) identifies the unique challenges of developing an identity as a reform-minded science teacher. These include: emotional risk and needs for repair work; lack of personal experiences with meaningful inquiry teaching and learning; need for environments where teachers can "try on" this new identity safely and to be recognized for this practice (Luehmann, 
2007). The author concludes that providing a reflective and scaffolded experience (e.g. Luehmann, 2016) is especially important because holding reform-minded ideas went against common practice and requires more than just learning new knowledge and acquiring new pedagogical skills (Luehmann, 2007).

Saka, Southerland, Kittleson, and Hutner (2013) investigated the journey of one beginning science teacher as his identity as a reform-minded teacher developed and how this influenced, and was influenced by, his teaching context and teaching practice. They concluded that it is a complex relationship, in which institutional context can dramatically impact practice, even in spite of a strong reform-minded identity. This identity is negotiated and then re-negotiated repeatedly as one reacts to institutional expectations and personal dispositions. Teachers need support to be successful along this developmental process and teacher educators should provide experiences to encourage a positive identity shift.

Teacher leaders. Hanuscin et al. (2014) situated their study within the identity framework of Luehmann's (2007) identity resources and Gee's descriptions of identity work as they consider the process of science teachers taking on an identity as a teacher leader. The authors identified three specific categories of participation that aided the teachers' path to envisioning themselves as teacher leaders: pedagogical transactions, such as sharing resources or giving advice; intellectual deliberations, like where teachers reflect and articulate a vision of leadership; and social interactions which includes examples of offering encouragement and expressing appreciation to others (Hanuscin et al., 2014). Through an online community and blogging, the teachers were able to envision themselves and others as leaders which "underscored the importance of offering opportunities for sustained reflection and social interaction" (Hanuscin et 
al., 2014, p. 220). This study makes clear that identity development needs targeted and specific support to assist teachers on their path.

STSE teacher. Pedretti and colleagues investigated the STSE perspectives and early teacher identities of Canadian science preservice teachers (2008). The authors described several categories of tensions in identity that influenced their implementation of STSE instruction: control and autonomy, support and belonging, expertise and negotiating curriculum, politicization and action, and biases and ideological bents (Pedretti et al., 2008). It is recommended that teacher education programs should encourage an identity that is inclusive of the norms and pedagogy related to the goals of STSE through actions such as explicitly examining opposing ideologies on controversial issues, deepening content and pedagogical content knowledge bases on specific topics, and engaging preservice teachers in both the theory and practice of STSE to experience both learning and teaching in this manner to motivate teachers' self confidence in future enactment of STSE.

Social justice agent. Moore (2008b) explored the desire and ability of preservice teachers to affect positive social change along with the development of a science teacher identity as a change agent for social justice. Moore describes a continuum of orientations held by the preservice teachers that varied based on the perceived strength of one's science teacher identity and one's critical agency. These findings showcase that preservice teachers have various perspectives regarding their identities and agency towards enacting social change (Moore, 2008b). The teachers needed additional support to better construct an understanding of the goals for equity and social justice oriented education within the overarching framework of science teaching as a pathway to affect change in and out of their future classrooms. 
Approaches for identity study. Observations play a vital role in confirming beliefs in action as well as actual and designated identities. However, since so little is currently understood about the development of an identity as a teacher of climate change, I contend that the first need to be addressed is to more fully understand the lived experiences and 'stories to live by' of this unique group of science teachers that enact climate change instruction. I conducted a narrative inquiry study that focused on teacher interviews and reflections to more fully describe this phenomenon.

This approach has been frequently utilized by other researchers in their efforts to more better understand the teacher behind the observable classroom practice. Stories are a vital component of this line of research because "they are the area where practice and professional identity meet" (Watson, 2006, p. 525) and they assist with layering meaning onto the collective impact of teachers' practices, beliefs about themselves as teachers, and the negotiation and renegotiation of their teacher identity (Flores \& Day, 2006). Goodson cautioned against a focus solely on teaching practice as this can mispresent the teacher $\underline{\text { as }}$ practice alone. "In understanding something so intensely personal as teaching it is critical we know about the person the teacher is" (1992, p. 234). He continues that when researchers only describe teacher actions, which are the most "exposed and problematic aspect of the teacher's world" (Goodson, 1992), the insights uncovered will portray teachers as vulnerable and powerless.

Justification of a narrative approach to identity. Battey and Franke (2008) demonstrated the impact of teacher identity on professional development experiences and on classroom practice. "Teacher's identities carry personal histories, emotion, values and knowledge" (p. 145). MacLure (1993) examined the positive and negative 
implications for educational research when the biographical attitude, or a teacher-asperson perspective, is adopted. These accounts work to "knit together the disparate dimensions of teachers' lives - curriculum, career, home life, pedagogy - in ways that are always bound up with values and with action" (MacLure, 1993, p. 320).

Carter and Doyle (1996) acknowledge the criticism of this approach that "personal narratives are seen as powerful instruments in either maintaining or transforming teaching practice" (p. 129). Britzman (1986) described three cultural myths about school situations and learning to teach that narratives perpetuate or reproduce current practice and instead suggests that teachers, especially those learning to teach, should situate their personal history within a much larger framework of politics, ideology, and history.

Frequently teacher development is perceived as a process of gathering knowledge and skills to obtain one's credentials to teach or continue teaching. But utilizing a narrative or biographical perspective, becoming a teacher involves shaping a professional teacher identity, modifying one's personal beliefs and values, and representing one's self in certain ways in the classroom to demonstrate one's persona. This theoretical lens paints a much more nuanced view of teacher development, which "promises to transform fundamentally how teachers are viewed and perhaps even how they are valued" (Carter \& Doyle, 1996, p. 139). MacLure concludes by establishing that professional developers, educational policy makers, teacher educators, and researchers should more carefully consider "a much more diverse range of needs, interests, and identities than they are doing at present" (1993, p. 320). The next section moves to provide two specific examples of narratives in action within educational 
research and then elaborates on their value in the broader research community to build our understanding of the relationship between teacher identity and practice.

Identity as narrative approaches. Drake (2006) presents an integrated view of narrative as "not only as a way to contextualize beliefs, knowledge, and experience, but also as a way to highlight who teachers are as learners and teachers of mathematics - an integration of what teachers know, believe, and have experienced, as well as the feelings and emotions that teachers associate with their knowledge, beliefs, and experiences" (p. 583). Drake draws from McAdams (1993) to continue that "the stories of individuals serve not only as a means through which individuals know themselves, but also as a framework for the interpretation of new ideas and experiences and as a guide for decision-making and action" (p. 582). This interpretative framework and methodology seek to demonstrate teacher beliefs and knowledge in the context of the experience.

To paraphrase Clandinin and Connelly, people in general experience the world narratively, so it is only logical to also study the world narratively. They describe a teacher's identity as one's "stories to live by" (1999, p. 4). Connelly and Clandinin (1999) and Clandinin and Connelly (2000) offer an influential approach to the conceptualization of teacher identity and in how to study identity through narrative inquiry. This methodological perspective was chosen for this study and will be described in more detail in chapter 3.

Value of narrative approaches on identity. In summarizing her own work and the research field at large, Avraamidou (2016a) concludes that "to become a science teacher is a distinctly personal and intimate affair influenced by myriads of interactions, events, and experiences that cause shifts in beliefs, values, emotions, 
knowledge and understandings - essentially, on identity development for science teaching. Life history approaches through a biographical lens have the potential to illuminate the impact of these factors and to identify critical experiences related to identity development. These approaches can serve as a significant input to teacher preparation aiming at supporting teachers first to reconstruct any negative science identities and second to develop reform-minded identities for science teaching" (Avraamidou, 2016a, p. 172). Additionally, with more in-depth understandings of teacher identity, researchers can more appropriately showcase how teachers connect to the curriculum and teaching practices (Enyedy et al., 2006). With this type of knowledge, curriculum developers can account for various orientations, perspectives and identities to be more supportive of struggling teachers as they build their pedagogical design capacity (Brown \& Edelson, 2003) through educative curriculum materials.

Besides informing teacher education, professional development practices, and curriculum design utilizing narrative approaches to study identity can help to highlight the impact that identity has on teaching practice and the implications of those identity aspects on student learning outcomes (Madden \& Wiebe, 2015).

\section{Chapter 2 Summary}

Identity as a theoretical framework offers an avenue to explore not only a teacher's espoused beliefs but also their reflections on instructional enactment and their reasonings for pedagogical choices. The examination of teacher narratives prioritizes how past, present, and future events influence the identity development of science teachers. The lived experiences through the obstacles and opportunities inherent in climate change instruction and within socioscientific issues education are 
valuable sources of information to better understand the teachers responsible for the enactment of climate change educational efforts. In the next chapter, I describe how the key ideas explored here drive my research efforts. Additionally, I will expand upon the methods I selected to investigate how the narratives of teachers' climate change teaching and learning experiences shape their identity development and sense of instructional agency. 


\section{Chapter 3}

\section{METHODOLOGY}

The purpose of this study is to investigate and describe the lived experiences of teachers of climate change. In applying the theoretical construct of identity as narrative to investigate the climate change related instructional experiences, I pose the central, overarching question: How do teachers' lived experiences shape their science teacher identity development as a 'teacher of climate change'? Breaking that question down further into issues sub-questions (Stake, 1995), I plan to investigate the following sub-questions:

1) How do science teachers describe their experiences of planning, enacting, and reflecting on climate change teaching?

2) How do teachers' personal histories and backgrounds, professional teaching experiences, and political local context influence their identity as a 'teacher of climate change'?

I used qualitative narrative inquiry methods to examine professional and personal stories of science teachers and their instructional enactment of climate change lessons. I collected empirical data to form insights regarding how teachers negotiate competing demands while planning, implementing, and reflecting on their instruction. Primary data sources included multiple interviews with each teacher and teacher reflections.

My analysis focused on the interviews and reflections generated by the teachers and utilized the lens of narrative inquiry, specifically Clandinin and 
Connelly's (2000) Three-Dimensional Narrative Structure to describe the science teacher identities and the contextual, dynamic, relational, and storied aspects of their teacher identities. In analyzing the collected data, I demonstrate how the identity narratives of each teacher play a role in their enactment of climate change instruction realized through the narrative structure components of continuity, context, and interaction (Clandinin \& Connelly, 2000) and how these components exhibit personal, professional, and political elements.

\section{Justification for the Use of Qualitative Approach and Narrative Inquiry}

I employ an overall perspective of social constructivism in which I am seeking to learn more about the meanings constructed by the teacher participants as they engage with the world and make sense of it utilizing their own social and historical perspectives (Crotty, 1998). I also use this perspective as I employ inductive measures to draw my own meanings and interpretations out of social interactions and from data collected through these social contexts (Creswell, 2009). My operationalization of identity is socioculturally, and not psychologically, focused.

Creswell (2009) puts forth nine characteristics of qualitative research - all of which relate to my study and further support my choice to approach this research inquiry using qualitative methodology. My research seeks to capitalize on the value of data collection from natural settings that aims to highlight participant teachers' own meanings of the experiences under study. I acknowledge that I as the researcher am a key instrument in this study and interpret what I see, hear, and understand through my own personal filters, while striving to do is in a reliably trustworthy fashion. I seek to develop a holistic account through primarily inductive analysis of multiple sources of data through the theoretical lens of identity. As my research efforts progressed, I 
sought to follow the original plan while also allowing the design to be emergent and responsive as required by the natural research setting through semi-structured interview protocols.

I employed narrative inquiry methods as imagined by Clandinin and Connelly who were influenced by Dewey's ideas that education, experience, and life are “inextricably intertwined" (2000, p. xxiii). We learn and give meaning to our lives narratively and it follows that we should also study our learning and our lived experiences narratively as well. Narrative inquiry is a valuable method to understand that experience and this approach can be operationalized as "stories lived and told" (Clandinin \& Connelly, 2000, p. 20).

Qualitative researchers draw from a bricolage (Denzin \& Lincoln, 1994) of methods and approaches to data collection and analysis. Narrative researchers also may utilize aspects of other methodologies (e.g. phenomenology, ethnography) in some respect (Josselson, 2011) but should remain primarily focused on the narrative stories of situated experiences that transpire on the contextual landscape in which we all work (Clandinin \& Connelly, 2000). As such, the primary methodology of this study is narrative inquiry though the analysis was also influenced by elements of case study in the comparisons across teachers' narratives and elements of phenomenology in the exploration of the commonalities across the experiences of teaching climate change.

The main advantage of a narrative inquiry approach is that this methodology allows for a broad, flexible and multifaceted construct to describe teacher identity development. Narrative approaches, and specifically Clandinin and Connelly's perspective, highlight the linkages between knowledge, context, and identity 
(Clandinin and Huber, 2005) - all of which are crucial to describe the phenomenon under study. Narrative research methods also encourage and elicit more reflective selfanalysis in participant's stories as “it is only as we look back at our practices that we realize that who we are as a teacher has shifted" (Clandinin \& Huber, 2005, p. 58).

Besides promoting self-reflection, Schwarz (2001) also states that narrative research methods offer teachers a more humanistic and constructivist platform to share their stories, to develop their voices in practice, to build agency, and to empower their future learning. This constructivistic element is also one of the five features of narrative, or biographical research as he calls it, identified by Kelchtermans (1993). The other four characteristics include narrative, contextualistic, interactionistic, and dynamic elements. Advocating for taking this perspective for research efforts, he succinctly states that "to understand the lives [of teachers], one must get the story" (Kelchtermans, 1993, p. 454). He summarizes the advantages of a narrative research perspective by highlighting how "this approach reveals the way teachers experience their careers themselves, the way they make sense of the numerous events and experiences during their career and integrate them in their personal teaching style" (Kelchtermans, 1993, p. 454). This research approach offers numerous advantages to understanding the role of past and current events, future experiences, personal and social interactions, and the role of context in the development of one's teacher identity.

\section{Study Description}

Participants. The participants in this study are science teachers who teach or have taught climate change in their middle and high school classrooms (grades 5-12). The participants were recruited from teachers who have participated in climate change 
professional development provided by MADE CLEAR (Maryland and Delaware Climate Change Education, Assessment, and Research), a National Science Foundation funded Climate Change Education Partnership grant that provides professional development to Maryland and Delaware science teachers related to climate science and climate change. There were approximately 70 teachers who are past participants that were eligible for recruitment efforts. More demographic and background information on all 70 teachers and the fifteen teachers recruited for this study can be found in Chapter 4 .

Sampling. The sampling approach that was utilized is Intensity Sampling which allows for examination of "information-rich cases that manifest the phenomenon intensely, but not extremely" (Cresswell, 2007; Miles \& Huberman, 1994). The other criteria for selection was the completion of a climate change instructional unit (of their design) with their students. This sampling strategy was chosen to gather teachers with a range of experiences, teaching situations, and life histories as interesting cases of likely science teacher identity development as a teacher of climate change. While a diverse group was desired, this qualitative sampling approach was not intended to be generalizable in any traditional sense (Merriam, 2009). Included within the population of about 70 teachers were several teachers who had retired or moved out of their original district since participating in the Climate Academy professional development. If these teachers met the one criteria (enactment of climate change instruction) then they were included within the recruitment pools because they may be "able to provide especially rich personal history data" (Maxwell, 1996) from their years of classroom teaching experience. 
Rationale for sample size. In examining the research articles reviewed in Chapter 2 and narrative dissertations recently published and available online, I present a summary table of the methods employed and sample obtained in Table 3 . The range of samples is 1-69 participants, with an average of around 10-11 participants. I recruited a sample of 15 teachers to account for possible participant attrition, however no attrition occurred once research efforts began with each teacher.

Table 3 Rationale for Sample Size

\begin{tabular}{|c|c|c|c|}
\hline Authors, Year & Type & Methods & $\begin{array}{l}\text { Sample } \\
\text { Size }\end{array}$ \\
\hline Watson, 2006 & Article & $\begin{array}{l}\text { Interviews and follow-up } \\
\text { emails }\end{array}$ & 1 \\
\hline Mensah, 2012 & Article & $\begin{array}{l}\text { Interviews and card sort } \\
\text { reflections }\end{array}$ & 3 \\
\hline Varelas et al., 2005 & Article & Interviews & 3 \\
\hline Sfard \& Prusak, 2005 & Article & Interviews & 19 \\
\hline Pedretti et al., 2008 & Article & $\begin{array}{l}18 \text { paired interviews; } 6 \text { solo } \\
\text { interviews }\end{array}$ & 36 \\
\hline MacLure, 1993 & Article & Interviews & 69 \\
\hline Eick \& Reed, 2002 & Article & Interviews and reflections & 12 \\
\hline Drake et al., 2001 & Article & $\begin{array}{l}\text { Interviews and some } \\
\text { observations }\end{array}$ & 10 \\
\hline $\begin{array}{l}\text { Danielsson \& } \\
\text { Warwick, 2014a and } \\
2014 \mathrm{~b}\end{array}$ & Article & $\begin{array}{l}\text { Interviews - two per } \\
\text { participant }\end{array}$ & 11 \\
\hline $\begin{array}{l}\text { Carlone \& Johnson, } \\
2007\end{array}$ & Article & Interviews & 15 \\
\hline Bukor, 2011 & $\begin{array}{l}\text { Dissertation - } \\
\text { Narrative } \\
\text { Inquiry } \\
\end{array}$ & $\begin{array}{l}\text { Interviews and journal } \\
\text { reflections }\end{array}$ & 4 \\
\hline Dickinson, 2012 & $\begin{array}{l}\text { Dissertation - } \\
\text { Narrative } \\
\text { Inquiry } \\
\end{array}$ & Multiple interviews & 5 \\
\hline Exton, 2008 & $\begin{array}{l}\text { Dissertation - } \\
\text { Narrative } \\
\end{array}$ & Interviews and documents & 4 \\
\hline
\end{tabular}




\begin{tabular}{|c|c|c|c|}
\hline & Inquiry & & \\
\hline Harrison, 2014 & $\begin{array}{l}\text { Dissertation - } \\
\text { Narrative } \\
\text { Inquiry }\end{array}$ & Interviews and focus group & 14 \\
\hline Keefer, 2012 & $\begin{array}{l}\text { Dissertation - } \\
\text { Narrative } \\
\text { Inquiry }\end{array}$ & Interviews & 5 \\
\hline Lerseth, 2013 & $\begin{array}{l}\text { Dissertation - } \\
\text { Narrative } \\
\text { Inquiry }\end{array}$ & $\begin{array}{l}\text { Interviews and work sample } \\
\text { artifacts }\end{array}$ & 4 \\
\hline Lipsey, 2013 & $\begin{array}{l}\text { Dissertation - } \\
\text { Narrative } \\
\text { Inquiry }\end{array}$ & Multiple interviews & 4 \\
\hline Markis, 2012 & $\begin{array}{l}\text { Dissertation - } \\
\text { Narrative } \\
\text { Inquiry }\end{array}$ & $\begin{array}{l}\text { Interviews and reflection } \\
\text { journal }\end{array}$ & 6 \\
\hline Nonnes-Austria, 2011 & $\begin{array}{l}\text { Dissertation - } \\
\text { Narrative } \\
\text { Inquiry }\end{array}$ & Interviews and questionnaire & 5 \\
\hline Nugent, 2007 & $\begin{array}{l}\text { Dissertation - } \\
\text { Narrative } \\
\text { Inquiry }\end{array}$ & $\begin{array}{l}\text { Interviews and reflection } \\
\text { journal }\end{array}$ & 8 \\
\hline Rodgers, 2006 & $\begin{array}{l}\text { Dissertation - } \\
\text { Narrative } \\
\text { Inquiry }\end{array}$ & Interviews & 19 \\
\hline Wilson, 2014 & $\begin{array}{l}\text { Dissertation - } \\
\text { Narrative } \\
\text { Inquiry }\end{array}$ & Interviews & 4 \\
\hline Wilt, 2013 & $\begin{array}{l}\text { Dissertation - } \\
\text { Narrative } \\
\text { Inquiry }\end{array}$ & Interviews and reflections & 4 \\
\hline
\end{tabular}

Recruitment. Teachers were recruited via an email containing a brief letter introducing the study and asking if they would be interested in voluntarily participating in the research study. The recruitment letter contained details of the study 
such as a brief study purpose, criteria for participation, anticipated time commitments and expectations, and benefits and risks of participation.

Climate Academy as unifying experience. Participants were recruited in spring 2017 after their participation in the Climate Academy, a climate change focused professional development for teachers which started in summer 2013 and ran through spring 2017. Each cohort of the Climate Academy experienced a slightly different professional development experience as the professional development providers revised the Climate Academy's lessons based on feedback from the teacher participants, project evaluators, and the professional development providers themselves. Participants for this study were recruited from all four cohorts of the Climate Academy. As a result, participants in this study may have experienced the Climate Academy workshop anywhere from 4 years ago to currently wrapping up the workshop experience at the time of the interviews.

Study participants as representative of Climate Academy participants. While participants in the Climate Academy professional development workshop could be formal educators, informal educators, or science administrators, for the current study the experiences of formal classroom teachers were the main focus. Therefore, out of a total of 117 Climate Academy participants, 28 participants were removed from consideration due to their teaching placement (6 science supervisors and 22 informal educators). Additionally, current contact information for 20 teachers could not be determined due to changes in school placement, retirements, or other types of relocation over the years since their participation in the Climate Academy. Since there was no way to reach these participants, they were also removed from further 
consideration for the current study. This left 69 possible teachers as the total population of classroom teachers who had participated in the Climate Academy.

Using intensity sampling (Creswell, 2007; Miles \& Huberman, 1994), whereby teachers showcase meaningful, but not overly excessive experience with climate change instruction, study participants were sequentially recruited to obtain a sample where key demographics of the sample were nearly representative of the entire Climate Academy teacher population. In total, 22 teachers were invited to participate, 15 ultimately agreed and participated, while one declined outright due to time constraints, one teacher agreed then later declined, and five teachers did not respond to the invitation.

\section{Data Collection Procedures}

The primary data collection method is individual, in-depth interviews because as Kvale plainly states: "If you want to know how people understand their world and their life, why not talk with them?" (Kvale, 1996, p. 1). My interview style reflected a conversational (Kvale, 1996), responsive, and flexible (Rubin \& Rubin, 2012) approach. At the request of the participants due to the geographic spread and/or personal schedules, all interviews were conducted via Skype or over the phone - even after I made repeated offers to meet the teachers at a convenient location of their

choosing. Due to my prior relationship with the teachers during the Climate Academy professional development workshops, I believe this format was not a determinant to the quality of our conversations.

Data sources. Primary data sources include two interviews per teacher and a written reflection on their climate change instruction. The first interview focused on gaining a good sense of the teacher's personal narrative of science teaching (their 
preparation and teaching experiences) as well as their general personal relationship with science (early encounters and more recent science experiences). The second interview pivoted to more closely focus on climate change teaching experiences, and the teacher's preparations and reflections on these experiences in their classroom.

The semi-structured interview protocols and reflection survey can be found in Appendix A. Each interview was intended to take about 60 minutes, though in practice ranged from $40-75$ minutes in duration. All interviews were digitally recorded by the researcher and transcribed verbatim.

An additional primary source of data is a written reflection completed by the teacher after the two interviews. This reflection included prompts for the teacher to think back about the planned design and the actual enactment of their most recent climate instruction experience. From my prior work with many of these teachers, I understand that climate change is taught at different times throughout the year depending on the various science curricula in place across the two states. Therefore, neither the interviews nor the reflection was required to be completed immediately after instruction. Instead, teachers were asked to think about their most recent instances of climate change instruction to complete the reflection prompts and when participating in the interviews.

\section{Ethical Considerations}

Narrative researchers do their work by (politely) intruding on people in the course of living real lives and asking them to help us learn something. We do this in hopes that what we learn will be of some benefit to others or will contribute to basic knowledge about aspects of human experience. (p. 538) 
As I conducted this study, the above quote by Josselson (2011) remained in the forefront of my perspective. As Hunter pointed out, "representing and interpreting another's voice is not a simple task and needs to be done with respect and humility" (2010, p. 50). I also acknowledge that too often research relationships between researcher and participant are one-sided with the researcher to benefit nearly exclusively. I worked to make "polite intrusions" (Josselson, 2011) and offer beneficial opportunities for personal reflection and development throughout the research process. Kelchtermans described the researcher's role in this type of narrative inquiry as "active, interested, and non-evaluative listening and observing" and that each person's stories should be "listened to with alert open mindedness" (1994, p. 101). I purposefully sought to integrate these mindsets into my approach through clarification of the non-evaluative function of the interviews prior to starting and a genuine and attentive interest in my conversations with the teachers.

Data management. I created a research database to organize, protect, and store the collected data as suggested by Yin (2014). Any paper copies of data artifacts or reflections were scanned and stored electronically. Hard copy consent forms were also scanned and stored electronically. All electronic project data is encrypted and stored in password protected digital folders. Any remaining hard copies of data are stored in a locked metal file cabinet and stored and saved pursuant to IRB guidelines.

Human subjects protections. Throughout the research project, I protected the teachers as guided by University of Delaware's IRB procedures. Prior to beginning the study, I sought and obtained IRB approval. During the study, I made sure to: gather informed consent from all participants; protect them from harm, which included protecting their privacy and confidentiality through the use of pseudonyms for their 
names, schools, and any other potentially identifiable details; and I followed all other guidelines as required by the IRB. Relevant documents from University of Delaware's Institutional Review Board (i.e. approval documents, continuing review documents, and approved consent forms) can be found in Appendix B.

\section{Data Analysis}

Transcription of interviews. All digital audio files of the interviews were transcribed verbatim for data analysis purposes. However, I worked to follow Kvale's advice: "Do not conceive of the interviews as transcripts: The interviews are living conversations" (1996, p. 182). The stories shared with me during the interview process were highly personal reflections. I made sure to recall that these ideas were not just collected by me, but instead they were "co-authored" (Kvale, 1996) between myself and the teacher and deserved an appropriate reverence.

Analytic approach. The interview transcripts and reflections were analyzed in two phases. Each phase was comprised of multiple steps the employed a reflexively iterative process. Broadly, phase 1 focused on vertical analysis to better understand who the teachers are, along with their backgrounds in science learning and teaching and their general experiences teaching climate change. Then the goal of phase 2 was to compare these personal, professional, and contextual or political elements of the climate change teaching experiences in order to construct a conceptual model for identity construction amongst the teachers. Over the next few paragraphs, I describe the analytic steps of each phase in more detail.

Phase 1 - step 0. Prior to any true analysis, the characteristics of the overall Climate Academy participants and the 15 study teachers were examined for their similarity. Quantitative means for statistical comparison were not employed due to 
sample size but a comparison of the population and the sample demonstrate the relative representative nature of these 15 teachers for the larger population of Climate Academy participants. Next, more detailed demographics and attributes of the 15 teachers were explored to denote the types of school placements, geographic locations, teaching experience, and etcetera.

Phase 1 - step 1. Next, I read the two interview transcripts and reflection of each teacher to get an overall sense of the narrative structure and each teacher's voice and I took the opportunity to "pre-code" (Layder, 1998) by highlighting interesting or noteworthy passages of the conversations. During these readings, I made initial notes on the possible "code-able moments" (Boyatzis, 1998) via preliminary jottings (Saldaña, 2013). I continued to read each set of teacher's documents iteratively as suggested by Saldaña (2013) and Bazeley (2007) to develop a "good Gestalt" (Josselson, 2011) to consider "how the whole illuminates the parts, and how the parts in turn offer a fuller and more complex picture of the whole, which then leads to a better understanding of the parts" (Josselson, 2011, p. 227). Throughout this process, more detailed jottings and initial thinking displays (Miles \& Huberman, 1994) were created to describe personal, professional, and political elements (where present) throughout each teacher's past, present, and future. These jottings and matrices are included in Appendix C.

The last part of this first analytic step was to create a narrative profile for each participant to briefly summarize their experiences, goals, motivations, etc. to demonstrate my initial understanding of their storied identities related to climate change teaching. These teacher narratives served to "distill the essence of the biography into more manageable form, retaining the teacher's 'ordinary' language for 
the most part, but organizing the material in a sociologically meaningful way" (Woods, 1985, p. 23). Kelchtermans (1994) describes the creation of these types of narrative profiles as a critical step in the research process and as more involved than simply relaying anecdotes or straightforward reporting of teachers' experiences. He recommends several general principles that I followed during the development of these profiles. They include: "careful phrasing (avoiding ambiguity), staying close to the original transcripts (use quotations), continuous checking of the interpretations, avoiding judgments (non-evaluative attitude" (Kelchtermans, 1994, p. 99). In these profiles I also included examples of how each teacher described their enactment of climate change teaching in their classroom and the motivations behind some of the pedagogical choices as shared during the teacher interviews and reflections. These profiles served as additional field texts (Clandinin \& Connelly, 1994) for the subsequent steps of this narrative inquiry.

Phase 1-step 2. Step 2 of phase 1 is where the deeper vertical analysis began. Each set of teacher documents were read once again and coded via structural coding (MacQueen, McLellan-Lemal, Bartholow, \& Milstein, 2008; Saldaña, 2013) utilizing the a priori codes from Clandinin and Connelly's Three-Dimensional Narrative Structure (2000) due to the close relationship between this theoretical framework and the research questions. The a priori codes were comprised of: personal, social, contextual, past, present, future. After all documents were coded preliminary quantitative analyses of code frequency by person, and by teacher attributes (i.e. high school vs. middle school, novice vs. veteran from Table 10 in Chapter 4) were conducted. No patterns or explanations were uncovered in these code frequency comparisons, so I progressed to the next step to dive more deeply into attempting to 
understand each teacher. However, I will note that these a priori codes allowed me to index segments of the transcripts that would prove to be useful in the analysis needed for each separate research question in subsequent steps (Namey, Guest, Thairu, \& Johnson, 2008).

Phase 1 - step 3. In this section of my analysis, I sought to unpack the broader codes employed in step 2 to get at a more nuanced understanding of the personal, social, and contextual components so I utilized descriptive coding (Miles \& Huberman, 1994; Wolcott, 1994). Once again, each teacher's complete set of documents (two interview transcripts and one reflection) were coded together to develop the clearest mental picture for each teacher. The selection of the first four teachers to be coded was purposeful so that they contrasted from one another in their attributes (middle school vs. high school, male vs. female, novice vs. veteran, traditional preparation routes vs. alternative certifications). From this first grouping of teachers to be analyzed, a preliminary set of codes were developed that was then used to code the remaining teachers' documents. Throughout the descriptive coding process, codes were revised, lumped, split to clarify each code and its description as needed. Additionally, I was open to the development of new emergent codes as needed to appropriately represent the data and to avoid forcing ideas into preconceived categories (Glaser, 1978). The final version of the codebook can be found in Appendix D. These codes underwent "code landscaping" (Saldaña, 2013) and are presented in an outline format to organize them by the several emergent categories of teacher, science teacher, and climate change educator. Once again, preliminary quantitative analysis of the frequency of codes by person and by teacher attributes produced no clear pattern of characteristics. In other words, for example there was no evidence high school 
teachers acted in some fashion or exhibited one code in a habitually different manner from the middle school teachers.

From these first two analytic steps (structural coding, then descriptive coding), I revised the preliminary narrative profile for each teacher to better organize my initial ideas into an individual profile story (Kelchtermans, 1993) of their identity as a teacher of climate change. This collection of analytic steps in phase 1 assisted me to understand the uniqueness and internal coherence of each teacher's experiences in identity development through vertical analysis (Kelchtermans, 1993). In summary, the teacher jottings and visual representations of the data matrices are presented in Appendix C. The code frequencies and codebook of descriptive codes are found in Appendix D and the final versions of the narrative profiles for each teacher are included with the study results in Chapter 4.

Phase 2 - step 4. In phase 2, a horizontal analysis (Kelchtermans, 1993) or a cross-case analysis explored across the participants' interview transcripts, reflections, and narratives (Josselson, 2011). Patterns of similarities or differences were explored through constant comparative analysis (Merriam, 2009). To start, each set of teacher's documents were re-read to review the key ideas from each narrative profile and were coded again via theoretical coding (Corbin \& Strauss, 2008; Saldaña, 2013) to highlight the major themes of personal, professional, and political elements for identity development. These three categories closely parallel the original structural codes from the Three-Dimensional Narrative Structure (Clandinin \& Connelly, 2000) whereby generally personal structural codes remained personal theoretical codes, social structural codes were similar to professional theoretical codes, and contextual structural codes were similar to political theoretical codes. 
However, there was not always a direct correlation between the earlier a priori structural codes and the emergent theoretical codes. Yet, these three theoretical codes of personal, professional, and political elements allowed for a more nuanced description of identity development specific to the social nature of teaching and the potentially controversial context for teaching climate change. At this point, I also applied the three theoretical codes to the 18 descriptive codes to parse out and categorize the varying influences on identity development for teachers of climate change as either personal, professional, or political. This iteration of coding and horizontal analysis sought to uncover "a set of recurring patterns and common themes among the professional biographies of the respondents" (Kelchtermans, 1994) and these themes were more fully developed via "code-weaving" (Saldaña, 2013) in the next step and are described in the subsequent section.

Phase 2-step 5. Once the transcripts were coded using these theoretical codes, I sought to organize the codes temporally into a thinking display (Miles \& Huberman, 1994) to visually represent how the 18 different descriptive codes from Phase 1, Step 3 were associated within the three theoretical codes applied in Phase 2, Step 4. Within this step, I employed Saldaña's approach to "code-weaving" (2013) to understand how individual codes were woven together into a larger network of influences on identity development for teaching climate change. I present an extended example of my approach to code-weaving in Appendix E, but generally speaking this code-weaving or operational model diagramming (Saldaña, 2013) allowed me to "disentangle the threads of our analysis and present results in a coherent and intelligible form" (Dey, 1993, p. 192). The final product is a conceptual model that is composed of the three theoretical codes of personal, professional, and political 
elements. During this phase I also employed constant comparative analysis to describe the characteristics of the teacher narratives and codes within the model to identify and describe the four types of identity constructions present in this study. Further description of these findings and the model are found in Chapter 4.

Phase 2 - step 6. Lastly, the final analytic step sought to link the vertical analyses with the horizontal analyses. From the two different approaches to analysis, in this step I aimed to "enter back into conversation with the larger theoretical literature" as suggested by Josselson (2011). Yet, I prioritized the voices portrayed as well as the content and structure of the teacher narratives, and I worked to keep my own presuppositions at a distance during this time. During this final analysis, I placed each teacher within the conceptual model and identified examples from their interviews and reflections to demonstrate how they enacted these identity constructions for teaching climate change and examples of descriptions of their climate change instruction. This final section demonstrates the bridge between the teachers' experiences and the emerging theory in development in Chapter 5.

Establishing trustworthiness. In following the suggestions of Creswell (2009), Gibbs (2007) and Rubin and Rubin (2012), I enacted the following plan of procedures to ensure trustworthy findings by checking for the accuracy to establish qualitative validity.

Over the course of this study, I selected teachers who have deep firsthand experiences in teaching climate change to keep the results "fresh and real" (Rubin \& Rubin, 2012), chose teachers that showcased a wide spectrum of teaching experience levels and geographic locations to maintain balance across the various stories, examined my data and my ongoing analysis for gaps and to consider alternative 
explanations wherever appropriate, strove to maintain the nuance of the teacher narratives by utilized detailed examples of experience in their own words.

Additionally, I employed strategies in an attempt to develop "converging lines of inquiry" (Yin, 2014) by: conducting peer debriefing when developing interpretations and coding schemes, maintaining a chain of evidence that was accompanied by detailed notes and descriptions of the procedures I am employed; seeking to avoid or bracket my own research bias through on-going self-reflection; and collecting similar data from several interviews and reflections to triangulate these efforts.

\section{Limitations}

While I have established the benefits of a methodology for narrative inquiry and my efforts to act ethically and to establish trustworthiness in my findings, I acknowledge that all research studies suffer from some limitations. First, I only recruited teachers who participated in the Climate Academy professional development activities. However, the goal of this study was not to present the Climate Academy as the gold standard for climate change professional development. I justify this choice as these are teachers who are truly motivated to engage in climate change teaching and have had extensive prior experiences teaching climate change. Also, these teachers self-selected to participate in the Climate Academy based on a desire to improve their practice, so it is likely that they also may be able to offer more reflective insight into their experiences as a result of this motivation to improve. This recruitment strategy has a secondary limitation as well in that the teachers all come from a fairly limited geographic area of two Mid-Atlantic states. I justify this data collection decision in that I believe I was able to obtain an interestingly diverse sample of teachers as these 
two states vary widely in numerous sociocultural and geographic factors. The areas from which I recruited teachers also implement different educational systems with local district curricular control in one area and a state-wide curriculum in the other state.

Another limitation of this study is that interviews serve as the primary data collection method. As Woods notes, that participants sometimes do not tell the whole truth or "they may tell the truth as they perceive it, but it may not represent what they felt or believed at that time - in other words, past events and states may be interpreted through current perceptual frameworks, and in the process transformed" (1985, p. 17). This phenomenon may be overcome by developing a trusting and respectful relationship with each teacher that lacks any hint of evaluative roles. Woods suggests to "cultivate the art of good listening... with a way of being interestedly quiet, with a smile, a slight look of astonishment, a tut, a what can you do about that look, or a isn't that always the way" (1985, p. 20). These informal contributions to the conversation act as reassurance to the teachers that I am listening and value their contributions while also probing more deeply to understand their motivations for sharing particular stories. Yin (2014) also describes a weakness in relying predominantly on interviews in that the participants may provide answers that they believe the researcher is seeking. As described earlier, I took a conversational approach (Kvale, 1996) to the interviews to establish a rapport with the teachers to encourage them to be comfortable expressing their true ideas (Yin, 2014). I also justify my selection of interviews as a primary data collection approach as my research interests are closely related to the meaning and the sense they make from their experiences and their relationship to their teaching - but not in the actual enactment of instruction itself. In other words, I am 
attuning my research focus on their perceptions of and reflections on teaching climate change as opposed to their teaching efficacy in climate change lessons.

A final limitation is that I did not employ a second coder for the multiple iterations of coding and analysis. However, I did not work completely in isolation and often discussed my ideas as they were under development with a high school teacher and colleague not affiliated with the overall research project. As Saldaña points out: "Discussion not only provides an opportunity to articulate your internal thinking processes, but also presents windows of opportunity for clarifying your emergent ideas and possibly making new insights about the data" (2013, p. 36). Throughout the research study, I attempted to be overly descriptive in the analytic process and in the descriptions of my findings to clearly demonstrate the steps that I took. Additionally, I incorporated numerous direct quotes to represent these findings in the original words of the teacher to build authenticity and reproducibility in my analysis.

\section{Chapter 3 Summary}

This chapter describes the narrative inquiry methodology I employed for data collection and analysis in this study. These methods allowed me to examine the professional and personal stories of science teachers and their experiences related to the enactment of their climate change lessons. Utilizing conversational interviews and reflections, I sought to apply the theoretical construct of identity and Clandinin and Connelly's (2000) Three-Dimensional Narrative Structure to better understand how teachers developed perspectives related to their role and identity as climate change educators and to address my research question of: How do teachers' lived experiences shape their science teacher identity development as a teacher of climate change? In the next chapter, I present the findings from the multiple iterations of coding and analysis 
to share the teacher narratives and identity constructions related to their climate change teaching experiences. 


\section{Chapter 4}

\section{RESULTS}

In this chapter, I present the findings of this study distributed over five sections. The first section, I highlight the similarities between the overall Climate Academy teacher population and the current study participants as an analytic 'step 0'. In the second section, the fifteen teachers are showcased through summaries of their personal narratives. In the third section, I focus on the different characteristics and attributes of each teacher uncovered during the vertical analysis. The fourth section turns to the results of the horizontal analysis and shows how the codes coalesced into broader patterns of experiences teaching climate change. The overall conceptual model and the four emergent aspects of identity for teaching climate change are discussed. In the final section, I show how each teacher demonstrates various identity aspects of the conceptual model. I conclude the chapter with a summary of the relevant findings.

\section{Section 1: Participant Characteristics}

Pilot study. From the original population of Climate Academy teachers, one teacher was initially recruited to act as a pilot participant to field-test the interview protocols and reflection survey. As a result of this piloting, no significant changes were made to the interview protocols. Therefore, no additional pilot testing was deemed necessary and this teacher was included in the current study sample of 
teachers as she differed in no significant ways from the other teachers recruited for participation.

Main study. As described in the methods chapter 3, 15 teachers were recruited to participate in this study to obtain a sample that was generally representative of the overall population of Climate Academy teachers. Tables 4-9 showcase the key characteristics of the 15 study teachers and the larger collection Climate Academy participants. From the entire Climate Academy population, $63.7 \%$ of participants were from Maryland school districts and 36.2\% from Delaware school districts. In the study sample, slightly more representation comes from Maryland (73.3\%) than from Delaware (26.7\%) as seen in Table 4. As shown in Table 5, the Climate Academy had a gender split of $30.4 \%$ male to $69.6 \%$ female, but the study sample is more heavily weighted to females due to an unavoidable sampling occurrence $(13.3 \%$ male, $86.7 \%$ female).

The school type of $55.1 \%$ of the Climate Academy population was middle school placements, while $33.3 \%$ were high school placements and $11.6 \%$ were other school types (i.e. joint middle/high schools). In the current sample, as seen in Table 6, one teacher taught in a joint middle/high school, though teaches only high school students; in later analyses she will be classified as a high school teacher. The other 14 teachers in the current sample were distributed with $60.0 \%$ at middle schools and $33.3 \%$ at high schools.

The two study states have a charter school system. Table 7 shows that $7.2 \%$ of the original Climate Academy population and $6.7 \%$ of the current teacher participants came from charter school systems. Table 8 highlights the geographic locale classification based on each school's location as determined by the National Center for 
Education Statistics Common Core of Dataset (NCES, 2018). The two most frequent classifications of 21 suburb, large and 41 rural, fringe are well represented in both the original Climate Academy population (39.5\% and $14.5 \%$ respectively) and the current teacher sample (33.3\% and $26.7 \%$ respectively).

Lastly, student demographic statistics were investigated for the schools of the Climate Academy participants and study teachers. Table 9 shows the means and medians for the schools' FARMS (free and reduced meals) percentage and the proportion of the student population that is identified as Caucasian. Tables 4-9 demonstrate clearly that the 15 teachers recruited for the current study justifiably represent the larger population of Climate Academy teachers. While as in any qualitative research, the results are not meant to be overly generalizable, but the findings of this study should represent the likely beliefs, understandings, orientations, motivations, etc., of the broader population of Climate Academy participants.

Table 4 State Representation of Participants

\begin{tabular}{|l|l|l|l|l|}
\hline & \multicolumn{2}{|l|}{ All Climate Academy Teachers } & \multicolumn{2}{l|}{ Current Study Participants } \\
\hline Maryland & $\mathrm{N}=44$ & $63.7 \%$ & $\mathrm{~N}=11$ & $73.3 \%$ \\
\hline Delaware & $\mathrm{N}=25$ & $36.2 \%$ & $\mathrm{~N}=4$ & $26.7 \%$ \\
\hline
\end{tabular}

Table 5 Gender Representation of Participants

\begin{tabular}{|l|l|l|l|l|}
\hline & \multicolumn{2}{|l|}{ All Climate Academy Teachers } & \multicolumn{2}{l|}{ Current Study Participants } \\
\hline Male & $\mathrm{N}=21$ & $30.4 \%$ & $\mathrm{~N}=2$ & $13.3 \%$ \\
\hline Female & $\mathrm{N}=48$ & $69.6 \%$ & $\mathrm{~N}=13$ & $86.7 \%$ \\
\hline
\end{tabular}


Table $6 \quad$ School Types of Participants

\begin{tabular}{|l|l|l|l|l|}
\hline & \multicolumn{2}{|l|}{ All Climate Academy Teachers } & \multicolumn{2}{l|}{ Current Study Participants } \\
\hline Middle School & $\mathrm{N}=38$ & $55.1 \%$ & $\mathrm{~N}=9$ & $60.0 \%$ \\
\hline High School & $\mathrm{N}=23$ & $33.3 \%$ & $\mathrm{~N}=5$ & $33.3 \%$ \\
\hline Other School Type & $\mathrm{N}=8$ & $11.6 \%$ & $\mathrm{~N}=1$ & $6.7 \%$ \\
\hline
\end{tabular}

Table 7 Charter School Representation of Participants

\begin{tabular}{|l|l|l|l|l|}
\hline & \multicolumn{2}{|l|}{ All Climate Academy Teachers } & \multicolumn{2}{l|}{ Current Study Participants } \\
\hline Charter School & $\mathrm{N}=5$ & $7.2 \%$ & $\mathrm{~N}=1$ & $6.7 \%$ \\
\hline Not a Charter School & $\mathrm{N}=64$ & $92.8 \%$ & $\mathrm{~N}=14$ & $93.3 \%$ \\
\hline
\end{tabular}

Table $8 \quad$ Geographic Locale Classifications

\begin{tabular}{|l|l|l|l|l|}
\hline & \multicolumn{2}{l|}{ All Climate Academy Teachers } & \multicolumn{2}{l|}{ Current Study Participants } \\
\hline 11 (City, Large) & $\mathrm{N}=3$ & $4.3 \%$ & $\mathrm{~N}=1$ & $6.7 \%$ \\
\hline 13 (City, Small) & $\mathrm{N}=9$ & $13.0 \%$ & $\mathrm{~N}=1$ & $6.7 \%$ \\
\hline 21 (Suburb, Large) & $\mathrm{N}=27$ & $39.1 \%$ & $\mathrm{~N}=5$ & $33.3 \%$ \\
\hline 22 (Suburb, Midsize) & $\mathrm{N}=6$ & $8.7 \%$ & $\mathrm{~N}=1$ & $6.7 \%$ \\
\hline 23 (Suburb, Small) & $\mathrm{N}=1$ & $1.4 \%$ & $\mathrm{~N}=0$ & $0 \%$ \\
\hline 31 (Town, Fringe) & $\mathrm{N}=3$ & $4.3 \%$ & $\mathrm{~N}=1$ & $6.7 \%$ \\
\hline 32 (Town, Distant) & $\mathrm{N}=4$ & $5.8 \%$ & $\mathrm{~N}=1$ & $6.7 \%$ \\
\hline 41 (Rural, Fringe) & $\mathrm{N}=10$ & $14.5 \%$ & $\mathrm{~N}=4$ & $26.7 \%$ \\
\hline 42 (Rural, Distant) & $\mathrm{N}=6$ & $8.7 \%$ & $\mathrm{~N}=1$ & $6.7 \%$ \\
\hline
\end{tabular}


Table 9 Student Population Characteristics

\begin{tabular}{|l|l|l|l|l|}
\hline & \multicolumn{2}{|l|}{$\begin{array}{l}\text { All Climate Academy } \\
\text { Teachers }\end{array}$} & \multicolumn{2}{l|}{ Current Study Participants } \\
\hline $\begin{array}{l}\text { Student Population } \\
\text { FARMS \% }\end{array}$ & Mean=37.5\% & Median=36.0\% & Mean=36.5\% & Median=25.1\% \\
\hline $\begin{array}{l}\text { Student Population } \\
\text { White \% }\end{array}$ & Mean=46.0\% & Median=53.5\% & Mean=51.0\% & Median=58.5\% \\
\hline
\end{tabular}

Participant demographics. Table 10 lists the fifteen teachers participating in this study where all names are pseudonyms. Key characteristics of the teachers including their gender, teaching placement type, general school location, the type of teacher preparation model they experienced, and their classroom teaching experience are displayed. In short, there are thirteen female teachers and two male teachers, and six high school and nine middle school teachers. The schools were distributed such that there were two urban areas, seven suburban areas, and six rural area schools. Five of the teachers came to the classroom via alternative certification routes after working in other professions, while the other ten hold traditional undergraduate and/or graduate teaching degrees and licensures. Six teachers are considered novices with five years of teaching experience or less and the other ten teachers have at least six years (and up to 18 years) of teaching experience. 
Table 10 Additional Teacher Demographics

\begin{tabular}{|l|l|l|l|l|l|}
\hline $\begin{array}{l}\text { Name } \\
\text { (pseudonyms) }\end{array}$ & Gender & School Type & $\begin{array}{l}\text { School } \\
\text { Location }\end{array}$ & $\begin{array}{l}\text { Teacher } \\
\text { Preparation }\end{array}$ & $\begin{array}{l}\text { Teaching } \\
\text { Experience } \\
\text { (Veteran }>5 \\
\text { years) }\end{array}$ \\
\hline Amanda Kerry & Female & High School & Suburban & Alternative Route & Novice \\
\hline Barbara Pender & Female & Middle School & Rural & Traditional & Veteran \\
\hline Beverley Sanders & Female & High School & Rural & Traditional & Veteran \\
\hline Connie Stevens & Female & Middle School & Urban & Traditional & Veteran \\
\hline Emily Skand & Female & Middle School & Suburban & Traditional & Veteran \\
\hline Fiona Henry & Female & Middle School & Rural & Traditional & Novice \\
\hline Fred Robbins & Male & Middle School & Suburban & Traditional & Veteran \\
\hline Garrett Tresler & Male & High School & Suburban & Traditional & Novice \\
\hline Karmen Losa & Female & High School & Suburban & Alternative Route & Veteran \\
\hline Krista Czapkas & Female & High School & Rural & Traditional & Novice \\
\hline Mary Jenkins & Female & High School & Rural & Alternative Route & Novice \\
\hline Melissa Eckerds & Female & Middle School & Rural & Traditional & Veteran \\
\hline Tara Thorpe & Female & Middle School & Suburban & Traditional & Novice \\
\hline Veronica Acker & Female & Middle School & Suburban & Alternative Route & Veteran \\
\hline Wanda Katz & Female & Middle School & Urban & Alternative Route & Veteran \\
\hline
\end{tabular}

Section 1 presented the findings related to my recruitment efforts to invite a diverse group of science teachers to participate in this study. I demonstrated how the 15 study teachers are similar to the larger population of Climate Academy past participants and how the 15 teachers are distributed across various professional attributes.

\section{Section 2: Teacher Narrative Profiles}

These initial quantitative findings of this study just presented paint the participants in broad strokes. In the following section, I present the results from Phase 1, Step 1 of my analysis: a summary of each teacher to better establish their narrative profile and lived experiences. These are the final versions of the profiles revised after 
the vertical analysis process. Earlier preliminary jottings and data matrices that served as initial profile summaries for each teacher can be found in Appendix C.

Amanda Kerry narrative profile. Amanda is a special education teacher for science at a suburban high school. A novice teacher with 5 years of classroom experience, she predominantly coteaches biology and environmental science courses for students with special learning needs. She originally pursued an animal science degree and came to teaching via alternative certification, first in biology and then in special education when no biology positions were available. "So, I feel more science than I do special education, but I'm paid by them. And they kind of control my life, so it's a tricky wicket" (Amanda, Interview \#1). Though she is new to teaching in a formal classroom, she has earlier instructional experience in informal conservation focused lessons as an educational interpreter at Disney’s Animal Kingdom park, which capitalized on her deep love of animals. "I really was not interested in science until I went to college. I didn't really like science that much, but I've always liked animals" (Amanda, Interview \#1). She described poignant memories of interacting with everything from cicadas to potbelly pigs to ostriches. Her focus is clearly more life science-oriented than science in general: "You know even I think I like nature more than science" (Amanda, Interview \#1).

Encouraging her students to also enjoy nature and have fun with science are her primary professional goals. "I think my biggest goal, and this is probably not exactly PC [politically correct], but really my biggest goal is always to make the students love science" (Amanda, Interview \#1). Drawing connections between her personal experiences with animals help to bring the curriculum to life for her students, 
since many of them have difficulty learning in general, and especially with complex science topics. She is challenged by the exceptional testing demands on her students and reports an extremely limited number of instructional days between April and June that are not negatively impacted by some type of high stakes testing, exam makeups, or extended time for her special education students. These testing demands limit Amanda's time and agency to diverge from her mandated curriculum on tested topics. Instead, she exhibits a deep empathy for her students and commiserates about the unfortunate pressures placed on them through high stakes testing and other learning challenges. "But they know that I care. And sometimes that's just worth it" (Amanda, Interview \#1). Amanda is sensitive to needing to prepare her students but also strives to make learning fun, engaging, and even entertaining for her students. "If it's fun to do it, then they are paying more attention. And the learning kind of slips in there" (Amanda, Interview \#2).

Amanda's focus on fun extends to her climate instruction as well. In fact, it seemed to be the primary motivation behind her inclusion of climate change as a topic of instruction. Amanda spoke of searching for "new, fun, engaging activities" to incorporate into her curriculum and climate change is one topic that she feels her students are interested to learn more about during her class. She wants to continue to teach climate change because it is a topic that she is now prepared to include because the Climate Academy provided her with more engaging and fun activities for her students. For example, Amanda added a greenhouse effect tag game that she played outside with her students, complete with pun-oriented name cards that Amanda developed for the activity like 'It's not easy being green-house gas'. She also brought in other interactive labs that she felt were fun for her students like a "water-stacking" 
activity that focused on density concepts and during which Amanda highlighted how changes in density and salinity would influence the oceans. She incorporated these "games" and fun activities with no negative pushback from her administration, nor students and believes that the students "enjoyed [the lessons] and they learned, and that's the whole goal" (Amanda, Interview \#2).

Amanda also felt that some of these activities were better suited to meet her students' learning needs. She spoke about doing a seasonal shift activity in which students act out the roles of birds and blooming flowers and she believes that her students really understand the negative impacts of a seasonal mismatch from this experience. "It was pretty easy to see, and we have a lot of ESOL [students] too, so even with the language barrier it was very visual and so it was really good. I liked that one a lot and it was fun too" (Amanda, Interview \#2). She did not describe any deep personal connection to the issue of climate change: "I mean animals are important to me, so the environment is important to me, but climate change itself is not..." (Amanda, Interview \#2). She also mentioned in passing a desire for students to make good decisions for the environment in the future, but this thought was clearly secondary to a desire to incorporate fun opportunities for learning about climate change.

Barbara Pender narrative profile. Barbara is a veteran middle school science teacher who is currently participating in a Teacher on Loan program through a federal government organization focused on science research and outreach. She plans to return to teaching $6^{\text {th }}$ grade science when her time ends working with science learners of all ages through the Teacher on Loan program. Barbara has spent her entire 
teaching career (over 16 years) in the same rural community and has developed deep ties to the area. These ties extend beyond the people into the natural environment around her. She fondly recalled an early love of nature: "I was always outside, which is where my wrinkles come from. I'm happiest outdoors and in nature" (Barbara, Interview \#1).

Barbara highlighted numerous early and more recent memories of being outside and developing a love for nature not only personally but also sharing that passion for learning about science and the natural world with her students. "The words that reverberate in my head are the more I learn, the more I know there is to learn. I mean that's the cool thing about science. It's not static, it's amazing. There's always something out there and it's relevant and it's authentic too" (Barbara, Interview \#1). Barbara spoke of how she would bring into her instruction stories of her youth and stories of positive environmental action after the enactment of the Clean Air and Water Acts. She also shares with her students that she is personally "passionate" about the environment and nature.

She has enjoyed numerous opportunities for meaningful science learning over her adolescent and adult life. Barbara's primary goal is to share that love of science and its real-world connections to "build some scientific literacy in our communities so that people make better decisions about things that affect all of us" (Barbara, Interview \#2). Professionally Barbara is afforded great curricular flexibility and instructional agency to design lessons to meet that goal. For example, her students have created schoolyard rain gardens and done projects to eradicate phragmites (an invasive plant) in order to bring meaning and opportunities for personal empowerment to combat the negative impacts of local environmental issues. She attributes this pedagogical 
freedom to teaching in a "rinky-dink little school" in a rural area. This drive towards developing scientific literacy in her students focuses on building personal and geographically local connections to environmental issues, like climate change.

She has a strong personal motivation to teach climate change in order to protect our planet for current and future generations. In the past, her efforts towards climate change education were met with some pushback from the community regarding the perceived controversial nature of the topic. However, even at that time 8-10 years ago, she felt supported by her administration to continue her instruction on climate change. She works to highlight the scientific evidence for climate change in her approach and reports not having these types of politically driven challenges any longer. "And I have seen attitudes shift with kids, year after year. We don't just 'believe' in climate change, we understand the data and there's less of a pushback" (Barbara, Interview \#2). She aims to expose her students to broader perspectives than the localized ideology that currently leans away from scientifically accurate understandings.

She further justifies her inclusion of climate change by highlighting the placement of climate change and human impacts on the environment in the Next Generation Science Standards (NGSS) which her school district quickly adopted several years ago. But beyond just needing to know about the topic, Barbara strives to prepare her students to be environmentally responsible citizens and to ready them to participate in future action towards mitigation and adaptation. "I think that once they have the background knowledge, you start with the content and the local issues, and then you move them towards the 'so what?' and 'now what can we do about it?'. And 
at the very least, to lay that groundwork to make critical decisions that affect them when they're older" (Barbara, Interview \#2).

She continued to explain how she demonstrates that the local area and nearby islands where her students' families grew up are becoming uninhabitable due to sea level rise and other impacts of climate change. Barbara highlights the valuable "symbiotic relationship" between where her students live and their natural surroundings through historical photos and media demonstrating the longstanding connection to their environment. By focusing on the clear changes that are already underway in their local community, Barbara motivates her students to grab onto that "watershed moment" (Barbara, Interview \#2) for the issue and to become better informed to participate in future social action to protect the environment they collectively love and value.

Beverley Sanders narrative profile. Beverley is a high school chemistry teacher who teaches various chemistry courses and a newly introduced, required freshmen course called Physics of Earth and Space Science. She is a veteran teacher of 11 years and is the science department chair for her rural high school. Beverley has extensive chemistry focused content knowledge and research experience from her undergraduate studies. While most of her formal training is in chemistry, more recently she has begun to get interested in learning more about agricultural and life sciences as her family now lives on a working farm with numerous cows, pigs, chickens, and other farm life. Beverley was inspired to be a chemistry teacher by her own high school chemistry teacher and the innovative science learning opportunities that she experienced. She enjoyed the challenge of "hard sciences" and works to share 
that excitement for, and success with science, especially chemistry, with her students. "I think the biggest reward for me is when I hear it from my students that it was the most challenging and fun class that they had and that it really made them think" (Beverley, Interview \#1).

Along with her colleagues, whom she refers to as her work family, she has collaborated to revise and implement a science curriculum that is strongly integrated among the different science disciplines, that is personally relevant to the students, and that is based on real-world science inquiry. "I'd say my number one [goal] is for them to enjoy it. Number two will be for them to not only understand [science content] but be able to apply it and make connections to the real world... because without those connections, why are we here, like what are we doing?” (Beverley, Interview \#1). For example, the same 'fun' greenhouse effect tag game that other teachers enjoyed, Beverley harshly critiqued because she felt the students really didn't learn accurate content knowledge due to the liberties taken to transform the actual greenhouse effect mechanism to an interactive learning experience.

Her efforts coincide with a desire to develop students that are scientifically literate and "be able to have a conversation about science because they're all going to be voters one day. They're all going to be citizens and they need to be knowledgeable enough that they can make the right decisions" (Beverley, Interview \#1). She hopes that by making direct connections to science content knowledge in her teaching that students will come to appreciate and love it as she does - which she hopes will encourage them to pursue science careers to address the issue of climate change.

Most of the topics on which she focuses science literacy development come directly from her curriculum and she generally follows these guidelines for instruction. 
In her chemistry courses, she feels that she is only able to highlight connections to climate change in passing, such as when writing chemical formulas, she mentions the $\mathrm{CO}_{2}$ molecule's presence and increase in abundance in the Earth's atmosphere and briefly how it affects students' lives. Conversely, the new Physics of Earth and Space Science curriculum includes many scientifically accurate references to climate change even though she describes her local area as strongly Republican. While she expected denialist pushback from more skeptical students, parents, and/or community members, she experienced none and instead her colleagues were "on board" and very excited to teach climate change as they "respect the science and the evidence" (Beverley, Interview \#2).

Her original expectations compared to the reality served to contextualize Beverley's experiences teaching climate change and solidified her desire to educate her students on the facts of climate change. Yet she views her role "more as the teaching and educating part, but in the hope that it would lead to inspiring action later. I don't think I ever want to be a teacher twisting a kid's arms to make an action... I feel like that's almost asserting your religion, it's a little too pushy for me personally" (Beverley, Interview \#2). Beverley clearly wants to help prepare her students to be literate about climate change in the future, but her community and school context seemingly have nudged her to take a more nuanced approach to teaching climate change that primarily focuses on content knowledge development to avoid the appearance of any undue influence on her students' beliefs.

Connie Stevens narrative profile. Connie is a veteran middle school science teacher. Originally from Australia, Connie grew up loving the interactive science 
lessons she experienced in the math and science track of her schooling. "We did a lot of hard science. We did a lot of math integrated with science, but we also did a lot of hands-on science inquiry. And that class I feel it was a class I came home thinking, 'well I did something hard and I actually understood it.' And as a girl in that era in a class that was nearly all boys, that felt good" (Connie, Interview \#1). Connie continued to benefit from powerful science teaching and learning experiences that demonstrated how her science lessons connect to everyday life in the real world through coursework that took her out to do bird watching field work, to visit a battery manufacturing plant, and to study everything from coastal rock pools to energy efficient air conditioning. She is dedicated to her own learning both in science content and in her professional experiences through extensive graduate and post-graduate studies and has been awarded National Board certification.

These experiences learning science have also influenced her to always encourage girls to participate more in science, and especially in STEM. Also, Connie strives to share her own passion for science with her students to enable them to see how it connects with their everyday lives. "So, all that eagerness and enthusiasm that they have as elementary school kids, I want that to persist for as long as possible. So, in terms of their science education and what happens when they come into my classroom is I want them to be engaged and to be excited about learning ... and to walk out talking about science" (Connie, Interview \#1). For example, Connie incorporates numerous hands-on, student-centered learning experiences, like role play and jigsaw activities, with student to student discourse and a collaborative learning focus. Connie has been lucky enough to have taught for administrators who are 
supportive of her efforts to incorporate novel science learning experiences for her students.

The innovative connections she emphasizes between her science curriculum and the real world are frequently based on her students' interests. For example, when discussing renewable and non-renewable energy sources, Connie has her students act out each individual step of electricity generation from energy for the students' computers or devices at home to power plants to steam turbines and beyond. Importantly, she also incorporates a discussion of how we could improve the sustainability of this scenario as well. A particularly motivating tangent has been climate change which Connie has integrated into her teaching for many years because she feels it is very important for her kids to know "something real" despite its perception as a seemingly contentious issue. Connie brings in multiple lines of evidence for climate change in a variety of real world concepts, from population statistics to fossil fuel consumption to coral reef bleaching. She brings her own "scientific mind" to teaching climate change and encourages her students to do the same through the evaluation of data from around the world and throughout the scientific community.

Through the support of her administration and her agency in the classroom, Connie takes her mandated curriculum and bridges several topics to local environmental issues of interest to her students, especially climate change. "[The students] know [climate change is] something that they hear in the news, they hear adults talking about it so they know it's current and it's relevant... They're at an age at 12 years old where they don't really understand high-level concepts, but they like being able to think about them and being able to access information at a level they can 
understand and being able to feel like I'm starting to really understand something real and important and big" (Connie, Interview \#2). She incorporates student discussions about how people may have different perspectives and diverse values but that the weight behind scientific evidence is powerful regardless of one's individual beliefs.

Connie focuses her climate change instruction on understanding the evidence for climate change and examining the issue "through the lens of science" and has not experienced any negative pushback due to these lessons. Her primary goal is to build her students' critical thinking skills to make important decisions in the future and to draw those conclusions based on scientific fact and without bias. Yet, she also is wary about her own influence on her students' understandings. 'I'm a little cautious about pushing students to force a lifestyle choice on their families. But I'm certainly not adverse to planting a seed for thought and exploring ideas because one day they'll be grownups and they'll live in their own homes and then they can make their own decisions about what they do with their plastic or their energy use" (Connie, Interview \#2). For example, Connie's students participate in a mock energy summit where students present their research on various energy alternatives for the future to community members and parents. Connie feels that this activity, along with the rest of her climate change instruction, are quite successful because "student learning is extended beyond the classroom to actions and discourse throughout the school community" (Connie, Reflection). Connie works to demonstrate the impact of their collective actions in school but also strives to empower the students to come to their own understandings of climate change as a real-world socioscientific issue. 
Emily Skand narrative profile. Emily is a veteran middle school science teacher. When she was young, she remembers experiencing lots of informal science learning, especially in nature outside of a traditional educational setting. "My parents were of the attitude that regardless of where you're going to be, you're engaging with the surroundings that you have, and you're going to be learning" (Emily, Interview \#1). Whether watching for hawks on road trips or trying raw oysters while out sailing, Emily was encouraged to appreciate the natural world around her and her connections to it by her informal science educator parents. She seeks to repeat these types of learning opportunities for her students to garner a similar appreciation of their connections to nature and a sense of concern for environmental protection efforts. For example, she has incorporated student research projects about how the Chesapeake Bay is utilized by people in their local area, how the area is also being impacted by climate, and how people can act through their choices to help slow the negative changes from climate change.

Emily grew up with several role models for authentic science learning - both her parents were in science education fields and she developed a close relationship with her high school environmental science teacher who acted as a great exemplar for effective pedagogy. Over her 18 years in the classroom, she has taught in private, Christian middle and high schools, as well as in a public high school. Throughout these teaching placements, Emily views herself as a perpetual learner of science content and professional practice. "Your curriculum and the activities that you do are not going to be stuck in place. There's always going to be an ebb and flow, especially depending upon the kids that you're teaching" (Emily, Interview \#1). Most recently in her current private school, Emily enjoys great curricular autonomy where she "can do 
whatever I want... and we can take a topic and we can teach it however we want there's a lot of flexibility there" (Emily, Interview \#1).

This freedom and agency allow Emily to engage students in science instruction around relevant and "cool" topics like nanotechnology that relate to her overall curriculum. She also integrates topics like climate change which she feels strongly that her students need to know about. But climate change also is a topic that "lends itself to every discipline and science because it deals with so much, there's something for everyone when it comes to climate change. There's chemistry involved, there's physics involved, there's meteorology involved, you can really infuse it wherever you want to" (Emily, interview \#2). To this end, Emily has her students create video PSAs to present to other students in their school to discuss climate change where her students examined the issue and its connections to curricular topics from photosynthesis and the carbon cycle, atmospheric changes and the greenhouse effect, and other environmental aspects found in their local area. Her students really were excited by this project and were responsible for all components from writing the scripts, performing, filming, and editing the videos for uploading to YouTube. Emily's climate change instruction has also been deeply influenced most recently as she believes there will be grave implications from the current denialist political landscape and the Trump administration's efforts related to climate change. She feels a newfound motivation to teach climate change to demonstrate that it is a science topic that is both personally relevant and current. "Not that it's not going to be any less urgent next year, but the fact that it's here and it's being discussed, and so hotly discussed to the point of somebody calling it a hoax. When you have that constantly going in news feeds, it does definitely make it difficult to not address it" 
(Emily, Interview \#2). Her instruction has been explicitly impacted by the broader political conversation when the EPA climate change websites quite literally were rewritten in the middle of her class using these online resources. Emily used this occurrence as an opportunity to discuss with her middle school students that science does not exist in a vacuum and will always be influenced by others' perspectives and that it is their responsibility to understand and be prepared to act on this issue in the future. "You want to give them the science that allows them to understand why they would be making changes in their lives. But then you also want to give them to tools to be able to make those changes and to get excited about it" (Emily, Interview \#2).

Emily also incorporated climate change related projects on wind turbine blade design and energy usage poster projects that allowed students to hone their scientific decision-making skills and civic awareness for their future role as climate literate citizens. She works to "give the kids something to do" and her students discussed with their families their collective carbon footprints and possible changes they can make together to reduce their impacts. Her stance on including student advocacy issues gathered a few parental concerns specifically related to a discussion on the economic versus environmental benefits of the Paris Accord, however her administration and colleagues strongly supported her empowering approach to climate change education.

Fiona Henry narrative profile. Fiona is a novice middle school science teacher who has been teaching $6^{\text {th }}$ and $7^{\text {th }}$ grade for five years in two different school districts. During her youth, she enjoyed numerous outdoor learning experiences that sharpened her love of nature while canoeing, kayaking, and camping. She strives to pass on this environmental connection to her students by incorporating opportunities 
to learn outside as often as possible during curricular units on weather and climate, and other environmental issues. "And I just find that connecting to the outdoors versus staying inside and watching it through a video, or reading about it, I just find [being outside] a lot more meaningful" (Fiona, Interview \#1). During her professional learning experiences to deepen her own science expertise, or through environmentally focused personal travel adventures or even through her role as Green School Coordinator, Fiona is always looking for ways to bring those experiences back to her classroom to expand her students' appreciation of the outdoors through items like glacier rocks from Iceland or black volcanic sand. Fiona believes "it really gets the kids more engaged" (Fiona, Interview \#1) and she hopes that it will also initiate a passion to protect these natural wonders globally and locally as well.

Fiona has benefited from numerous good role model science teachers from whom she models her practice to share her love of the environment. She does this by infusing outdoor learning and interactive classroom experiences like raising mosquito eating Gambusia fish and participating in canoeing field trips to study local SAV (submerged aquatic vegetation) plant life. She takes these novel experiences and bridges them to her curriculum, but more importantly to personally relevant issues for her students like how releasing the adult Gambusia fish in a local river may help to protect them from mosquito-borne illness like Zika, or how wetlands and SAVs protect and enhance the local river and shorelines from flooding during severe weather due to climate change.

Broadening these environmental connections beyond local ties, she also introduces climate change during these conversations. However, she feels beholden to her assigned curriculum due to the role of high stakes testing in her district and the 
importance placed on the assessed curricular topics. Instead, she leaves these locally and personally relevant connections to climate change until later in the school year when testing is over. "For the most part, the only pushback [to teaching climate change] has been time and just fighting the battle of what I have to teach and then climate change has not been one of those things I have to teach, and so it just gets put on the back burner" (Fiona, Interview \#1).

Yet, she still feels it is very important to introduce these topics because "it's very relatable to them" due to their geographically low-lying area that floods frequently with sudden downpours. "And we're big with crabs and with fishing and a lot of my students like to fish out on their boats, so just being able to tie in the local economy and impacts with climate change I think is a lot more meaningful with the kids" (Fiona, Interview \#2). Through online interactives from National Geographic and the Environmental Protection Agency, Fiona also works to capture student interests in changing temperature and environmental impacts from climate change occurring around the world.

In creating these interesting climate change connections for her students, Fiona has been able to avoid any politically charged pushback to her teaching as she believes her younger students know about the topic somewhat, but do not have strong opinions about climate change yet. With her delayed inclusion of climate change after testing, and as a curricular connection but not an instructional focus (i.e. not a unit solely dedicated to climate change), Fiona seems hesitant to push too much on including this topic but might be imposing such boundaries on herself as opposed to any actual impediments to the inclusion. "I haven't gone too much deeper into it, I've just been doing the basics because I'm testing the waters a little bit right now" (Fiona, interview 
\#2). Currently, she introduces her students to the importance of carbon dioxide during instruction on elements and molecular compounds and explains how the carbon dioxide molecule moves through cells during photosynthesis and cellular respiration. She then also highlights the anthropogenically induced imbalance of carbon dioxide in our atmosphere without getting too deep into her climate change instruction at this time. However, as she gets more fully situated in her new school, she hopes that she will be able to expand her presence as an environmental leader both in and out of the classroom.

Fred Robbins narrative profile. Fred is a veteran middle school science teacher. Fred has always loved science, especially for its challenging puzzles related to figuring out how things work. "I really enjoyed science throughout high school, and even in middle school, but like chemistry was the first real course that I started to enjoy because the material got more and more complicated, you know I just enjoyed the complexities of it" (Fred, Interview \#1). This interest in science and problem solving was more of a self-developed hobby as his family was in the military when he was growing up and Fred was often left to his own devices to figure things out. However, now Fred loves to encourage his own children and his $8^{\text {th }}$ grade students to enjoy the process of scientific inquiry with innovative projects like testing the properties of homemade slime to launching weather balloons with cameras up to the stratosphere. "The nature of how I approach science is very physically, like I like to do science, and I think scientifically in terms of the way I solve problems, the way I approach problems and the way I think about problems, and the way I was trained to teach science was a lot of literally doing science [with students]" (Fred, Interview \#1). 
His primary goal is to support his students' interest and curiosity in any science topic. "I want them to be able to ask any question they want in my classroom - and then be able to explore it" (Fred, Interview \#1). He capitalizes on student interest in their local surroundings to bring in climate change topics like changing ocean levels. Fred feels that without purposeful engagement with personally relevant connections, climate change could be a difficult topic to get his students to really relate to in the classroom.

Unfortunately, Fred's ability to allow students to investigate far-reaching science topics with his guidance has been hampered by current reform efforts at his school. Previously when he first started teaching over 13 years ago, he had great support from his administration and "that kind of freedom to let me do something so strange [to demonstrate science ideas] that's what made me really into who I am [as a teacher]" (Fred, Interview \#1). However, in his current school district, there recently has been the adoption of a science curriculum which he is required to teach with great fidelity. "I've come up through a whole culture of freedom. And to have that, I don't want to say stripped away, but at least constrained is, I don't think uncomfortable is a strong enough word, but it's uncomfortable" (Fred, Interview \#1). Fred struggles with how to continue to meet the school administration's requirements while still doing what he feels is most appropriate for his students' science learning.

For topics like climate change, which is included minimally in his new curriculum, he focuses on ways to address student interest in this popular and relevant concept through curricular connections throughout the year via students' natural curiosity. "When they're asking, I mean I grab onto that moment and get in front of that wave and just surf it because I can tell them about [required] stuff anytime I want, 
but it's when they're asking that it is actually sinking in because they are interested in it" (Fred, Interview \#1). Fred talked about his approach to teaching climate change as one that starts with student interest and adds in multiple avenues of scientific evidence, then lets the students sift through the data to come to an understanding of it intrinsically. "The more the science evolves, it seems like the kids are evolving with it. They're more open-minded and accepting of [climate change] as the reality of what we live in and less of only 'theoretical' science” (Fred, Interview \#2).

This content focused and evidence-based approach has created little negative feedback from students, administration, nor parents. At times, Fred described how students become "emotionally attached" to the climate change issue but that he appreciates those contributions because "they bring that passion with them and that passion is really what you want to tap into at the center of the questions to get them to find answers and ask questions themselves, that's where the learning is" (Fred, Interview \#2). These pedagogical choices allow the students to explore and understand various perspectives and evidence to inform their scientific decisions. Approaches incorporating student-driven inquiry with strong connections to "bring it home" to demonstrate the likely impacts from climate change in their individual lives have given Fred the ability to develop his students' interest in and knowledge of climate change even within a restrictive curricular framework.

Garrett Tresler narrative profile. Garrett is a novice high school physics teacher. Garrett loves the challenge and opportunities for problem-solving that science offers and he was really "into exploring the unknown" (Garrett, Interview \#1). He remembers enjoying the productive struggle he experienced even back in middle 
school when there were no easy answers to the questions in his science fair project. "While it was frustrating, it was really fascinating too. It caught my attention and then in high school that spawned into really being interested in science and finding out I had a gift for figuring stuff out and problem-solving" (Garrett, Interview \#1). This has transformed today into a teaching style that focuses on constructivist and inquiry approaches to science. He tries to incorporate "a great example of inquiry each day [where] kids...construct knowledge, build [a model], and then follow it up with some teaching to fill in the gaps" (Garrett, Interview \#1).

Garrett benefitted from the tutelage of his high school physics teacher, who continues to mentor him today in his physics teaching style. During high school, Garrett struggled with the difficult AP Physics coursework and contemplated quitting. But instead he was persuaded by this teacher to "challenge himself to work hard and that [he was] not going to fail because you didn't try, instead you're going to fail because you're quitting" (Garrett, Interview \#1). That push to persevere despite challenges is a message he tries to instill in his own current students, especially in a school environment with numerous behavioral issues and other distractions.

Garrett has an extensive background in physics knowledge but is out of his content expertise while teaching an aquatic science elective course. However, the aquatic science course allows Garrett great flexibility to refine his instructional agency to modify the course greatly from his predecessors' approach. He now works to use climate change as a motivating theme with personally relevant and local implications. For example, instead of teaching a straightforward approach to oyster anatomy as written in his curriculum, Garrett extends the concepts to their broader role in the 
ecosystem and the impacts of climate change induced ocean acidification on their shells through a student driven inquiry investigation.

After the Climate Academy, Garrett also felt inspired to bring climate change into his physics courses to extend less engaging topics like the electromagnetic spectrum to include discussions about "climate change to talk about infrared radiation and UV radiation and how does incoming radiation affect ozone molecules and the greenhouse effect and give kids a way bigger picture of physics, and here's where physics is happening right now" (Garrett, Interview \#2). These opportunities allow Garrett to develop his students' science understanding of the world around them and to question others if they make dubious claims about science in the real world.

That deep content understanding is especially important for issues like climate change in Garrett's mind. For all of his students - college bound or not - he wants them "to know that climate change is real and its happening and to have some scientific evidence to back it up... The second thing is to understand how climate change impacts the world, their local and national community and really ultimately, how does it affect them" (Garrett, Interview \#2). This content-driven approach to teaching climate change focuses on the known science alongside the established and expected impacts of climate change. Garrett feels the online simulations, such as those offered through PhET, "enable students to peel back the layers of complexity in explaining the mechanisms of climate change starting with the macroscopic view...then zooming to the molecular view" (Garrett, Reflection). This knowledge focused method has not gotten negative attention or pushback from his students, their parents, nor his administration. 
This pedagogical style also mirrors Garrett's own involvement in the broader climate change issue in that he wants to learn more about climate science and "we can talk about reducing energy use and how we can reduce our $\mathrm{CO}_{2}$ emissions, but when push comes to shove, I really don't put as much stake in the game as I would say I want to" (Garrett, Interview, \#2). He stated that he is working to strengthen this advocacy aspect but first is working to integrate other content-driven connections to climate change via modeling for a deeper understanding of climate graphs and data sources.

Karmen Losa narrative profile. Karmen is a veteran high school biology and environmental science teacher who came into teaching through several science and education related experiences (e.g. marine science, Montessori, ESOL) and an alternative route to teacher certification. She recalls always being outside as a child with a fascination with the natural world - on farms, in lakes and streams, in boats, etc. These experiences left a deep imprint on her educational priorities for her students. She justifies their need to learn required biology topics by uncovering how they are "intertwined with everything in your life" (Karmen, Interview \#1).

To this end, she finds ways of incorporating numerous authentic science learning opportunities both inside of her classroom via raising various creatures like trout and horseshoe crabs, and outside the school with canoeing field trips and tree planting projects. "I have always felt just like the guy who built the baseball field - if you build it, they will come. If you show students, or give them the opportunity, or take them somewhere, or bring it to the classroom, then they will learn it better" (Karmen, Interview \#1). 
To garner support for these unique opportunities, Karmen pursues several environmental qualifications for her school like Green Ribbon and Ocean Guardians certifications. These pathways provide her with a way to integrate curricular content within climate change and other environmental issues. "With all the extra activities that I do, I'm trying to teach them how they can be responsible citizens and stewards of the environment... and I think I try to embed a few of those things here and there [throughout the content]" (Karmen, Interview \#2). These programs allow Karmen to discuss with her students the reasons behind their tree planting efforts and how it is helping to offset carbon emissions via the carbon cycle. Karmen focuses on content knowledge development with tie-ins to demonstrate examples of climate-related action. However, she states that action is not her main educational priority, even while she espouses deep personal concern for the environmental health of our planet in the future.

Karmen sought out professional learning opportunities like the Climate Academy to improve her understanding of the technical scientific evidence for climate change. These activities have given her the confidence to discuss a wide range of climate change data and connections to her students' lives. She often has her students evaluate current events news articles for their claims, evidence, and reasoning. Karmen hopes that these types of activities will help students with the epistemic tools they need to "approach the issue calmly and with purpose" (Karmen, Reflection).

Yet she still has some hesitation around engaging her students in broader political conversations. "I just talk about science and facts and I make sure I tell students, "politics aside, this is fact'” (Karmen, Interview \#2). Even with her reluctance towards incorporating political discussion, Karmen does bring in numerous 
pedagogical approaches that allow her students to participate in making and evaluating scientific claims supported by evidence, and to understand the broader environmental changes happening today, especially those that will continue to be exasperated by climate change. Karmen also has integrated projects where students explore a wide variety of perspectives and impacts of climate change from droughts in California and the effects on produce distribution to having a live video conference call from a science educational researcher in Antarctica and then comparing Antarctica to other locations around the world to see how choices related to climate change will influence areas differently. "That's the hope - that [I'm] giving them a platform of knowledge so they have a better understanding of it and how they are involved with it [via their consumer choices]" (Karmen, Interview \#2). Her goal is that armed with knowledge and the right skills to evaluate their decisions, her students will feel empowered to do something about this environmental issue.

Krista Czapkas narrative profile. Krista is a novice high school science teacher with a background in biology but currently is teaching environmental and earth science courses in her small, rural school. Krista was effusive while describing her love of nature when she was growing up that developed through experiences with her family. "All of our vacations were to lakes to go fishing. It was never to the beach, it was never Disney, it was always find a state, pick a lake and go fishing. I mean I went on hikes to go see waterfalls and things like that too" (Krista, Interview \#1). She also fondly recalled a memory from college where she gave up a highly coveted homecoming weekend to participate in a course field trip to search for ferns as one of her most memorable college experiences. "And we just went out all weekend hiking 
through the woods, looking for ferns, falling down hills, getting muddy - it was just awesome" (Krista, Interview \#1).

In her current teaching, Krista works to motivate her students to also appreciate the natural world and their personal place within it, especially as it connects to human's role in causing and hopefully addressing climate change, because of her personal concern for our environmental future. "And though climate change is not specifically written into my curriculum, I know it is important because I'm worried about our world. I don't think I can do anything on my own, so I have to get these kids on board" (Krista, Interview \#2) by helping them to understand the importance of climate change to their future abilities to do the things that they like to do - going out on the Chesapeake Bay and the Atlantic Ocean to fish and play and continuing family traditions of farming the local area. "I think that's the only way to get people to care about climate change is to make it really personal to them" (Krista, Interview \#1). Discussing these specific connections has given Krista a path into the hearts and minds of her students who may have been otherwise influenced by the overwhelmingly politically conservative area in which they live.

Krista has benefited from strong role models for good science teaching throughout her educational history. These experiences have demonstrated the value of a personally relevant and innovative teaching style. As such, Krista works hard to incorporate novel, and at times almost adventurous, teaching practices in her classroom pushing beyond the expectations of her colleagues “even if I wasn't sure that [a lesson] would work out - because it's better for the kids and it's more engaging" (Krista, Interview \#1). Krista has been supported in these efforts to get her students doing real science by her principal and science supervisor "as long as it's not 
too crazy". For example, she designed a student-led inquiry project where her students created an experiment relating ocean acidification to mussel shells to explore the effects of three different $\mathrm{pH}$ solutions on the shell's density and weight. She then challenged her students to extend their developing understanding by investigating the likely impacts from climate change on other aquatic species locally and globally, i.e. on fish migration, coral reef communities, etc.

Her science supervisor has also championed her efforts to specifically incorporate climate change into her teaching. Krista realizes her professional obligation to her curriculum but believes that "you can just tie [climate change] into your curriculum no matter what you're teaching" (Krista, Interview \#2). She incorporates climate change connections while teaching curricular units on meteorology and the atmosphere, ecology, food chains and symbiotic relationships, and environmental studies with energy sources and the impacts of pollution. Throughout the year, Krista's students explored climate change topics in numerous unique contexts because she feels it is valuable to showcase the vastness of the issue.

Focusing on curricular content connections to climate change has also strengthened her position in teaching it, even in her politically conservative area with her admittedly liberal personal perspective. "I think you get the kids to believe in it and you get the buy in by the content. Though I think action has to be the priority because just knowing about something doesn't change anything" (Krista, Interview \#2). Though when she starts those action oriented or politically connected conversations, she always makes sure to stay focused on the science of the issue and less of the controversial aspects. "Just because it's a politicized issue, doesn't mean that it doesn't belong in the classroom" (Krista, Interview \#2). 
Instead, Krista focuses her climate change connections on the scientific data and evidence for the causes and impacts of climate change in the hopes that her students trust in science more and think for themselves to evaluate the different perspectives on climate change. In her instruction she explicitly discusses why the occurrence of snow one year does not disprove climate change and addresses the various perspectives behind why the issue has become so polarized socially and culturally. These efforts are to encourage her students to understand the depth and accuracy of scientific beliefs as compared to personal or political beliefs, and to develop an orientation towards taking action to address the problem within their own lives. "The kids I think were genuinely interested in it because it's one of those scary things. But it's also one of those things where I think they feel empowered, like this is such a big issue, but our generation's going to have to find a solution, so we will and that's going to be cool" (Krista, Interview \#2). She is working to show the students, with small steps now and hopefully bigger future impacts, that they have great strength within the power of their voices - and their votes.

Mary Jenkins narrative profile. Mary is a novice high school science teacher. Prior to teaching, Mary was a clinical psychologist for 19 years. From this earlier career and her training in this field, Mary has extensive scientific research experience in animal and human behavior studies that she links to her classroom. Even before these research experiences, Mary has had a lifelong interest in nature. This fascination with being outdoors has transformed more recently to be more focused on protecting natural spaces and sustainability. "I became aware of climate change and environmental degradation and that has become something that I feel really concerned 
and passionate about" (Mary, Interview \#1). Living sustainably is a key personal issue for Mary and she shares the lifestyle changes that she has made in her life with her students. "I made a decision five years ago to move my lifestyle. I became a vegetarian because of climate change. I mean I've done everything in my personal life because I realized I can't say anything to anybody if I haven't done everything in my power" (Mary, Interview \#2).

Her prioritization of personal advocacy on climate change issues has added an additional layer to her teaching whereby she wants her students to develop a deep understanding of how humans are negatively impacting the planet both globally and locally. "I wanted them to walk away with some understanding of the issue [of climate change] and an awareness that this is a real and pressing issue that they must deal with and the importance of it being dealt with now" (Mary, Interview \#2). For example, her students have researched high risk areas locally and beyond to explore how the earth is currently changing and how it will likely change in the future from the cascading effects of climate change.

One of Mary's biggest challenges to effectively conveying this message in the past has been that in her nearly five years of teaching, she has been in four different school districts and except for her current placement, she had to deal with vast issues of student misbehavior and other demanding instructional challenges. "It is the most demoralizing thing that you cannot do anything [instructionally] if you don't have a way of managing behavior (Mary, Interview \#1). She is now teaching in a stable high school and is teaching AP Biology and biology courses in addition to a half course elective on sustainability. 
Mary has limited flexibility to make major changes to the biology and AP Biology courses, but in her elective offering she can wholly direct the curriculum and its goals. However, she has a more challenging student population in this science elective, both in their dedication to their studies and their perspectives on the course topics. Yet she still tries to integrate interactive science inquiry lessons that push her students to fully understand the practices and skills of science. "I want them to be critical thinkers and how to question information and come to their own conclusions because it's more valid that way. I have to also be politically careful because I'm in this area that overwhelmingly went for Trump...It's very important to educate first, because otherwise the door closes, and you can't get anything in" (Mary, Interview \#2). She works hard to bring in content focused information on climate change that builds her students' knowledge and awareness on the issue in ways that are grounded in evidence that they are able to explore from multiple perspectives and diverse sources.

Mary's instructional approach for climate change, sustainability, and other environmental issues is deliberate in its inclusion of extensive data because she perceives that the larger culture of her local community can be "scientifically hostile" and "anti-intellectual" (Mary, Interview \#2). She tries to tackle these perceptions directly by exposing her students to numerous concepts that relate to their lives and that allow them to evaluate the various claims and perspectives. She also works to develop her students' epistemic skills to appreciate the nature of science and how we can come to know things scientifically and based on evidence. Mary confided that she was not confident that this approach would always work with her students, "so I don't 
know if anything will make a difference, I just know I have to plant the seed" (Mary, Interview \#2).

She is frustrated by a general lack of urgency on mitigating climate change impacts but remains committed to building her students' knowledge and awareness, as well as her personal actions for environmental protection. "I would say that my job is to educate them, to make them scientifically and ecologically literate as I can. In terms of action...in my experience when most kids really understand things, a natural part of them wants to take action and I don't have to advocate for that. But I also think it's probably not appropriate for me in my role to do that [overt advocacy]. But I do feel like I can share what I do, and I share with them why I do that. I have every right to do that, that's part of who I am as their teacher. But I think maybe I cross the line if I say you should do that too" (Mary, Interview \#2).

For example, she incorporates a project where students created infomercials to encourage others to take one small step. Students explored various possible choices for mitigation and adaptation to build their awareness of the options, though not necessarily to participate in these actions immediately. Instead of pushing her students to be coerced into climate change action, Mary wants to best prepare her students to understand the issue scientifically and its urgency but also to allow them to make up their own minds about making personal lifestyle changes, or not. She hopes that she models this environmentally mindful lifestyle.

Melissa Eckerds narrative profile. Melissa is a veteran middle school science teacher. Early in her life, Melissa discovered her love of animals. From horses to gerbils to frogs, she was encouraged to learn all about animals and how to raise them 
by her family. "In middle school, instead of being one of the cool kids who went to the mall and bought hairspray and leggings back in the ' 80 s, I went out and went in the woods, got frog eggs and went out a night with a flashlight to try to catch spring peepers and bullfrogs. I took them back to my pond and threw them in there and raised them" (Melissa, Interview \#1). This passion for animals extended to nature and later more broadly to science. Once she was in the classroom as a teacher, Melissa sought to get her students to enjoy science as well: "My goal conceptually is that I want them to love science, and that everybody can be a scientist and not just like the super advanced [students]. I want them to understand that science is everywhere" (Melissa, Interview \#1). She focuses her climate change instruction on possible solutions as opposed to a "doomsday, depressing approach" to keep a productive mindset towards science in her students.

These goals of wanting students to feel supported to do science likely comes from her prior classroom learning opportunities where she had mixed experiences, with some positive and supportive science teachers and others who were more negative with a didactic focus on book learning and later an emphasis on animal production aspects while studying animal science and agriculture. In her classroom, Melissa instead incorporates innovative science lessons that provide a supportive learning environment with developmentally appropriate methods: "I try to understand that every kid is different, and I try to encourage creativity and that you could answer questions not always in the same way depending on how the kids learn. It's really important to be sensitive to that because I remember that awkwardness of middle school” (Melissa, Interview \#1). 
Melissa encourages this positive learning perspective in her students as they work through their required science curriculum. For example, when working on graphing and visual literacy she utilized climate change oriented examples to show different types of data, or when exploring volume and mass, she connected it to sea level rise, and when incorporating genetic diversity and evolution topics she connected it to the changing environmental features and how wildlife populations are being affected. She was able to integrate climate change into her teaching through an additional enrichment block but not throughout all her classes. She felt that she only had limited agency to make broad curricular changes that diverge from the topics on the district's science assessment. "You have the verbal support of people to do stuff, but you are on your own when it comes to actually implementing it due to materials and resources" (Melissa, Interview \#1). She admits that she has lower confidence in her ability to "be like Mrs. Han Solo, rogue teacher and just do whatever" (Melissa, Interview \#2) to integrate new topics like climate change into her regular curriculum.

However, the Climate Academy helped her to understand ways that she could infuse climate change into her teaching and made her realize how important climate change is as an environmental issue and "it really makes me mad that it's not even included" (Melissa, Interview \#2). Melissa believes that it is her responsibility to teach others about climate change as her way of dealing with the larger problem. "I think my way of addressing climate change is to educate others about it because I know that I'm just one person and I could do little things like turn off lights or recycle...but what's really going to make a difference is educating the generations who are growing up right now" (Melissa, Interview \#2). Her intentions were to not "preach at them" but 
instead to stay focused on content on how climate change works and inform them about its impacts.

However, one component that Melissa tries to avoid is any outright discussion of politics related to climate change. She saw no problem with drawing connections between climate change, her curriculum, and some local civic issues, but when asked to reflect on the role of political conversations on her teaching she shared: "I don't want politics to interfere in what I'm actually trying to educate the kids about...because it's not appropriate [i.e. to bring in politics]" (Melissa, Interview \#2). Even without integrating politics into the conversation, Melissa works to prepare her students to be scientifically literate citizens through the development of their content knowledge of climate change and their abilities to evaluate the evidence and claims. "And then it's their decision individually as a growing young adult to do something about it and how they're going to do stuff about it, because I know if you preach at people, especially young adolescents, a person is only going to do what they what to do. If they're informed and educated about what's going on, then they can make the decision to do it or not” (Melissa, Interview \#2). So even though climate change is not wholly integrated into her curriculum, Melissa brings in those connections because in her opinion, it is important for her students to know about it generally and to be prepared to make their own minds up about what should be done.

Tara Thorpe narrative profile. Tara is a novice middle school science teacher. Tara has experienced a lot of family encouragement to do science over the years and as a result, she is deeply interested in nature and science more broadly. Mimicking how she was supported to pursue her own explorations in science, Tara 
believes that her students "should be involved as much as possible [so when] they come into the classroom, they should take ownership of what they are learning" (Tara, Interview \#1). For Tara, that ownership led her to seek a deeper understanding of the evidence for, and negative impacts of climate change through a teacher fellowship program that included travel to the Arctic after her initial participation in the Climate Academy.

These experiences have expanded her horizons (literally) and ignited a passion about the need for climate change education to protect these fragile environments. "I mainly just love talking with kids about it and sharing my passion and I think that comes across a lot when I teach it" (Tara, Interview \#2). She incorporates her travels witnessing climate change in action into her teaching: "I really try to pull in that firsthand experience because it's one thing to talk about it but it's another thing to actually be there and see this visual evidence, hear from the people who live up there about how the glaciers are receding and how they have seen that the ice is getting thinner. It's amazing and very terrifying and enlightening” (Tara, Interview \#2). Tara shares her firsthand accounts to motivate her students to share her passion for protecting our planet from these severe impacts. She shared in her reflection that she believes humans collectively have a "moral duty to protect our environment in any way we can to advocate, and to keep ourselves open minded and informed" (Tara, Reflection). Tara also tries to infuse the idea of personal responsibility into her instruction by building her lessons from their individual interests and values related to the natural world.

Tara had several strong influences on her teaching style from earlier science teachers and mentors who loved science. "When I became a science teacher...I try to 
think back on [those experiences] and remember what it felt like to be hands-on, to get the kids up and moving and really questioning things. And so, I really try to do that, so they love it just as much as I have come to love it” (Tara, Interview \#1). She focuses on including innovative and active lessons that are driven by her students' science interests to combat some of the disengagement she sees in students as they enter middle school. For example, Tara described a portfolio her students created to explore their understanding of carbon via concept mapping, inquiry investigations, and even field trips to various sites to examine water quality and other human induced environmental impacts.

Her school administrators allow her extraordinary flexibility in her current placement as a gifted and talented teacher. But even when her placement was primarily science focused, Tara found ways to integrate novel connections to current science issues like climate change, which her students were greatly interested in learning. This approach allows her to "really try to engage them as much as possible so that means getting them involved and often letting them have their say with their learning and what they are researching about" (Tara, Interview \#1). The issue of climate change has been one of these student-driven topics that Tara uses to bridge the standard science curriculum and real-world, personal topics. When talking about her climate change student research projects, Tara explained: “I don't have a bored student in my class, maybe sometimes they... have questions but they're all really excited about and also really curious about this topic" (Tara, Interview \#2).

The curiosity Tara sees in her students is reminiscent of her own past experiences learning about climate change. Tara shared that her family was politically conservative and questioned the role humans could have on the earth's temperatures 
and passed on these doubts to her growing up. This pushed her to explore beyond her parents' political perspectives to do her own investigation into the evidence for climate change and "to develop my own understanding of the subject from a scientific point of view" (Tara, Interview \#2). As much as possible, Tara avoids “feeding them" her personal opinions and instead pushes them to think critically about their own learning to build their epistemic understanding of science and especially for climate change knowledge.

After her initial forays into teaching climate change and her trip to the Arctic region, she brings these ideas to the classroom to expose her students to various forms of the substantial data demonstrating the link between humans and the Earth's climate. Yet she does this in a way that allows her students to weigh the evidence to decide for themselves and construct their own understandings. She does this because "these students are going to grow up in this world where they need to know about things and make important decisions about our environment and what we can do" (Tara, Interview \#2). She takes this scientific literacy development approach because she wants her students to enhance their scientific decision-making skills and "I really want them to think like scientists, and to think critically and to see all the evidence and data that is out there and then draw those conclusions for themselves because that's the most authentic way for them to really understand what they are learning” (Tara, Interview \#2).

Tara spoke a lot about promoting scientific literacy and understanding how to make informed science decisions, but also prioritized the need for students to take action related to addressing climate change as another goal for instruction. Educating her students is important, but the larger motivation during that content knowledge 
development is answering the question of 'What should be done now?'. 'I would say out of everything that I've taught this year, this has been the topic that they've grabbed onto the most because they feel that they can do something about it...a lot of them really want to help the world in some way and they feel it is a personal justice to fix and solve problems and this [learning about climate change] ties in with that greatly" (Tara, Interview \#2). She has incorporated several different action projects to share the possible answers the students have found to address the "what next?" type of questions with each other and beyond the school into their local communities. Tara's deep personal connections, alongside the students' natural curiosity about climate change serve as a bridge to preparing her students to be active and informed citizens both now and in the future.

Veronica Acker narrative profile. Veronica is a veteran middle school science teacher. Her original degree in oceanography and prior career as a marine animal trainer and educational interpreter at an aquarium demonstrate her deep connection to the natural world. Yet even before her profession in marine science, Veronica recalls always being an "outdoorsy person" (Veronica, Interview \#1) and doing everything from baiting her own fishing hooks to dissecting owl pellets to being a dedicated fan of Jack Hanna (an American zookeeper and television host of multiple nature and animal oriented shows). Now as a teacher, Veronica believes that "all of my experiences I bring into the classroom - all the little artifacts, all my pictures and the kids are always like, what haven’t you done?" (Veronica, Interview \#1).

She loves exploring the natural world to understand science and she wants her students to also get excited about learning science: "I want them to embrace their 
innermost nerd and to be okay with that title" (Veronica, Interview \#1). Veronica talked about getting students to "notice the world around them" (Veronica, Interview \#1) and seems to focus on developing an understanding of those connections. She did not explicitly discuss any driving passion to work to protect that environment from human damage in relation to her love of it, instead her climate change instructional focus employed a different lens whereby she sought to focus on epistemic practices, climate change content knowledge development, and a general preparation for the students' roles as future leaders on a wide array of environmental issues.

Veronica had her excitement for science teaching and learning enhanced by a great role model science teacher in high school biology. This teacher's excitement and enjoyment while teaching impacted Veronica deeply and now she wants her students to engage in science learning with a similar joy. Veronica's general approach to creating those appealing lessons is to show how these topics are connected to the students' lives and the real world, "because they are in middle school and that all seems really far away, even when it is not” (Veronica, Interview \#2).

Along this same line of thinking, she works to focus her curriculum so that connections to climate change come easily throughout her curriculum and so that her students are prepared to read and interpret graphs, to understand scientific data and its sources, and the valuable nature of scientific knowledge. "To me it just makes sense that as you are talking about something, you can just draw that connection to bring it back with the thread [of climate change], so the students aren't just filling their heads with information and then dumping it after the test and moving on with the next unit" (Veronica, Interview \#2). Instead, she feels it is very important for her students to 
understand climate change due to its likely influence on their personal lives and society at large.

Teaching in a politically conservative area presented Veronica with some pushback from parents the very first time she introduced the topic of climate change. In subsequent years, she has modified the one troublesome assignment and she heard no further complaints from parents of students. She attributes most of this confidence to teach and freedom from the politicization of the topic to the trust the school community (students, administrators, and parents) places in her because of her many years teaching in the same school "and so that it makes it easier because parents know me" (Veronica, Interview \#2). However, Veronica still encourages her students to think beyond the belief systems of their parents and to develop critical thinking skills to better evaluate "what was the true science and what was not" and to "get them to think for themselves and not what their parents say or what I say, and that way their parents can't say that I'm forcing something on them" (Veronica, Interview \#2). For example, Veronica introduced students to the Skeptical Science website which is a resource that examines popular denialist claims related to climate change and presents multiple lines of data and evidence to critique those false assertions.

Veronica prioritizes an evidence-based approach that complements the development of an appreciation of nature and our collective roles in, and for, the environment. "It's not just me teaching them about the science, it's also how to be a better person, and then even a better person for the environment" (Veronica, Interview \#2). In a research project on protecting endangered species from climate change impacts, Veronica strongly encouraged her students to "think things through a little bit more" than to simply suggest paying a fine when a proposed law was broken, but to 
really connect solution-oriented actions to mitigating the negative impacts of climate change more directly. This evidence driven approach leads Veronica to work with her students to become scientifically literate and educated on environmental issues like climate change to hopefully be prepared to act to mitigate the impacts of climate change in the future.

Wanda Katz narrative profile. Wanda is a veteran middle school science teacher. She exhibits a deep and self-cultivated love of science. This passion was enhanced through several careers prior to becoming a classroom teacher, namely a marine science field researcher and a science journalist. Even though these earlier careers helped Wanda to achieve her childhood aspiration to "be an oceanographer like Jacques Cousteau” (Wanda, Interview \#1), she sought out a new career 14 years ago and has been teaching middle school science in a poor urban school district ever since. Her students are not typically accustomed to learning to appreciate nature, but Wanda does all she can to turn those attitudes around. "In one of the most violent parts of the city, I would get my kids outside, I'd say already we're going to go. And they're like it's dirty and dangerous in a park and I said you'll be safe with me and we're off and gone. And they learned how to be outside" (Wanda, Interview \#1). This 'learning to be outside' is critical in Wanda's eyes because she views her students as needing to step into the role of future environmental caretakers.

As a self-described old lady, Wanda jokingly admitted that very likely few of the impacts from climate change would be impacting her directly even as they are occurring around the world. But "as a guardian, as an elder in this society who's responsible for stewardship, it's my responsibility to make sure that I'm passing on 
wise ways of living to the next generation (Wanda, Interview \#2). Over the years, she has implemented tree planting and other environmentally focused service learning projects around her school's campus with her students to build the students' personal connections with their local surroundings in a positive fashion.

Besides the challenges of an urban school location with prevalent violence and little nature to experience, Wanda's school is also in a perpetual state of inadequate funding and the loss of teaching and support staff positions every year. However, she's taken on these difficulties as a "personal challenge" and works very hard to motivate her students to learn science knowledge and skills in meaningful ways to for them to be successful down the road. "It's coming back to [the idea that it's] not 'Can you remember all this stuff [i.e. science facts]?' but 'Can you remember how to go about asking questions and solving them in a thoughtful and critical way?' And it makes complete sense because there's so much science to know" (Wanda, Interview \#1). This personal motivation to inspire her students is coupled with tremendous agency from her school administration that is fairly hands-off and a flexible curriculum that Wanda regularly modifies as needed to meet her students' progress and abilities.

One of the adjustments that she has made to her curriculum is to add climate change related segments to all her instructional units throughout the year. "Because I think that [climate change] is a really big issue for this generation that's influencing a lot of what's going on in their lives, that will influence the economy, that will influence the weather and all this stuff, so they need to be knowledgeable about it...so I think it's my obligation to have educated kids coming out of the classroom" (Wanda, Interview \#1). For example, during a unit on light, she introduces how energy from sunlight warms the earth and how atmospheric changes impact that temperature. Or in 
a unit on ecological diversity, she describes the concepts of the current sixth extinction and how changing environmental features due to climate change are driving these different species extinctions. Bridging climate change to all her science units might be difficult for some teachers, but for Wanda, between her extensive scientific research experiences prior to becoming a teacher and her dedication to pursuing countless professional development courses and professional learning opportunities, she has developed an expertise in this environmental issue that she seems to easily connect it throughout her curriculum.

Wanda's approach throughout her science instruction, and especially her climate change lessons, is to help students understand the scientific arguments for the topic. This focus on the evaluation of evidence has led to no controversy from her community regarding climate change - though she hypothesizes that there could be more political pushback if she taught in "Trump land... an area where there's more people who seem to buy into the hoax statement" (Wanda, Interview \#2). Instead, Wanda works with her students to examine claims, understand the evidence, and evaluate reasonings using the C-E-R framework. "I don't take a stand [politically]. I don't argue personally. I handle the class using scientific thinking. What's the claim? What's the evidence? What's the reasoning? It's that simple" (Wanda, Interview \#2). Generally, she strives to truly build her students' appreciation of the nature of science and their abilities to meaningfully participate in epistemic practices like scientific argumentation and reasoning from evidence.

She aims to get her students asking questions about the real-world issues surrounding their lives and answering those questions through guided research and inquiry such 'that it's not just what's happening, but what is it that I can do to make a 
difference?” (Wanda, Interview \#2). This subtle inclusion of ideas for climate change activism and/or advocacy is intentional even if Wanda doesn't want to focus on the political implications of these types of additions. Instead, she frames these actionoriented discussions as proper preparation for their future lives. "I think it's irresponsible to teach climate change without being able to talk about what can be done, especially with young people because it could feel like, whether intended or not, a doomsday scenario" (Wanda, Interview \#2). Fr example, several times over the past few years, she has partnered with a local non-profit organization to not only plant trees around the school community, but also to calculate the $\mathrm{CO}_{2}$ absorption from those trees to demonstrate the positive impacts students can make on their nearby areas. Overall, she hopes that her students are knowledgeable and prepared to address the issue of the climate change in the future.

This section presented the collection of teacher narratives based on the experiences and backgrounds the teachers described during the interviews and through their reflections. The development of these narrative profiles represented a "critical step" of the narrative inquiry research process (Kelchtermans, 1994) and serve as useful "field texts" (Clandinin \& Connelly, 2000) throughout the subsequent analyses.

\section{Section 3: Differences Within Teachers' Climate Change Experiences}

This section showcases the results from coding efforts undertaken during the vertical analysis phase - Phase 1, Step 2 (structural a priori coding) and Phase 1, Step 3 (descriptive emergent coding). Vertical analysis allowed for intensive analytic attention on each teacher individually before making comparisons between teachers during later horizontal analyses. 


\section{Coding process}

Structural a priori coding. This section contains the results of Phase 1, Step 2 during which each set of teacher documents were coded via structural coding (MacQueen et al., 2008; Saldaña, 2013) utilizing the a priori codes from Clandinin and Connelly's Three-Dimensional Narrative Structure (2000). The a priori codes were comprised of: personal, social, contextual, past, present, future. Table 11 shows the code counts and frequency for these a priori codes.

Table 11 Structural Codes and Code Frequency

\begin{tabular}{|l|l|l|l|}
\hline Code & Short Description & $\begin{array}{l}\text { Total } \\
\text { Code } \\
\text { Count }\end{array}$ & $\begin{array}{l}\% \text { of } \\
\text { Teachers } \\
\text { Represented }\end{array}$ \\
\hline PS & Past experience & 758 & $100 \%$ \\
\hline CU & Current experience & 342 & $100 \%$ \\
\hline FT & Future experience & 128 & $100 \%$ \\
\hline CX & Contextual element & 386 & $100 \%$ \\
\hline PR & Personal attribute & 388 & $100 \%$ \\
\hline SL & Social relationship & 405 & $100 \%$ \\
\hline
\end{tabular}

A preliminary review of the code frequency by teacher showed that all teachers relayed experiences that contained all elements of the Three-Dimensional Narrative Structure, comprised of Continuity aspects (past, present, future), Contextual aspects, and Interaction aspects (personal, social). This is important information for the utility of this theoretical structure, but more nuanced coding was needed to delve more deeply into the development of teacher identities.

Descriptive emergent coding. The findings from descriptive coding efforts were able to peel back some of the layers from the overarching structural codes 
provided by the Three-Dimensional Narrative Structure. The codes presented in Table 12 below were emergent during the multiple reviews of each teacher's documents (two interview transcripts and a reflection). A fully expanded codebook for this collection of emergent descriptive codes, including exemplar teacher codes for each of the 18 codes and 90 sub-codes can be found in Appendix D.

Code frequency analysis. Once again, a preliminary review of code frequencies for each individual teacher and teachers grouped by several key attributes (as found in Table 10) was completed to determine if patterns could be found among the descriptive codes. Several variations of comparisons were conducted, and none proved to yield poignant results. This quantification of qualitative data was set aside to continue with a more productive horizontal analysis as described in the next section. 
Table 12 Emergent Codes and Code Frequency

\begin{tabular}{|c|c|c|c|}
\hline Code & Short Description & $\begin{array}{l}\text { Total } \\
\text { Count }\end{array}$ & $\begin{array}{l}\text { \% of } \\
\text { Represented }\end{array}$ \\
\hline \multicolumn{4}{|l|}{ Teacher } \\
\hline Agent & Teacher Agency in the Classroom & 58 & $93.3 \%$ \\
\hline DTT & 'Drawn to Teaching' & 84 & $100 \%$ \\
\hline Ed_Ch & Educational Challenges & 78 & $93.3 \%$ \\
\hline \multicolumn{4}{|l|}{$\begin{array}{l}\text { Science } \\
\text { Teacher }\end{array}$} \\
\hline Build & Build Interest in Science & 85 & $100 \%$ \\
\hline Display & Display Self as a Science Person & 38 & $100 \%$ \\
\hline Do_Sci & Enjoys Doing Science & 63 & $100 \%$ \\
\hline DPI & Deep Personal Interest in Science & 99 & $100 \%$ \\
\hline Learn & Love of Science Learning & 56 & $80 \%$ \\
\hline Res & Participation in Scientific Research & 18 & $53 \%$ \\
\hline \multicolumn{4}{|l|}{$\begin{array}{l}\text { Climate } \\
\text { Educator }\end{array}$} \\
\hline Activ & Incorporate Climate Activism or Advocacy & 63 & $100 \%$ \\
\hline Confid & Confidence to Teach Climate Change & 35 & $80 \%$ \\
\hline Curr_Conn & $\begin{array}{l}\text { Cross-Curricular Connections to Climate } \\
\text { Change }\end{array}$ & 95 & $100 \%$ \\
\hline Evid & $\begin{array}{l}\text { Evidence Based Approach to Climate } \\
\text { Change Education }\end{array}$ & 47 & $86.7 \%$ \\
\hline Geo & $\begin{array}{l}\text { Geographically Local or Relevant } \\
\text { Connections to Climate Change }\end{array}$ & 48 & $93.3 \%$ \\
\hline Need & $\begin{array}{l}\text { Resources Needed to Encourage Climate } \\
\text { Change Instruction }\end{array}$ & 101 & $100 \%$ \\
\hline Poli & $\begin{array}{l}\text { Political Influence on Teaching Climate } \\
\text { Change }\end{array}$ & 107 & $100 \%$ \\
\hline Role & $\begin{array}{l}\text { Perceptions of Role and Responsibility for } \\
\text { Teaching Climate Change }\end{array}$ & 79 & $100 \%$ \\
\hline Support & Support for Teaching Climate Change & 112 & $100 \%$ \\
\hline
\end{tabular}




\section{Section 4: Similarities Across Climate Change Teaching Experiences}

Patterns of similarities and differences between teachers and their climate change teaching experiences are explored in this section.

Theoretical coding. The personal, professional, and political elements served as overarching categories for the descriptive codes previously explored for each teacher. As shown in Table 13, the stories shared by teachers most frequently contained professional elements.

Table 13 Personal, Professional, and Political Categorization of Descriptive Codes

\begin{tabular}{|c|c|c|c|}
\hline \multirow[t]{2}{*}{ Descriptive Code } & \multicolumn{3}{|c|}{ Predominant element(s) } \\
\hline & Personal & Professional & Political \\
\hline Agency in Classroom & & $X$ & \\
\hline Drawn to Teaching & & $\mathrm{X}$ & \\
\hline Educational Challenges & & $\mathrm{X}$ & \\
\hline Build Science Interest & & $\mathrm{X}$ & \\
\hline Display Self as Science & $\mathrm{X}$ & & \\
\hline Do Science with Others & & $\mathrm{X}$ & \\
\hline Deep Personal Interest & $\mathrm{X}$ & & \\
\hline Learn More about Science & & $\mathrm{X}$ & \\
\hline Research Experience & & & $\mathrm{X}$ \\
\hline Activism towards Climate & & & $\mathrm{X}$ \\
\hline Confidence to Teach CC & & $\mathrm{X}$ & \\
\hline Curricular Connections & & $\mathrm{X}$ & \\
\hline Evidence Focused Approach & & & $\mathrm{X}$ \\
\hline Geographic Connections & & $\mathrm{X}$ & \\
\hline Needs for Teaching CC & & $\mathrm{X}$ & \\
\hline Political Influences & & & $\mathrm{X}$ \\
\hline Role for Teaching CC & $X$ & $X$ & $\mathrm{X}$ \\
\hline Support to Teach CC & & $\mathrm{X}$ & \\
\hline
\end{tabular}


Process for code-weaving. Code-weaving illustrates how the individual descriptive codes are interwoven into a network of influences on teacher identity for climate change. Code-weaving integrated the theoretical constructs of personal, professional, and political alongside a temporal component that reflects the dynamic nature of teacher identity development. In the Appendix E, I provide an example of how I used code-weaving to create a thinking display for the personal elements.

At the conclusion of Phase 2, Step 5, the 18 emergent descriptive codes were grouped, visually organized temporally (past and present experiences, and future aspirations) and thematically into personal, professional, and political elements as shown in Figure 1 as a conceptual model for identity development as a climate change educator. This model is not meant to suggest required pathways that all teachers must follow, nor is it meant to imply that all teachers encompass all components of the model. 


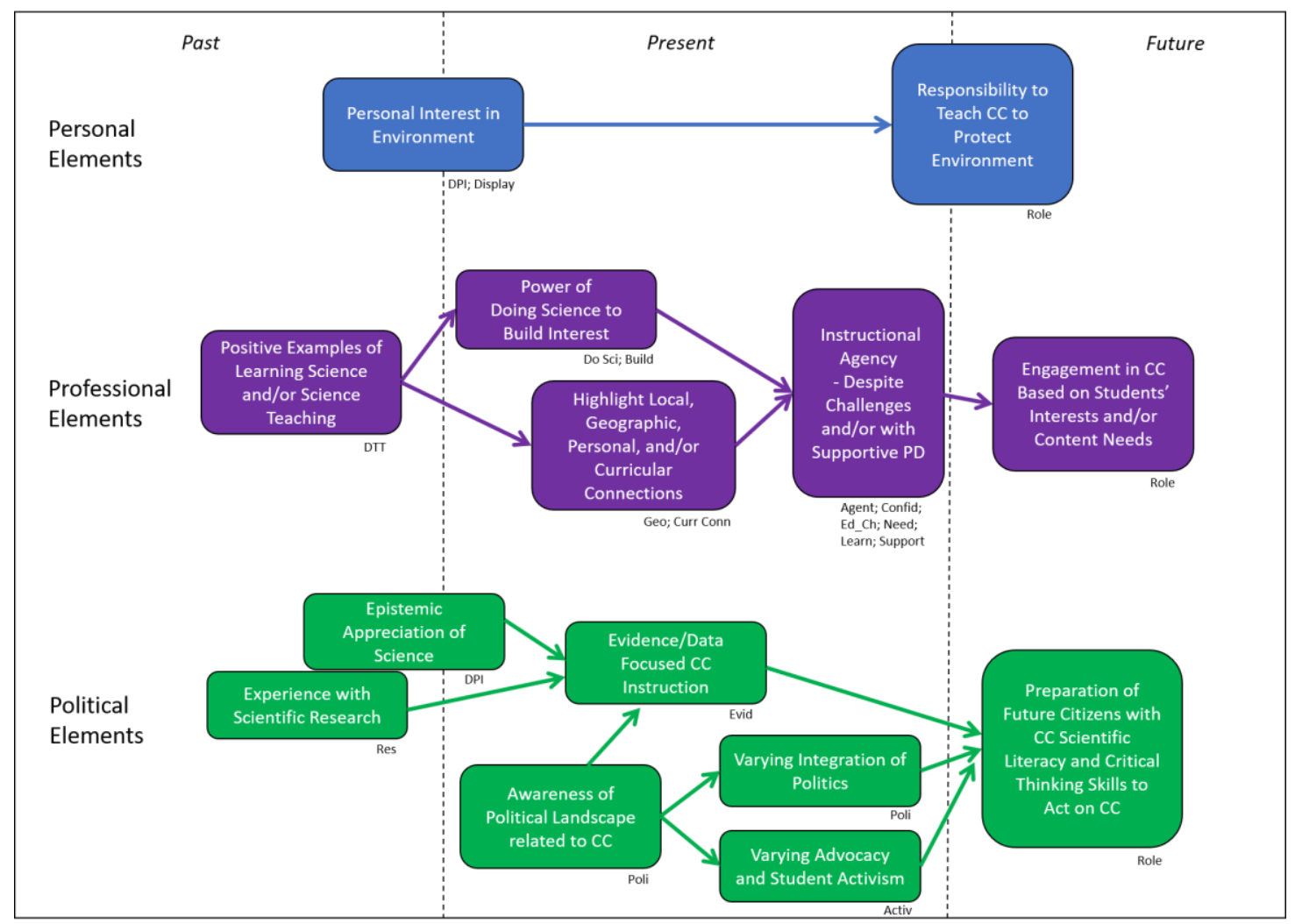

Figure 1 Conceptual Model for Climate Change Teaching

Conceptual Model for Climate Change Teaching Identity. Climate change teaching identity is multifaceted and influenced by personal, professional, and political elements over a teacher's past and present experiences and future aspirations. These components manifest differently in individual teachers and the competing identity constructions are in constant flux depending on the external contextual factors of the classroom and the internal commitments and values of the teacher.

This conceptual model is comprised of five trends, or patterns of influence and teacher actions (Figure 2). I utilize the term trend here to refer to the aspects of identity common across several teachers, but that may not apply thematically to all 
teachers in the study. The first trend is highlighted in blue across the uppermost row of the model and describes the personal elements of the conceptual model. The next two trends encompass the professional elements and are located within the middle section of the model in purple, red, and pink. The final two trends describe the political elements in the lower section of the conceptual model and are highlighted in yellow and green. 


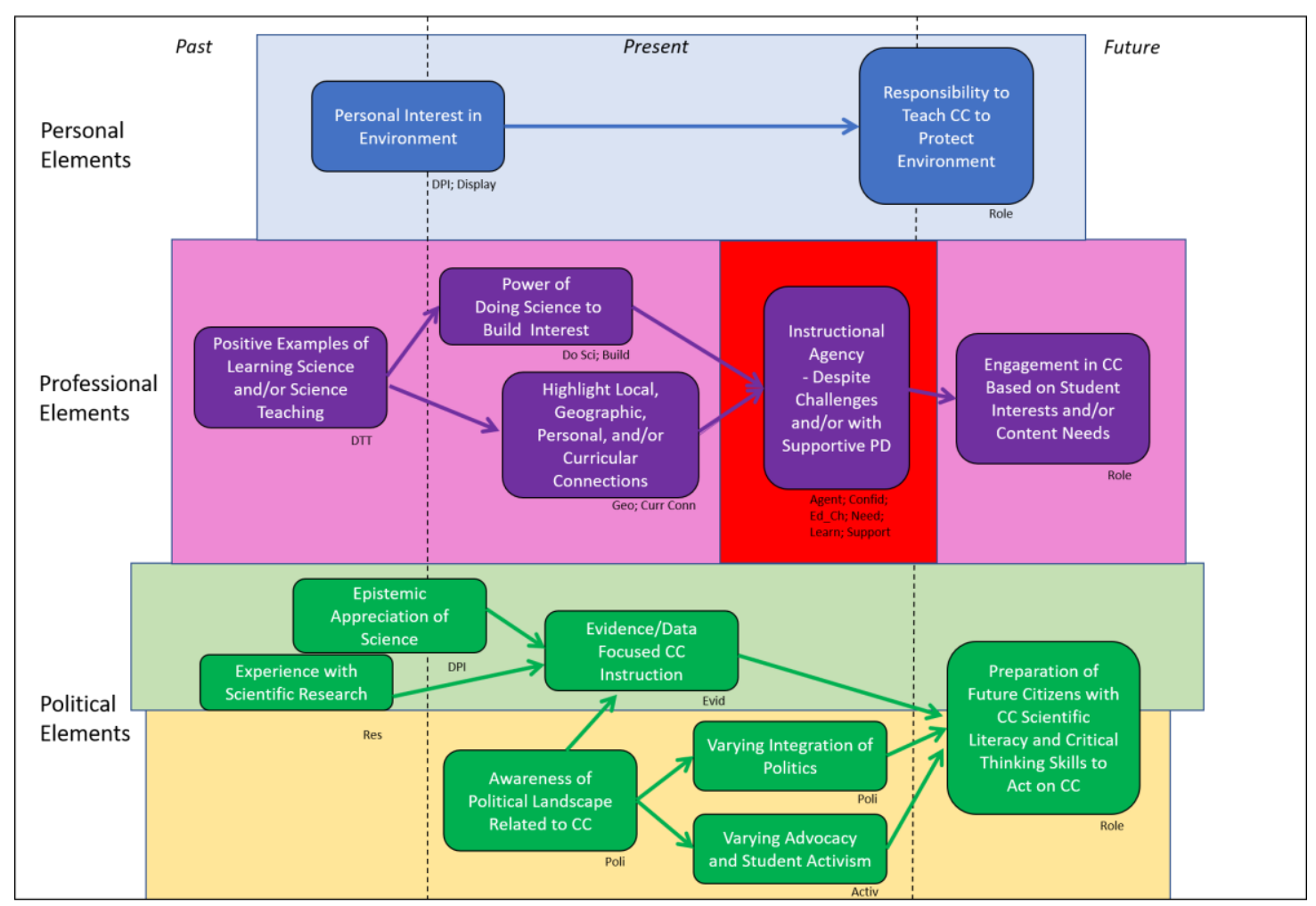

Figure 2 Conceptual Model Classified by Trend

Depending on the predominant influences on teacher instructional choices related to climate change, each person was described as holding one or more constructions of teaching identity. Each trend and corresponding identity(ies) are detailed in the following sections.

Trend 1: Personal Valuation of Nature. Trend 1 showcases the personal elements related to climate change teaching experiences and includes teacher's personal valuation connections to nature, both past and present, along with their current and likely efforts to teach climate change as a result of a sense of responsibility 
to protect the environment (Figure 3). In the narratives of numerous teachers, they described the influence of early outdoor experiences for their appreciation of the natural world. Later these same teachers evoked a sense of obligation to protect the environment and to share that passion or sense of guardianship with their students. Teachers who described this personal trajectory I name as "Passionate Environmentalist" identity construction.

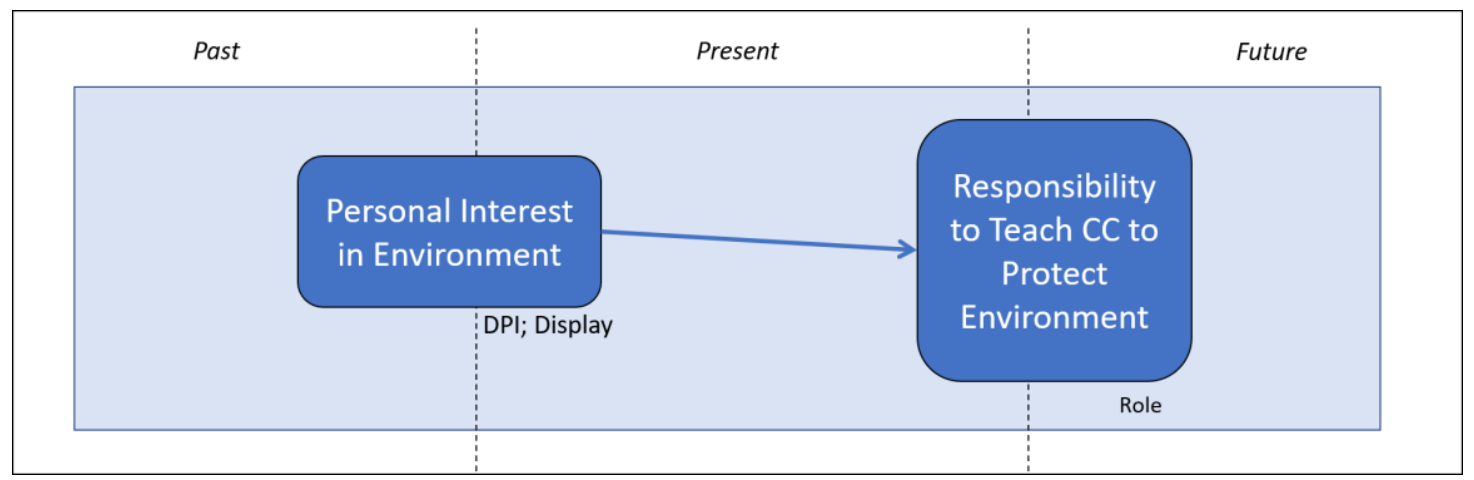

Figure 3 Trend 1: Personal Valuation of Nature

Often Passionate Environmentalist teachers incorporated clear displays of their dedication to the environment by sharing nature-based travel experiences, like Tara's trip to the Arctic region or Fiona's journey to collect black volcanic sands and Icelandic glacial deposits. Other teachers discussed their personal actions to demonstrate their desire to protect the environment, such as Mary's inclusion of her personal civic participation in marches and rallies to support action against climate change impacts. Another common strategy employed by Passionate Environmentalist teachers was to showcase how the community depends on the local environment for valuable resources related to their livelihoods and leisure. Barbara took this approach 
by discussing with her students how important this "symbiotic" relationship was between their families with their fishing, farming, and crabbing occupations and the health of their natural surroundings. Lastly, some Passionate Environmentalist teachers, like Tara, often incorporated class conversations more broadly about how people should be working diligently to protect the environment and not damage it because of our grander responsibility and "moral duty" (Tara, Interview \#2) to take care of our planet.

Trend 2: Experiences in Science Teaching and Learning. Trends 2 and 3 most closely relate to professional elements of the teachers' experiences in science teaching and learning throughout their lives. As shown in Figure 4, Trend 2 begins with frequent participation in positive science learning experiences in their past which serve as effective models for demonstrating how to teach science effectively. Here teachers often described especially influential middle or high school science teachers and how these teachers provoked their own desire to become a science teacher in the future. Looking at present-day teaching experiences, teachers found within Trend 2 often talked about the power of student participation in the practices of science. These active and hands-on opportunities to do science work to build student interest and engagement in science. Often teachers in this track often highlighted the need to incorporate geographically local and personally relevant connections to the curriculum overall, and especially for teaching climate change.

Skipping over the next block in the thinking display for now (as this "Instructional Agency" concept encompasses its own discussion as Trend 3), teachers within this trend work to engage students through those climate change connections 
and depending on their overall emphasis - either focusing on students' individual interests in climate change or the cross-curricular connections to climate change teachers were classified as one of two identity constructions: "Student Interest Engager" or "Content Focused Educator".

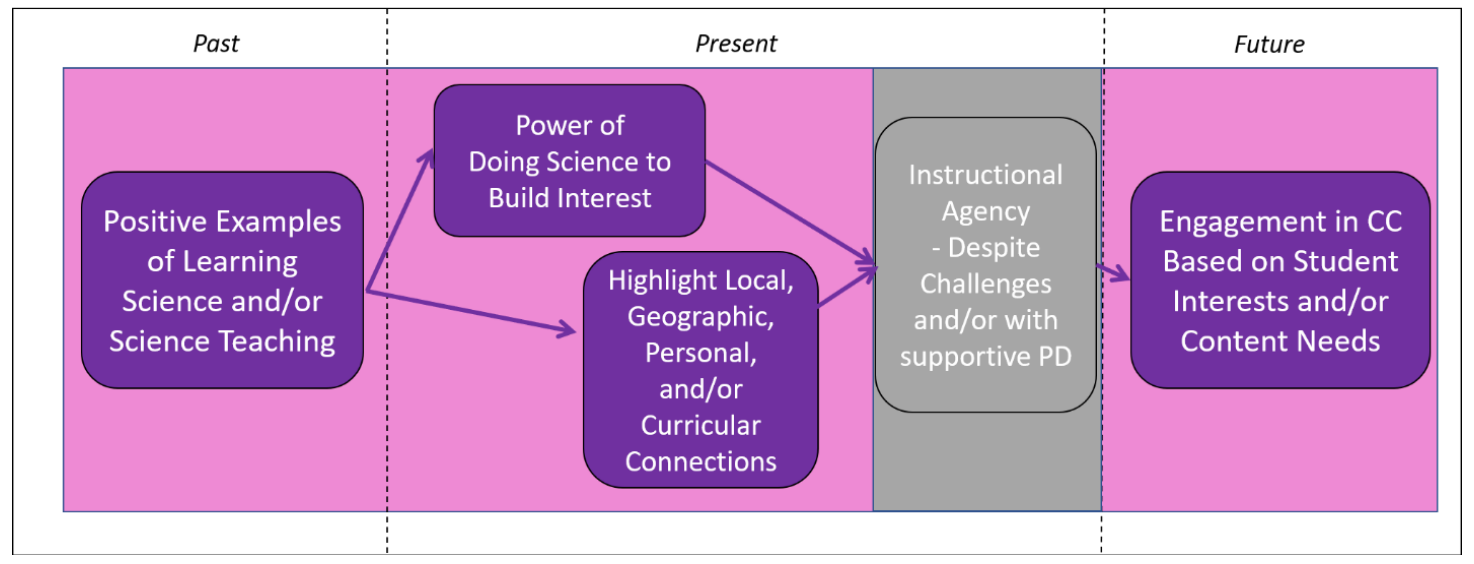

Figure 4 Trend 2: Experiences in Science Teaching and Learning

Student Interest Engager teachers often drove their climate change instruction via connections to small-scale, local geography, like nearby flooding events, or to student hobbies, like crabbing and fishing, and how these pastimes are, and will continue to be, affected by climate change. Fiona even took this a step further by actually raising fish to be released with her students to introduce climate change impacts and mitigation efforts. Other Student Interest Engager teachers focus on incorporating student centered and hands-on interactive lessons about climate change that showcase how to ask and answer their own questions about climate change. Several teachers talked about the games they include in their student interest oriented 
lessons (e.g., Amanda and greenhouse effect tag, Fred with Cool It! card game) or the experiments they worked with students to design to understand the observable nature of carbon dioxide's impact on temperature in Connie's classroom or the role of salinity and temperature on water density in Amanda's classroom.

Alternatively, Content Focused Educator teachers tend to focus their climate change lessons as thematic motivators to engage students in learning required curriculum - either required by a mandated science curriculum or more frequently 'required' in the sense that the teachers believe that a fundamental understanding of climate change is an essential component of their students' science knowledge base because of the importance of this environmental issue. In practice, the climate change instruction conducted by Content First Educators frequently was integrated across a number of curricular topics beyond the classic weather and climate curricular approach. This was done in an effort to demonstrate how climate change will have broader impacts as seen in Garrett's physics connections to the electromagnetic spectrum or Melissa's bridge from climate change to genetic diversity. Other Content First Educators focused the climate change lessons more deeply on the accumulation of climate change content knowledge and refinement of needed epistemic skills to create or critique scientific explanations for climate change. For example, Veronica strongly emphasized honing her students' graphing skills, while Fred sought to empower his students to engage in scientific argumentation from appropriate data and evidence sources. These pedagogical choices were made most frequently to support standards driven skills found in their respective curricula and climate change was added as an extra layer or relevant context and not necessarily the main justification for inclusion. 
Trend 3: Teacher Instructional Agency. The opportunities to enact either of the professional identity constructions described in Trend 2 are mediated by Trend 3 . Trend 3 describes the critical role that teacher agency and empowerment play to make instructional decisions that prioritize the inclusion of climate change (Figure 5). Without the influence of a strong sense of instructional agency, teachers are limited in their efforts to meaningfully engage students in climate change focused instruction. Yet, when present, this agency will persist despite contextual educational challenges like a restrictive or overloaded science curriculum. Additionally, this agency flourishes when the teacher is supported by professional development efforts and when teachers can build their confidence and self-efficacy to teach climate change through a community of like-minded educators.

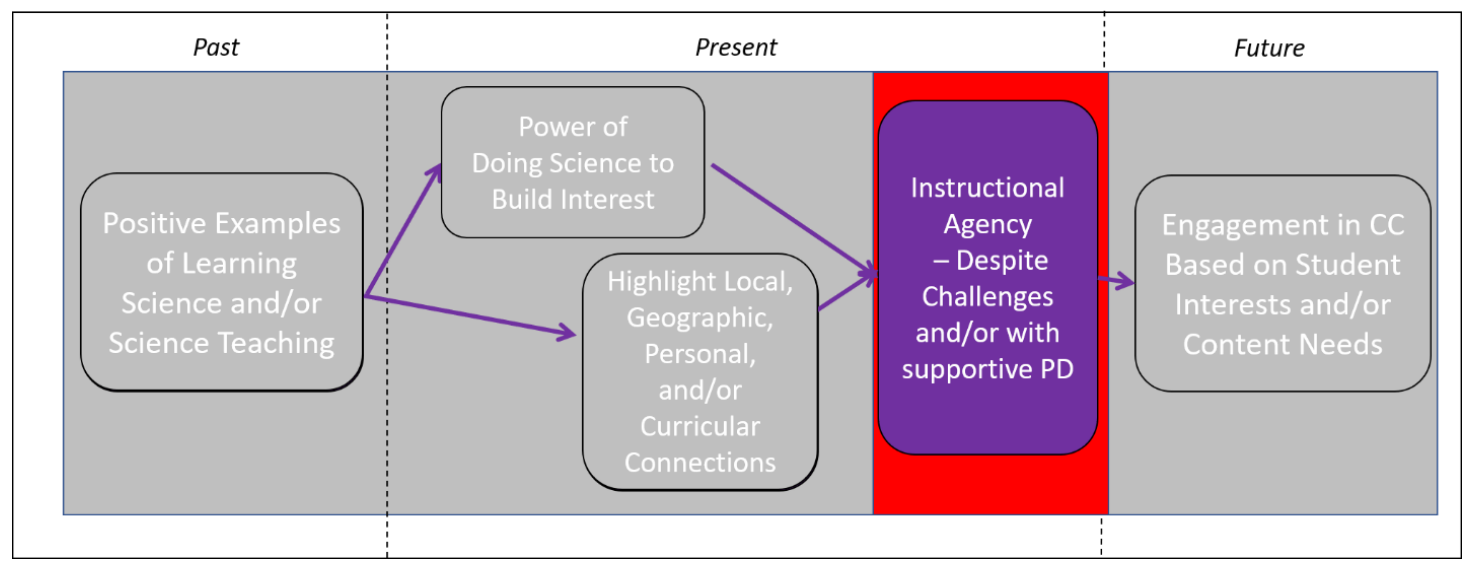

Figure 5 Trend 3: Teacher Instructional Agency

Trend 4: Epistemic Evidence-Based Instruction. I now move on to Trends 4 and 5 which describe the political elements related to identity development as a 
climate change educator. While not overtly political in nature, Trend 4 reveals the epistemic understandings of teachers related to the nature of science and related to the weight of evidence for scientific explanations and ideas (Figure 6). Often teachers here have in-depth scientific research experience generally from their college coursework or through prior careers. These past experiences appear to lend the teachers a strong appreciation for science broadly, and especially for the scientific process of investigation, discovery and knowing. In their current teaching experiences, they often focus their climate change teaching primarily on evaluating and understanding the scientific data as evidence for climate change. Additionally, these teachers may include instructive opportunities for their students to evaluate data to support scientific arguments related to climate change and to refute climate denialism's weak reasoning and false claims. These instructional efforts are specifically designed to imbue critical thinking skills for the scientific decision-making process to their students to best prepare them to evaluate claims based on evidence in the students' future lives as scientifically literate citizens.

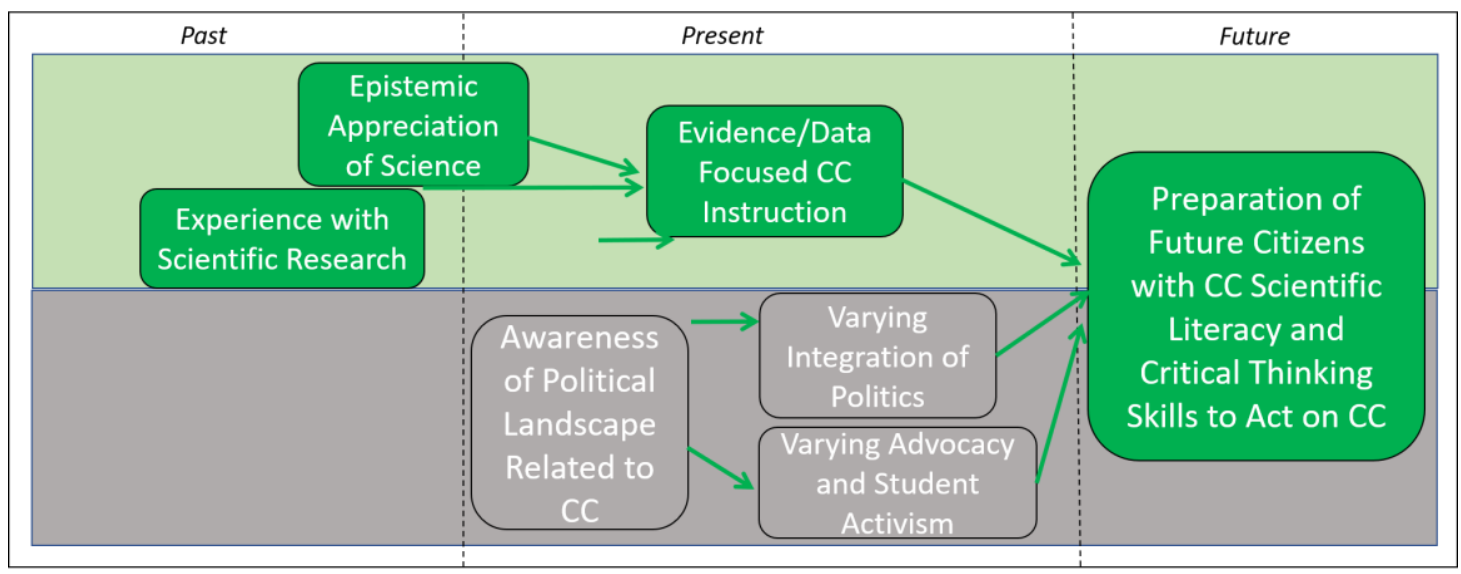

Figure 6 Trend 4: Epistemic, Evidence-Based Instruction 
Trend 5: Civic and Social Awareness via Socioscientific Literacy. Lastly,

Trend 5 incorporates the more obvious political influence on climate change teaching experiences and its role in identity development (Figure 7). Teachers linked to this identity construction are currently dealing with a wide variety of impacts from their school community's political leanings - from quite liberal to very conservative - and their own personal political values. As a result of these diverse situations, teachers vary in how willing they are to integrate explicit political conversations from the local, state, national and/or international scales.

This identity construction also showcases the most variability in the degree to which teachers feel comfortable asking or requiring their students to participate in climate-related activism and advocacy for this topic as a socioscientific issue. Some teachers described their own personal actions to mitigate climate change as examples, others directly involved their students and brought them outdoors to plant trees in direct connection to climate change mitigation, while still others only discussed what people, broadly speaking, could be doing to reduce the impact of climate change.

Collectively, these teachers have socioscientific related instructional goals for climate change teaching that aims to prepare their students to understand and discuss the numerous perspectives on climate change and how they can utilize a variety of information sources to come to their own decisions regarding actions they want to take towards climate change in the future (or not). This Trend 5, along with Trend 4, jointly influence the last identity construction of "Civic and Epistemic Skills Promoter". The Civic and Epistemic Skills Promoter teachers look to empower students with content knowledge and awareness of this socioscientific issue to allow students to be scientifically educated, productive citizens in the future. 


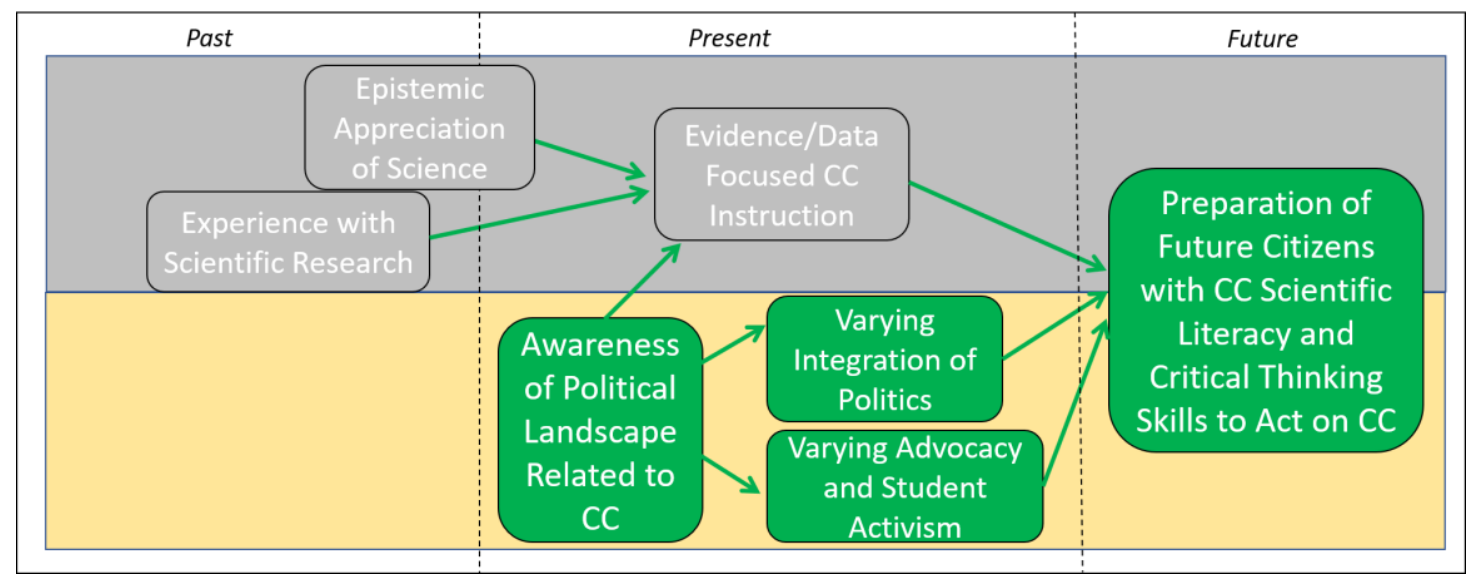

Figure 7 Trend 5: Civic and Social Awareness via Socioscientific Literacy

In this conceptual model, Teacher Identity Development as a Climate Change Educator, four constructions of identity emerged as possible paths towards the development of an identity as a climate change educator. These are: Passionate Environmentalist, Student Interest Engager, Content Focused Educator, Civic and Epistemic Skills Promoter. Passionate Environmentalists rely on their love of nature to focus their climate change lessons on demonstrating a responsibility to protect the environment from damage. Student Interest Engagers are teachers who highlight students' curiosity and interest in climate change as the motivation for teaching about climate change. Content Focused Educators are teachers who engage students in climate change lessons that connect broadly to the science curriculum and relate these lessons as necessary content knowledge. Civic and Epistemic Skills Promoters are educators that aim to prepare their students to be effective critical thinkers who can evaluate various claims and perspectives on climate change as a socioscientific issue and who can come to their own informed decisions about appropriate action related to 
climate change. These four identity constructions point to the multiple motivations and reasonings that teachers may utilize during the development of one's teacher identity.

\section{Section 5: Multifaceted Constructions of Teacher Identity for Climate Change}

As shown in the previous section, four identity constructions from the predominant influences inherent in personal and professional experiences and the political contexts experienced by each teacher. These constructions of identity are: Passionate Environmentalist, Student Interest Engager, Content Focused Educator, and Civic and Epistemic Skills Promoter. The alignment between personal, professional, and political elements, the five trends, and the four identities are shown in Table 14.

Table 14 Alignment of Elements, Predominant Trends, and Identity Constructions

\begin{tabular}{|l|l|c|}
\hline Element & Predominant Trend(s) & Identity Construction(s) \\
\hline Personal & 1) Personal Valuation of Nature & Passionate Environmentalist \\
\hline Professional & $\begin{array}{l}\text { 2) Experiences in Science Teaching and } \\
\text { Learning }\end{array}$ & $\begin{array}{c}\text { Student Interest Engager } \\
\text { or }\end{array}$ \\
\cline { 2 - 2 } & 3) Teacher Instructional Agency & Content First Educator \\
\hline Political & $\begin{array}{l}\text { 4) Epistemic Evidence-Based } \\
\text { Instruction }\end{array}$ & $\begin{array}{c}\text { Civic and Epistemic Skills } \\
\text { Promoter }\end{array}$ \\
\cline { 2 - 2 } & $\begin{array}{l}\text { 5) Civic and Social Awareness via } \\
\text { Socioscientific Literacy }\end{array}$ \\
\hline
\end{tabular}

However, the 15 teachers in this study infrequently demonstrated only one identity construction. Most often, teachers espouse ideas and describe lived experiences that align themselves with two or three constructions of identity. Figure 8 shows how the fifteen teachers simultaneously are located among the four identity constructions. Figure 10 demonstrates how each combination of identity aspects 
manifested for each teacher. In section 5, I describe the increasingly complex identity constructions of the 15 teachers in this study. Throughout I prioritize the teacher's voices as evidence for their enactment of these identities for teaching climate change.

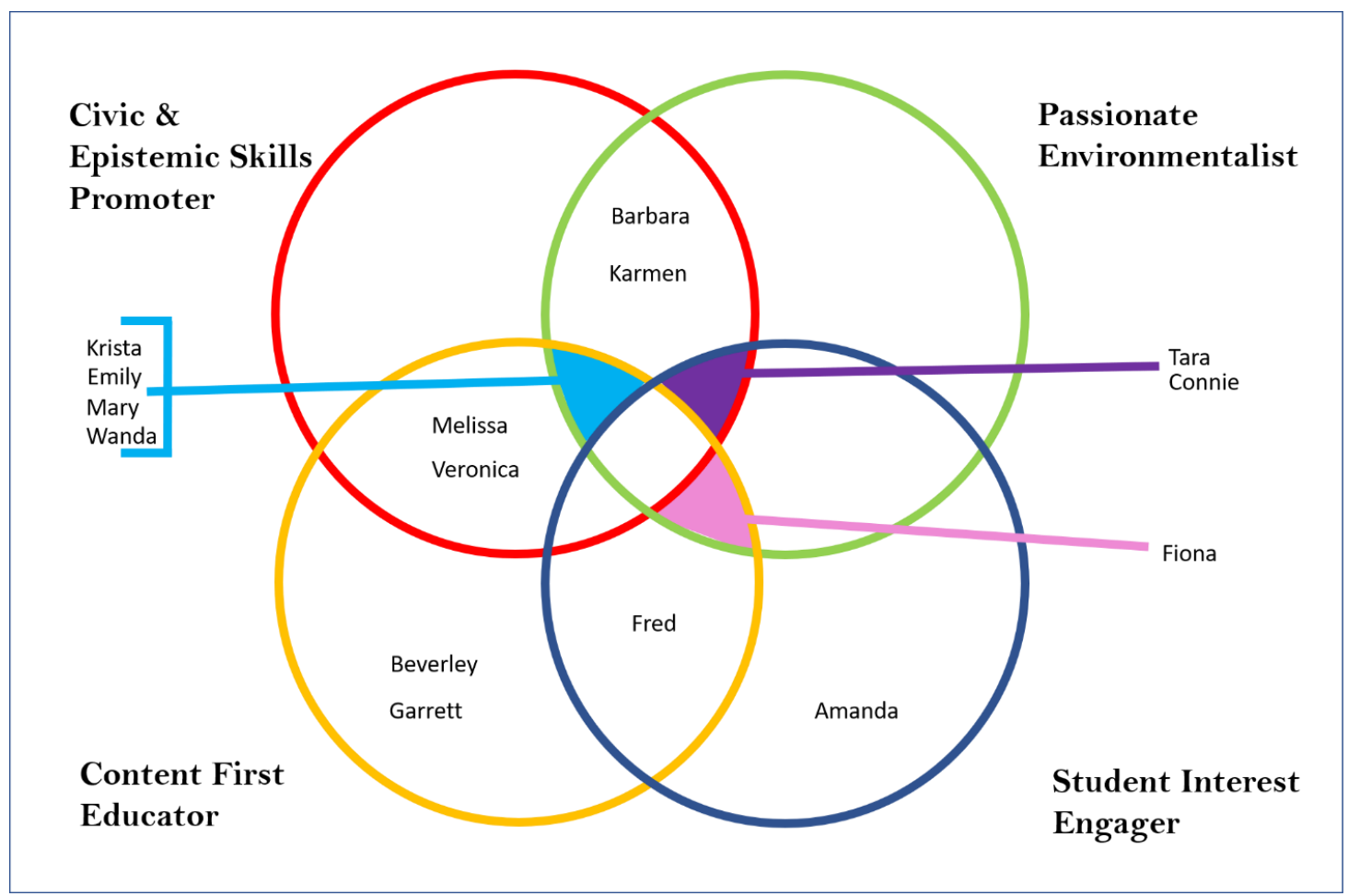

Figure 8 Integrated Diagram of Identity Constructions 


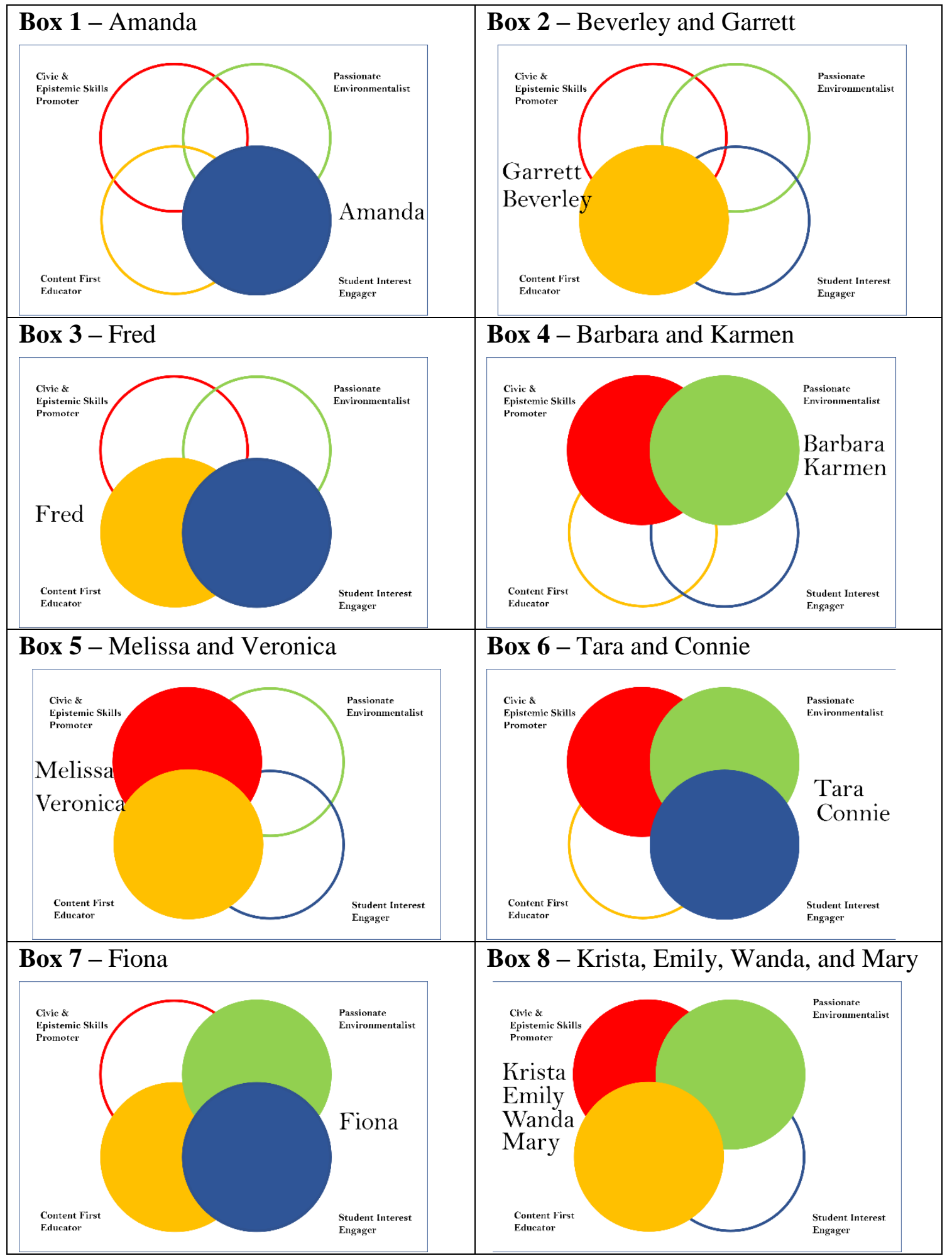

Figure 9 Combinations of Identity Constructions by Teacher 
Single identity teachers. The main focus of the experiences and reflections that single identity teachers shared during the interviews pointed to a singularly driven motivation for becoming a climate change educator. In the current study, Amanda presented ideas that are most closely affiliated with being a Student Interest Engager (Figure 9, Box 1) while Garrett and Beverley aligned with the Content First Educator identity (Figure 9, Box 2).

Amanda - Student Interest Engager. Student Interest Engager teachers, like Amanda, work to highlight student curiosity and interest in climate change. This most likely has a basis in her own interest and enjoyment while teaching the topic. Amanda recounted during the interviews that "because we prepped it and it was fun, they enjoyed it, the kids enjoyed it, and they learned, and that's the whole goal. If they learned the content, and they had fun doing it and it was fun, we're definitely doing it again. If we could add some stuff to make it more engaging and more informational, all the better" (Amanda, Interview 2). She described how she had fun singing silly songs that connected with the material, like "It's Getting Hot in Here" and making pun filled nametags for students for when they participated in a greenhouse effect game of tag. "If it's fun to do it, then they are paying more attention. And the learning kind of slips in there" (Amanda, Interview 1).

Amanda's most frequently shared beliefs focused on the idea that students like the topic and it's fun to learn about, but she did not mention any personal drivers for teaching climate change: "I mean, animals are important to me, so the environment is important to me, but climate change itself is not" (Amanda, Interview 2). For these reasons, I believe Amanda would describe herself as a Student Interest Engager teacher of climate change. 
Garrett and Beverley - Content First Educators. Garrett and Beverley are both high school science teachers with an extensive expertise in their content areas. Yet they both most frequently integrate climate change in courses that lie outside of those respective subjects - Garrett, a physics expert teaches an aquatic science course, and Beverley, a chemistry expert, teaches a course called Physics of Earth and Space Science. They are both primarily Content First Educators due to their emphasis on helping students to understand the science of climate change and some of the evidence related to the phenomenon.

Garrett described how he wants his students "to know that climate change is real and it's happening and to have some scientific evidence to back it up... The second thing is to understand how climate change impacts the world, their local and national community and really ultimately, how does it affect them" (Garrett, Interview 2). Though he usually just teaches climate change in the environmental science focused aquatics course, he has also taken steps to bring in climate change connections to his physics classes. "I think where I struggled when it's not in the curriculum, it's not on the final exam, but it's something I feel like that this is something that kids should know. It's a relevant topic in science. It gives some excitement and meaning to physics more than just Newton's Laws and forces, but it was a hard balance" (Garrett, Interview 2).

Beverley also described similar goals for content knowledge development due to the importance of this real-world issue: "I'd say my number one [goal] is for them to enjoy it. Number two will be for them to not only understand [science content] but be able to apply it and make connections to the real world... because without those connections, why are we here, like what are we doing?” (Beverley, Interview 1). Yet 
Beverley wants to maintain her role as an educator as compared to an advocate. She sees herself as "more as the teaching and educating part, but in the hope that it would lead to inspiring action later. I don't think I ever want to be a teacher twisting a kid's arms to make an action... I feel like that's almost asserting your religion, it's a little too pushy for me personally" (Beverley, Interview 2).

Garrett and Beverley both expressed ideas that showed how important it is to relate climate change to their respective curricula as motivation for the students to engage in this topic. These beliefs demonstrate how both Garrett and Beverley hold a predominantly Content First Educator identity.

Dual nature teachers. One third of the teachers demonstrated teacher identities that had dual pathways. These multiple identity constructions at times presented tensions, such as for Fred, within the different beliefs, motivations, and requirements, but for others the dual nature allowed the teachers to simultaneously meet multiple goals within their climate change instruction. Fred demonstrates Content First Educator and Student Interest Engager identity constructions (Figure 9, Box 3), while Barbara and Karmen showcased Civic and Epistemic Skills Promoter and Passionate Environmentalist identity constructions (Figure 9, Box 4), and Melissa and Veronica exhibited the combination of Content First Educator and Civic and Epistemic Skills Promoter (Figure 9, Box 5).

Fred - Content First Educator and Student Interest Engager. Fred has dual identity constructions, both within the professional elements of Content First Educator and Student Interest Engager. He focuses his instruction on motivating students via their interest in climate change but also feels deeply responsible for educating his students according to the curricular standards. "So, my first job is content and then the 
secondary level is I can foster activism..., but ultimately, I'm governed by a standard." (Fred, Interview 2).

As a veteran teacher, Fred has found ways to be pedagogically strategic to bring in student interest driven instruction within his restrictive curriculum and school policies by prioritizing student questions: "When they're asking, I mean I grab onto that moment and get in front of that wave and just surf it because I can tell them about [required] stuff anytime I want, but it's when they're asking that it is actually sinking in because they are interested in it" (Fred, Interview 1). Fred has partially been held back by the district mandated curriculum which has limited his instructional agency to enact these two professional oriented identities. However, Fred has support systems from prior professional developments that have instilled a confidence in him to continue to find pedagogical approaches to meet his students' needs and interest in learning climate change.

\section{Barbara and Karmen - Passionate Environmentalists and Civic and}

Epistemic Skills Promoters. Barbara and Karmen both possess Passionate Environmentalist and Civic and Epistemic Skills Promoter identity constructions and they bring a lot of their personal dedication to environmental protection into the classroom while discussing climate change. Barbara keeps this personal attribute at the forefront of her teaching: "I made sure that they understood right away that the environment and ecosystems and nature was something I was passionate about anyway" (Barbara, Interview 2).

They both also have a deep concern for the negative environmental impacts that will be felt by the next generation. Barbara talked about how "I care about what happens to the world where my grandbabies are growing up, and I care about quality 
of their life and I care about the aesthetics, the economics, the recreation, the food. I mean, all of it. All of it. It's just a part of what I am, it's what I do" (Barbara, Interview 2). Karmen also shares Barbara's concern for our future environment and the likely impacts on children. She discussed how climate change "is [important to me], because it worries me for one. And then it worries me how some people will tell me, "Oh, it doesn't matter if there's a change, it's gonna be after my lifetime." And then I say, "Yeah, but what about your children's children?" (Karmen, Interview 2). These teachers are both Passionate Environmentalists as clearly shown by Karmen in how she is "trying to teach them how they can be responsible citizens and stewards of the environment" (Karmen, Interview 2).

As Civic and Epistemic Skills Promoters, Barbara and Karmen also are trying to "build some scientific literacy in our communities so that people make better decisions about things that affect all of us" (Barbara, Interview 1). Karmen also shared that her "goals are to inform them of these changes and give them some tools that will help them approach the issues calmly and with purpose" (Karmen, Reflection 2). Even if their students are not making decisions about climate change action now, Barbara believes that "once they have the background knowledge, you start with the content and the local issues, and then you move them towards the 'so what?' and 'now what can we do about it?'. And at the very least, to lay that groundwork to make critical decisions that affect them when they're older" (Barbara, Interview 2). Overall, with this combination of Civic and Epistemic Skills Promoter and Passionate Environmentalist, Barbara and Karmen want to prepare their students to not only care about, but also act on climate change issues in the future. 


\section{Melissa and Veronica - Content First Educator and Civic and Epistemic}

Skills Promoter. Veronica and Melissa hold Civic and Epistemic Skills Promoter and Content First Educator identity constructions and like Karmen and Barbara, they want to prepare their students for future responsibilities, but these two teachers focus more on doing this through content knowledge about this critically important issue. One way that Veronica does this is by thematically connecting her lessons to climate change throughout the science curriculum all year long. Similarly, Melissa's curriculum also does not officially contain climate change, and "it really makes me mad that it's not even included" (Melissa, Interview 2), Melissa has brought the topic into her teaching and feels that her "position lies in teaching the science behind what it is and what's happening" (Melissa, Interview 2) because it is such an important topic to understand. Both strategies are strong examples of Content First Educators in action.

These two teachers also infuse their Civic and Epistemic Skills Promoter identity through their efforts to ready the students to do something with their newfound knowledge. Veronica works with her students to understand "what was the true science and what was not" and to "get them to think for themselves and not what their parents say or what I say, and that way their parents can't say that I'm forcing something on them" (Veronica, Interview 2). Yet she still brings in possible action and approaches to mitigation because "it's not just me teaching them about the science, it's also how to be a better person, and then even a better person for the environment" (Veronica, Interview 1). Melissa is also wary of imposing beliefs about activism on her students but wants to help them to understand the issue "and then it's their decision individually as a growing young adult to do something about it and how 
they're going to do stuff about it, because I know if you preach at people, especially young adolescents, a person is only going to do what they what to do. If they're informed and educated about what's going on, then they can make the decision to do it or not" (Melissa, Interview 2).

These middle school teachers work in more politically conservative districts which may be influencing the enactment of their Content First Educator and Civic and Epistemic Skills Promoter identity constructions and their overall approach of preparing their students for the reality of climate change and the need for future action through evidence backed content knowledge without pushing too hard to impose any one perspective.

Multifaceted teachers. Much like climate change is a complex issue with social, cultural, economic, political, and scientific components, nearly half of the study teachers exhibited multiple identity constructions that cut across personal, professional, and political elements. The highest proportion of teachers held the three varying identity constructions of Passionate Environmentalist, Content First Educator, and Civic and Epistemic Skills Promoter (Figure 9, Box 8) while three other teachers held different combinations of three identity constructions. Tara and Connie exhibited Passionate Environmentalist, Civic and Epistemic Skills Promoter, and Student Interest Engager identity constructions (Figure 9, Box 6) and Fiona demonstrated Passionate Environmentalist, Student Interest Engager, and Content First Educator tendencies (Figure 9, Box 7). Interestingly, no teacher was determined to hold all four identity constructions.

Tara and Connie - Passionate Environmentalist, Civic and Epistemic Skills Promoter, and Student Interest Engager. Connie and Tara are both middle school 
teachers with identity constructions of Passionate Environmentalist, Student Interest Engager, and Civic and Epistemic Skills Promoter that show how by combining their own interests in the environment with student interest in climate change, they can help prepare their students to be ready to act on this issue now and in the future.

Both Tara and Connie as Passionate Environmentalists spoke avidly about the importance of the environment in their lives. Connie shared "I think definitely [it is important to me personally], but not just climate change as an isolated topic, but the whole issue of environmental protection and making our lifestyle less damaging to the environment." (Connie, Interview 2). Tara extended this personal connection to also include her perception of a responsibility for the environment in which "regardless of the science or not, as humans and creatures of the amazing planet, we have a moral duty to protect our environment in any way we can, to advocate, and to keep ourselves open-minded and informed" (Tara, Reflection). Showing the students just how important nature is to them plays an important role in who they are as science teachers.

Student Interest Engagers, like Connie and Tara, also recognize that the interests of their students also can deeply influence motivation to learn about complex topics. By bringing in real-world topics like climate change, Connie discussed how her students "know [climate change is] something that they hear in the news, they hear adults talking about it so they know it's current and it's relevant... They're at an age at 12 years old where they don't really understand high-level concepts, but they like being able to think about them and being able to access information at a level they can understand and being able to feel like I'm starting to really understand something real and important and big" (Connie, Interview 2). Tara explains further that meaningful 
climate change instruction builds upon her students' curiosity: “I think so far, my climate change instruction has been mostly successful, simply because my students are excited and curious about the topic. We are learning together, them from me and me from them, so it has been a wonderful collaborative process. I define successful as a unit that interests and "pulls" students in, something they feel they can personally relate to and apply in their own lives" (Tara, Reflection).

Some students' interest lies in better understanding the controversy to be ready to address this in the future, and so Tara as a Civic and Epistemic Skills Promoter works to help them understand the situation by focusing on skills they can use. "I really want them to think like scientists, and to think critically and to see all the evidence and data that is out there and then draw those conclusions for themselves because that's the most authentic way for them to really understand what they are learning" (Tara, Interview 2). These types of skills are important for Tara to include because "these students are going to grow up in this world where they need to know about things and make important decisions about our environment and what we can do" (Tara, Interview 2). Connie poses a similar approach as a Civic and Epistemic Skills Promoter but also is wary of leading the students down a path of expected advocacy: "I'm a little cautious about pushing students to force a lifestyle choice on their families. But I'm certainly not adverse to planting a seed for thought and exploring ideas because one day they'll be grownups and they'll live in their own homes and then they can make their own decisions about what they do with their plastic or their energy use" (Connie, Interview 2).

By bridging teacher and student interests in the environment broadly and specific to climate change, Tara and Connie provide ample motivation and authentic 
context for their students to get ready to feel strongly about climate change as a personal issue and to be ready to act on this issue someday.

\section{Fiona - Passionate Environmentalist, Student Interest Engager, and}

Content First Educator. Fiona is her own unique blend of climate change identity constructions. She has strong personal ties and a deep value for her immediately local environment from growing up outdoors a lot and doing environmental education work with children at her local wetlands sanctuary. Through field trips and service learning opportunities, she is sharing the Passionate Environmentalist identity construction with her students.

Also, even though climate change is not currently a part of her curriculum, she still finds ways to connect it to other various curricular topics as a Content First Educator. 'I'm definitely bummed about that but I'm still planning on doing a couple of little things related to that after the final exam because I can" (Fiona, Interview 1).

This topic specifically gets her students more engaged in their learning because of their inherent curiosity and connection to the outdoors. This is especially true because Fiona enacts her Student Interest Engager identity by highlighting the numerous tie-ins between climate change and the students' interests and hobbies: "and we're big with crabs and with fishing and a lot of my students like to fish out on their boats, so just being able to tie in the local economy and impacts with climate change I think is a lot more meaningful with the kids" (Fiona, Interview 2). Using a variety of approaches - environmentally focused, content-driven, and personal connections Fiona integrates climate change accordingly with her three identity constructions working in harmony. 


\section{Krista, Emily, Mary, and Wanda - Content First Educator, Civic and}

Epistemic Skills Promoter, and Passionate Environmentalist. Krista, Emily, Mary, and Wanda all demonstrate a complex identity structure with Content First Educator, Civic and Epistemic Skills Promoter, and Passionate Environmentalist constructions. Brought on by their collective love and concern for the environment, these teachers are working to develop their students' awareness of the climate change issue to help them to see how the students could play an important role in the future as an informed citizen.

Emily's personal inspiration to teach climate change lies with her young son and a desire to help future generations "to keep an open mind and look for new ways to adapt and to mitigate" (Emily, Interview 2) to avoid climate change disasters. Wanda and Krista's motivation as Passionate Environmentalist are more personal and harken back to their deep love of nature and a desire to protect that environment which they both so greatly appreciate. Mary demonstrates her Passionate Environmentalist identity construction enthusiastically through her activism: "And they know that I go to marches ...I don't just talk about it, I live it like it matters because I believe it does. I think that probably has had the biggest impact on my students. Only just because it's so important to me" (Mary, Interview 2).

Because of their respective love for the environment, they each have deep knowledge of the topic of climate change and work to share that knowledge with their students as Content First Educators. Wanda described the enormity of this task: "I think that [climate change] is a really big issue for this generation that's influencing a lot of what's going on in their lives, that will influence the economy, that will influence the weather and all this stuff, so they need to be knowledgeable about it...so 
I think it's my obligation to have educated kids coming out of the classroom" (Wanda, Interview 1). Mary expressed a similar sentiment about the importance of the issue, albeit more colorfully: "I think it is the defining issue of their generation. I don't think anything [else] comes close. It's like the Titanic and everything else is the furniture. So, to me, they should be worried about it. Do they worry about it? Hell no! I haven't met a single student that identifies climate change as the challenge of their generation. I tell them, but not one - not yet" (Mary, Interview 2).

While Mary and Wanda exhibit their Content First Educator status due to their perspectives regarding the critical need to understand climate change, Krista and Emily demonstrate their Content First Educator identity in their approaches to infusing climate change throughout their curriculum and using it as a justification for learning other science information. Emily explained that climate change "lends itself to every discipline and science because it deals with so much, there's something for everyone when it comes to climate change. There's chemistry involved, there's physics involved, there's meteorology involved, you can really infuse it wherever you want to" (Emily, Interview 2).

Similarly, Krista mentions "though climate change is not specifically written into my curriculum, I know it is important because I'm worried about our world. I don't think I can do anything on my own, so I have to get these kids on board" (Krista, Interview 1). Krista, as a Content First Educator, also works to reach all of her students because "it is clear to me that I need to get through to these kids. I think the year before, I thought about my clientele and I was like, 'Well these kids aren't going into science careers, some of them aren't even going to college. It's okay if I don't reach them about climate change because I know there's all those high fliers in the AP 
classes that probably believe in it.' Then within a year, I was like, 'No,' kind of as a result of the election, I mean I'm not trying to get political, pretty much ever, but I realized that people need to be educated" (Krista, Interview 1).

In addition to their concern for the environment as Passionate Environmentalists and their desire to deepen their students' understanding as Content First Educators, these four teachers exhibit Civic and Epistemic Skills Promoter identity and are working to bring these two motivations together to prepare their students for a future in which they take active roles in climate change mitigation and adaptation efforts through civic action. Emily described her actions as a Civic and Epistemic Skills Promoter where "you want to give them the science that allows them to understand why they would be making changes in their lives. But then you also want to give them tools to be able to make those changes and to get excited about it" (Emily, Interview 2). Passing along this knowledge on how to act and her role in sharing that knowledge is echoed by Wanda. "As a guardian, as an elder in this society who's responsible for stewardship, it's my responsibility to make sure that I'm passing on wise ways of living to the next generation" (Wanda, Interview 2).

Mary and Krista's focus as Civic and Epistemic Skills Promoters is more civically minded. Mary sought to work with her students to break down faulty claims and to value scientific evidence: "I want them to be critical thinkers and how to question information and come to their own conclusions because it's more valid that way... It's very important to educate first because otherwise, the door closes, and you can't get anything in" (Mary, Interview 2). And Krista succinctly summed up her role as a Civic and Epistemic Skills Promoter by stating “it's really important for me to get 
through to these kids because they have a vote and they have a voice and they have a say" (Krista, Interview 2).

All four of these teachers are very knowledgeable on this topic and want to prepare their students to use that information and their own personal connections to care about this issue. They incorporate climate change into their teaching because it is important for all people, young and old, to not only understand but to also do something about it as well - now, or in the future.

This section explored the various combinations of identity constructions found within each of the 15 teachers. The multifaceted nature of each teacher's overall identity for teaching climate change, including their perceived role, motivations, values, beliefs and knowledge, demonstrate the unique variables at play when a teacher decides to incorporate climate change into their instruction.

\section{Chapter 4 Summary}

In summary, the conceptual model for teacher identity development for teaching climate change builds first from individual teachers and their narrative profiles. The conceptual model incorporates teachers' beliefs, values, motivation, and identities, and the broader patterns of climate change teaching experiences to understand how those experiences influence the development of an identity for teaching climate change. The personal, professional, and political elements of climate change teaching identity development are represented through five trends, which may be enacted differentially by teachers dependent on their unique enactment of the four different constructions of teacher identity. 


\section{Chapter 5}

\section{DISCUSSION AND IMPLICATIONS}

\section{Study Synopsis}

Climate change is a societal, environmental challenge as well as an educational one. Obstacles abound within the teaching and learning of climate change, including its complex abstract nature, the proliferation of misconceptions and misinformation, and its absence from many science curricula. Efforts have been made to study teacher content knowledge and beliefs on climate change with broad and differing results. In this study, I employed identity as a theoretical framework to examine aspects of climate change teaching experiences - both the teachers responsible for the enactment of the climate change lessons and their reflections related to the planning and implementation of these lessons. I sought to better understand these lived experiences alongside the professional and personal stories related to climate change teaching and learning.

To address my research questions, I collected data to develop insight on how science teachers negotiated various demands during the planning, enactment, and reflection on climate change related instruction. Through multiple interviews and a written reflection with 15 middle and high school teachers, I conducted a narrative inquiry to describe the development of science teacher identity for teaching climate change.

Teachers were recruited from a pool of Climate Academy participants (a climate change focused professional development) who had implemented instruction 
on climate change in their classroom. The larger pool of possible participants varied in many attributes, such as teaching experience and geographic distribution, and the 15 study teachers were recruited to similarly reflect these characteristics where possible. Each teacher was interviewed twice - the first time with a focus on the past, present, and future orientations towards science teaching and learning to explore their teacher identity narratives, and the second interview sought to understand the diversity of climate change teaching experiences, their goals for instruction, and perceptions of their own role and responsibility to teach this complex and seemingly controversial socioscientific issue. Additionally, a written reflection was employed to allow for multiple lines of evidence to support ongoing analysis and interpretations of findings.

This study utilized narrative inquiry analytic methods and the development of field text narratives, followed by vertical and horizontal analyses (similar to within and cross-case analyses). Finally, a code-weaving procedure allowed for the emergent codes to be interwoven to establish of a network of influences on science teacher identity. This was a reflexively iterative process that enabled the construction of a conceptual model for identity development as a teacher of climate change. This model demonstrates the variable and multifaceted influences on teacher identity development including personal, professional, and political elements, and the dynamism these elements exhibit over time. This conceptual model is best described via five main trends of identity development: Personal Valuation of Nature; Experiences in Science Teaching and Learning; Teacher Instructional Support and Agency; Epistemic Evidence-based Instruction; and Civic and Social Awareness via Socioscientific Literacy. The presence and strength of enactment of each of these five trends lead to the development of four possible constructions of identity as a teacher of climate 
change. These four identities are: Passionate Environmentalist, Student Interest Engager, Content First Educator, and Civic and Epistemic Skills Promoter. Most frequently teachers exhibit multifaceted combinations of these teacher identities for climate change and often created a unique amalgam of identity that incorporated multiple dimensions of the Passionate Environmentalist, Student Interest Engager, Content First Educator, and Civic and Epistemic Skills Promoter identities in action.

\section{Discussion of the Main Research Findings}

This study sought to answer the call to better understand teachers' instructional experiences and perspectives towards climate change education, especially considering the current public perception of a climate change controversy (Colston \& Ivey, 2015; Liu et al., 2015). By exploring the lived experiences of individual science teachers as they planned, enacted, and reflected on the climate change instruction, this study offers 15 narratives each with a unique perspective on how the teachers made sense of their experiences through the stories they shared (Sachs, 2001) and how those narratives relate to various themes and storylines reveal even more about the values, beliefs, attitudes, and identities held by the teachers (Drake et al., 2001). Through examination of these narratives, I uncovered and classified the more common experiences of climate change teaching and how these events influenced the development of an identity as a teacher of climate change.

Throughout this process, a framework to examine the various components was utilized that modified a previous model (Connelly \& Clandinin, 2000) to best suit the emergent needs to accurately describe teaching and learning a controversial socioscientific issue like climate change. The predominant elements of personal values and beliefs, professional learning and teaching experiences, and political context of 
student and community interactions were examined and situated temporally to explore the developmental trajectory of identity. These elements infused aspects of identity theoretical frameworks posed by prior researchers and modified the ThreeDimensional Narrative Framework as others have similarly done (e.g. Avraamidou, 2014b, 2016a; Carrier, Whitehead, Walkowiak, Luginbuhl, \& Thomson, 2017). For example, there are parallels between the identity characteristics of storied, dynamic, relational, and contextual components (Rodgers \& Scott, 2008) to my modified framework which can be seen in Table 15 below.

Table 15 Comparison of Identity Theoretical Frameworks

\begin{tabular}{|l|c|c|c|c|}
\hline \multirow{2}{*}{$\begin{array}{l}\text { Proposed Identity } \\
\text { Framework }\end{array}$} & \multicolumn{3}{|c|}{ Primary Framework Elements } \\
\hline $\begin{array}{l}\text { Current Study - } \\
\text { Drewes, 2018 }\end{array}$ & Personal & Professional & Political & Temporal \\
\hline $\begin{array}{l}\text { Connelly \& } \\
\text { Clandinin, 2000 }\end{array}$ & \multicolumn{2}{|c|}{$\begin{array}{l}\text { Interaction (both social and } \\
\text { personal aspects) }\end{array}$} & Context & Continuity \\
\hline $\begin{array}{l}\text { Avraamidou, } \\
\text { 2014a }\end{array}$ & $\begin{array}{l}\text { Personal } \\
\text { histories }\end{array}$ & $\begin{array}{c}\text { Process of teacher } \\
\text { learning and } \\
\text { development }\end{array}$ & $\begin{array}{l}\text { Role of } \\
\text { context }\end{array}$ & $\begin{array}{l}\text { Histories } \\
\text { (implicit) }\end{array}$ \\
\hline $\begin{array}{l}\text { Rodgers \& Scott, } \\
2008\end{array}$ & Storied & Contextual & Dynamic \\
\cline { 2 - 3 } & \multicolumn{2}{|c|}{ Relational } & & \\
\hline
\end{tabular}

However, the critical difference is the acknowledgment of a political contextual influence on teacher identity construction when teaching a socioscientific issue like climate change. I contend that the political landscape could influence, support, or constrain other developmental pathways for identity and should be attended to more explicitly, especially in light of the particularly contentious 
environment surrounding the social controversy of climate change and related educational efforts.

My study's findings primarily focus on the three elements of personal, professional, and political influences, but also extend our collective understanding of identity development and climate change instructional experiences in several key ways. In the following subsections, I explore each element separately and then also consider the broader contributions of this study to teacher identity educational research efforts.

\section{Modifications to an identity theoretical framework - Personal elements.}

Trend 1 of this study's findings focused on the depth of influence from values and beliefs on the perceived importance of protecting the environment. These commitments to personal environmentalism manifest in a motivation towards teaching students about the need to preserve these places for our current and future benefits. This study reiterates the strong influence of intensely held personal values and beliefs on teacher identity (Helms, 1998) and how past experiences, such as frequent outdoor play and leisure activities, can initiate shifts in those attitudes and orientations related to identity development for science teaching (Avraamidou, 2016b).

The direct influences from one's teacher identity and personal values are clear in the teachers' motivations for teaching climate change as an important environmental issue. This finding supports the work of Eick and Reed (2002) where they concluded that in pre-service teachers, there are innate predispositions in one's teacher identity that may lead teachers to enact particular pedagogical practices. Additionally, my results extend the findings of Lee and Witz (2009) which found that teachers were teaching socioscientific issues due to their personal commitments to the 
issues, but that this led to a wide variety of learning goals for their students, from cognitive development to critical thinking skills to civic and political action.

Professional elements. Professional considerations for science teaching and learning also had an impact on the identity development for teaching climate change in this study. The dialectic between prioritizing content knowledge development in students and engaging students via their individual interests shows that these goals are not mutually exclusive. Yet, this study found that teachers often hold distinct priorities for their climate change instruction which impact the development of their teacher identity(ies) for climate change (Trend 2). The focus on content knowledge supports a teacher identity as an expert in the subject area (Mitchener \& Anderson, 1989) and often the Content First Educator identity types in this study expressed a commitment to teaching their assigned curriculum while infusing connections to climate change throughout these required topics. The issue of the fit of climate change into curricular standards was salient in this study, as well as others (e.g. Hughes, 2000; Wise, 2010) but generally was not an overwhelming concern voiced by the teachers. More frequently teachers described the integration of climate change due to its broader importance as a timely issue and included climate change through novel or informal approaches (Baker \& Loxton, 2013; Colston \& Ivey, 2015).

The professional considerations in identity development also were evident in the perceptions teachers shared of what makes a "good" science teacher. Engaging student interest in climate change through explicit connections between their lives outside of school and the science content was a priority for Student Interest Engager identity teachers in this study, similar to other research findings (e.g. Barrett, 2008; Bossér et al., 2015; Mansour, 2010). Development of an identity as a teacher of 
climate change was more broadly impacted by the expected roles and visions of what it means to be an effective science teacher (Volkmann \& Anderson, 1998). Most often the teachers expressed an emphasis on getting students to meaningfully engage in the practices of science and to ask and answer questions about climate change. This participation in the Discourses (Gee, 2005) of an effective, reform-based, inquiry science teacher demonstrates their professional commitment to the expectations of how to be and act (Sachs, 2001) as a teacher of climate change.

Political elements. The most modified element of the identity theoretical framework is that of context, for which my findings support viewing more as the political landscape for the contextual elements of teaching socially and/or scientifically controversial topics like climate change. The two trends related to the political context for identity development first take into consideration how a teacher's personal and professional knowledge are enacted in context (Trend 4) and how the broader contextual elements, namely political, cultural, and moral factors, can direct the enactment of climate change instruction (Trend 5).

These results demonstrate the importance of a teacher's epistemic understandings of the nature of science, scientific research procedures, and the weight of scientific evidence (Hashweh, 1996). When teachers were able to draw upon their epistemological orientations for science, they more frequently provided instructional opportunities for students to examine climate change data patterns and to critique the omission of evidence in the claims made by climate change denialists. Through the promotion of epistemic cognition and skills development, students were encouraged to think more about "definitions of knowledge, how knowledge is constructed, and how knowledge is evaluated" (Hofner \& Pintrich, 1997, p. 88). This instructional focus 
also allowed students to delve more deeply into their social, epistemic, and conceptual understandings (Duschl, 2008; Sezen-Barrie et al., 2017) to combat misinformation and naïve ideas on climate change that exist all around them culturally.

Seeing the educative value of these lessons and understanding a teacher's expected professional role in such experiences are key points in the development of a Civic and Epistemic Skills Promoter identity for teaching climate change. In addition, the incorporation of these types of learning opportunities demonstrates the value of epistemologically driven socioscientific issues education (Bossér et al., 2015; Lee et al., 2006) and how numerous learning goals can be met through these lessons. Such learning goals include enacting science and inquiry practices, like hypothesizing and experimentation, highlight how these epistemic practices encompass the nature of science and scientific understanding and how that knowledge develops over time (Jimenez-Aleixandre \& Crujeiras, 2017; Sinatra \& Chinn, 2012). Many teachers discussed how their jobs as science educators were to help students understand science as more than just factual content knowledge to be absorbed, but also, as Osborne puts it, to "explain how we know what we know or why we believe what we do" (2014, p. 580, emphasis added).

Additionally, through careful evaluation of the claims made and the views held by others, this type of epistemically oriented climate change educational enactment helps to ready students to deal with the uncertainty of future local and global impacts and to manage disagreeing perspectives (Baker \& Loxton, 2013; Seow \& Ho, 2016) all while preparing students to be informed citizens that understand the wider relationship between themselves, the environment, and our society (Kirk et al., 2014). The prioritization of including these epistemically driven climate change lessons is an 
important component of an identity as a teacher of climate change, specifically that of the Civic and Epistemic Skills Promoter mindset.

The other contextual aspect of the Civic and Epistemic Skills Promoter identity is more overtly political in nature. This study has demonstrated the strong influence that the political landscape imposes on teachers and the development of identities as teachers of climate change. Most teachers in this study described a perceived responsibility for preparing their students to live, work, and effectively interact with the issue of climate change within a politicized future as civic minded adults. Walsh and Tsurusaki (2018) suggest that this responsibility includes practices such as promoting meaningful dialogue, critical thinking, and complex problem solving even if conflicting worldviews are present. In fact, "rather than seeing controversies as something to be feared...we should instead view this as an opportunity to foster deeper science learning and to engage students in exciting cutting-edge science" (Walsh \& Tsurusaki, 2014, p. 262). Teachers in this study often spoke of climate change as a novel occasion to enact these types of positive perspectives on socially and politically interesting scientific ideas.

The imperative need to address climate change is a key problem of our time (Feierabend et al., 2011; Liu et al., 2015) and the overall volatility of the climate change issue with the purposeful efforts of climate skeptics and deniers to misrepresent the data through anti-science campaigns (Colston \& Ivey, 2015; Lambert \& Bleicher, 2014; NCSE, 2012) has led to the development of a teacher identity that includes strong mentoring roles to model for students how to address such a politicized socioscientific issue. Many of the study teachers did seek to teach about climate change within their local political context which allowed their students to 
become aware of how "science relates to societal concerns" (Walsh \& Tsurusaki, 2014, p. 261).

Teachers also employed strategies like deliberative discussion about political worldviews, interactions with scientists and the scientific process, and the design and implementation of local community action projects - all of which are pedagogical approaches suggested by Monroe and colleagues (2017) as successful for moving students beyond the basics of the climate change phenomenon. These instructional efforts described by the teachers in this study worked to bring home the larger issue of climate change to the students' local, personal, and social environments. This is similar to Filho's suggestions for science education's contribution towards addressing climate change where teachers should "make knowledge personal by contextualizing it and actively involving the learner in finding solutions to what is a global problem, but one which also has strong regional and local impacts" (Filho, Pace, \& Manolas, 2010, p. 153). Similar to other broader socioscientific issues educational research (e.g. Gayford, 1998; Pedretti et al., 2008; Zeidler \& Keefer, 2003), the teachers in this study often described the need to entertain multiple perspectives of stakeholders through civic participatory approaches that allowed students to partake in the scientific decision-making process to come to their own conclusions about what should be done about climate change.

Personally relevant science connections (Evagorou et al., 2014; Monroe et al., 2017) allowed students to consider their own interests and moral values within the political context of climate change. This attention to one's own personal beliefs and values has been shown to be the greatest influence on adolescents' concern for climate change risks, followed closely by students' perceptions of how their friends and family 
members perceive the topic and its associated risk (Stevenson, Peterson, \& Bondell, 2016a).

However, teachers in this study often mentioned a need to avoid any possible "indoctrination" or too strong of advocacy towards their personal positions on this topic, which supports an identity as a climate change educator as compared to a climate change activist. These findings support the work of other climate change and socioscientific issues educational researchers (e.g. Barrett \& Nieswandt, 2010; Barrue \& Albe, 2013; Kilinc et al., 2015; Waldron et al., 2016) in which teachers varied on the depth of their personal advocacy missions to transfer particular mindsets through their instruction. As in those studies, the teachers here most frequently were hesitant to give even a hint of "propaganda" and purposefully worked with their students to evaluate and critique their personal and political perspectives to individually decide upon a position on the issue of climate change and the next appropriate steps to be taken.

Overall, this modified theoretical framework for identity development with the key components of personal, professional, and political elements more suitably fits the lived experiences and identity development trajectories most commonly undertaken by the teachers in this study. This framework would also contribute to other studies of teacher identity development surrounding politically charged issues beyond climate change - anything from other socioscientific issues to educational reform efforts and the integration of high stakes testing programs.

Conflicting versus cohesive constructions of identity. Another contribution to the field that this study makes is strong support for viewing teacher identity as a dynamic and multifaceted concept. Frequently teachers espoused beliefs from multiple 
constructions of identity that at times conflicted but other times were cohesive. Fred, for example, spoke at length about working to engage students via their questions and curiosity about science and climate change, which demonstrates his clear role as a Student Interest Engager teacher identity. However, he also lamented the strong negative influence of a restrictive curricular mandate that pushed him into the perspective of a Content First Educator attuned to the needs of his assigned curriculum. This situation is similar to the science teacher studied by Saka and colleagues (Saka et al., 2013) where the institutional context dramatically influenced pedagogical practice even despite the teacher's strongly held beliefs in reform-based science. Danielsson and Warwick (2014a, 2014b) also took into consideration the multiple Discourses with which beginning science teachers may engage and the competing tensions between these perspectives that pulled teachers into conflicting roles and practice - much like Fred experienced.

However, many of the teachers in this study exhibited more cohesive pairings between constructions of identity. The natural segue between a Passionate Environmentalist identity and a Civic and Epistemic Skills Promoter identity is clear in the teaching choices enacted by Barbara to share and instill a love of the local environment through a place-based focus to develop deeper understandings of how to act to protect that local environment in the future as voting citizens. In another example of a cohesive pairing, Tara demonstrates how Passionate Environmentalist and Student Interest Engager identities can be developed in tandem whereby Tara models her personal passion and drive to explore the natural world and prevent additional negative impacts from climate change. Then she encourages her students to investigate their own climate change questions about how the places and activities 
they care about will be affected by climate change. These pedagogical choices are driven by her complex, yet cohesive construction of identity for teaching climate change. These are just two examples from many of the teachers in this study whose multifaceted constructions of identity were collaborative in nature instead of in opposition.

The tensions of identity exhibited by Fred and the enmeshed identities shown in Tara and Barbara are similar to the competing perspectives and identities described by the work of Saka and Pedretti (Pedretti et al., 2008; Saka et al., 2013). Fred is able to work to resolve his conflicting identities through the support of professional development opportunities like the Climate Academy which assisted him in negotiating tensions between expertise and curriculum, similar to the teachers in a study led by Pedretti (2008) in which they examined the negotiation of opposing ideologies and identities to encourage future enactment of STSE education.

Vital nature of instructional agency. The final contribution from these research findings is a deeper understanding of how a teacher's instructional agency can mediate the performance of identity and how the support gained through teacher professional learning can invigorate this agency to more fully integrate topics like climate change into the classroom. This finding is described as Trend 3 in the professional elements of the conceptual model but truly influences the construction and enactment of any teacher identity. In this study, incorporating instructional agency explicitly into a conceptual model for identity development highlights the emerging role it can play to overcome institutional, professional, or contextual challenges by providing opportunities for teachers to build their self-efficacy and confidence to integrate climate change instruction that is effective and meaningful. 
A similar phenomenon was seen in teachers adopting nature of science focused instruction despite obstacles as a result of a deep feeling of agency to empower their choices (Akerson et al., 2014; 2016). Reis described these types of agentive teachers as ones who "assume the role of active curriculum constructors" $(2014$, p. 570) where the teachers modify learning goals and instruction to best align with their values, beliefs, and orientations - in essence, their science teacher identities.

Krista exhibits this strong instructional agency and actively infuses climate change across all of her curricular topics through novel approaches to science teaching, despite working in one of the most politically conservative areas. She is able to accomplish her climate change related instructional goals because of her own confidence, her strong personal drive, and the backing of her science supervisor.

Melissa is an example of a teacher in this study who would benefit from additional opportunities to build her instructional agency through identity resources (Hanuscin et al., 2014; Luehmann, 2007) as she describes a dedication to integrating climate change her first year after the Climate Academy when the serendipitous opportunity to teach an elective enrichment course appeared. However, she doesn't believe that she would be able to, as she described, play the rogue teacher to reconstruct her standardized curricular goals to incorporate climate change in the long term. Instead, her perception of her own low instructional agency holds her back from attempting to overcome the challenge of feeling the pressures of educational assessments and school policies of high stakes testing. This supports the conclusions drawn by Lee and colleagues (2006) where there is little institutional incentive to modify her curriculum until the district's learning goals or the structure of the required assessments change. 
Yet others like Krista and Connie have infused climate change into their teaching through small changes in curriculum throughout the year. Connie is able to accomplish her goals because of her extensive experiences in professional learning opportunities and the communities of supportive educators that often form in the aftermath of this professional learning. These activities have allowed Connie to interact with others who are also developing identities for teaching climate change and as a result, these relationships help to build her agency towards enacting this type of instruction. This finding supports the results of other researchers who have also prioritized the opportunities afforded in agency building communities for identity work (e.g. Akerson et al., 2014; Luehmann, 2007; Moore, 2008b).

This study has offered findings that explore the diverse range of roles and identities (MacLure, 1993) to better explain how teachers develop, enact, and reflect on their climate change instruction. Through the use of a narrative approach, the "area where practice and professional identity meet" (Watson, 2006) was examined to describe how identities for teaching climate change are constructed, how these identities are multifaceted in nature, at times are conflicting or cohesive, and can be described through their personal, professional, and political elements.

\section{Implications and Recommendations}

Several implications for educational practice can be developed from these findings. They include recommendations for teaching climate change, supporting climate change educators, and exploring similar avenues of research in future studies.

Climate change as SSI instructional approaches. Teachers in this study approached teaching climate change in a variety of ways, likely as a result of their diverse personal and professional experiences, political contexts, and climate change 
teaching identities. A number of these pedagogical strategies incorporated aspects of socioscientific issues education, but these connections were not particularly purposeful nor comprehensive in style. This is likely due to the teachers' inexperience with dealing with controversial topics, which is similar to the findings of studies led by Ekborg and Sullivan (Ekborg et al., 2013; Sullivan et al., 2014). These findings of limited well-rounded socioscientific issues based approaches support those of Monroe and her colleagues' recent review of literature on climate change educational interventions. They found that only a handful of empirical studies have approached teaching climate change with both social and science oriented framings (Monroe et al., 2017).

Future efforts in climate change education need to continue to strive towards including more comprehensive socioscientific issues oriented pedagogy to achieve learning goals across the "three-part harmony" of integrated domains for conceptual, epistemic, and social frameworks (Duschl, 2008). A thoroughly enmeshed socioscientific issues approach where learners develop conceptual and epistemic understandings (the scientific of socio-scientific) and consider social contexts and personal ethics (the socio of socio-scientific) is the ultimate goal for climate change education.

Socioscientific issues approaches allow learners to build epistemic knowledge through scientific investigations, then to apply that skeptical science mindset (Lambert \& Bleicher, 2014), to respectfully critique claims of others, and to understand why ideological biases and motivated reasoning may influence those perspectives (NCSE, 2012; Sinatra, Kienhues, \& Hofer, 2014). Elements of this epistemically oriented instruction were found in the motivations of many Civic and Epistemic Skills 
Promoter teachers, as well as Content First Educators when instruction was driven by the skills and practices of science that enable learners to come to truly know something in science.

A focus on deeper content learning is also a component of socioscientific issues instruction (Barrett, 2008; Bossér et al., 2015). This was also observed in a number of teachers in this study, foremost the Content First Educators, who sought to incorporate aspects of the climate change phenomenon across a number of curricular connections. By often focusing on not only the atmospheric mechanics of climate change, but also on the impacts of climate change across every planetary sphere and the role of humans within both the causes and hopeful solutions, teachers in this study displayed the vastness of this issue.

The other aspect of socioscientific issues education is the social context which is especially poignant for climate change with its broad social, cultural, and political implications. A socioscientific issues approach to climate change allows educators and learners to incorporate evaluations of personal values and ethical guideposts when considering the importance of the issue at hand (Sadler et al., 2006; Zeidler et al., 2005). This motivation was found in the Passionate Environmentalist and Student Interest Engager identity teachers in this study, but again deeper integration is desired for broader acceptance and support for the imperative nature of climate change action.

Deciding the appropriate level of action and then exploring their civic responsibilities are the final components of a socioscientific issues approach to climate change education. This pedagogical style to teaching climate change is also valuable to explore the various direct and indirect influences on climate change content knowledge and beliefs across diverse contexts in this "global climate change era" 
(Sharma, 2012) and to examine these topics in the midst of the perceived controversy (Colston \& Ivey, 2015). This approach also prepares learners to deal with the global and local aspects of climate change that will impact them and others in the future (Seow \& Ho, 2016) and it educates students on how to engage with uncertainty and manage conflicts in situations inside and outside of the classroom (Baker \& Loxton, 2013). Once again, elements of these instructional efforts and learning goals were found in Civic and Epistemic Skills Promoter teaching identities within this study, but more integration of these efforts is desired.

Taking a socioscientific issues approach to climate change affords learners opportunities to think about climate change as a socioscientific issue, and not just as scientific phenomenon. The implications from this study align with Stapleton's directive that "studying the science should not be the only way we teach about climate change" (2018, p. 16, emphasis in original). As described above, teachers in this study did encompass a number of aspects of socioscientific issues education, but collectively science teachers should continue to examine their current practice and also work to expand the diversity of how they frame this topic. Numerous studies (e.g. Busch, 2016; Manzo, 2010) have explored nature-centric foci to climate change education and more recently a social justice orientation has been investigated (e.g. Howell \& Allen, 2016; Stapleton, 2018). Both contexts have been found to be motivating for some learners, but as this issue continues to be intensely debated along a partisan divide, educators should be wary of utilizing only one approach to discussing climate change. Careful consideration of how science educators can vary and diversify their instructional framings and approaches is critical for the broader success of climate change educational efforts across different worldviews in learners (Bentley et al., 
2016; Kahan et al., 2012; Stevenson et al., 2014; Walsh \& Tsurusaki, 2018; Wibeck, 2014). By building stronger links between their current teaching identity and socioscientific issues pedagogical approaches, science education can achieve this style of diversified messaging and improved outcomes in climate change educational efforts.

Supporting CC as SSI instruction. Approaching climate change in this manner will require resources to support the instruction to achieve such learning outcomes described above. Educators need materials such as climate change specific lessons to infuse into curricula across many science disciplines and resources that integrate not only the 'what' of climate science, but also the 'what next' for climate change (Drewes et al., 2018). These types of resources would allow for teachers and students to engage directly with the moral and controversial aspects of climate change that have often been omitted by teachers in other studies (e.g. Barrett, 2008; Van Rooy, 1999). Other educational support materials like a learning progression for climate change and associated formative and summative assessments have been developed (e.g. Breslyn, Drewes, McGinnis, Hestness, \& Mouza, 2017; Drewes et al., 2017) to help guide conceptual understanding and development. This work has begun in MADE CLEAR research team's efforts but much more needs to be done to expand other educative resources and curriculum offerings for teaching climate change via socioscientific issues and to effectively share these resources with a broader audience of classroom teachers.

In order to assist teachers to be prepared with their own content knowledge and pedagogical skills to teach climate change as a socioscientific issue, teacher educators need to reconsider how to prepare pre-service science teachers and how to offer 
continuing education for in-service science teachers related to climate change.

Teachers in this study attributed much of their readiness to teach climate change to their participation in the Climate Academy and/or similarly focused professional learning opportunities (e.g. Levinson, 2006; Mitchener \& Anderson, 1989; Sadler et al., 2006; Shea, Mouza, \& Drewes, 2016). Therefore, we must continue to expand the availability of these types of support to allow educators to engage with and explore climate change oriented pedagogy and resources.

Teacher educators also should explore the creation of professional communities comprised of science educators in various stages of identity construction as a teacher of climate change (Luehmann, 2007) which would allow interaction between novice and veteran teachers to strategize enactment of climate change lessons, to discuss efforts to overcome obstacles, and to provide safe places for teachers to "try on and develop new identities" (Luehmann, 2007, p. 822). Evidence from this study provides support that professional development assists teachers to build confidence in their climate change teaching and to develop agency to find innovative ways of incorporating climate change across their curriculum in diverse ways. These communities of like-minded educators also offer opportunities for teachers to address emotions like frustration and hopelessness that can interfere with their ability to provide meaningful instruction in their students (Hufnagel, 2015; Lombardi \& Sinatra, 2013).

Prioritization of climate change by educational policy. Collectively we need to evaluate the priorities for science educational efforts (described above) of science teachers and teacher educators as well as those of administrators and policy makers. If climate literacy is truly a goal of these efforts, then the need to support continued work 
to include instruction about responsible decisions about action (USGCRP, 2009) is paramount in future revisions of educational policy mandates. The adoption of NGSS, including its climate change related standards, is an important first step for many states and school districts. But as seen both in this study and in other states (Colston \& Ivey, 2015), the mere adoption of standards without the support of professional development and curricular resources and lacking any modification of science assessments is not enough for effective climate change education.

Teachers in this study often seemed to be pacing their own paths for the inclusion of climate change in their curriculum even though it is often found in their curricular standards. Instead, we need to extend these infusion efforts into schools both more deeply and more broadly. With new institutional incentives (Lee et al., 2006) such as revised assessment priorities, climate change can take a prioritized place in the structure of K-12 education and beyond to support accurate understandings of climate change content knowledge and the collective positioning of teachers and learners as scientifically and climate literate citizens.

Educational research. The implications for educational research include several possible avenues for future study. Additional research is needed to explore the lived experiences of a more diverse collection of science teachers, with special attention paid to gathering more representative distributions of gender, broader geographic distributions, and incorporating teachers who did not self-select into participation in climate change professional developments. This study also had a number of teachers who were certified to teach through alternative route options, yet not enough to make conclusions about the impacts from this preparation model compared to traditional undergraduate models. Another possible future study could be 
envisioned to explore the influences from certification pathways on the development of identity and agency to teach climate change.

Further investigation is also warranted to explore how teacher preparation programs and professional development can direct support educators through learning opportunities to encourage agentive identities for teaching climate change. This direct support could be documented through classroom observations and student learning outcomes. The data sources utilized in this study were collected through interviews or written reflections by the participants, therefore another possible pathway for additional study would be to gather sources of data that are not self-reported to further explore the influence of identities for teaching climate change on actual pedagogical practice and its associated outcomes.

Lastly, future research efforts should also consider other socioscientific issues aside from climate change. Work is needed in related instructional contexts to gather more detailed understandings of the impact of professional learning and teaching experiences as teachers incorporate socioscientific issues more broadly and how identity developmental trajectories differ for other socioscientific issues beyond climate change.

\section{Conclusion}

An identity theoretical framework exposed the multitude of past, present, and future influences on teachers' constructions of identities including their values, beliefs, understandings, commitments, and actions related to climate change education. Broadly these influences on identity were categorized as personal, professional, and political to reflect the nature of these different factors in identity development. The findings suggest that frequently teacher identities for climate change are multifaceted 
in nature and these various identities are usually cohesive within an individual, but at times, they may present competing tensions for enactment. Additionally, this study demonstrates the critical need to support climate change educators to strengthen their perceptions of instructional agency to effectively overcome challenges to the enactment of climate change lessons. If a climate literate population that is ready to civically and democratically engage with climate change, then need to lift up the voices of climate change educators and empower them in their efforts for the teaching and learning of climate change in and outside of the K-12 classroom and beyond.

Author's note: This material is based on work supported by the National Science Foundation under Grant No. 1239758. Any opinions, findings, conclusions, or recommendations expressed are those of the author and do not necessarily reflect the views of the National Science Foundation. 


\section{REFERENCES}

Akerson, V. L., Carter, I. S., \& Elcan, N. (2016). On the nature of professional identity for nature of science: Characteristics of teachers who view themselves as teachers of nature of science, and their classroom practice. In L. Avraamidou (Ed.), Studying science teacher identity: Theoretical, methodological and empirical explorations (pp. 89-110). Rotterdam, Netherlands: Sense Publishers. doi:10.1007/978-946300-528-9

Akerson, V. L., Pongsanon, K., Weiland, I. S., \& Nargund-Joshi, V. (2014). Developing a professional identity as an elementary teacher of nature of science: A self-study of becoming an elementary teacher. International Journal of Science Education, 36(12), 2055-2082. doi:10.1080/09500693.2014.890763

Andersson, B., \& Wallin, A. (2000). Students' understanding of the greenhouse effect, the societal consequences of reducing $\mathrm{CO}_{2}$ emissions and the problem of ozone layer depletion. Journal of Research in Science Teaching, 37(10), 1096-1111. doi:10.1002/1098-2736(200012)37:10<1096::AID-TEA4>3.0.CO:2-8

Avraamidou, L. (2014a). Studying science teacher identity: Current insights and future research directions. Studies in Science Education, 50(2), 145-179. doi:10.1080/03057267.2014.937171

Avraamidou, L. (2014b). Tracing a beginning elementary teacher's development of identity for science teaching. Journal of Teacher Education, 65(3), 223-240. doi: $10.1177 / 0022487113519476$

Avraamidou, L. (2016a). Intersections of life histories and science identities: The stories of three preservice elementary teachers. International Journal of Science Education, 38(5), 861-884. doi:10.1080/09500693.2016.1169564

Avraamidou, L. (2016b). Telling stories: Intersections of life histories and science teaching identities. In L. Avraamidou (Ed.), Studying science teacher identity: Theoretical, methodological and empirical explorations (pp. 153-175). Rotterdam, Netherlands: Sense Publishers. doi:10.1007/978-946300-528-9 
Baker, J., \& Loxton, J. (2013). Climate change knowledge and attitudes of pre-and in- service Nova Scotia teachers. Retrieved from https://climatechange.novascotia.ca/sites/default/files/uploads/20122013_Dal_1.pdf

Barrett, S. E. (2008). Mutual misunderstanding: Preservice science teachers' and instructors' mismatching(?) priorities. Canadian Journal of Science, Mathematics and Technology Education, 8(4), 313-330. doi:10.1080/14926150802506282

Barrett, S. E., \& Nieswandt, M. (2010). Teaching about ethics through socioscientific issues in physics and chemistry: Teacher candidates' beliefs. Journal of Research in Science Teaching, 47(4), 380-401. doi:10.1002/tea.23343

Barrue, C., \& Albe, V. (2013). Citizenship education and socioscientific issues: Implicit concept of citizenship in the curriculum, views of French middle school teachers. Science and Education, 22(5), 1089-1114. doi:10.1007/s11191-012-9571-4

Battey, D., \& Franke, M. L. (2008). Transforming identities: Understanding teachers across professional development and classroom practice. Teacher Education Quarterly, 35(3), 127-149.

Bazeley, P. (2007). Qualitative data analysis with NVivo. London, England: Sage.

Bedford, D. (2010). Agnotology as a teaching tool: Learning climate science by studying misinformation. Journal of Geography, 109(4), 159-165. doi:10.1080/00221341.2010.498121

Beijaard, D., Meijer, P. C., \& Verloop, N. (2004). Reconsidering research on teachers' professional identity. Teaching and Teacher Education, 20(2), 107-128. doi:10.1016j.tate.2003.07.001

Bentley, A. P. K., Petcovic, H. L., \& Cassidy, D. P. (2016). Development and validation of the anthropogenic climate change dissenter inventory. Environmental Education Research, 1-16. doi:10.1080/13504622.2016.1250150

Boon, H. J. (2010). Climate change? Who knows? A comparison of secondary students and pre-service teachers. Australian Journal of Teacher Education, 35(1), 104-120. doi:10.14221/ajte.2010v35n1.9 
Bossér, U., Lundin, M., Lindahl, M., \& Linder, C. (2015). Challenges faced by teachers implementing socio-scientific issues as core elements in their classroom practices. European Journal of Science and Mathematics Education, $3(2), 159-176$.

Boyatzis, R. E. (1998). Transforming qualitative information: Thematic analysis and code development. Thousand Oaks, CA: Sage.

Boyes, E., \& Stanisstreet, M. (1993). The greenhouse effect: Children's perception of causes, consequences and cures. International Journal of Science Education, 15(5), 531-552. doi:10.1080/0950069930150507

Boyes, E., \& Stanisstreet, M. (1997). Children's models of understanding of two major global environmental issues: Ozone layer and greenhouse effect. Research in Science \& Technological Education, 15(1), 19-28. doi:10.1080/0263514970150102

Boykoff, M. T., \& Boykoff, J. M. (2004). Bias as balance: Global warming and the U.S. prestige press. Global Environmental Change, 14(2), 125-136. doi:j.gloenvcha.2003.10.001

Breslyn, W., Drewes, A., McGinnis, J. R., Hestness, E., \& Mouza, C. (2017). Development of an empirically-based conditional learning progression for climate change. Science Education International, 28(3), 214-223.

Brickhouse, N. W. (1990). Teachers' beliefs about nature of science and their relationship to classroom practice. Journal of Teacher Education, 41(3), 53-62. doi:10.1177/002248719004100307

Britzman, D. (1986). Cultural myths in the making of a teacher: Biography and social structure in teacher education. Harvard Educational Review, 56(4), 442-457. doi:10.17763/haer.56.4.mv28227614144u66

Brown, M., \& Edelson, D. (2003). Teaching as design. Evanston, IL. Retrieved from http://www.inquirium.net/people/matt/teaching_as_design-Final.pdf

Bruner, J. (2004). A short history of psychological theories of learning. Daedalus, 133(1), 13-20. doi:jstor.20027892

Bryce, T., \& Gray, D. (2004). Tough acts to follow: The challenges to science teachers presented by biotechnological progress. International Journal of Science Education, 26(6), 717-733. doi:10.1080/0950069032000138833 
Bukor, E. (2011). Exploring teacher identity: Teachers' transformative experiences of re-constructing and re-connecting personal and professional selves (Unpublished doctoral dissertation). University of Toronto, Ontario, Canada.

Busch, K. C. (2016). Polar bears or people? Exploring ways in which teacers frame climate change in the classroom. International Journal of Science Education, Part B, 6(2), 137-165. doi:10.1080/21548455.2015.1027320

Carlone, H. B., \& Johnson, A. (2007). Understanding the science experiences of successful women of color: Science identity as an analytic lens. Journal of Research in Science Teaching, 44(8), 1187-1218. doi:10.1002/tea.20237

Carrier, S. J., Whitehead, A. N., Walkowiak, T. A., Luginbuhl, S. C., \& Thomson, M. M. (2017). The development of elementary teacher identities as teachers of science. International Journal of Science Education, 39(13), 1733-1754. doi:10.1080/09500693.2017.1351648

Carter, K., \& Doyle, W. (1996). Personal narrative and life history in learning to teacher. In J. Sikula, T. J. Buttery, \& E. Guyton (Eds.), Handbook of research on teacher education (2nd ed., pp. 120-142). New York, NY: Macmillan.

Choi, S., Niyogi, D., Shepardson, D. P., \& Charusombat, U. (2010). Do earth and environmental science textbooks promote middle and high school students' conceptual development about climate change? Textbooks' consideration of students' misconceptions. Bulletin of the American Meteorological Society, 91(7), 889-898. doi:10.1175/2009BAMS2625.1

Clandinin, D. J., \& Connelly, F. M. (1994). Personal experience methods. In N. K. Denzin \& Y. S. Lincoln (Eds). Handbook of qualitative research (pp. 413427). Thousand Oaks, CA: Sage.

Clandinin, D. J., \& Connelly, F. M. (2000). Narrative inquiry: Experience and story in qualitative research. San Francisco, CA: Jossey Bass Publishers.

Clandinin, D. J., \& Huber, M. (2005). Shifting stories to live by. In D. Beijaard, P. C. Meijer, G. Morine-Dershimer, \& T. Harm (Eds.), Teacher professional development in changing conditions (pp. 43-59). Netherlands: Springer. doi:10.1007/1-4020-3700-9

Cochran-Smith, M., \& Lytle, S. L. (1999). Relationships of knowledge and practice: Teacher learning in communities. Review of Research in Education, 24, 249305. doi:10.2307/1167272 
Colston, N. M., \& Ivey, T. A. (2015). (un)Doing the Next Generation Science Standards: Climate change education actor-networks in Oklahoma. Journal of Education Policy, 30(6), 773-795. doi:10.1080/02680939.2015.1011711

Connelly, F. M., \& Clandinin, D. J. (1999). Shaping a professional identity: Stories of educational practice. New York, NY: Teachers College Press.

Cook, J., Oreskes, N., Doran, P. T., Anderegg, W. R. L., Verheggen, B., Maibach, E. W., \& Sarah, A. (2016). Consensus on consensus: A synthesis of consensus estimates on human-caused global warming. Environmental Research Letters, 11(4), 1-7. doi:10.1088/1748-9326/11/4/048002/pdf

Cooper, K., \& Olson, M. R. (1996). The multiple "I's" of teacher identity. In M. Kompf, W. R. Bond, D. Dworet, \& R. T. Boak (Eds.), Changing research and practice: Teachers' professionalism, identities, and knowledge (pp. 78-89). London, England: Routledge.

Corbin, J., \& Strauss, A. (2008). Basics of qualitative research: Techniques and procedures for developing grounded theory. Thousand Oaks, CA: Sage.

Cotton, D. R. E. (2006). Teaching controversial environmental issues: Neutrality and balance in the reality of the classroom. Educational Researcher, 48(2), 223241. doi:10.108d0/00131880600732306

Creswell, J. W. (2007). Qualitative inquiry and research design: Choosing among five approaches (2nd ed.). Thousand Oaks, CA: Sage.

Creswell, J. W. (2009). Research design: Qualitative, quantitative, and mixed methods approaches (3rd ed.). Thousand Oaks, CA: Sage.

Cronin-Jones, L. L. (1991). Science teacher beliefs and their influence on curriculum implementation: Two case studies. Journal of Research in Science Teaching, 28(3), 235-250. doi:10.1002/tea.3660280305

Cross, R. T., \& Price, R. F. (1996). Science teachers' social conscience and the role of controversial issues in the teaching of science. Journal of Research in Science Teaching, 33(3), 319-333. doi:10.1002/(SICI)10982736(199603)33:3<319::AID-TEA5>3.0.CO;2-W

Crotty, M. (1998). The foundations of social research: Meaning and perspective in the research process. Thousand Oaks, CA: Sage. 
Danielsson, A. T., \& Warwick, P. (2014a). 'All we did was things like forces and motion...": Multiple discourses in the development of primary science teachers. International Journal of Science Education, 36(1), 103-128. doi:10.1080/09500693.2012.734639

Danielsson, A. T., \& Warwick, P. (2014b). "You have to give them some science facts": Primary student teachers' early negotiations of teacher identities in the intersections of discourses about science teaching and about primary teaching. Research in Science Education, 44, 289-305. doi:10.1007/s11165-013-9383-9

Denzin, N. K., \& Lincoln, Y. S. (1994). Handbook of qualitative research. Thousand Oaks, CA: Sage.

Dey, I. (1993). Qualitative data analysis: A user-friendly guide for social scientists. London, England: Routledge.

Dickinson, S. J. (2012). A narrative inquiry about teacher identity construction: Preservice teachers share their stories (Unpublished doctoral dissertation). University of Missouri, Columbia, MO.

Ding, D., Maibach, E. W., Zhao, X., Roser-Renouf, C., \& Leiserowitz, A. (2011). Support for climate policy and societal action are linked to perceptions about scientific agreement. Nature Climate Change, 1(9), 462-466. doi:10.1038/nclimate1295

Drake, C. (2006). Turning points: Using teachers' mathematics life stories to understand the implementation of mathematics education reform. Journal of Mathematics Teacher Education, 9, 579-608. doi:10.1007/s10857-006-9021-9

Drake, C., Spillane, J. P., \& Hufferd-Ackles, K. (2001). Storied identities: Teacher learning and subject-matter context context. Journal of Curriculum Studies, 33(1), 1-23. doi:10.1080/00220270119765

Drewes, A., Breslyn, W., McGinnis, J. R., Mouza, C., Hestness, E., \& Henderson, J. (2017). Designing and validating a climate change knowledge instrument. Paper presnted at American Educational Research Association Annual Meeting, San Antonio, TX.

Drewes, A., Henderson, J., \& Mouza, C. (2018). Professional development design considerations in climate change education: Teacher enactment and student learning. International Journal of Science Education, 40(1), 67-89. doi:10.1080/09500693.2017.1397798 
Dunlap, R. E., \& McCright, A. M. (2011). Organized climate denial. In J. S. Dryzek, R. B. Norgaard, \& D. Schlosberg (Eds.), The Oxford handbook of climate change and society (pp. 1-21). Oxford, England: Oxford University Press.

Duschl, R. (2008). Science education in three-part harmony: Balancing conceptual, epistemic, and social learning goals. Review of Research in Education, 32(1), 268-291. doi:10.3102/0091732X07309371

Eick, C. J., \& Reed, C. J. (2002). What makes an inquiry-oriented science teacher? The influence of learning histories on student teacher role identity and practice. Science Education, 86, 401-416. doi:10.1002/sce.10020

Ekborg, M., Ottander, C., Silfver, E., \& Simon, S. (2013). Teachers' experience of working with socio-scientific issues: A large scale and in depth study. Research in Science Education, 43(2), 599-617. doi:10.1007/s11165-0119279-5

Enyedy, N., Goldberg, J., \& Welsh, K. M. (2006). Complex dilemmas of identity and practice. Science Education, 90(1), 68-93. doi:10.1002/sce.20096

Evagorou, M., Guven, D., \& Mugaloglu, E. (2014). Preparing elementary and secondary pre-service teachers for everyday science. Science Education International, 25(1), 68-78.

Exton, V. N. (2008). A qualitative case study of developing teacher identity among American Indian secondary teachers from the UTE teacher training program (Unpublished doctoral dissertation). Utah State University, Logan, UT.

Feierabend, T., Jokmin, S., \& Eilks, I. (2011). Chemistry teachers' views on teaching "climate change": An interview case study from research-oriented learning in teacher education. Chemistry Education Research and Practice, 12(1), 85-91. doi:10.1039/C1RP90011K

Filho, W. L., Pace, P., \& Manolas, E. (2010). The contribution of education towards meeting the challenges of climate change. Journal of Baltic Science Education, 9(2), 142-155.

Flores, M. A., \& Day, C. (2006). Contexts which shape and reshape new teachers' identities: A multi-perspective study. Teaching and Teacher Education, 22, 219-232. doi:10.1016/j.tate.2005.09.002

Forbes, C. T., \& Davis, E. A. (2008). The development of preservice elementary teachers' curricular role identity for science teaching. Science Education, 92(5), 909-940. doi:10.1002/sce.20265 
Fortner, R. W. (2001). Climate change in school: Where does it fit, and how ready are we? Canadian Journal of Environmental Education, 6, 18-31.

Friedrichsen, P. J., Van Driel, J. H., \& Abell, S. K. (2011). Taking a closer look at science teaching orientations. Science Education, 95(2), 358-376. doi:10.1002/sce.20428

Gardner, G., \& Jones, G. (2011). Perceptions and practices: Biology graduate teaching assistants' framing of a controversial socioscientific issue. International Journal of Science Education, 33(8), 1031-1054. doi:10.1080/09500691003743244

Gayford, C. (1998). The perspectives of science teachers in relation to current thinking about environmental education. Research in Science \& Technological Education, 16(2), 101-113. doi:10.1080/0263514980160201

Gayford, C. (2002). Controversial environmental issues: A case study for the professional development of science teachers. International Journal of Science Education, 24(11), 1191-1200. doi:10.1080/09500690210134866

Gee, J. P. (2000-2001). Identity as an analytic lens for research in education. Review of Research in Education, 25, 99-125. doi:10.2307/1167322

Gee, J. P. (2005). An introduction to discourse analysis: Theory and method (2nd ed.). New York, NY: Routledge. doi:10.1016/0346-251X(88)90022-X

Gess-Newsome, J., \& Lederman, N. G. (Eds.). (1999). Examining pedagogical content knowledge: The construct and its implications for science education. Dordrecht, Netherlands: Kluwer Academic Publishers. doi:10.1007/0-30647217-1

Gibbs, G. R. (2007). Analyzing qualitative data. London, England: SAGE Publications.

Glaser, B. G. (1978). Theoretical sensitivity: Advances in the methodology of grounded theory. Mill Valley, CA: Sociology Press.

Goldston, M. J., \& Kyzer, P. (2009). Teaching evolution: Narratives with a view from three southern biology teachers in the USA. Journal of Research in Science Teaching, 46(7), 762-790. doi:10.1002/tea.20289

Goodson, I. F. (Ed.). (1992). Studying teachers' lives. New York, NY: Teachers College Press. 
Griffith, J. A., \& Brem, S. K. (2004). Teaching evolutionary biology: Pressures, stress, and coping. Journal of Research in Science Teaching, 41(8), 791-809. doi:10.1002/tea.20027

Hanuscin, D. L., Cheng, Y., Rebello, C., Sinha, S., \& Muslu, N. (2014). The affordances of blogging as a practie to support ninth-grade science teachers' identity development as leaders. Journal of Teacher Education, 65(3), 207222. doi: $10.1177 / 0022487113519475$

Harrison, M. C. (2014). A narrative inquiry of successful black male college students (Unpublished doctoral dissertation). Walden University, Minneapolis, MN.

Hashweh, M. Z. (1996). Effects of science teachers' epistemological beliefs in teaching. Journal of Research in Science Teaching, 33(1), 47-63. doi:10.1002/(SICI)1098-2736(199601)33:1<47::AID-TEA>3.0.CO;2-P

Helms, J. V. (1998). Science and me: Subject matter and identity in secondary school science teachers. Journal of Research in Science Teaching, 35(7), 811-834. doi:10.1002/(SICI)1098-2736(199809)35:7<811::AID-TEA9>3.0.CO;2-O

Herman, B. C., Feldman, A., \& Vernaza-Hernandez, V. (2017). Florida and Puerto Rico secondary science teachers' knowledge and teaching of climate change science. International Journal of Science and Mathematics Education, 15(3), 451-471. doi:10.1007/s10763-015-9706-6

Hestness, E., McGinnis, J. R., Riedinger, K., \& Marbach-Ad, G. (2011). A study of teacher candidates' experiences investigating global climate change within an elementary science methods course. Journal of Science Teacher Education, 22(4), 351-369. doi:10.1007/s10972-011-9234-3

Hofer, B. K., \& Pintrich, P. R. (1997). The development of epistemological theories: Beliefs about knowledge and knowing and their relation to learning. Review of Educational Research, 67(1), 88-140. doi:10.3102/00346543067001088

Howell, R. A., \& Allen, S. (2016). Significant life experiences, motivations and values of climate change educators. Environmental Education Research, 1-19. doi:10.1080/13504622.2016.1158242

Hufnagel, E. (2015). Preservice elementary teachers' emotional connections and disconnections to climate change in a science course. Journal of Research in Science Teaching, 52(9), 1296-1324. doi:10.1002/tea.21245 
Hughes, G. (2000). Marginalization of socioscientific material in ScienceTechnology-Society science curricula: Some implications for gender inclusivity and curriculum reform. Journal of Research in Science Teaching, 37(5), 426-440. doi:10.1002/(SICI)1098-2736(200005)37:5<426::AIDTEA3>3.0.CO;2-U

Hunter, S. V. (2010). Analysing and representing narrative data: The long and winding road. Current Narratives, 2, 44-54.

Inman, M. (2012). Schools of thought. Nature Climate Change, 2, 303-305. doi:10.1038/nclimate1494

Intergovernmental Panel on Climate Change (IPCC). (2007). Climate change 2007: Synthesis report. Contribution of working groups to the fourth assessment report of the Intergovernmental Panel on Climate Change. Geneva, Switzerland.

Intergovernmental Panel on Climate Change (IPCC). (2014). Climate change 2014: Synthesis report. Contribution of working groups to the fifth assessment report of the Intergovernmental Panel on Climate Change. Geneva, Switzerland.

Jimenez-Aleixandre, M. P., \& Crujeiras, B. (2017). Epistemic practices and scientific practices in science education. In K. S. Taber \& B. Akpan (Eds.) Science Education: An International Course Companion (pp. 69-80). Rotterdam, Netherlands: Sense.

Josselson, R. (2011). Narrative research: Constructing, deconstructing, and reconstructing story. In F. J. Wertz, K. Charmaz, L. M. McMullen, R. Josselson, R. Anderson, \& E. McSpadden (Eds.), Five ways of doing qualitative analysis: Phenomenological psychology, grounded theory, discourse analysis, narrative research, and intuitive inquiry (pp. 224-242). New York, NY: Guilford Press.

Kagan, D. M. (1992). Implications of research on teacher belief. Educational Psychologist, 27(1), 65-90. doi:10.1207/s15326985ep2701_6

Kahan, D. M., Peters, E., Wittlin, M., Slovic, P., Ouellette, L. L., Braman, D., \& Mandel, G. (2012). The polarizing impact of science literacy and numeracy on perceived climate change risks. Nature Climate Change, 2, 732-735. doi:10.1038/nclimate1547

Keefer, N. E. (2012). Teachers' narratives of experience with social class (Unpublished doctoral dissertation). University of South Florida, Tampa, FL. 
Kelchtermans, G. (1993). Getting the story, understanding the lives: From career stories to teachers' professional development. Teaching and Teacher Education, 9(5-6), 443-456. doi:10.1016/0742-051X(93)90029-G

Kelchtermans, G. (1994). Biographical methods in the study of teachers' professonal development. In I. Calgren, G. Handal, \& S. Vaage (Eds.), Teachers' minds and actions: Research on teachers' thinking and practice (pp. 93-108). London: Falmer.

Kempton, W. (1991). Public understanding of global warming. Society \& Natural Resources, 4(4), 331-345. doi:10.1080/08941929109380765

Kilinc, A., Kelly, T., Eroglu, B., Demiral, U., Kartal, T., Sonmez, A., \& Demirbag, M. (2017). Stickers to facts, imposers, democracy advocators, and committed impartialists: Preservice science teachers' beliefs about teacher's roles in socioscientific discourses. International Journal of Science and Mathematics Education, 15(2), 195-213. doi:10.1007/s10763-015-9682-х

Kirk, K. B., Gold, A. U., Ledley, T. S., Sullivan, S. B., Manduca, C. A., Mogk, D. W., \& Wiese, K. (2014). Undergraduate climate education: Motivations, strategies, successes, and support. Journal of Geoscience Education, 62, 538-549. doi: $10.5408 / 13-054$

Kolstø, S. D. (2001). Scientific literacy for citizenship: Tools for dealing with the science dimension of controversial socioscientific issues. Science Education, 85(3), 291-310. doi:10.1002/sce.1011

Koulaidis, V., \& Christidou, V. (1999). Models of students' thinking concerning the greenhouse effect and teaching implications. Science Education, 83(5), 559576. doi:10.1002/(SICI)1098-237X(199909)83:5<559::AID-SCE4>3.0.CO;2$\mathrm{E}$

Kunkle, K. A., \& Monroe, M. C. (2018). Cultural cognition and climate change education in the U.S.: Why consensus is not enough. Environmental Education Research, 1-21. doi:10.1080/13504622.2018.1465893

Kvale, S. (1996). InterViews: An introduction to qualitative research interviewing. Thousand Oaks, CA: SAGE Publications.

Lambert, J. L., \& Bleicher, R. E. (2014). Improving climate change communication starting with environmental educators. Journal of Geoscience Education, 62(3), 388-401. doi:10.5408/13-062.1 
Layder, D. (1998). Sociological practice: Linking theory and research. London, England: Sage.

Lee, H., Abd-El-Khalick, F., \& Choi, K. (2006). Korean science teachers' perceptions of the introduction of socio-scientific issues into the science curriculum. Canadian Journal of Science, Mathematics and Technology Education, 6(2), 97-117. doi:10.1080/14926150609556691

Lee, H., \& Witz, K. G. (2009). Science teachers' inspiration for teaching socioscientific issues: Disconnection with reform efforts. International Journal of Science Education, 31(7), 931-960. doi:10.1080/09500690801898903

Leiserowitz, A., Maibach, E. W., Roser-Renouf, C., Rosenthal, S., \& Cutler, M. (2017). Climate change in the American mind: November 2016. New Haven, CT. Retrieved from: climateconnection.yale.edu/publications/climate-changein-the-american-mind-november-2016

Leiserowitz, A., \& Smith, N. (2010). Knowledge of climate change across global warming's six Americas. Yale project on climate change. New Haven, CT. Retrieved from: climateconnection.yale.edu/publications/knowledge-ofclimate-change-across-global-warmings-six-americas

Lerseth, K. A. (2013). Identity development among pre-service teacher candidates (Unpublished doctoral dissertation). Iowa State University, Ames, IA.

Lester, B. T., Ma, L., Lee, O., \& Lambert, J. L. (2006). Social activism in elementary science education: A science, technology, and society approach to teach global warming. International Journal of Science Education, 28(4), 315-339. doi:10.1080/09500690500240100

Levinson, R. (2006). Towards a theoretical framework for teaching controversial socio-scientific issues. International Journal of Science Education, 28(10), 1201-1224. doi:10.1080/09500690600560753

Lipsey, T. M. (2013). A qualitative study of teachers' identities, ideologies, and commitment to teach in urban and subrurban schools (Unpublished doctoral dissertation). University of Wisconsin - Milwaukee, Milwaukee, WI.

Liu, S., Roehrig, G. H., Bhattacharya, D., \& Varma, K. (2015). In-service teachers' attitudes, knowledge and classroom teaching of global climate change. Science Educator, 24(1), 1-11. 
Lombardi, D., \& Sinatra, G. M. (2013). Emotions about teaching about humaninduced climate change. International Journal of Science Education, 35(1), 167-191. doi:10.1080/09500693.2012.738372

Loughran, J., Mulhall, P., \& Berry, A. (2004). In search of pedagogical content knowledge in science: Developing ways of articulating and documenting professional practice. Journal of Research in Science Teaching, 41(4), 370391. doi:10.1002/tea.20007

Luehmann, A. L. (2007). Identity development as a lens to science teacher preparation. Science Education, 91(5), 822-839. doi:10.1002/sce.20209

Luehmann, A. L. (2016). Practice-linked identity development in science teacher education. In L. Avraamidou (Ed.), Studying science teacher identity: Theoretical, methodological and empirical explorations (pp. 15-47). Rotterdam, Netherlands: Sense Publishers. doi:10.1007/978-946300-528-9

MacLure, M. (1993). Arguing for your self: Identity as an organising principle in teachers' jobs and lives. British Educational Research Journal, 19(4), 311-322. doi:10.1080/0141192930190401

MacQueen, K. M., McLellan-Lemal, E., Bartholow, K., \& Milstein, B. (2008). Teambased codebook development: Structure, process, and agreement. In G. Guest, \& K. M. MacQueen (Eds.), Handbook for team-based qualitative research (pp. 119-135). Lanham, MD: AltaMira.

Madden, L., \& Wiebe, E. (2015). Multiple perspectives on elementary teachers' science identities: A case study. International Journal of Science Education, 37(3), 391-410. doi:10.1080/09500693.2014.987715

Magnusson, S., Krajcik, J. S., \& Borko, H. (1999). Nature, sources, and development of pedagogical content knowledge for science teaching. In J. Gess-Newsome \& N. G. Lederman (Eds.), Examining pedagogical content knowledge: The construct and its implications for science education (pp. 95-132). Dordrecht, Netherlands: Kluwer Academic Publishers.

Makris, S. (2012). Spoken stories: A narrative inquiry on the lives and experiences of "outsider teachers" (Unpublished doctoral dissertation). University of Maryland, College Park, MD.

Mansour, N. (2010). Impact of the knowledge and beliefs of Egyptian science teachers in integrating a STS based curriculum: A sociocultural perspective. Journal of Science Teacher Education, 21(5), 513-534. doi:10.1007/s10972-010-9193-0 
Mansour, N. (2013). Consistencies and inconsistencies between science teachers' beliefs and practices. International Journal of Science Education, 35(7), 12301275. doi:10.1080/09500693.2012.743196

Manzo, K. (2010). Beyond polar bears? Revisioning climate change. Meteorological Applications, 17(2), 196-208. doi:10.1002/met.193

Maxwell, J. A. (1996). Qualitative research design: An interactive approach. Thousand Oaks, CA: SAGE Publications.

McAdams, D. P. (1993). The stories we live by: Personal myths and the making of the self. New York, NY: Guilford Press.

McCright, A. M., \& Dunlap, R. E. (2011). The politicization of climate change and polarization in the American public's view of global warming, 2001-2010. Sociological Quarterly, 52(2), 155-194. doi:10.1111/j.15338525.2011.01198.X

McNeal, K. S., Hammerman, J. K. L., Christiansen, J. A., \& Carroll, F. J. (2014). Climate change education in the southeastern U.S. through public dialogue: Not just preaching to the choir. Journal of Geoscience Education, 62(4), 631644. doi:10.5408/13-061.1

Meehan, C. (2012). Global warming in schools: An inquiry about the competing conceptions of high school social studies and science curricula and teachers. (Unpublished doctoral dissertation). University of Wisconsin-Madison, Madison, WI.

Melillo, J. M., Richmond, T., \& Yohe, G. W. (2014). Highlights of climate change impacts in the United States: The third national climate assessment. U.S. Global Change Research Program. Retrieved from:

globalchange.gov/browse/reports/highlights-climate-change-impacts-unitedstates-third-national-climate-assessment

Mensah, F. M. (2012). Positional identity as a lens for connecting elementary preservice teachers to teaching in urban classroom. In M. Varelas (Ed.), Identity construction and science education research: Learning teaching and being in multiple contexts (pp. 105-121). Rotterdam, Netherlands: Sense Publishers. doi:10.1007/978-94-6209-043-9

Merriam, S. B. (2009). Qualitative research: A guide to design and implementation. San Francisco, CA: Jossey Bass Publishers. 
Miles, M. B., \& Huberman, A. M. (1994). Qualitative data analysis: An expanded sourcebook (2nd ed.). Thousand Oaks, CA: SAGE Publications.

Mitchener, C. P., \& Anderson, R. (1989). Teachers' perspective: Developing and implementing an STS curriculum. Journal of Research in Science Teaching, 26(4), 351-369. doi:10.1002/tea.3660260407

Monroe, M. C., Oxarart, A., \& Plate, R. R. (2013). A role for environmental education in climate change for secondary science educators. Applied Environmental Education \& Communication, 12(1), 4-18. doi:10.1080/1533015X.2013.795827

Monroe, M. C., Plate, R. R., Oxarart, A., Bowers, A., \& Chaves, W. A. (2017). Identifying effective climate change education strategies: A systematic review of the research. Environmental Education Research, 1-22. doi:10.1080/13504622.2017.1360842

Moore, F. M. (2008a). Agency, identity and social justice education: Preservice teachers' thoughts on becoming agents of change in urban elementary science classrooms. Research in Science Education, 38, 589-610. doi:10.1007/s11165007-9065-6

Moore, F. M. (2008b). Positional identity and science teacher professional development. Journal of Research in Science Teaching, 45(6), 684-710. doi:10.1002/tea.20258

Namey, E., Guest, G., Thairu, L., \& Johnson, L. (2008). Data reduction techniques for large qualitative data sets. In G. Guest \& K. M. MacQueen (Eds.), Handbook for team-based qualitative research (pp. 137-161). Lanham, MD: AltaMira.

National Center for Educational Statistics (NCES). (2018). Search for public schools Common core of data. Revtrieved from https://nces.ed.gov/ccd/schoolsearch/

National Center for Science Education (NCSE). (2012). Climate change denial is affecting education. Retrieved from https://ncse.com/library-resource/climatechange-denial-is-affecting-education

Nespor, J. (1987). The role of beliefs in the practice of teaching. Journal of Curriculum Studies, 19(4), 317-328. doi:10.1080/0022027870190403

NGSS Lead States. (2013). Next Generation Science Standards: For states, by states. Washington, DC: National Academies Press. doi:10.17226/18290 
Nisbet, M. C. (2009). Communicating climate change: Why frames matter for public engagement. Environment, 51(2), 12-23.

Nisbet, M. C., \& Mooney, C. (2007). Framing science. Science, 316(5821), 56. doi:10.1126/science. 1142030

Nonnes-Austria, M. D. (2011). Surviving and thriving: A narrative inquiry into the lives of five Filipina teachers in a U.S. school district (Unpublished doctoral dissertation). Univeristy of Maryland, College Park, MD.

Nugent, T. A. (2007). A narrative inquiry of teachers' perceptions regarding their professional development experiences (Unpublished doctoral dissertation). Western Michigan University, Kalamazoo, MI.

Olsen, B. (2008). Teaching what they learn, learning what they live. Boulder, CO: Paradigm Publishers.

Oreskes, N., \& Conway, E. M. (2010). Merchants of doubt: How a handful of scientists obscured the truth on issues from tobacco smoke to global warming. New York, NY: Bloomsbury Press.

Osborne, J. (2014). Scientific practices and inquiry in the science classroom. In N. G. Lederman \& S. K. Abell (Eds.) Handbook of research on science education (Vol. II, pp. 579-599). New York, NY: Routledge.

Oulton, C., Day, V., Dillon, J., \& Grace, M. (2004). Controversial issues: Teachers' attitudes and practices in the context of citizenship education. Oxford Review of Education, 30(4), 489-507. doi:10.1080/0305498042000303973

Pajares, M. F. (1992). Teachers' beliefs and educational research: Cleaning up a messy construct. Review of Educational Research, 62(3), 307-332. doi:10.3102/00346543062003307

Pedretti, E., Bencze, L., Hewitt, J., Romkey, L., \& Jivraj, A. (2008). Promoting issuesbased STSE perspectives in science teacher education: Problems of identity and ideology. Science and Education, 17(8-9), 941-960. doi:10.1007/s11191006-9060-8

Pew Research Center. (2015). Global concern about climate change, broad support for limiting emissions: U.S., China less worried, partisan divides in key countries. Retrieved from: www.pewglobal.org/2015/11/05/global-concernabout-climate-change-broad-support-for-limiting-emissions/ 
Plutzer, E., McCaffrey, M., Hannah, A. L., Rosenau, J., Berbeco, M., \& Reid, A. H. (2016). Climate confusion among US teachers. Science, 351(6274), 664-665. doi:10.1126/science.aab3907

Reis, P. (2014). Promoting students' collective socio-scientific activism: Teachers' perspectives. In L. Bencze \& S. Alsop (Eds.), Activist science and technology education (pp. 547-574). Dordrecht, Netherlands: Springer Science \& Business Media. doi:10.1007/978-94-007-4360-1

Roberts, D. A. (1982). Developing the concept of "curriculum emphases" in science education. Science Education, 66(2), 243-260. doi:10.1002/sce.3730660209

Roberts, D. A. (2007). Scientific literacy/science literacy. In S. K. Abell \& N. G. Lederman (Eds.), Handbook of research on science education (pp. 729-780). New York, NY: Routledge.

Rodgers, P. E. (2006). What goal is of most worth? The effects of the implementation of the Texas assessment of knowledge and skills on elementary science teaching (Unpublished doctoral dissertation). Texas A\&M University, College Station, TX.

Rodgers, C. R., \& Scott, K. H. (2008). The development of the personal self and professional identity in learning to teach. In M. Cochran-Smith, S. FeimanNemser, D. J. McIntyre, \& K. E. Demers (Eds.), Handbook of research on teacher education (pp. 732-755). New York, NY: Routledge.

Roehrig, G. H., Kruse, R. A., \& Kern, A. (2007). Teacher and school characteristics and their influence on curriculum implementation. Journal of Research in Science Teaching, 44(7), 883-907. doi:10.1002/tea.20180

Román, D., \& Busch, K. C. (2016). Textbooks of doubt: Using systemic functional analysis to explore the framing of climate change in middle school science textbooks. Envrionmental Education Research, 22(8), 1158-1180. doi:10.1080/13504622.2015.1091878

Rubin, H. J., \& Rubin, I. (2012). Qualitative interviewing: The art of hearing data. Thousand Oaks, CA: SAGE Publications. doi:10.4135/9781452226651

Rye, J. A., Rubba, P. A., \& Wiesenmayer, R. L. (1997). An investigation of middle school students' alternative conceptions of global warming. International Journal of Science Education, 19(5), 527-551. doi:10.1080/0950069970190503 
Sachs, J. (2001). Teacher professional identity: Competing discourses, competing outcomes. Journal of Educational Policy, 16(2), 149-161.

doi:10.1080/02680930116819

Sadler, T. D. (2004). Informal reasoning regarding socioscientific issues : A critical review of research. Journal of Research in Science Teaching, 41(5), 513-536. doi:10.1002/tea.20009

Sadler, T. D., Amirshokoohi, A., Kazempour, M., \& Allspaw, K. M. (2006). Socioscience and ethics in science classrooms: Teacher perspectives and strategies. Journal of Research in Science Education, 43(4), 353-376. doi:10.1002/tea.20142

Sadler, T. D., \& Zeidler, D. L. (2005). The significance of content knowledge for informal reasoning regarding socioscientific issues: Applying genetics knowledge to genetic engineering issues. Science Education, 89(1), 71-93. doi:10.1002/sce.20023

Saka, Y., Southerland, S. A., Kittleson, J., \& Hutner, T. (2013). Understanding the induction of a science teacher: The interaction of identity and context. Research in Science Education, 43(3), 1221-1244. doi:10.1007/s11165-0129310-5

Saldaña, J. (2013). The coding manual for qualitative researchers (2nd ed.). New York, NY: SAGE Publications.

Sarewitz, D. (2011). Does climate change knowledge really matter? WIRES Climate Change, 2(4), 1-7. doi:10.1002/wcc.126

Sezen-Barrie, A., Shea, N., \& Borman, J. H. (2017). Probing into sources of ignorance: Science teachers' practices of constructing arguments or rebuttals to denialism of climate change. Environmental Education Research, 1-21. doi:10.1080/13504622.2017.1330949

Schwarz, G. (2001). Using teacher narrative research in teacher development. The Teacher Educator, 37(1), 37-48. doi:10.1080/08878730109555279

Seow, T., \& Ho, L.-C. (2016). Singapore teachers' beliefs about the purpose of climate change education and student readiness to handle controversy. International Research in Geographical and Environmental Education, 25(4), 358-371. doi:10.1080/10382046.2016.1207993 
Sfard, A., \& Prusak, A. (2005). In search of an analytic tool for investigating learning as a culturally shaped activity. Educational Researcher, 34(4), 14-22. doi:10.3102/0013189X034004014

Sharma, A. (2012). Global climate change: What has science education got to do with it? Science \& Education, 21(1), 33-53. doi:10.1007/s11191-011-9372-1

Shea, N. A., Mouza, C., \& Drewes, A. (2016). Climate change professional development: Design, implementation, and initial outcomes on educator learning and student beliefs. Journal of Science Teacher Education, 27(3), 235-238. doi:10.1007/s10972-016-9456-5

Shepardson, D. P., Choi, S., Niyogi, D., \& Charusombat, U. (2011a). Seventh grade students' mental models of the greenhouse effect. Environmental Education Research, 17(1), 1-17. doi:10.1080/13504620903564549

Shepardson, D. P., Niyogi, D., Choi, S., \& Charusombat, U. (2011b). Students' conceptions about the greenhouse effect, global warming, and climate change. Climatic Change, 104(3-4), 481-507. doi:10.1007/s10584-009-9786-9

Shulman, L. S. (1986). Those who understand: Knowledge growth in teaching. Educational Researcher, 15(2), 4-14. doi:10.3102/0013189X015002004

Sinatra, G. M., \& Chinn, C. (2012). Thinking and reasoning in science: Promoting epistemic conceputal change. In K. R. Harris, S. Graham, \& T. Urdan (Eds.) APA educational pyschology handbook: Application to learning and teaching (pp. 257-282). Washington, D.C.: American Psychological Association. doi:10.1037/13275-011

Sinatra, G., Kienhues, D., \& Hofer, B. K. (2014). Addressing challenges to public understanding of science: Epistemic cognition, motivated reasoning, and conceptual change. Educational Psychologist, 49(2), 123-138.

doi:10.1080/00461520.2014.916216

Spillane, J. P. (2000). A fifth-grade teacher's reconstruction of mathematics and literacy teaching: Exploring interactions among identity, learning, and subject matter. The Elementary School Journal, 100(4), 307-330. doi:10.1086/499644

Stake, R. E. (1995). The art of case study research. Thousand Oaks, CA: SAGE Publications.

Stapleton, S. R. (2018). A case for climate justice education: American youth connecting to intragenerational climate injustice in Bangladesh. Environmental Education Research, 1-19. doi:10.1080/13504622.2018.1472220 
Stevenson, R. B. (2007). Schooling and environmental education: Contradictions in purpose and practice. Envrionmental Education Research, 13(2), 139-153. doi:10.1080/13504620701295726

Stevenson, K. T., Peterson, M. N., Bondell, H. D., Moore, S. E., \& Carrier, S. J. (2014). Overcoming skepticism with education: Interacting influences of worldview and climate change knowledge on perceived climate change risk among adolescents. Climatic Change, 126(3-4), 293-304. doi:10.1007/s10584014-1228-7

Stevenson, K. T., Peterson, M. N., \& Bondell, H. D. (2016a). The influence of personal beliefs, friends, and family in building climate change concern among adolescents. Environmental Education Research, 1-14.

doi:10.1080/13504622.2016.1777712

Stevenson, K. T., Peterson, M. N., \& Bradshaw, A. (2016b). How climate change beliefs among U.S. teachers do and do not translate to students. PLOS One, 11(9), 1-11. doi:10.1371/journal.pone.0161642

Sullivan, S. B., Ledley, T. S., Lynds, S. E., \& Gold, A. U. (2014). Navigating climate science in the classroom: Teacher preparation, perceptions and practices. Journal of Geoscience Education, 62(4), 550-559. doi:10.5408/12-304.1

Union of Concerned Scientists (UCS). (2007). Smoke, mirrors, and hot air: How ExxonMobile uses big tobacco's tactics to manufacture uncertainy on climate science. Cambridge, MA: Union of Concerned Scientists.

United Nations (UN). (2014). UN climate summit 2014: Chair's summary. Retrieved from http://www.un.org/climatechange/summit/2014/09/2014-climate-changesummary-chairs-summary/

United Nations (UN). (2015). Secretary general's closing remarks at COP21. Retrieved from https://www.un.org/sg/en/content/sg/statement/2015-1212/secretary-generals-remarks-closing-cop21

U.S. Global Change Research Program (USGCRP). (2009). Climate literacy: The essential principles of climate science. Retrieved from downloads.globalchange.gov/Literacy/climate_literacy_lowres_english.pdf

U.S. Global Change Research Program (USGCRP). (2014). 2014 National climate assessment. Retrieved from: nca2014.globalchange.gov/report 
Van der Zande, P., Akkerman, S. F., Brekelmans, M., Waarlo, A. J., \& Vermunt, J. D. (2012). Expertise for teaching biology situated in the context of genetic testing. International Journal of Science Education, 34(11), 1741-1767. doi:10.1080/09500693.2012.671557

Van Rensburg, W. (2015). Climate change scepticism: A conceptual re-evaluation. SAGE Open, 5(2), 1-13. doi:10.1177/2158244015579723

Van Rooy, W. S. (1999). Controversial biological issues: An exploratory tool for accessing teacher thinking in relation to classroom practice. In NARST 1999 Proceedings (pp. 1-15).

Varelas, M., House, R., \& Wenzel, S. (2005). Beginning teachers immersed into science: Scientist and science teacher identities. Science Education. doi:10.1002/sce.20047

Volkmann, M. J., \& Anderson, M. (1998). Creating professional identity: Dilemmas and metaphors of a first-year chemistry teacher. Science Education, 82, 293310. doi:10.1002/(SICI)1098-237X(199806)82:3<293::AID-SCE1>3.0.CO;2-7

Waldron, F., Ruane, B., Oberman, R., \& Morris, S. (2016). Geographical process or global injustice? Contrasting educational perspectives on climate change. Environmental Education Research, 1-17. doi:10.1080/13504622.2016.1255876

Wallace, C. S., \& Kang, N. H. (2004). An investigation of experienced secondary science teachers' beliefs about inquiry: An examination of competing belief sets. Journal of Research in Science Teaching, 41(9), 936-960. doi:10.1002/tea.20032

Walsh, E. M., \& Tsurusaki, B. K. (2014). Social controversy belongs in the climate science classoom. Nature Climate Change, 4, 259-263. doi:10.1038/nclimate2143

Walsh, E. M., \& Tsurusaki, B. K. (2018). "Thank you for being republican": Negotiating science and political identities in climate change learning. Journal of the Learning Sciences, 27, 8-48. doi:10.1080/10505406.2017.1362563

Waters-Adams, S. (2006). The relationship between understanding of the nature of science and practice: The influence of teachers' beliefs about education, teaching and learning. International Journal of Science Education, 28(8), 919944. doi:10.1080/09500690500498351 
Watson, C. (2006). Narratives of practice and the construction of identity in teaching. Teachers and Teaching, 12(5), 509-526. doi:10.1080/13540600600832213

Wibeck, V. (2014). Enhancing learning, communication and pubilc engagement about climate change: Some lessons from recent literature. Environmental Education Research, 20(3), 387-411. doi:10.1080/13504622.2013.812720

Wilson, M. (2014). Life after study abroad: A narrative inquiry of graduate student study abroad returnees (Unpublished doctoral dissertation). Clemson University, Clemson, SC.

Wilt, M. E. (2013). Becoming a teacher in multiple voices: An exploration of teacher identity formation among teachers of students with Austism Spectrum Disorder (Unpublished doctoral dissertation). University of South Florida, Tampa, FL.

Wise, S. B. (2010). Climate change in the classroom: Patterns, motivations, and barriers to instruction among Colorado science teachers. Journal of Geoscience Education, 58(5), 297-309.doi:10.5408/1.3559695

Witz, K. G., \& Lee, H. (2009). Science as an ideal: Teachers' orientations to science and science education reform. Journal of Curriculum Studies, 41(3), 409-431. doi:10.1080/00220270802165640

Woods, P. (1985). Conversations with teachers: Some aspects of life-history method. British Educational Research Journal, 11(1), 13-26. doi:10.1080/0141192850110102

Wolcott, H. E. (1994). Transforming qualitative data: Description, analysis, and interpretation. Thousand Oaks, CA: Sage.

Wysession, M. E. (2013). The Next Generation Science Standards and the Earth and space sciences. The Science Teacher, 80(4), 31-37.

Yin, R. K. (2014). Case study research: Design and methods (5th ed.). Thousand Oaks, CA: Sage.

Zeidler, D. L. (2014). Socioscientific issues as curriculum emphasis: Theory, research, practice. In N. G. Lederman \& S. K. Abell (Eds.), Handbook of research on science education (pp. 697-726). New York, NY: Routledge.

doi:10.4324/9780203097267 
Zeidler, D. L., \& Keefer, M. (2003). The role of moral reasoning and the status of socioscientific issues in science education. In D. L. Zeidler (Ed.), The role of moral reasoning on socioscientific issues and discourse in science education (pp. 7-40). Dordrecht, Netherlands: Kluwer Academic Publishers. doi:10.1007/1-4020-1411-6

Zeidler, D. L., \& Nichols, B. H. (2009). Socioscientific issues: Theory and practice. Journal of Elementary Science Education, 21(2), 49-58. doi:10.1007/BF03173684

Zeidler, D. L., Sadler, T. D., Simmons, M. L., \& Howes, E. V. (2005). Beyond STS: A research-based framework for socioscientific issues education. Science Education, 89(3), 357-377. doi:10.1002/sce.20048 


\section{Appendix A \\ INTERVIEW PROTOCOLS \& INSTRUMENTATION}

\section{Interview protocol \#1}

Before we get started, did you have a chance to look over the consent form? Did you have any questions about it? Is it okay to record our conversation today? Thank you!

Today I'd like to try to really get to know you better as a science teacher. We're going to be chatting about your background in science and your experiences growing up and becoming a teacher. In the next interview, we will be more focused on your teaching of climate change.

First, I'd like to talk to you about your experiences learning science.

1. Can you tell me about an experience that you had with science when you were young?

2. Could you describe a memorable science learning experience during school?

○ Additional Probes: What about at university?

- Any particular science memory outside of school?

- Any thoughts about connections to science learning with your family?

Now thinking a bit more about your science teaching

3. How did you decide that you wanted to become a science teacher?

- And how did you get here? 
4. Could you please describe your science background?

○ And what about your educational or teaching background?

5. How have these experiences when you were learning science or learning pedagogy shaped the way you teach science?

○ Did you have any influential teachers?

O Or influential lessons that shaped your teaching approach?

6. Could you describe your goals for teaching science?

○ The things that you described are all very important. Are there things that you feel are a lesser priority for you in the classroom?

7. How would you describe your science teaching style?

8. Is there anything you'd like to change about your teaching style?

9. What do you feel are the most meaningful ways to teach science?

○ Could you describe an example of when you taught something in that way that was effective?

10. How do you decide what to teach and what not to teach?

- I know there's always so many things that can be incorporated. How do you make those decisions?

11. How do you decide when you need to add something that is not a part of your assigned curriculum?

12. What things influence the way you teach? (possible ideas could be state or district policies, opinions of admin/supervisor, curriculum, student interests)

13. What question should I have asked to get to know you better as a science teacher?

14. What else has made you the science teacher you are today? 
15. Is there anything else that you would like to share with me at this time?

\section{Interview protocol \#2}

Thank you again for talking with me today. I want to remind you that our conversations are completely confidential and are protected in the ways listed on the consent form that we discussed that last. Is it still okay that I record our conversation?

I also want to let you know that this interview is not meant to be evaluative of you as a teacher in any way, nor of the MADE CLEAR program. Really, as a researcher, I just want to get to know more about your experiences and your beliefs towards teaching climate change. Thank you very much for taking the time to share with me.

16. Broadly speaking, what has been your experience teaching about climate change?

17. What experiences have (or have not) prepared you to teach climate change?

- Can you tell me a little more about how those experiences influenced your climate change teaching?

18. Is climate change an important topic for you personally? Why?

19. Is climate change an important topic for your students? How do you know?

20. Has your curriculum changed to officially include climate change? So, why try to teach it now versus in years past?

21. Where do you think your role is as far as either teaching for content knowledge about the science of climate change versus encouraging students to take action 
on this issue? Where do you see yourself on that spectrum of teaching it to learn about the science and evidence versus trying to inspire action?

22. So, I know from reviewing the implementation plan that you submitted previously a bit about your original plans for teaching, but could you give me a broad overview of how you approach teaching climate change currently?

- How do you connect it to the rest of your curriculum?

- What are your main goals for the unit?

23. What kind of ideas are your students bringing to the table to start with about climate change?

24. What have you struggled with when teaching climate change?

25 . What do you wish you could change about your climate change instruction?

26. If you were talking to a new teacher who wanted to integrate climate change, what would you recommend them to do? Like what kind of general advice would you give to this colleague who wants to teach climate change?

27. Do you have a favorite activity to really drive home the point or message about climate change? Could you describe it and why you like it?

28. What role does NGSS play in your planning and instruction?

○ Have you made modifications to your prior plans because of NGSS?

29. What role does scientific research play in your planning?

- What about in your instruction? What role does scientific evidence (research) play in your actual teaching?

30. Have you experienced any pushback for your climate change teaching?

$\circ$ What about any positive recognition for including climate change in your teaching? 
31. So, as you and I both know, our culture and media in America talk about climate change in a specific manner. How does that media environment or that external conversation influence what happens inside your classroom when teaching climate change?

32. What question should I have asked in order to better understand your experiences teaching climate change?

33. Do you feel like your experiences working to integrate climate change into your teaching are the norm for other science teachers as well? Or do you feel like you are one of the few people teaching this topic?

34. Is there anything else that I missed talking about with you related to your experiences working to incorporate climate change?

Well thank you again, that's all that I have for you tonight. If anything else comes up, can I send you an email to follow up? Thank you!

Also, I'm going to email you the link to the online reflection part for you to complete. If you have any questions, please let me know. Thank you for your candid contributions to our discussion! 


\section{Reflection Survey}

\section{Teaching Climate Change Reflection Survey}

You have unlocked your survey. When you have finished editing, please lock your survey again.

$\square$ Q5 For the first group of reflection questions, please think about your most recent

2. efforts to design, modify, and prepare to teach your climate change implementation plan.

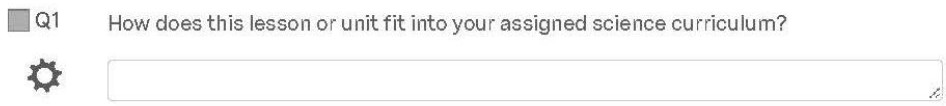

Q2 What changes have you made to the implementation plan you submitted to MADE CLEAR? Can you b give an example of a specific modification?

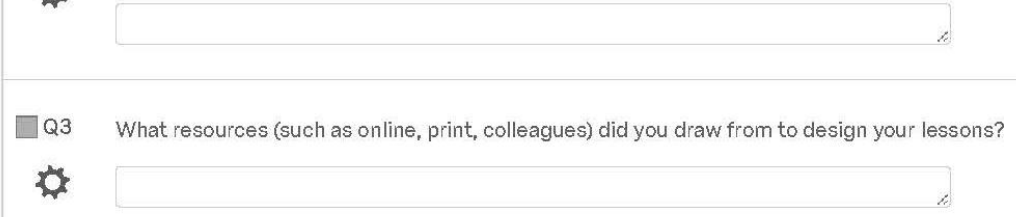

$\square$ Q4 What is the 'take away' message that you want your students to know about climate change? 女

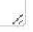

Page Break

Add Block

$\square$ Q6 For this second group of questions, think about your most recent efforts to b implement climate change related lessons in your classroom. 


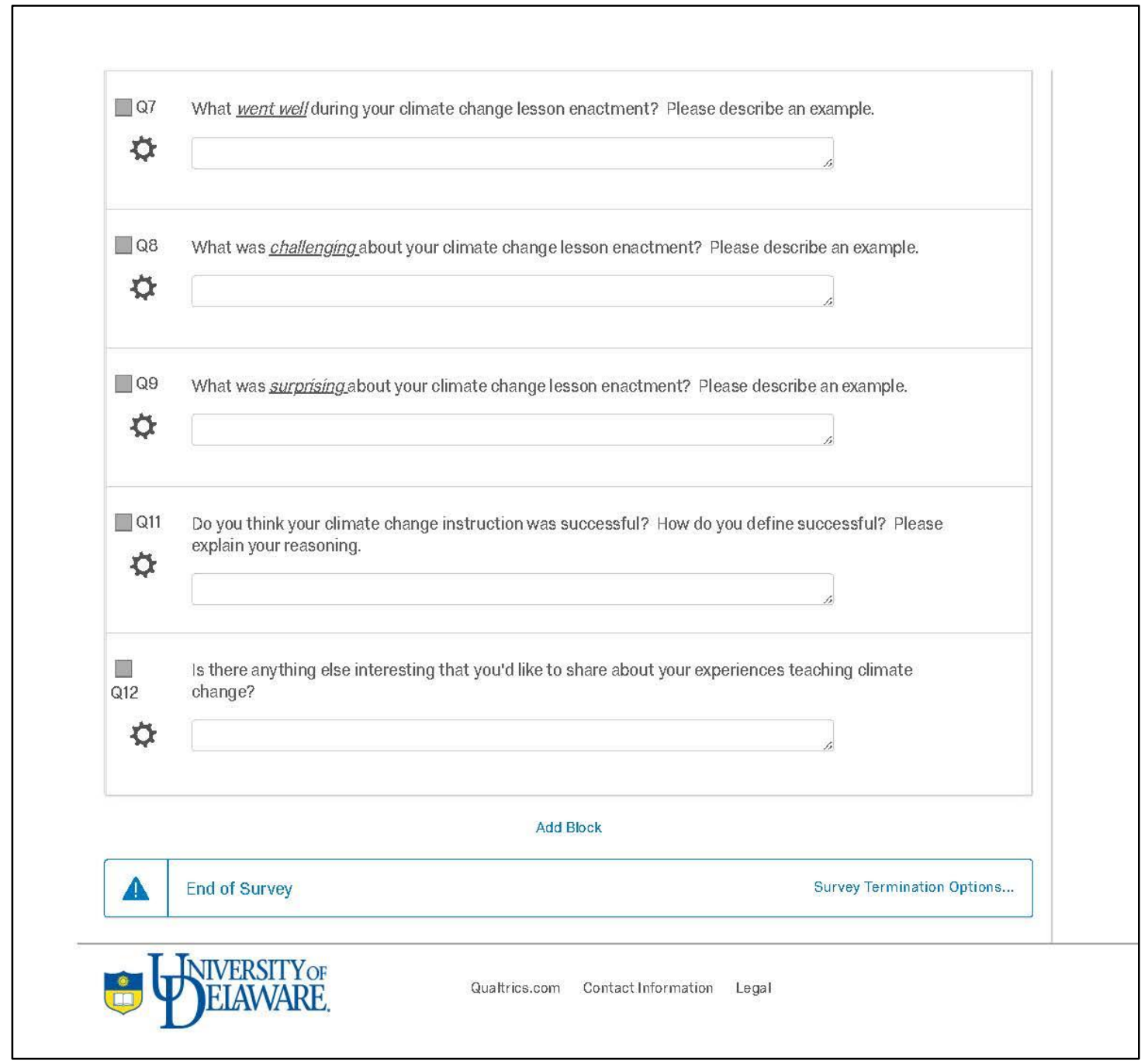




\section{Appendix B}

\section{INSTITUTIONAL REVIEW BOARD DOCUMENTS}

Pilot Study Approval Documents

Documents begin on next page. 
DATE:

TO

FROM:

STUDY TITLE:

SUBMISSION TYPE:

ACTION:

APPROVAL DATE:

EXPIRATION DATE:

REVIEW TYPE:

REVIEW CATEGORY:
March 6, 2017

Andrea Drewes, MEd

University of Delaware IRB

[1028896-1] Teacher Perceptions of Teaching Climate Change in a Maryland Middle School - Pilot Instrument Refinement

New Project

APPROVED

March 6, 2017

March 5, 2018

Expedited Review

Expedited review category \# $(6,7)$

Thank you for your submission of New Project materials for this research study. The University of Delaware IRB has APPROVED your submission. This approval is based on an appropriate risk/benefit ratio and a study design wherein the risks have been minimized. All research must be conducted in accordance with this approved submission.

This submission has received Expedited Review based on the applicable federal regulation.

Please remember that informed consent is a process beginning with a description of the study and insurance of participant understanding followed by a signed consent form. Informed consent must continue throughout the study via a dialogue between the researcher and research participant. Federa regulations require each participant receive a copy of the signed consent document.

Please note that any revision to previously approved materials must be approved by this office prior to initiation. Please use the appropriate revision forms for this procedure.

All SERIOUS and UNEXPECTED adverse events must be reported to this office. Please use the appropriate adverse event forms for this procedure. All sponsor reporting requirements should also be followed.

Please report all NON-COMPLIANCE issues or COMPLAINTS regarding this study to this office.

Please note that all research records must be retained for a minimum of three years. 
Based on the risks, this project requires Continuing Review by this office on an annual basis. Please use the appropriate renewal forms for this procedure.

If you have any questions, please contact Nicole Farnese-McFarlane at (302) 831-1119 or

nicolefm@udel.edu. Please include your study title and reference number in all correspondence with this office. 
TO:

FROM:

STUDY TITLE:

SUBMISSION TYPE:

ACTION:

APPROVAL DATE:

EXPIRATION DATE:

REVIEW TYPE:

REVIEW CATEGORY:
Andrea Drewes, MEd

University of Delaware IRB

[1028896-2] Teacher Perceptions of Teaching Climate Change in a Maryland Middle School - Pilot Instrument Refinement

Continuing Review/Progress Report

Approved for Data Analysis Only

February 26, 2018

March 5, 2019

Expedited Review

Expedited review category \# $(6,7)$

Thank you for your submission of Continuing Review/Progress Report materials for this research study. The University of Delaware IRB has APPROVED your submission. This approval is based on an appropriate risk/benefit ratio and a study design wherein the risks have been minimized. All research must be conducted in accordance with this approved submission.

This submission has received Expedited Review based on the applicable federal regulation.

Please remember that informed consent is a process beginning with a description of the study and insurance of participant understanding followed by a signed consent form. Informed consent must continue throughout the study via a dialogue between the researcher and research participant. Federal regulations require each participant receive a copy of the signed consent document.

Please note that any revision to previously approved materials must be approved by this office prior to initiation. Please use the appropriate revision forms for this procedure.

All SERIOUS and UNEXPECTED adverse events must be reported to this office. Please use the appropriate adverse event forms for this procedure. All sponsor reporting requirements should also be followed.

Please report all NON-COMPLIANCE issues or COMPLAINTS regarding this study to this office.

Please note that all research records must be retained for a minimum of three years. 
Based on the risks, this project requires Continuing Review by this office on an annual basis. Please use the appropriate renewal forms for this procedure.

If you have any questions, please contact Nicole Farnese-McFarlane at (302) 831-1119 or

nicolefm@udel.edu. Please include your study title and reference number in all correspondence with this office. 
UD IRB Approval from 03/06/2017 to 03/05/2018

Teacher Perceptions of Teaching Climate Change in a Maryland Middle School

\begin{tabular}{|l|l|}
\hline Andrea Drewes, M.Ed. & Dr. Danielle Ford \\
Doctoral Candidate & Associate Professor \\
School of Education, University of Delaware & School of Education, University of Delaware \\
213 Willard Hall, Newark, DE 19716 & 132 F Willard Hall, Newark, DE 19716 \\
Phone: & Phone: \\
Email: & Email: \\
\hline
\end{tabular}

Dear Teacher,

We are investigating how teachers implement climate science education in their science classrooms. We are specifically investigating how teachers design, implement and reflect on their climate change curriculum. The study's results will serve as a resource for consideration during refinement of interview protocols for future research in climate science education.

Three to five Maryland middle school teachers are being invited to participate in this study. Your participation includes two main parts: (a) participating in a 45-60 minute interviews with a research staff person that focuses on your background in science, your educational background, and your approaches to science teaching and learning, and (b) participating in a second 60-75 minute interview that focuses on your design, enactment, and reflections on your instruction related to climate change.

Your participation includes interviews with a research staff member that will take place at a time and location of your choosing. Face-to-face interviews will be audio-taped to facilitate transcription of the data. If you would not like your interview to be audio-taped we will keep detailed notes instead. Interview questions will focus on the following topics: (a) design of your instructional unit, (b) your educational background, (c) reflections on implementation, (d) reflections on revision and optimization of your instructional unit.

We believe that there are no risks in participation in this study. The research equipment (i.e. digital voice recorder) is safe and poses no physical harm. The audio files containing interview data will be used to help in the transcription of information. They will only be accessible to the investigators and will be encrypted and stored in password-protected computers in the investigators' office. Only non-identifiable data files will be encrypted and stored on the researcher's laptop which is protected by a different, strong password.

Other data, which will not list your name, will be stored in a locked file cabinet for six years after completion of this study, until March 1, 2023. Participation in the activities is strictly voluntary. Even if you decide to participate, you may withdraw from this study at any time without any consequences or penalty. If you choose to withdraw from this study, data collected from you will be destroyed immediately.

The study offers no direct benefits to participants. Findings from this study might result in scholarly publications and conference presentations. Pseudonyms will be used in all reports resulting from this study. Results will be aggregately reported, even though individual participants' comments might be used to illustrate a particular theme emerged from the data. 
Page 1 of 2 Teacher Initials

If you agree to participate in this study, please do the following:

1. Sign and date the form where indicated on page 2 and initial where indicated on pages 1 .

2. Return the signed copy of both pages of the form to Andrea Drewes, School of Education, 213 Willard Hall Education Building, Newark, DE 19716. If you prefer, you may scan the form onto your computer and email it to

Be sure to keep a copy of this form for your own records.

If you have any questions, please contact the principal investigator. Andrea Drewes, at

$$
\text { or Dr. Danielle Ford I If you have any }
$$

concerns or questions about your rights as a study participant, please contact Chair, Human

Subjects Review Board, 210 Hullihen Hall, University of Delaware, Newark, DE 19716-1551 or 302-831- 2137.

Sincerely,

Andrea Drewes

Doctoral Candidate

School of Education, Newark, DE 19716

Dr. Danielle Ford

Associate Professor

School of Education, Newark, DE 19716

I voluntarily agree to participate in the study, "Teacher Perceptions of Teaching Climate Change in a Maryland Middle School", as explained above. Any questions that I had have been explained satisfactorily.

I do not want to participate in the study, "Teacher Perceptions of Teaching Climate Change in a Maryland Middle School", as explained above.

Teacher's Name (printed):

Teacher's Signature: Date:

I would like to receive a summary report of the findings of this study.

Home Address: 
Full Study Approval Documents

() WIVERSITYoF

Research Office

210 Hullihen Hall

University of Delaware

Tew ark, Delaw are 19716-1551

Fax: $302 / 831-2828$
DATE:

TO:

FROM:

STUDY TITLE:

SUBMISSION TYPE:

ACTION:

APPROVAL DATE:

EXPIRATION DATE:

REVIEW TYPE:

REVIEW CATEGORY:
April 3, 2017

Andrea Drewes

University of Delaware IRB

[1046437-1] Exploring Science Teacher Identity and Perceptions of Teaching Climate Change

New Project

APPROVED

March 28, 2017

March 27, 2018

Expedited Review

Expedited review category \# $(6,7)$

Thank you for your submission of New Project materials for this research study. The University of Delaware IRB has APPROVED your submission. This approval is based on an appropriate risk/benefit ratio and a study design wherein the risks have been minimized. All research must be conducted in accordance with this approved submission.

This submission has received Expedited Review based on the applicable federal regulation.

Please remember that informed consent is a process beginning with a description of the study and insurance of participant understanding followed by a signed consent form. Informed consent must continue throughout the study via a dialogue between the researcher and research participant. Federa regulations require each participant receive a copy of the signed consent document.

Please note that any revision to previously approved materials must be approved by this office prior to initiation. Please use the appropriate revision forms for this procedure.

All SERIOUS and UNEXPECTED adverse events must be reported to this office. Please use the appropriate adverse event forms for this procedure. All sponsor reporting requirements should also be followed.

Please report all NON-COMPLIANCE issues or COMPLAINTS regarding this study to this office.

Please note that all research records must be retained for a minimum of three years. 
Based on the risks, this project requires Continuing Review by this office on an annual basis. Please use the appropriate renewal forms for this procedure.

If you have any questions, please contact Nicole Farnese-McFarlane at (302) 831-1119 or

nicolefm@udel.edu. Please include your study title and reference number in all correspondence with this office. 
TO:

FROM:

STUDY TITLE:

SUBMISSION TYPE:

ACTION:

APPROVAL DATE:

EXPIRATION DATE:

REVIEW TYPE:

REVIEW CATEGORY:
Andrea Drewes

University of Delaware IRB

[1046437-2] Exploring Science Teacher Identity and Perceptions of Teaching Climate Change

Continuing Review/Progress Report

Approved for Data Analysis Only

February 28, 2018

March 27, 2019

Expedited Review

Expedited review category \# $(6,7)$

Thank you for your submission of Continuing Review/Progress Report materials for this research study. The University of Delaware IRB has APPROVED your submission. This approval is based on an appropriate risk/benefit ratio and a study design wherein the risks have been minimized. All research must be conducted in accordance with this approved submission.

This submission has received Expedited Review based on the applicable federal regulation.

Please remember that informed consent is a process beginning with a description of the study and insurance of participant understanding followed by a signed consent form. Informed consent must continue throughout the study via a dialogue between the researcher and research participant. Federal regulations require each participant receive a copy of the signed consent document.

Please note that any revision to previously approved materials must be approved by this office prior to initiation. Please use the appropriate revision forms for this procedure.

All SERIOUS and UNEXPECTED adverse events must be reported to this office. Please use the appropriate adverse event forms for this procedure. All sponsor reporting requirements should also be followed.

Please report all NON-COMPLIANCE issues or COMPLAINTS regarding this study to this office.

Please note that all research records must be retained for a minimum of three years. 
Based on the risks, this project requires Continuing Review by this office on an annual basis. Please use the appropriate renewal forms for this procedure.

If you have any questions, please contact Nicole Farnese-McFarlane at (302) 831-1119 or

nicolefm@udel.edu. Please include your study title and reference number in all correspondence with this office. 
UD IRB Approval from 03/28/2017 to 03/27/2018

Exploring Science Teacher Identity and Perceptions of Teaching Climate Change

\begin{tabular}{|l|l|}
\hline Andrea Drewes, M.Ed. & Dr. Danielle Ford \\
Doctoral Candidate & Associate Professor \\
School of Education, University of Delaware & School of Education, University of Delaware \\
213 Willard Hall. Newark, DE 19716 & $132 \mathrm{~F}$ Willard Hall, Newark, DE 19716 \\
Phone: & Phone \\
Email: & Email \\
\hline
\end{tabular}

Dear Teacher,

We are investigating how teachers implement climate science education in their science classrooms. We are specifically investigating how teachers design, implement and reflect on their climate change curriculum. The study's results will serve as a resource for consideration during refinement of interview protocols for future research in climate science education.

Fifteen to twenty middle and high school teachers are being invited to participate in this study. Your participation includes three main parts: (a) participating in a 45-60 minute interview with a research staff person that focuses on your background in science, your educational background, and your approaches to science teaching and learning, (b) participating in a second 45-60 minute interview that focuses on your design and enactment of climate change instruction, and (c) a written reflection on your instruction related to climate change.

Your participation includes interviews with a research staff member that will take place at a time and location of your choosing. Face-to-face or online interviews will be audio-taped to facilitate transcription of the data. If you would not like your interview to be audio-taped we will keep detailed notes instead. Interview questions will focus on the following topics: (a) design of your instructional unit, (b) your educational background, (c) reflections on implementation, (d) reflections on revision and optimization of your instructional unit.

We believe that there are no risks in participation in this study. The research equipment (i.e. digital voice recorder) is safe and poses no physical harm. The audio files containing interview data will be used to help in the transcription of information. They will only be accessible to the investigators and will be encrypted and stored in password-protected computers in the investigators' office. Only non-identifiable data files will be encrypted and stored on the researcher's laptop which is protected by a different, strong password.

Other data, which will not list your name, will be stored in a locked file cabinet for six years after completion of this study, until March 1, 2023. Participation in the activities is strictly voluntary. Even if you decide to participate, you may withdraw from this study at any time without any consequences or penalty. If you choose to withdraw from this study, data collected from you will be destroyed immediately.

You will be paid $\$ 125$ for your participation in this study (two interviews and the written reflection). While this research study is not intended to directly help you or your students, the results may help to improve climate change education efforts. Findings from this study might result in scholarly publications and conference presentations. Pseudonyms will be used in all reports resulting from this study. Results will be aggregately reported, even though individual participants' comments might be used to illustrate a particular theme emerged from the data. 
UD IRB Approval from 03/28/2017 to 03/27/2018

Page 1 of 2 Teacher Initials

If you agree to participate in this study, please do the following:

1. Sign and date the form where indicated on page 2 and initial where indicated on pages 1 .

2. Return the signed copy of both pages of the form to Andrea Drewes, School of Education, 213

Willard Hall Education Building, Newark, DE 19716. If you prefer, you may scan the form onto

your computer and email it to

Be sure to keep a copy of this form for your own records.

If you have any questions, please contact the principal investigator, Andrea Drewes, at or $\quad$ or Dr. Danielle Ford 1 If you have any

concerns or questions about your rights as a study participant, please contact Chair, Human Subjects Review Board, 210 Hullihen Hall, University of Delaware, Newark, DE 19716-1551 or 302-831- 2137.

Sincerely,

Andrea Drewes

Doctoral Candidate

Dr. Danielle Ford

School of Education, Newark, DE 19716

Associate Professor

School of Education, Newark, DE 19716

I voluntarily agree to participate in the study, "Exploring Science Teacher Identity and Perceptions of Teaching Climate Change", as explained above. Any questions that I had have been explained satisfactorily.

I do not want to participate in the study, "Exploring Science Teacher Identity and Perceptions of Teaching Climate Change", as explained above.

Teacher's Name (printed):

Teacher's Signature: Date:

I would like to receive a summary report of the findings of this study.

Home Address: 


\section{Appendix C}

\section{NARRATIVE PROFILE JOTTINGS}

\section{Amanda Kerry}

\section{SCIENCE LEARNER \& TEACHER ASPECTS}

Current Position

- 5 years teaching

- High School special education teacher

- Teaches co-taught environmental science and biology

Training

- Alternative track to Certification (via master's degree)

- Biology/animal science/environmental science background

- Undergrad major - Animal science

- Also has experience in informal education and conservation education via Disney; also worked in product development at dog food company;

- Graduate major - Education, with biology certification

\section{Science Experiences}

- Focuses on love of nature and animals (not necessarily science, nor education)

- Has experience doing scientific research in animal science during undergraduate years

Science Teaching Goals

- Wants to teach so students have fun learning, as opposed to how she learned

- Goal is to make students love science, and fun in class, and feel comfortable doing science (asking questions,

- Enormously empathetic and caring for her students

\section{School Background}

- Got SpEd teaching position without any SpEd experience

- Teaches in a rough school - low SES and poor behavior, lots of admin mismanagement and interpersonal issues among teaching staff

Curricular Agency

- Feels restricted and pressured by high stakes testing to follow mandated curriculum 


\section{CLIMATE CHANGE ASPECTS}

Goals for Climate Instruction

- Feels climate change is an important issue to know about (but little emotional depth/passion behind this idea)

Curricular Incorporation

- Introduces climate change as instructional topic only after testing is completed as additional content

Motivation for Inclusion

- Incorporates climate lessons that are hands-on, BECAUSE they are fun and engaging (doesn't seem to have a deep underlying motivation)

\section{Personal Connection}

- Exhibits an almost defeatist attitude about climate change and feels the issue is out of her hands - a future problem

- Accepts the clear evidence for human causality and impending impacts from climate change, but is more concerned about environment generally

Pushback?

- Experienced no negative pushback for incorporating climate change - attributes to lack of parental engagement

Action vs Education

- Hopes students will make "good choices" in future; talks more about the fun climate "games" and songs played as opposed to content/skills development

\begin{tabular}{|l|l|l|l|}
\hline & Past & Present & Future \\
\hline Personal & $\begin{array}{l}\text { - love of nature, } \\
\text { especially animals }\end{array}$ & $\begin{array}{l}\text { - lots of activities where } \\
\text { students relate to animals } \\
\text { - share love of science and } \\
\text { animals with students }\end{array}$ & $\begin{array}{l}\text { - cares about planet and } \\
\text { animals broadly, not CC } \\
\text { specific }\end{array}$ \\
\hline Profess. & $\begin{array}{l}\text { - scientific research } \\
\text { experience in } \\
\text { college } \\
\text { - mixed science } \\
\text { teaching and } \\
\text { learning } \\
\text { experiences }\end{array}$ & $\begin{array}{l}\text { - limited agency due to testing } \\
\text { (esp. with SpEd students), } \\
\text { required curriculum, and other } \\
\text { educational challenges } \\
\text { - desire to have students enjoy } \\
\text { science and have fun in class } \\
\text { - empathetic for diverse needs } \\
\text { of her SpEd students }\end{array}$ & $\begin{array}{l}\text { - incorporates "fun" } \\
\text { opportunities for learning } \\
\text { CC with students }\end{array}$ \\
\hline Political & $\begin{array}{l}\text { - CC is an "important" issue but } \\
\text { too big for her to do anything } \\
\text { about } \\
\text { - has disengaged students, } \\
\text { parents, and admin } \\
\text { - no pushback politically }\end{array}$ & $\begin{array}{l}\text { - hopes students make } \\
\text { good choices for the } \\
\text { environment in the future, } \\
\text { but avoids any discussion } \\
\text { of politics or civic issues }\end{array}$ \\
\hline
\end{tabular}




\section{Barbara Pender}

\section{SCIENCE LEARNER \& TEACHER ASPECTS}

Current position

- Middle school science teacher (6th grade)

- 13? plus years teaching (I've known to be in classroom since at least 2005)

Training

- Elementary education undergrad

- Participates in a lot of science professional development and benefits from a strong

community of like-minded science teachers and science experts

\section{$\underline{\text { Science Experiences }}$}

- Drawn to science and to science teaching about the world and how everything works when young child/teen

- Perpetual science learner, constantly pursuing new science learning experiences for her own development

- Happiest outdoors and in nature - deep love for the environment

Science Teaching Goals

- Goal is to pass on the passion for science and build scientific literacy in students

- Focuses lessons on doing science via guided inquiry to improve sci practices/skills, esp.

NGSS

$\underline{\text { School Background }}$

- Teaches in a rural, poorer area but with a lot of outside funding and support from external organizations

\section{Curricular Agency}

- Enjoys great curricular flexibility and instructional freedom with a very supportive administration/principal

\section{CLIMATE CHANGE ASPECTS}

Goals for Climate Change Instruction

- Encourages students to not just believe in climate change, but to understand the data/evidence for it

\section{Curricular Integration}

- Teaches climate change as part of weather/atmosphere unit and a unit on local environmental issues due to human impact NGSS indicator

- Has been integrating climate change into her teaching for many years

Motivation for Inclusion

- Stronger justification for inclusion due to NGSS adoption but has attempted to integrate across a local environmental issues unit 
Personal Connection

- Strongly motivated to care about climate issue due to personal values and caring about world for next generation's quality of life

$\underline{\text { Pushback? }}$

- Initially when intro climate 7-8 years ago, experienced community pushback but with a science oriented and supportive administration, she has continued to integrate climate change throughout her instruction without negative influence from others

- Alludes to some avoidance of 'climate change' term due to ideological pushback from parents - Feels more recently it is a "watershed moment" and students/community is ready to really hone in on climate change and its evidence without interference from larger political/denialist environment

$\underline{\text { Action/Education }}$

- Focuses climate instruction to relate to local community issues and to "lay groundwork" for future responsible, scientifically literate decision making in students and to highlight possible social action

\begin{tabular}{|c|c|c|c|}
\hline & Past & Present & Future \\
\hline Personal & $\begin{array}{l}\text { - extraordinary interest in } \\
\text { science and the } \\
\text { environment } \\
\text { - perpetual science } \\
\text { learner }\end{array}$ & $\begin{array}{l}\text { - share passion for nature } \\
\text { with students and for } \\
\text { learning about science }\end{array}$ & $\begin{array}{l}\text { - need to teach CC and } \\
\text { environmental issues to } \\
\text { protect our planet }\end{array}$ \\
\hline Profess. & $\begin{array}{l}\text { - enjoys science teaching } \\
\text { and learning experiences } \\
\text { extensively }\end{array}$ & $\begin{array}{l}\text { - build scientific literate } \\
\text { students } \\
\text { - great curricular } \\
\text { flexibility and teacher } \\
\text { agency }\end{array}$ & $\begin{array}{l}\text { - create opportunities to } \\
\text { build personal and local } \\
\text { geographic connections to } \\
\text { CC lessons (as a } \\
\text { motivating factor to } \\
\text { protect the planet) }\end{array}$ \\
\hline Political & $\begin{array}{l}\text { - previously dealt with } \\
\text { some political pushback } \\
\text { but had support from } \\
\text { administration to continue } \\
\text { to include CC in } \\
\text { instruction }\end{array}$ & $\begin{array}{l}\text { - focuses on evidence and } \\
\text { data of CC } \\
\text { - justification to teach } \\
\text { more so because NGSS } \\
\text { includes CC and human } \\
\text { impacts on the } \\
\text { environment }\end{array}$ & $\begin{array}{l}\text { - prepare students to be } \\
\text { environmentally } \\
\text { responsible future citizens } \\
\text { - lay groundwork for } \\
\text { future action }\end{array}$ \\
\hline
\end{tabular}




\section{Beverley Sanders}

\section{SCIENCE LEARNER \& TEACHER ASPECTS}

\section{Current Position}

- High school Chemistry teacher

- Teaches chemistry and a new integrated physics \& earth science course with climate change

- Veteran teacher and teacher leader for science department

- 11 years teaching

\section{Training}

- Has research experience in chemistry during undergraduate years

- Undergraduate major - chemistry educ (extensive chemistry content knowledge)

- Doesn't see herself as a particularly strong student but continually strives to improve her professional practice

\section{Science Experiences}

- Had a very powerful chemistry teacher as mentor in high school (Beverley later became HS chemistry teacher)

- Drawn to chemistry/science and to chemistry teaching when young child/teen

- Lives with family on farm with numerous animals, but love for animals has grown because of husband and daughter interest

\section{Science Teaching Goals}

- Enjoys the challenge of "hard sciences" like chemistry and wants students to share the fun/excitement for topic and believe that they can also be successful and find connections to the real world

- Teaches what she feels her students need to know utilizing student driven inquiry when possible, so they are scientifically literate, feel connected to, and love science

$\underline{\text { School Background }}$

- Teaches in a rural and politically conservative area

- Colleagues work together as a family to address curriculum changes and student/instructional needs via a supportive professional community

Curricular Agency

- Follows the mandated curriculum but is skeptical of its long-term durability

\section{CLIMATE CHANGE ASPECTS}

Goal for Climate Instruction

- Goal for climate instruction is to prepare students as future citizens who will deal with issue on a local, personal level

Curricular Incorporation

- Teaches climate change because of its inclusion in new NGSS-aligned, multidisciplinary science course that is mandated by county curriculum

- Mentions climate change only in passing in other chemistry courses taught 
Motivation for Inclusion

- It is part of the new county curriculum and is now included by all teachers in one course

Personal Connection

- Deals with climate skepticism within her own family and community members though does not feel that the political climate influenced her climate change instruction

Pushback?

- Anticipated a lot of negative pushback from students/parents/community regarding climate change but received none - instead they "respected the science" and colleagues and admin enthusiastically supported/participated in teaching climate change as well

Action vs. Education

- Attempts to avoid perception of arm-twisting via overt social action with students but instead wants inspire care and understanding the urgency of the issue via personally relevant local connections

\begin{tabular}{|c|c|c|c|}
\hline & Past & Present & Future \\
\hline Personal & - loved learning science & $\begin{array}{l}\text { - share the excitement of } \\
\text { doing science, esp. } \\
\text { chemistry } \\
\text { - current love of animals } \\
\text { with family farm }\end{array}$ & \\
\hline Profess. & $\begin{array}{l}\text { - great science teaching } \\
\text { and learning experiences } \\
\text { and mentors } \\
\text { - scientific research } \\
\text { experience in college }\end{array}$ & $\begin{array}{l}\text { - connect students to } \\
\text { science via inquiry } \\
\text { - "work family" } \\
\text { collaborates to create } \\
\text { strong integrated science } \\
\text { curriculum }\end{array}$ & $\begin{array}{l}\text { - develop scientifically } \\
\text { literate students } \\
\text { - teach new curriculum } \\
\text { with CC included because } \\
\text { it's now required }\end{array}$ \\
\hline Political & $\begin{array}{l}\text { - spouse and some } \\
\text { community friends are } \\
\text { skeptical of CC issue }\end{array}$ & $\begin{array}{l}\text { - anticipated a lot of } \\
\text { pushback but received } \\
\text { none } \\
\text { - instead students and } \\
\text { colleagues are on board } \\
\text { and respect the science } \\
\text { and evidence }\end{array}$ & $\begin{array}{l}\text { - prepare future citizens } \\
\text { to deal with this local } \\
\text { issue, but is very hesitant } \\
\text { to avoid the perception of } \\
\text { undue influence on } \\
\text { students }\end{array}$ \\
\hline
\end{tabular}




\section{Connie Stevens}

\section{SCIENCE LEARNER \& TEACHER ASPECTS}

Current Position

- Middle school science teacher (6th grade)

- Veteran teacher on School Leadership team

- 14 years teaching

- Teach in suburban area but very close to a very large city

Training

- Had a science research experience in undergraduate in field studies/bird populations

- Education undergrad major, specialty in science (Australia) - focus on environmental science and physics

- National Board Certified, extensive graduate and post graduate training

- Continually trying to improve personal pedagogy via mentorship and professional

development

$\underline{\text { Science Experiences }}$

- Enjoyed engaging, hands-on science lessons at early age even though it was a challenge and perceived as not for girls

- Had strong science role models as professors in college who connected science learning to real world

Science Teaching Goals

- To share the passion and engagement in science to see the connections to everyday things

- Utilize student centered cooperative approaches that highlight learning about life

- Cares to develop personal relationships with students to support them through struggles

$\underline{\text { School Background }}$

- New school that is more of neighborhood school, still partially affluent but higher SES need and diversity

- Experienced very supportive admin and encouraging principals to explore novel outdoor teaching experiences

Curricular Agency

- Follows a "good" mandated curriculum, but adapts its emphasis based on her interests, students' needs, and the quality of instruction she feels she can provide on various topics

\section{CLIMATE CHANGE ASPECTS}

Goals for Climate Instruction

- To present evidence focused information to allow students to draw their own conclusions without bias

- To understand the broad influences that humans have on the whole ecosystem, but that there are/can be solutions to these negative impacts 


\section{Curricular Incorporation}

- Infuses climate change connections throughout environmental science focused units even though it is not technically included in her curriculum

- Has been including climate change in her instruction for a long time

Motivation for Inclusion

- Climate change is a topic that develops naturally out of student questions/interests related to a variety of science topics in the curriculum

- Believes there has been an evolution of public concern for the topic which is now reflected in her mandated curriculum

\section{Personal Connection}

- Feels she has seen the impacts of climate change and is concerned about the lack of sustainability of human actions

Pushback?

- No pushback from parents/students because teaches it "in the lens of science" using evidence and data

- Reports positive feedback from parents who are impressed with students learning about complex real-world issues like climate change

Action vs Education

- Tries to incorporate suggestions for meaningful action at the school level, but is quite wary of advocating broader lifestyle changes

\begin{tabular}{|c|c|c|c|}
\hline & Past & Present & Future \\
\hline Personal & - loved hands on science & $\begin{array}{l}\text { - encourage girls } \\
\text { especially, to participate } \\
\text { in STEM }\end{array}$ & \\
\hline Profess. & $\begin{array}{l}\text { - great science teaching } \\
\text { and learning experiences }\end{array}$ & $\begin{array}{l}\text { - share passion for science } \\
\text { and to see connections to } \\
\text { their everyday lives } \\
\text { - supportive } \\
\text { administration to pursue } \\
\text { novel science experiences } \\
\text { for her students }\end{array}$ & $\begin{array}{l}\text { - build/capture student } \\
\text { interest in the } \\
\text { environment and CC } \\
\text { topics for instruction }\end{array}$ \\
\hline Political & $\begin{array}{l}\text { - has included CC for a } \\
\text { while because she thinks } \\
\text { it's important in spite of } \\
\text { its seemingly } \\
\text { controversial nature }\end{array}$ & $\begin{array}{l}\text { - mandated curriculum } \\
\text { offers a number of } \\
\text { connections to topics via } \\
\text { local issues } \\
\text { - focus on the evidence } \\
\text { for CC and has } \\
\text { experienced no pushback }\end{array}$ & $\begin{array}{l}\text { - evidence focused } \\
\text { approach to build critical } \\
\text { thinking skills to make } \\
\text { important decisions } \\
\text { - wary of pushing too } \\
\text { much on CC activism }\end{array}$ \\
\hline
\end{tabular}




\section{Emily Skand}

\section{SCIENCE LEARNER \& TEACHER ASPECTS}

\section{Current Position}

- Middle school science teacher (6th and 7th grade) at small private Christian school

- Previously taught in public middle school science and high school science classrooms

- 18 years teaching experience in total

Training

- Environmental Studies major and came to teaching after college (due to indecision of job aspirations)

- "Figured out" teaching and got certified after teaching in religious school and moving to public high school

- Focused on learning from her mistakes and seeking additional training/PD over the years

Science Experiences

- Deep experiences learning science outdoors via field trips and excursions with family

- Strong role model of father as informal science educator and mother was former science teacher

- Strong role model of high school biology teacher who was deeply passionate about science teaching (Emily later became HS bio/environmental science teacher)

- Feels she is not a "science person", but loves science content and science teaching

Science Teaching Goals

- To engage students in practices of science and to be adept at science communication/writing - Has high expectations of all students to do science, communicate effectively, and learn from mistakes

- Wants to share same passion and enthusiasm for science learning as she had/has

School Background

- Very small private Christian denomination school with an environmental science focus and a supportive administration that allows teachers great flexibility

Curricular Agency

- Has complete autonomy in curriculum decisions and topics to include/omit

\section{CLIMATE CHANGE ASPECTS}

Goals for Climate Instruction

- To address student questions and interest in this important issue and one with future implications for students' lives

- Understand human role in driving changes in global temperature and larger impacts and local effects, and then also examine what can be done to help

Curricular Incorporation

- Included specifically in the 6th grade curriculum but purposefully infuses with a biological perspective in 7 th grade curriculum

Feels that climate change can/should be infused across many science disciplines 
Motivation for Inclusion

- Felt that climate science was being politically silenced, and this created an impetus to teach students about climate change in light of the need for scientific literacy in future generations - Personally engaged in topic and students are deeply interested to learn more about important issue

\section{Personal Connection}

- Concerned for future generations (and young son) having to deal with the mess that is left behind

- Personally motivated by denialist political landscape and results of 2016 election and its implications and the newfound urgency of the climate change issue

Pushback?

- Feels it is currently a struggle to effectively teach climate change due to political landscape and perceived controversy by "powers that be"

- Some parental pushback when discussing economic as well as political aspects of climate change issue but admin and colleagues supported additional climate change instruction

Action vs Education

- Encouraged students to discuss meaningful action and pledge to reduce ecological footprints - Aims to teach the science behind the issue so students realize why they should be making lifestyle changes

\begin{tabular}{|l|l|l|l|}
\hline & Past & Present & Future \\
\hline Personal & $\begin{array}{l}\text { - lots of informal science } \\
\text { learning experiences }\end{array}$ & $\begin{array}{l}\text { - connect learning to } \\
\text { outdoors }\end{array}$ & $\begin{array}{l}\text { - concerned for the status } \\
\text { of the future environment } \\
\text { for her young son }\end{array}$ \\
\hline Profess. & $\begin{array}{l}\text { - numerous strong } \\
\text { examples of meaningful } \\
\text { science teaching and } \\
\text { learning experiences }\end{array}$ & $\begin{array}{l}\text { - engage students in } \\
\text { relevant and cool topics } \\
\text { that relate to curriculum }\end{array}$ & $\begin{array}{l}\text { - students are interested } \\
\text { and NEED to know about } \\
\text { CC }\end{array}$ \\
\hline Political & - previously unaware & $\begin{array}{l}\text { - strongly motivated by } \\
\text { current political } \\
\text { administration's actions }\end{array}$ & $\begin{array}{l}\text { - need for scientific } \\
\text { decision-making skills in } \\
\text { future citizens, especially } \\
\text { in light of the controversy } \\
\text { surrounding CC }\end{array}$ \\
\hline
\end{tabular}




\section{Fiona Henry}

\section{SCIENCE LEARNER \& TEACHER ASPECTS}

Current Position

- Middle school science teacher (6th and 7th grade)

- 5 years teaching

\section{Training}

- undergraduate - Elementary education (middle school science focus, life science orientation)

- worked as educator/naturalist

- quickly pursued master's degree and additional PD as a beginning teacher

\section{Science Experiences}

- Great model science teacher in 7th grade (Fiona later became 7th grade science teacher in same district she grew up in) who made learning science fun and brought outdoor learning

$\underline{\text { Science Teaching Goals }}$

- Passionate about teaching kids to learn/care about the environment and love science class

- Always looks for ways to connect lessons to outdoors and to bring class outside

School Background

- Rural school district, hometown environment

- Support principal/admin but science colleagues are lackluster

Curricular Agency

- Freedom to do interesting experiences (fish tanks, outdoor learning) but otherwise beholden to mandated curricular topics

\section{CLIMATE CHANGE ASPECTS}

Goals for Climate Instruction

- Better understand climate change as it becomes a popular national issue and one that affects their local natural environment

Curricular Incorporation

- Not really a part of her current curriculum, saves introduction to climate change for end of school year

- Limited infusion/connections made to other topics throughout year

Motivation for Inclusion

- Students are interested and feel connected to this issue personally and through other curricular connections

Personal Connection

- Cares deeply about nature, especially her local environment and is concerned about the negative impacts of climate change 
Pushback?

- None experienced, attributes this to youth of students and a lack of a developed opinion on the topic

Action vs Education

- Wants to build connections to everyday actions at school and how to bring those efforts home

\begin{tabular}{|l|l|l|l|}
\hline & Past & Present & Future \\
\hline Personal & $\begin{array}{l}\text { - lots of outdoor learning } \\
\text { experiences }\end{array}$ & $\begin{array}{l}\text { - connect students to their } \\
\text { natural environment }\end{array}$ & $\begin{array}{l}\text { - build students' valuation } \\
\text { of their environment to } \\
\text { protect it }\end{array}$ \\
\hline Profess. & $\begin{array}{l}\text { - great role model } \\
\text { teachers }\end{array}$ & $\begin{array}{l}\text { - want to share passion } \\
\text { and love for science } \\
\text { - beholden to a focused } \\
\text { curriculum for topics } \\
\text { testing }\end{array}$ & $\begin{array}{l}\text { - kids want to learn about } \\
\text { CC }\end{array}$ \\
\hline Political & $\begin{array}{l}\text {-no pushback } \\
\text {-no political influence } \\
\text { - wants to discuss every } \\
\text { day and small steps to } \\
\text { help }\end{array}$ & \\
\hline
\end{tabular}




\section{Fred Robbins}

\section{SCIENCE LEARNER \& TEACHER ASPECTS}

Current Position

- Middle school science teacher (8th grade)

- over 13 years teaching experience

Training

- Started in education during undergrad "by chance"

- Undergrad major - secondary science education, earth science track

- Earned masters and EdD degrees in educational technology and leadership

- Trained to take concept and develop most creative/clever/engaging way to teach the topic

Science Experiences

- Enjoyed the challenge of science and its complexity

- Innate interest in natural environmental patterns and technical problem solving/engineering

Science Teaching Goals

- Engage students in the practice of science and scientific thinking/problem solving, to experience science

- Get students to ask, and answer, their own scientific questions

$\underline{\text { School Background }}$

- Had great support and freedom to pursue novel teaching experiences in first school placement and had supportive admin up until recently

- Currently has district mandated curriculum that is stifling to his creativity and student driven teaching style and focuses on meeting standards for testing

\section{Curricular Agency}

- Previously had large amounts of curricular freedom to address standards creatively, but now is held strictly to teach mandated curriculum with high fidelity and feels exceptionally constrained and uncomfortable

\section{CLIMATE CHANGE ASPECTS}

Goals for Climate Instruction

- To understand that climate change is real and exacerbated by human activity

\section{Curricular Incorporation}

- Teaches within a weather and climate unit at end of year

- Laments inability to introduce/infuse topic earlier and throughout the year

Motivation for Inclusion

- Local geographic connections make it important for students to understand topic and its impacts as it relates to things/places that students care about 
Personal Connection

- Fascination with climatology dynamics/patterns

- Inspired by climate experts met via climate PD and their interesting research pathways

Pushback?

- Years ago felt some pushback but now feels that students are less influenced by opinions of others and are more driven by their own interest in the topic

- No negative feedback on including climate change, instead just

- Emotion laden nature of the topic helps to bring it to life

Action vs Education

- Leans more towards educating students about topic due to his own deep content knowledge on evidence for and impacts of climate change

- Feels this approach also reaches a wider audience for his middle school students

\begin{tabular}{|l|l|l|l|}
\hline & Past & Present & Future \\
\hline Personal & $\begin{array}{l}\text { - loves science and its } \\
\text { challenges/puzzles }\end{array}$ & $\begin{array}{l}\text { - prioritizes the practice } \\
\text { of science with students }\end{array}$ & \\
\hline Profess. & $\begin{array}{l}\text { - used to have great } \\
\text { curricular flexibility and } \\
\text { agency }\end{array}$ & $\begin{array}{l}\text { - gets students to enjoy } \\
\text { science inquiry and to } \\
\text { DO science } \\
\text { - now mandated to teach } \\
\text { a restrictive curriculum } \\
\text { (which is a big issue for } \\
\text { him!) }\end{array}$ & $\begin{array}{l}\text { - support students' } \\
\text { questions and curiosity } \\
\text { about science and CC } \\
\text { - focus on ways to } \\
\text { address student interest } \\
\text { in CC via content } \\
\text { curricular connections } \\
\text { where possible }\end{array}$ \\
\hline Political & & $\begin{array}{l}\text { - politics and media } \\
\text { environment brings out } \\
\text { emotions which enliven } \\
\text { CC education } \\
\text { - no negative pushback } \\
\text { about including CC in } \\
\text { teaching } \\
\text { - evidence based focus to } \\
\text { instruction }\end{array}$ & $\begin{array}{l}\text { - help students } \\
\text { understand various } \\
\text { perspectives to inform } \\
\text { scientific decisions as } \\
\text { they relate to their lives } \\
\text { (local geographic } \\
\text { connections mainly) }\end{array}$ \\
& & & \\
\hline
\end{tabular}




\section{Garrett Tresler}

\section{SCIENCE LEARNER \& TEACHER ASPECTS}

Current Position

- HS physics and aquatic science teacher (partially teaching out of expertise)

-3 years teaching

Training

- Undergraduate major - physics with education track

- Limited experience in environmental science, so sought PD opportunities

- Graduate degree in educational leadership

$\underline{\text { Science Experiences }}$

- Supportive family to engage with science but on fairly superficial level when young

- Enjoys the productive struggle and challenge of doing science and scientific problem solving

- Benefited from mentorship from a role model HS physics teacher to persist and work hard on difficult science challenges (Garrett later became a HS physics teacher)

\section{Science Teaching Goals}

- Problem-based or phenomenon-focused inquiry learning to build student motivation/interest - Strong empathy for students regardless of their interest in physics and wants to develop their scientific literacy for future citizenship

$\underline{\text { School Background }}$

- Low income, widespread difficult student behavior and limited student motivation

Curricular Agency

- Attempts to be strategic to teach required exam topics but also reflexive to students' needs and interests in physics

- Enjoys a lot of flexibility and agency to adapt and modify aquatic science (elective) curriculum

\section{CLIMATE CHANGE ASPECTS}

Goals for Climate Instruction

- Better understand the evidence for human caused climate change and the anticipated global, local, and personal impacts

- Especially focused on the physics related mechanistic happenings (photons, energy, reradiation, etc.)

Curricular Incorporation

- Felt inspired to introduce climate change connections into physics course as real-world topic in one unit

- Infuses climate change throughout numerous topics in Aquatic Science course as a driving phenomenon to understand environmental impacts

- Helping to write new county mandated curriculum that formalizes climate changes as a topic in the required freshman science course 
Motivation for Inclusion

- Climate change offers an exciting and meaningful motivation for studying various topics that build personal and real-world relevancy in learning about a cutting-edge important issue

Personal Connection

- Cares about the issue due to its local geographic relevance and anticipated impacts but not engaged at an advocacy/activism level

- Believes it is an important/hot topic for students to better understand for their future adult lives

- Personally felt he didn't know a lot about climate change so sought PD/content to share with students

Pushback?

- Anticipated problems with students but instead most students jumped right into learning topic and other students are habitually academically unengaged

- Anticipated problems with administration, instead had no issues but may just be flying under the radar

Action vs Education

- Focuses more on developing content knowledge about the topic

- Desires, but struggles, to showcase meaningful steps that students can take to help mitigate the issue and deepen student engagement in the topic

\begin{tabular}{|c|c|c|c|}
\hline & Past & Present & Future \\
\hline Personal & $\begin{array}{l}\text { - loves the challenge of } \\
\text { doing science }\end{array}$ & $\begin{array}{l}\text { - utilizes a problem } \\
\text { based teaching approach } \\
\text { where possible }\end{array}$ & \\
\hline Profess. & $\begin{array}{l}\text { - great role models of } \\
\text { science teachers }\end{array}$ & $\begin{array}{l}\text { - lots of flexibility and } \\
\text { agency to modify one } \\
\text { course to include local, } \\
\text { personal, geographic } \\
\text { connections to CC, but } \\
\text { little agency in other } \\
\text { (AP) course }\end{array}$ & $\begin{array}{l}\text { - integrate CC via various } \\
\text { topics throughout } \\
\text { curriculum because it's } \\
\text { important for students to } \\
\text { know about this topic and it } \\
\text { has meaningful connections } \\
\text { to required content }\end{array}$ \\
\hline Political & & $\begin{array}{l}\text { - no student, parent, or } \\
\text { admin pushback } \\
\text { - not engaged in } \\
\text { advocacy nor activism } \\
\text { on topic }\end{array}$ & $\begin{array}{l}\text { - important to know about } \\
\text { the topic for their future } \\
\text { lives, but no broad } \\
\text { connections/discussions of } \\
\text { civic issues }\end{array}$ \\
\hline
\end{tabular}


Karmen Losa

\section{SCIENCE LEARNER \& TEACHER ASPECTS}

Current Position

- High school biology teacher (biology, biotech, environmental science courses)

- 10 years teaching at this high school (additional experience in support staff/Montessori teaching)

Training

- Undergrad major, natural sciences (AA) and Biology/marine science (BA)

- Pursued Montessori teaching position/certification after college within young son

- Taught ESOL for several years while attempting to land HS biology position

$\underline{\text { Science Experiences }}$

- Always outside as a child, playing in nature and on a farm

- Fascinated with natural world, animal life

Science Teaching Goals

- Strives for experiential (outdoor) or hands-on learning in all lessons

- Incorporates a lot of unique authentic learning experiences inside classroom (raising trout, horseshoe crabs) and outdoors (numerous field trips, canoeing, tree planting)

- Wants students to see how biology intertwines with their lives

$\underline{\text { School Background }}$

- Teaches in a Science/Technology/Industry school (similar to a vo-tech school)

Curricular Agency

- Follows the curriculum but feels empowered to add things when she desires/feels it is necessary

- Pursues a lot of environmental certifications for her school outside of the classroom (Green

School, Ocean Guardians, etc.) via grant writing

\section{CLIMATE CHANGE ASPECTS}

Goals for Climate Instruction

- to understand human role in changing the environment more broadly, and the climate/global temperatures more specifically

Curricular Incorporation

- NGSS and state policy efforts towards improving environmental literacy have initiated changes in curriculum that incorporate climate change under the topic of human impact on the environment

- Her instruction aims to highlight connections to climate change through various life science topics, but not a separate unit on climate change 
Motivation for Inclusion

- Cares deeply for the natural world and wants students to understand how humans in general are negatively impacting the ecosystem and ways in which they can help mitigate these impacts

\section{Personal Connection}

- Feels more confident in her understanding but still seeks to learn more about issue and through PD has experience increased confidence from a shared community of likeminded climate educators

- Concerned for future generations and negative impacts of climate change but doesn't feel particularly active in her advocacy/climate action

Pushback?

- Alludes to some efforts to not name the issue as climate change but instead to present only evidence and preclude any discussion of politics (but hasn't experienced any negative situations)

\section{Action vs Education}

- Feels students should learn how to be responsible citizens and environmental stewards but tends to focus on content knowledge development in class and add extra activities to demonstrate climate action

\begin{tabular}{|c|c|c|c|}
\hline & Past & Present & Future \\
\hline Personal & $\begin{array}{l}\text { - fascination with } \\
\text { outdoors and natural } \\
\text { world }\end{array}$ & $\begin{array}{l}\text { - wants students to } \\
\text { understand how biology } \\
\text { intertwines with their } \\
\text { lives }\end{array}$ & $\begin{array}{l}\text { - develop personal } \\
\text { connections to nature so } \\
\text { they care to protect and to } \\
\text { be environmental } \\
\text { stewards }\end{array}$ \\
\hline Profess. & & $\begin{array}{l}\text { - limited agency to } \\
\text { incorporate lots of } \\
\text { outdoor learning } \\
\text { experiences but often } \\
\text { finds a way through } \\
\text { afterschool opportunities } \\
\text { - integrate CC across the } \\
\text { curriculum in multiple } \\
\text { ways }\end{array}$ & \\
\hline Political & $\begin{array}{l}\text { - wants to learn more } \\
\text { about the CC evidence }\end{array}$ & $\begin{array}{l}\text { - avoids naming issue as } \\
\text { CC but no actual } \\
\text { pushback experienced for } \\
\text { teaching CC } \\
\text { - avoids the discussion of } \\
\text { politics }\end{array}$ & $\begin{array}{l}\text { - learn how to be } \\
\text { responsible citizens }\end{array}$ \\
\hline
\end{tabular}




\section{Krista Czapkas}

\section{SCIENCE LEARNER \& TEACHER ASPECTS}

\section{Current Position}

- HS science teacher (certified in biology but teaching environmental science and earth sciences)

- 2 years teaching experience

\section{Training}

- Undergraduate degree in Biology Education

- Confident in pursuing additional training, reflection, self-study, and other modifications to her professional practice in efforts to be more effective and engaging, and more knowledgeable in other science content areas

- Extensive training and experience in scientific research during undergraduate years

Science Experiences

- Enjoys being in nature, especially as young child with family on outdoor vacations and later during college courses and research experiences

- Had a strong role model HS biology teacher who inspired a deeper love of life sciences (Krista later got certified to become a HS biology teacher)

Science Teaching Goals

- Engages students in their own long-term research experiences that relate to the curricular topics to build deeper personal connections, engagement, and motivation

- Aims to deepen student appreciation and trust in science and the scientific process

- Showcase real world connections to science topics being taught

School Background

- Very rural and politically conservative surrounding area with high SES needs

- School is experiencing a lot of turnover with principals and administration, sending mixed messages of support

- District science supervisor is very supportive in terms of resources, outside training, and instruction innovations

Curricular Agency

- Teaches in non-state tested subjects so reports more freedom with instructional experimentation and can slow down to adjust to student needs and interests and important current events

\section{CLIMATE CHANGE ASPECTS}

\section{Goals for Climate Instruction}

- Help students understand the importance of climate change as a personal issue for them, especially because of their geographic location and outdoor interests/hobbies

- Introduce ways to reduce outcomes and mitigate impacts of climate change that students can do 
Curricular Incorporation

- Infuses climate change as examples for a variety of environmental science topics

- Curriculum includes section on human impact on environment, which she interprets as climate change

Motivation for Inclusion

- Felt supported by a community of climate educators and very engaged science supervisor to address an important, but politicized science issue in her classroom

\section{Personal Connection}

- Exceptionally strong belief in the scientific evidence and justification for anthropogenic climate change due to her deep connection to scientific research efforts

- Believes that all people/students, regardless of political identification, should prioritize environmental protection

Pushback?

- Experienced some negative pushback from students as first year teacher but since has not had similar types of expressed denialism or pushback, attributes this mostly to developing confidence in own teaching abilities, deeper personal content knowledge, and in growing importance of teaching climate change

Action vs Education

- Wants to achieve buy in via deepening content knowledge on topic, but to engage in action as the priority

- Tries to introduce small steps students can take now, with intention to lay groundwork of understanding and caring that bigger actions will be taken when students are adults - Attempts to empower students to understand the power of their own voice and vote when they are older to take more drastic action down the road

\begin{tabular}{|l|l|l|l|}
\hline & Past & Present & \multicolumn{1}{|c|}{ Future } \\
\hline Personal & - great love of nature & $\begin{array}{l}\text { - motivate to see personal } \\
\text { place within nature }\end{array}$ & $\begin{array}{l}\text { - work to protect } \\
\text { environment especially } \\
\text { because of their } \\
\text { geographic location and } \\
\text { their outdoor related } \\
\text { hobbies and interests }\end{array}$ \\
\hline Profess. & $\begin{array}{l}\text { - great role models of } \\
\text { science teachers } \\
\text { - past experience in } \\
\text { scientific research }\end{array}$ & $\begin{array}{l}\text { - very supportive } \\
\text { administration to DO } \\
\text { science and incorporate } \\
\text { CC as a meaningful and } \\
\text { relevant topic }\end{array}$ & $\begin{array}{l}\text { - evidence for CC and } \\
\text { content knowledge is } \\
\text { important to provide a } \\
\text { base or justification }\end{array}$ \\
\hline Political & $\begin{array}{l}\text { - very conservative area } \\
\text { geographically }\end{array}$ & $\begin{array}{l}\text { - strongly bases } \\
\text { instruction on evidence, } \\
\text { acknowledge the politics } \\
\text { but prioritize } \\
\text { environmental protection }\end{array}$ & $\begin{array}{l}\text { - work to include small } \\
\text { steps to lay groundwork } \\
\text { for bigger actions related } \\
\text { to CC as adults } \\
\text {-realize the power of } \\
\text { their own voice and vote }\end{array}$ \\
\hline
\end{tabular}




\section{Mary Jenkins}

\section{SCIENCE LEARNER \& TEACHER ASPECTS}

Current Position

- High school Biology teacher (bio, AP bio, and a half course elective on sustainability currently)

- Less than 5 years teaching experience

Training

- Clinical psychologist for 19 years before teaching

- Extensive research experiences with animal behavior and people in college and after

$\underline{\text { Science Experiences }}$

- Sustainability is a key personal issue

- Lifelong interest in nature and fascination with being outdoors

Science Teaching Goals

- Build students' critical thinking skills, scientific literacy, and trust in science via constructivist, real world learning

- Develop ecological literacy where students understand the natural world and their

relationship to it and to others

$\underline{\text { School Background }}$

- Has bounced around in a lot of difficult teaching situations/schools

- School is working to slowly adopt NGSS aligned curriculum that has a sustainability focus

- Located in a strongly conservative political and rural area

Curricular Agency

- Feels stuck with the assigned curricula for biology and AP biology but can reorder/reorganize the broader narrative of the courses to meet her goals

- Very important for her to feel that she is good at teaching and puts extraordinary effort to revise and modify her lessons as needed/desired

\section{CLIMATE CHANGE ASPECTS}

Goals for Climate Instruction

- Prioritize environmental/sustainability issues like climate change so that students develop an understanding of their ecological connection to the world

\section{Curricular Incorporation}

- Sustainability elective - taught through lens of climate change throughout but had difficulty finding enough appropriately engaging lessons

- Biology curriculum does not include climate change, but AP biology was able to highlight connections to climate change effects 
Motivation for Inclusion

- Very passionate about issues of environmental degradation and climate change and educating others

- Doesn't want to just talk about the issues, but lives like it truly matters and to share that with her students as it is the challenge of their generation

\section{Personal Connection}

- Emotionally impacted by political climate and perceived hopelessness of situation

- Active in political resistance movements (Women's March etc.) to make climate change a more important topic

- Immensely important, core issue for her and has made extreme changes to her own lifestyle to mitigate her impacts (became vegetarian, carbon neutral)

Pushback?

- Perceives a scientifically hostile, anti-intellectual culture currently

- Feels that many others around her (students, colleagues) hold similar values but instead have a different view on what is real (political ideologies)

- Has had a few students question the issue but this changed over the course of the year

- But no actual negative feedback from parents or administration

Action vs Education

- Priority is to educate and the natural next step students want to do is to take action

- But she avoids pushing/suggesting advocacy efforts to her students and instead just shares what she does herself to take action

\begin{tabular}{|l|l|l|l|}
\hline & Past & Present & Future \\
\hline Personal & $\begin{array}{l}\text { - lifelong interest in } \\
\text { nature and fascination } \\
\text { with being outdoors }\end{array}$ & $\begin{array}{l}\text { - sustainability is a key } \\
\text { personal issue } \\
\text { - incredible personal } \\
\text { advocate for CC }\end{array}$ & $\begin{array}{l}\text { - share passion about } \\
\text { preventing environmental } \\
\text { degradation }\end{array}$ \\
\hline Profess. & $\begin{array}{l}\text { - very challenging } \\
\text { teaching placements in } \\
\text { the past } \\
\text { - extensive scientific } \\
\text { research experiences }\end{array}$ & $\begin{array}{l}\text { - limited agency with } \\
\text { curriculum in some } \\
\text { courses, but also has great } \\
\text { freedom with sustainability } \\
\text { course }\end{array}$ & $\begin{array}{l}\text { - students need to } \\
\text { understand CC content } \\
\text { knowledge because it is } \\
\text { the defining issue of their } \\
\text { generation }\end{array}$ \\
\hline Political & $\begin{array}{l}\text { - perceives local area as } \\
\text { environtifically hostile }\end{array}$ & $\begin{array}{l}\text { - no pushback from admin } \\
\text { on CC teaching } \\
\text { - political background of } \\
\text { area brings some } \\
\text { questioning/pushback from } \\
\text { students }\end{array}$ & $\begin{array}{l}\text { - priority to educate on } \\
\text { the content, but next } \\
\text { natural step is for } \\
\text { students to take action }\end{array}$ \\
\hline
\end{tabular}




\section{Melissa Eckerds}

\section{SCIENCE LEARNER \& TEACHER ASPECTS}

Current Position

- Middle school science teacher (7th grade)

- 17 years teaching experience

Training

- Started college in agricultural school but didn't like animal production side of things (animal science research?)

- Undergrad major -science education; graduate degree - science curriculum/instruction

$\underline{\text { Science Experiences }}$

- Loved animals growing up and initially wanted to be a veterinarian

- Had negative experience with chemistry teacher which still impacts her today

Science Teaching Goals

- Wants to integrate the full spectrum of science, technology, creativity, problem solving (i.e. Odyssey of the Mind)

- Empathetic to her students, especially their adolescent awkwardness, being a nerd, and wanting to fit in socially

- To get students to love science and realize anyone can be/is a scientist

$\underline{\text { School Background }}$

- Mostly rural, low income school district

- Currently has supportive principal (who is leaving) who encourages creativity and supports NGSS alignment, but school is unable to offer quality curriculum or appropriate resources when needed

Curricular Agency

- Perceives gaps in her assigned curriculum and works to add in where she feels is necessary/important

- "Respects" her job, the mandated curriculum, and values staying aligned with colleagues' instruction so is hesitant to make drastic changes, admits to not having confidence to go out on her own

- Feels frustrated by long/slow NGSS adoption period and is beholden to high stakes testing results across standards

\section{CLIMATE CHANGE ASPECTS}

Goals for Climate Instruction

- Wants students to know about the issue, and to hopeful that there are actions that can be taken to "feel successful"

Curricular Incorporation

- Was able to use climate change as the focal issue for a new enrichment course but is unsure how to incorporate deeply in the future if enrichment course goes away 
Motivation for Inclusion

- Feels educating others about climate change issue and actions needed to mitigate is her personal contribution to combating/taking action on the issue

- Doesn't think she will continue to teach it as in depth unless admin/district/standards

determine it is a priority to incorporate in the future

Personal Connection

- Personally felt she didn't know a lot about climate change so sought PD/content to share with students

- Feels mad that this important issue is not included in curriculum (though this may be lip service as she admits having other possible connections to curriculum) and is sending a "passive aggressive" message to students that they should question the topics they are told to study (...?)

Pushback?

- Doesn't feel district/colleagues support climate change instruction, so not overt pushback but she feels constrained in attempting to find connections to climate change in current curriculum - Some students were apathetic about issue as they don't see how climate change is impacting them currently and feel it isn't a meaningful issue

- Experienced no actual pushback from admin, parents, nor colleagues

Action vs Education

- Heavily leans towards educating about the phenomenon and letting students make own decisions about taking supportive action, or not, in the future and wants to avoid the appearance of undue influence from her or political overtures

\begin{tabular}{|l|l|l|l|}
\hline & Past & Present & Future \\
\hline Personal & - great love of animals & $\begin{array}{l}\text { - believes that everyone is a } \\
\text { scientist }\end{array}$ & \\
\hline Profess. & $\begin{array}{l}\text { - some negative } \\
\text { science teaching and } \\
\text { learning experiences }\end{array}$ & $\begin{array}{l}\text { - include creative ways of } \\
\text { developing science skills } \\
\text { - push to encourage all } \\
\text { students to love science and } \\
\text { have a positive learning } \\
\text { mindset } \\
\text { - limited agency and } \\
\text { confidence to make broad } \\
\text { curricular changes }\end{array}$ & $\begin{array}{l}\text { - teach CC content } \\
\text { knowledge because it is } \\
\text { important for students to } \\
\text { know } \\
\text { - unsure how to fully } \\
\text { integrate CC in courses }\end{array}$ \\
\hline Political & - mostly rural area & $\begin{array}{l}\text { - no pushback experienced } \\
\text { - seeks to avoid appearance } \\
\text { of undue influence or } \\
\text { political overtures in } \\
\text { instruction }\end{array}$ & $\begin{array}{l}\text { - empower students to } \\
\text { understand and make } \\
\text { their own decisions about } \\
\text { taking action }\end{array}$ \\
\hline
\end{tabular}




\section{Tara Thorpe}

\section{SCIENCE LEARNER \& TEACHER ASPECTS}

\section{Current Position}

- Middle school gifted education teacher (4th-6th grade)

- Formerly middle school science teacher (6th grade) teaching out of content area

- 4 years teaching experience

Training

- Undergraduate major - MATH education

- Graduate major - Gifted and Talented education

- Sought numerous PD and help from family related to science to fill in gaps from alternative content area (math educ training previously)

\section{Science Experiences}

- Lots of fun, hands-on experiences learning/participating/doing science

- Innately drawn to teaching, and then science teaching even though at first pursued math but really didn't enjoy it

- Several strong science teacher role models that exhibited personalized student learning experiences and student-centered approaches

Science Teaching Goals

- Wants to share her love of science knowledge and practices with her students

- Pushes student driven learning and follow own interests to ask/answer scientific questions, especially with personally relevant, real-world connections

\section{$\underline{\text { School Background }}$}

- Charter school has very supportive with mentorship, resources, and encouragement

- Current supervisor is supportive but hands-off with gifted education program

Curricular Agency

- Felt strongly about moving away from scripted curriculum to better reflect student needs and interests

- Currently has great freedom on curricular topics and modifications as a gifted teacher, though collaborates with two other gifted teacher colleagues

\section{CLIMATE CHANGE ASPECTS}

Goals for Climate Instruction

- To develop scientifically literate future citizens who understand climate change and what needs to be done to be proactive about it

- Avoids sharing personal opinion (but her passion is clearly evident) and attempts to allow students to examine data and make their own deductions about the topic

Curricular Incorporation

- Uses human impact on the environment as yearlong curricular theme and how students/people can be better advocates for the environment 
Motivation for Inclusion

- Climate change is an issue that is "amazing, very terrifying, and enlightening" that students need to know about to be scientifically literate

- Topic is very relevant, cross-disciplinary, engaging, and important to better understand

\section{Personal Connection}

- Personally felt she didn't know a lot about climate change as her family was/is more politically conservative so sought $\mathrm{PD} /$ content knowledge on her own to share with students - After traveling to Arctic region, feels very passionate about the topic now and wants to share that passion with her students

\section{Pushback?}

- Surprised to have experienced no pushback even though she perceives current school/geographic location to be more politically conservative

\section{Action vs Education}

- Prioritizes taking action after students learn about the issue and come to their own conclusions about why it is meaningful and relevant to them and how it is an important topic to bring out to the broader local community

\begin{tabular}{|l|l|l|l|}
\hline Personal & Past & Present & Future \\
& $\begin{array}{l}\text { - lots of family } \\
\text { encouragement to do and } \\
\text { love science/nature }\end{array}$ & $\begin{array}{l}\text { - share love of science } \\
\text { knowledge and practices } \\
\text { with students }\end{array}$ & $\begin{array}{l}\text { - be passionate and care } \\
\text { about nature }\end{array}$ \\
\hline Profess. & $\begin{array}{l}\text { - math background but } \\
\text { love of science learning } \\
\text { - several great science } \\
\text { teaching and learning role } \\
\text { models }\end{array}$ & $\begin{array}{l}\text { - extraordinary agency } \\
\text { and supportive } \\
\text { administration to modify } \\
\text { to meet needs of students } \\
\text { - get students to DO } \\
\text { science }\end{array}$ & $\begin{array}{l}\text { - establish meaningful } \\
\text { and relevant interests in } \\
\text { CC }\end{array}$ \\
\hline Political & $\begin{array}{l}\text { - family politically } \\
\text { conservation and pushed } \\
\text { her to do own CC } \\
\text { research into the evidence }\end{array}$ & $\begin{array}{l}\text { - use human impact on } \\
\text { environment as yearlong } \\
\text { theme } \\
\text { - no pushback to CC } \\
\text { teaching } \\
\text { - acknowledge politics of } \\
\text { local issues but focus on } \\
\text { need for environmental } \\
\text { protection }\end{array}$ & $\begin{array}{l}\text { - prioritize taking action } \\
\text { and coming to own } \\
\text { conclusions about CC } \\
\text { - build literacy on CC to } \\
\text { be ready for future } \\
\text { demands }\end{array}$ \\
& \multicolumn{2}{|l}{}
\end{tabular}


Veronica Acker

\section{SCIENCE LEARNER \& TEACHER ASPECTS}

Current Position

- Middle school science teacher (8th grade) focus on earth and space science background

- 16 years teaching experience

Training

- Undergraduate major - Oceanography

- Worked at aquarium as animal trainer and as informal educator

- Graduate degree to get teaching certification

$\underline{\text { Science Experiences }}$

- An outdoorsy person

- Had strong science teacher role model in HS environmental science teacher (she later became a MS earth/environmental science teacher)

Science Teaching Goals

- Tries to bring in her varied personal science experiences into the classroom to make it more relevant and connected to students' lives

- Wants students to "embrace their innermost [science] nerd" and better understand the world around them and their role in it

- Aims to push students to become "better people"

$\underline{\text { School Background }}$

- Students have a lot of socio/emotional needs and she feels motherly/empathetic towards them

- Rural area that is politically conservative and lower SES

Curricular Agency

- Feels that she does what admin asks of her, but freely admits to modifying to best meet her students' needs and interests

- Feels pressured to get through mandated county curriculum to meet testing demands

\section{CLIMATE CHANGE ASPECTS}

Goals for Climate Instruction

- To better understand the things that are affecting the phenomenon of climate change

- To become critical thinkers and to develop their own conclusions about the importance of the issue (as opposed to family/political influences)

Curricular Incorporation

- Tries to bring in climate change connections through varied curricular aspects

Motivation for Inclusion

- Wants students to understand their position in the world and connections to nature and to be a better person for the environment 
Personal Connection

- Very environmentally minded, nature/animal oriented and is concerned about the impact of climate change broadly, but has some lingering questions about the depth of human influence on changing temperatures

- Additional PD/training on climate change has made her more knowledgeable and much more confident in her instruction on the issue, especially as a community of climate educators

Pushback?

- One instance of pushback from parents but in following years, no negative experiences - Attributes lack of negative pushback to her being a part of the local community and parents/admin knowing and trusting her as a part of the community

Action vs Education

- Includes projects to build civic awareness and some allusion towards personal action/responsibility but more towards critical consumption of information and resources

\begin{tabular}{|c|c|c|c|}
\hline & Past & Present & Future \\
\hline Personal & $\begin{array}{l}\text { - outdoorsy person } \\
\text { - lots of various science } \\
\text { experiences and interests }\end{array}$ & $\begin{array}{l}\text { - students to embrace } \\
\text { their innermost nerd }\end{array}$ & $\begin{array}{l}\text { - love nature and } \\
\text { understand their } \\
\text { connection }\end{array}$ \\
\hline Profess. & $\begin{array}{l}\text { - great science teacher } \\
\text { role model }\end{array}$ & $\begin{array}{l}\text { - supportive } \\
\text { administration with a fair } \\
\text { amount of agency but lots } \\
\text { of testing demands }\end{array}$ & $\begin{array}{l}\text { - focus on curriculum } \\
\text { connections to CC across } \\
\text { numerous topics }\end{array}$ \\
\hline Political & $\begin{array}{l}\text { - some personal questions } \\
\text { regarding the depth of } \\
\text { human influence on CC } \\
\text { - politically conservative } \\
\text { local area }\end{array}$ & $\begin{array}{l}\text { - limited to no pushback } \\
\text { on CC teaching } \\
\text { - attributes this to } \\
\text { community trust in her to } \\
\text { avoid bias and focus on } \\
\text { civic awareness (not } \\
\text { action) }\end{array}$ & $\begin{array}{l}\text { - be a better person for } \\
\text { the environment } \\
\text { - become critical thinkers } \\
\text { to develop own } \\
\text { conclusions about the } \\
\text { importance of the CC } \\
\text { issue }\end{array}$ \\
\hline
\end{tabular}


Wanda Katz

\section{SCIENCE LEARNER \& TEACHER ASPECTS}

Current Position

- Middle school science teacher (6th grade)

- 14 years teaching experience

Training

- Extensive environmental science research during and after college years

- Got into science journalism and then digital science learning via Discovery Educ and PBS

- Master's degree in educational technology to get certification

\section{Science Experiences}

- Drawn to the outdoors and learning how the world works through outdoor explorations

- Self cultivated science interest with not many memorable formal science learning experiences

- Drifted to science teaching via inquiry and problem-based learning experiences

$\underline{\text { Science Teaching Goals }}$

- Connect urban students to the outdoors and learning in the environment around them

- Get students to confidently participate in the practice of science themselves via inquiry

(ask/answer questions and to justify their thinking via scientific explanations/argumentation)

School Background

- Urban, high needs school that frequently loses budget funding for instructional and support positions (i.e. science/social studies, librarians, mental health counselors, computers and tech resources) while supporting students with extensive personal challenges

Curricular Agency

- School does not "micromanage" her with a scripted curriculum and she designs her own curriculum to be flexible to meet her students' changing needs

- Instruction she develops is strongly aligned with NGSS and she inserts topics wherever she feels is appropriate (i.e. climate change)

\section{CLIMATE CHANGE ASPECTS}

Goals for Climate Instruction

- Better understand how this scientific phenomenon and how it relates to their everyday lives - Apply critical scientific thinking to this topic and related resources/materials from other sources

Curricular Incorporation

- Carves out space within each curricular unit to integrate climate change

Motivation for Inclusion

- Believes climate change is a prevailing issue for this generation with direct impacts on students' lives and offers opportunities for action as well 
Personal Connection

- An elder in our society, she feels responsibility for building environmental stewardship in her students

- Concerned that there is not a greater societal push towards including climate change in public education

Pushback?

- Believes her middle school students often have more pressing personal issues than to be concerned about climate change

- Believes that district suggested curriculum purposefully had left climate change for political reasons

- However has experienced no negative pushback when teaching climate change and partially attributes this to her local political environment (urban and politically liberal leaning)

Action vs Education

- Feels it is irresponsible to teach climate change without also address positive opportunities for student action related to the issue (i.e. home energy audits, local tree planting)

\begin{tabular}{|l|l|l|l|}
\hline & Past & Present & Future \\
\hline Personal & $\begin{array}{l}\text { - deep love of outdoors } \\
\text { - self cultivated interest } \\
\text { in science }\end{array}$ & $\begin{array}{l}\text { - see nature even in urban } \\
\text { areas }\end{array}$ & $\begin{array}{l}\text { - need to build } \\
\text { environmental } \\
\text { stewardship }\end{array}$ \\
\hline Profess. & $\begin{array}{l}\text { - lots of challenges in } \\
\text { urban school setting }\end{array}$ & $\begin{array}{l}\text { - get students comfortable } \\
\text { learning outside } \\
\text { - lots of agency to } \\
\text { integrate CC across } \\
\text { curricular units }\end{array}$ & $\begin{array}{l}\text { - critical for students to } \\
\text { understand content } \\
\text { knowledge behind CC and } \\
\text { how it relates to their lives }\end{array}$ \\
\hline Political & $\begin{array}{l}\text { - focus on evidence and } \\
\text { CER approach }\end{array}$ & $\begin{array}{l}\text { - concerned there is not } \\
\text { more widespread urgency } \\
\text { related to the CC issue } \\
\text { - no negative pushback } \\
\text { but dealing with lots of } \\
\text { other challenges }\end{array}$ & $\begin{array}{l}\text { - feels it would be } \\
\text { irresponsible to teach CC } \\
\text { without also addressing } \\
\text { opportunities for action by } \\
\text { the students }\end{array}$ \\
\hline
\end{tabular}




\section{Appendix D}

\section{CODING MANUAL - DESCRIPTIVE CODES}

\begin{tabular}{|c|c|c|c|c|}
\hline $\begin{array}{l}\text { Code - } \\
\text { Subcode }\end{array}$ & $\begin{array}{l}\text { Total } \\
\# \\
\text { Code }\end{array}$ & $\begin{array}{l}\text { Code Count } \\
\text { among } \\
\text { Participants }\end{array}$ & Code Description & Sample Code \\
\hline DTT & 84 & 15 & $\begin{array}{l}\text { "Drawn to Teaching" } \\
\text { Personal ambitions to } \\
\text { become a teacher } \\
\text { throughout childhood, } \\
\text { adolescence, and/or } \\
\text { early adulthood }\end{array}$ & $\begin{array}{l}\text { (see below for specific } \\
\text { examples amongst subcodes) }\end{array}$ \\
\hline $\begin{array}{l}\text { DTT - Positive } \\
\text { Role Models }\end{array}$ & 21 & 10 & $\begin{array}{l}\text { Past experiences with } \\
\text { positive science teaching } \\
\text { and learning role models }\end{array}$ & $\begin{array}{l}\text { When in high school, I just had } \\
\text { an absolutely amazing chemistry } \\
\text { teacher. She's the reason that I'm } \\
\text { a chemistry teacher. She actually } \\
\text { a couple of years ago won } \\
\text { National Teacher of the Year of } \\
\text { all, yeah, but she was [rural] } \\
\text { County Teacher of the Year, } \\
\text { State Teacher of the Year and } \\
\text { then National Teacher of the } \\
\text { Year. But she was just } \\
\text { phenomenal, like she just was so } \\
\text { excited and so into each of her } \\
\text { students and made it so real life } \\
\text { and relatable. And it was just } \\
\text { awesome. - Beverley Sanders }\end{array}$ \\
\hline $\begin{array}{l}\text { DTT - } \\
\text { Negative Role } \\
\text { Models }\end{array}$ & 5 & 5 & $\begin{array}{l}\text { Past experiences with } \\
\text { negative science } \\
\text { teaching and learning } \\
\text { role models }\end{array}$ & $\begin{array}{l}\text { And I guess the downfall in my } \\
\text { science career was my chemistry } \\
\text { teacher. And I avoided physics } \\
\text { and I avoided chemistry and to } \\
\text { this day I regret that very much. I } \\
\text { could blame it on the teacher } \\
\text { whatever, but I think the } \\
\text { approach of teaching just kind of } \\
\text { scared me and turned me off. - } \\
\text { Melissa Eckerds }\end{array}$ \\
\hline
\end{tabular}




\begin{tabular}{|c|c|c|c|c|}
\hline $\begin{array}{l}\text { DTT - Long } \\
\text { time aspirations }\end{array}$ & 5 & 5 & $\begin{array}{l}\text { Early memories of a } \\
\text { desire to become a } \\
\text { teacher from childhood }\end{array}$ & $\begin{array}{l}\text { So that's when I decided to just } \\
\text { stick with education because it } \\
\text { came naturally to me. Like } \\
\text { growing up I went to school with } \\
\text { my mom because my mom was a } \\
\text { teacher at my school and I would } \\
\text { write her objectives and warm- } \\
\text { ups on the board for her and I } \\
\text { would help her grade her papers. } \\
\text { So, I mean it was just very } \\
\text { natural for me to go to that route } \\
\text { in that direction. - Fiona Henry }\end{array}$ \\
\hline $\begin{array}{l}\text { DTT - 'Meant } \\
\text { to be' a teacher }\end{array}$ & 11 & 7 & $\begin{array}{l}\text { Beliefs that one was } \\
\text { meant to become a } \\
\text { teacher }\end{array}$ & $\begin{array}{l}\text { When I turned up at university } \\
\text { for my first year of teacher } \\
\text { training after being a fairly } \\
\text { apathetic high school student, I } \\
\text { really found a love for education } \\
\text { for the first time. I mean school } \\
\text { is okay. Through high school, I } \\
\text { was certainly not a big fan of it. } \\
\text { But when I got to university and } \\
\text { I started to study with these } \\
\text { professors who weren't just high } \\
\text { school teachers who were really } \\
\text { passionate about their field. And } \\
\text { when I started to learn the } \\
\text { intricacies of education that I had } \\
\text { never considered when I chose it } \\
\text { as a career, I realized that I was } \\
\text { really enjoying the learning. And } \\
\text { that I was really glad that this is } \\
\text { where I ended up because I was } \\
\text { really enjoying it and I started to } \\
\text { really excel. And then when I got } \\
\text { into the classroom and started } \\
\text { working with students, then I } \\
\text { knew this is the right place, this } \\
\text { is the right place for me. - } \\
\text { Connie Stevens }\end{array}$ \\
\hline $\begin{array}{l}\text { DTT - } \\
\text { Educational } \\
\text { goals for } \\
\text { inquiry }\end{array}$ & 4 & 2 & $\begin{array}{l}\text { Professional goals } \\
\text { related to a desire to be a } \\
\text { 'good' teacher with an } \\
\text { inquiry focused, } \\
\text { constructivist practice }\end{array}$ & $\begin{array}{l}\text { I'm an inquiry teacher. So, I will } \\
\text { pose a challenge for the kid, talk } \\
\text { with them about how we're } \\
\text { going to go about figuring that } \\
\text { out, were the activities and } \\
\text { things and then I will guide } \\
\text { conversation. So, I'm sort of the } \\
\text { facilitator of inquiry learning is }\end{array}$ \\
\hline
\end{tabular}




\begin{tabular}{|c|c|c|c|c|}
\hline & & & & $\begin{array}{l}\text { how I would describe my style. - } \\
\text { Wanda Katz }\end{array}$ \\
\hline $\begin{array}{l}\text { DTT - } \\
\text { Educational } \\
\text { goal for student } \\
\text { driven } \\
\text { pedagogy }\end{array}$ & 9 & 7 & $\begin{array}{l}\text { Professional goals } \\
\text { related to a desire to be a } \\
\text { teacher with a student } \\
\text { driven pedagogy }\end{array}$ & $\begin{array}{l}\text { Yeah, because I just think all } \\
\text { through my life I've been held to } \\
\text { a high standard. And when you } \\
\text { push kids, when you have those } \\
\text { high expectations and when you } \\
\text { say I know you can do better and } \\
\text { let's raise the bar, let's explore } \\
\text { this topic more in depth, I feel } \\
\text { like kids respond to that. - Emily } \\
\text { Skand }\end{array}$ \\
\hline $\begin{array}{l}\text { DTT - } \\
\text { Educational } \\
\text { goals focused } \\
\text { on solving } \\
\text { teaching } \\
\text { problems }\end{array}$ & 6 & 3 & $\begin{array}{l}\text { Professional goals } \\
\text { towards solving } \\
\text { teaching-related } \\
\text { problems }\end{array}$ & $\begin{array}{l}\text { So sometimes they just grab right } \\
\text { on, and that's it. It's so simple. } \\
\text { Sometimes I don't even have to } \\
\text { do what I planned because they } \\
\text { get it so fast, and it's like oh } \\
\text { well, why waste time? If you } \\
\text { guys already all know exactly } \\
\text { what's going to happen, let's } \\
\text { move on to something else. But } \\
\text { if they have no idea regardless, } \\
\text { well, you've got to do something } \\
\text { else. You've got to figure out } \\
\text { another thing to add in there. - } \\
\text { Fred Robbins }\end{array}$ \\
\hline $\begin{array}{l}\text { DTT - Strong } \\
\text { relationships } \\
\text { with students }\end{array}$ & 14 & 8 & $\begin{array}{l}\text { Evidence of strong } \\
\text { personal relationships } \\
\text { with students and deep } \\
\text { empathy to the students' } \\
\text { situations }\end{array}$ & $\begin{array}{l}\text { In this, I try to understand that } \\
\text { every kid is different, and I try to } \\
\text { encourage creativity and you } \\
\text { could answer questions, not } \\
\text { always in the same way } \\
\text { depending on how the kids learn. } \\
\text { And it is really important to be } \\
\text { sensitive of that. And I just } \\
\text { remember how I felt in middle } \\
\text { school like kind of but it's hard } \\
\text { now because I am freaking } 40 \text {. } \\
\text { But I kind of remember that } \\
\text { awkwardness of middle school } \\
\text { and you just kind of want to be } \\
\text { accepted and wanted, you just } \\
\text { want to be wanted. And kept the } \\
\text { balance that is understanding of } \\
\text { age and the developmental brain } \\
\text { structure of an adolescent with } \\
\text { content knowledge and I just } \\
\text { kind of keep that in my mind }\end{array}$ \\
\hline
\end{tabular}




\begin{tabular}{|c|c|c|c|c|}
\hline & & & & $\begin{array}{l}\text { when I'm teaching. - Melissa } \\
\text { Eckerds }\end{array}$ \\
\hline $\begin{array}{l}\text { DTT - Personal } \\
\text { relationships }\end{array}$ & 3 & 3 & $\begin{array}{l}\text { Appeal to students as a } \\
\text { 'real' or normal person, } \\
\text { i.e. not just their teacher }\end{array}$ & $\begin{array}{l}\text { Yeah, I think just bringing all my } \\
\text { experiences into the classroom } \\
\text { makes me a better teacher, to } \\
\text { connect, to make it a little bit } \\
\text { more real. It's not two separate } \\
\text { entities type of thing. - Veronica } \\
\text { Acker }\end{array}$ \\
\hline Ed_Ch & 78 & 14 & $\begin{array}{l}\text { Educational challenges } \\
\text { experienced }\end{array}$ & \\
\hline $\begin{array}{l}\text { Ed_Ch - } \\
\text { Forced } \\
\text { Educational } \\
\text { Policy and/or } \\
\text { Standards }\end{array}$ & 29 & 11 & $\begin{array}{l}\text { Educational policy and } \\
\text { standards that are strictly } \\
\text { mandated by school } \\
\text { administrators }\end{array}$ & $\begin{array}{l}\text { So, there are certain like nitpicky } \\
\text { kinds of things where districts } \\
\text { want our kids to be able to recite } \\
\text { whatever their learning question } \\
\text { is for the day. I don't necessarily } \\
\text { embrace that, but I don't drop it } \\
\text { to the wayside. I just don't } \\
\text { prioritize it that way. - Fred } \\
\text { Robbins }\end{array}$ \\
\hline $\begin{array}{l}\text { Ed_Ch- } \\
\text { General } \\
\text { Teaching } \\
\text { Challenges }\end{array}$ & 9 & 4 & $\begin{array}{l}\text { General, non-specific } \\
\text { challenges experienced } \\
\text { by teachers }\end{array}$ & $\begin{array}{l}\text { And I think that's one thing that } \\
\text { is the double-edged sword about } \\
\text { teaching because you can't just } \\
\text { go to your job and do it. You } \\
\text { personally are always going to be } \\
\text { challenged to find new ways of } \\
\text { going about doing things. Just } \\
\text { when you think you have it all } \\
\text { covered..., you know? - Emily } \\
\text { Skand }\end{array}$ \\
\hline $\begin{array}{l}\text { Ed_Ch-Lack } \\
\text { of Resources }\end{array}$ & 5 & 3 & $\begin{array}{l}\text { Lack of resources, i.e. } \\
\text { paper, technology, } \\
\text { curriculum }\end{array}$ & $\begin{array}{l}\text { I'm trying to incorporate more } \\
\text { technology. But the only } \\
\text { problem is with my classroom I } \\
\text { only have two computers } \\
\text { whereas other teachers have an } \\
\text { entire laptop cart. Like all the } \\
\text { math teachers have their own } \\
\text { class set of computers because } \\
\text { they do a program that is entirely } \\
\text { online for the math curriculum in } \\
\text { our county. So, I'm trying to } \\
\text { battle for the computers to even } \\
\text { just get the resources for it. - } \\
\text { Fiona Henry }\end{array}$ \\
\hline
\end{tabular}




\begin{tabular}{|c|c|c|c|c|}
\hline $\begin{array}{l}\text { Ed_Ch- } \\
\text { Personal } \\
\text { Challenges }\end{array}$ & 4 & 4 & & $\begin{array}{l}\text { I wish I was more confident, and } \\
\text { again that goes back to the way } \\
\text { you carry yourself I wish. } \\
\text { Sometimes I wish I had more } \\
\text { charisma because in my head, it } \\
\text { sounds really good and in } \\
\text { delivery sometimes I struggle } \\
\text { with projecting myself in a } \\
\text { confident manner that causes } \\
\text { most people to be like hey } \\
\text { what's up. - Melissa Eckerds }\end{array}$ \\
\hline $\begin{array}{l}\text { Ed_Ch - } \\
\text { Student } \\
\text { Problems }\end{array}$ & 13 & 7 & $\begin{array}{l}\text { Challenges of student } \\
\text { misbehavior and } \\
\text { resulting challenges to } \\
\text { instruction }\end{array}$ & $\begin{array}{l}\text { At [city] High, we've never been } \\
\text { able to do that. Well I did once, } \\
\text { and one scale got stolen. So, } \\
\text { that's always an issue. - Mary } \\
\text { Jenkins }\end{array}$ \\
\hline $\begin{array}{l}\text { Ed_Ch - } \\
\text { Testing } \\
\text { Pressures }\end{array}$ & 18 & 9 & $\begin{array}{l}\text { Pressures to get students } \\
\text { to succeed on high stakes } \\
\text { tests and on teachers to } \\
\text { administer numerous } \\
\text { testing efforts }\end{array}$ & $\begin{array}{l}\text { But because of that, this year we } \\
\text { had to use the curriculum they } \\
\text { provided us. And we had to go } \\
\text { straight from the curriculum and } \\
\text { push through as much as we } \\
\text { could, as fast as we could, to try } \\
\text { and get the stuff covered on the } \\
\text { tests. - Amanda Kerry }\end{array}$ \\
\hline Agent & 58 & 14 & $\begin{array}{l}\text { Instances of exhibiting } \\
\text { agency, or challenges to } \\
\text { demonstrating agency }\end{array}$ & \\
\hline $\begin{array}{l}\text { Agent - Student } \\
\text { Led Learning }\end{array}$ & 6 & 4 & $\begin{array}{l}\text { Agency to allow student } \\
\text { led learning via their } \\
\text { interests }\end{array}$ & $\begin{array}{l}\text { The students are huge of } \\
\text { influence on curriculum because } \\
\text { we do have that freedom and the } \\
\text { flexibility, so we really try to get } \\
\text { the kids to have a say in what } \\
\text { they're doing because in their } \\
\text { normal classes they're often left } \\
\text { to their own devices because } \\
\text { they already know the content } \\
\text { and curriculum in their normal } \\
\text { classes they get kind of bored. - } \\
\text { Tara Thorpe }\end{array}$ \\
\hline $\begin{array}{l}\text { Agent - Meet } \\
\text { Needs }\end{array}$ & 9 & 8 & $\begin{array}{l}\text { Agency to modify } \\
\text { instruction to best meet } \\
\text { students' needs }\end{array}$ & $\begin{array}{l}\text { I still try to ultimately do what } \\
\text { they are asking of me, but I } \\
\text { know my students, and I know } \\
\text { what they can handle, what they } \\
\text { want to know, what they don't } \\
\text { want to know, and I think it's }\end{array}$ \\
\hline
\end{tabular}




\begin{tabular}{|c|c|c|c|c|}
\hline & & & & $\begin{array}{l}\text { more important that I know my } \\
\text { students, so I adapt my } \\
\text { classroom to them. - Veronica } \\
\text { Acker }\end{array}$ \\
\hline $\begin{array}{l}\text { Agent - Strong } \\
\text { Pedagogy }\end{array}$ & 21 & 10 & $\begin{array}{l}\text { Agency to teach students } \\
\text { 'good stuff' via strong } \\
\text { pedagogy }\end{array}$ & $\begin{array}{l}\text { So, then we would do something } \\
\text { in the schoolyard, either the rain } \\
\text { garden or eradicate phragmites } \\
\text { or whatever needed to be done. } \\
\text { Yeah, having the freedom and } \\
\text { the luxury and the support to do } \\
\text { that kind of thing is really } \\
\text { amazing. - Barbara Pender }\end{array}$ \\
\hline $\begin{array}{l}\text { Agent - } \\
\text { General }\end{array}$ & 15 & 10 & $\begin{array}{l}\text { General teacher agency - } \\
\text { non-specific examples }\end{array}$ & $\begin{array}{l}\text { I mean also, because I'm not } \\
\text { teaching a tested subject, so I can } \\
\text { get into these things without fear } \\
\text { of them failing some big tests } \\
\text { and me losing my job or } \\
\text { something crazy. - Krista } \\
\text { Czapkas }\end{array}$ \\
\hline Agent - Lack & 7 & 3 & $\begin{array}{l}\text { Lack of teacher agency } \\
\text { due to external/internal } \\
\text { forces }\end{array}$ & $\begin{array}{l}\text { I am trying to work through [the } \\
\text { challenge of the curriculum], but } \\
\text { it's a struggle because it's } \\
\text { stifling. That's a good word. I } \\
\text { feel somewhat stifled, and that } \\
\text { not where I want to have become } \\
\text { as an educator. - Fred Robbins }\end{array}$ \\
\hline Build & 85 & 15 & $\begin{array}{l}\text { Build/develop student } \\
\text { interest in science }\end{array}$ & \\
\hline $\begin{array}{l}\text { Build - Science } \\
\text { Literacy }\end{array}$ & 9 & 6 & $\begin{array}{l}\text { Desire to build science } \\
\text { literacy in students }\end{array}$ & $\begin{array}{l}\text { I mean it affects us and one of } \\
\text { my goals is to not only build the } \\
\text { next generation of innovators, } \\
\text { scientists, and technicians and try } \\
\text { to pass that passion on. Because } \\
\text { kids, they know if you're } \\
\text { passionate about something. But } \\
\text { also, to build some scientific } \\
\text { literacy in our communities so } \\
\text { that people make better decisions } \\
\text { about things that affect all of us. } \\
\text { It doesn't get any more real than } \\
\text { that. - Barbara Pender }\end{array}$ \\
\hline $\begin{array}{l}\text { Build - } \\
\text { Curiosity }\end{array}$ & 12 & 5 & $\begin{array}{l}\text { Encourage questions and } \\
\text { curiosity from students }\end{array}$ & $\begin{array}{l}\text { My goals for my kids is for them } \\
\text { to love science. Whether that } \\
\text { comes across in how I deal with } \\
\text { them or what I bring to the table }\end{array}$ \\
\hline
\end{tabular}




\begin{tabular}{|c|c|c|c|c|}
\hline & & & & $\begin{array}{l}\text { or what they're already bringing } \\
\text { to the table, that's what I want. I } \\
\text { want them to love my class, and } \\
\text { I want them to love my class } \\
\text { both because science is really } \\
\text { cool when you start asking } \\
\text { questions and because I want my } \\
\text { class to be that place. I want my } \\
\text { class to be full of questions all } \\
\text { the time. I always have my kids } \\
\text { sign my lab coat, but that } \\
\text { tradition didn't start until about } \\
13 \text { years ago and I had a kid } \\
\text { actually write once on my lab } \\
\text { coat, he said - or it maybe was a } \\
\text { girl. It said, "Ask him any } \\
\text { question you can think of, he will } \\
\text { always answer it honestly" and } \\
\text { that's it, that's the crux. I want } \\
\text { them to be able to ask any } \\
\text { question they want in that } \\
\text { classroom. And then be able to } \\
\text { explore it. - Fred Robbins }\end{array}$ \\
\hline $\begin{array}{l}\text { Build - } \\
\text { Connections }\end{array}$ & 25 & 14 & $\begin{array}{l}\text { Highlight real-world } \\
\text { connections to science } \\
\text { instruction }\end{array}$ & $\begin{array}{l}\text { Well, I think that, what I } \\
\text { remember, besides the fact that I } \\
\text { feel like bringing stuff to the } \\
\text { classroom so that I know that I } \\
\text { would like to see things that way } \\
\text { and understand it better if it's put } \\
\text { in front of me. You know like I } \\
\text { raise trout in the classroom, I } \\
\text { raise horseshoe crabs and it's } \\
\text { easier to understand how this is } \\
\text { the saltwater environment versus } \\
\text { the fresh water because it right } \\
\text { there. So, how my learning about } \\
\text { the horseshoe crabs has help me } \\
\text { to teach a little bit about certain } \\
\text { environment. And I think that it } \\
\text { is also important and what I } \\
\text { found because I just started } \\
\text { doing it, was that it peaks their } \\
\text { interest. Because, for instance } \\
\text { like the horseshoe crab if } \\
\text { students have ever been to the } \\
\text { beach and they've seen even just } \\
\text { the shell, they're always asking }\end{array}$ \\
\hline
\end{tabular}




\begin{tabular}{|c|c|c|c|c|}
\hline & & & & $\begin{array}{l}\text { about the crabs and are like eww, } \\
\text { what's that? This way they are } \\
\text { learning that it's nothing to be } \\
\text { afraid of. - Karmen Losa }\end{array}$ \\
\hline $\begin{array}{l}\text { Build - } \\
\text { Engaging } \\
\text { Experiences }\end{array}$ & 39 & 14 & $\begin{array}{l}\text { Offer engaging } \\
\text { experiences, esp. } \\
\text { outdoors }\end{array}$ & $\begin{array}{l}\text { My students, the sixth graders } \\
\text { who are } 11 \text { and } 12 \text { years old. My } \\
\text { real driving passion is that I do } \\
\text { not want them to lose an } \\
\text { enthusiasm for learning. } \\
\text { Sometimes along the way, } \\
\text { especially in high school, it's } \\
\text { easy for kids to develop apathy } \\
\text { about school and about learning. } \\
\text { I know I was there when I was a } \\
\text { high school kid. So, all that } \\
\text { eagerness and enthusiasm that } \\
\text { they have as elementary school } \\
\text { kids, I want that to persist for as } \\
\text { long as possible. So, in terms of } \\
\text { their science education and what } \\
\text { happens when they come to my } \\
\text { classroom is I want them to be } \\
\text { engaged, to be excited about } \\
\text { learning. I want them to be } \\
\text { walking through the door every } \\
\text { day saying "Hey, what's going to } \\
\text { happen today? What are we } \\
\text { going to learn today? What are } \\
\text { we doing today?" And I want } \\
\text { them to walk out talking about } \\
\text { science. And you know, the days } \\
\text { that that happens, then I know } \\
\text { that it's been a really good day } \\
\text { regardless of what they score on } \\
\text { the multiple-choice science tests } \\
\text { the county says that they have to } \\
\text { take. I think it's that inquiring } \\
\text { mind and that eagerness to learn } \\
\text { is what I really want to see from } \\
\text { my students. - Connie Stevens }\end{array}$ \\
\hline Do_Sci & 63 & 15 & $\begin{array}{l}\text { Excitement to do } \\
\text { science with others }\end{array}$ & \\
\hline $\begin{array}{l}\text { Do_Sci- } \\
\text { Inquiry }\end{array}$ & 61 & 15 & $\begin{array}{l}\text { Belief in the value of } \\
\text { authentic inquiry via } \\
\text { science participation }\end{array}$ & $\begin{array}{l}\text { Seeking evidence based on } \\
\text { observations and other vetted } \\
\text { research is what scientists do and } \\
\text { I'm always trying to model to the }\end{array}$ \\
\hline
\end{tabular}




\begin{tabular}{|c|c|c|c|c|}
\hline & & & & $\begin{array}{l}\text { best of my ability, the way } \\
\text { science is done in real world, in } \\
\text { my classroom, but at a level at } \\
\text { which the kids could be } \\
\text { successful doing it. And trying to } \\
\text { stretch that. - Barbara Pender }\end{array}$ \\
\hline $\begin{array}{l}\text { Do_Sci- } \\
\text { Negative } \\
\text { Experiences }\end{array}$ & 2 & 2 & $\begin{array}{l}\text { Past negative } \\
\text { experiences doing } \\
\text { science }\end{array}$ & $\begin{array}{l}\text { Read the textbook, answer the } \\
\text { question. Read the textbook, } \\
\text { answer the questions. And in the } \\
\text { biology textbook that I'd had the } \\
\text { year before was - no, actually it } \\
\text { was two before that, the biology } \\
\text { textbook was incredibly heavy. } \\
\text { Huge thing and I remember } \\
\text { lugging it the two miles home } \\
\text { every day just to read the chapter } \\
\text { and answer the questions. - } \\
\text { Connie Stevens }\end{array}$ \\
\hline DPI & 99 & 15 & $\begin{array}{l}\text { Deep personal interest } \\
\text { in science }\end{array}$ & \\
\hline DPI - Nature & 79 & 14 & Love of nature & $\begin{array}{l}\text { I feel like I'm a different kind of } \\
\text { science teacher because a lot of } \\
\text { science teachers, well I think } \\
\text { most science teachers are big in } \\
\text { the fields of math and science. } \\
\text { Growing up I was not the best at } \\
\text { math, I actually didn't really like } \\
\text { math but as far as science when } \\
\text { it comes to memorizing plants, } \\
\text { memorizing climate, memorizing } \\
\text { weather patterns, memorizing } \\
\text { like different types of animals, } \\
\text { and the environmental portion of } \\
\text { it that's what I really enjoy and } \\
\text { that's what I really find my } \\
\text { passion towards. - Fiona Henry }\end{array}$ \\
\hline DPI-Science & 20 & 6 & Passion for science & $\begin{array}{l}\text { I would say my middle school } \\
\text { science fair, it was pretty } \\
\text { memorable having to do one of } \\
\text { the classic plant experiments, } \\
\text { "which plant will grow better in } \\
\text { freshwater or saltwater?". And } \\
\text { looking back, I mean it was an } \\
\text { easy project, but I remember it, } \\
\text { just really diving into all the } \\
\text { control variables and reading up }\end{array}$ \\
\hline
\end{tabular}




\begin{tabular}{|c|c|c|c|c|}
\hline & & & & $\begin{array}{l}\text { online and I remember being } \\
\text { fascinated seeing some of my } \\
\text { own results and then that was } \\
\text { like sixth grade. I remember one } \\
\text { I really was fascinated with was } \\
\text { oil spills and trying to come up } \\
\text { with the best way to clean up an } \\
\text { oil spill and like mixing all sorts } \\
\text { of cleaners to try and degrease } \\
\text { the oil. I was just fascinated with } \\
\text { like what could you come up } \\
\text { with to solve a problem, and } \\
\text { being frustrated with the fact } \\
\text { there wasn't like an answer out } \\
\text { there, you start seeing and } \\
\text { hoping for like a recipe that - } \\
\text { just mix two parts of this } \\
\text { detergent and one-part baking } \\
\text { soda. And it wasn't, and so you } \\
\text { had to just figure it out. And } \\
\text { while it was frustrating, it was } \\
\text { really fascinating too. It kind of } \\
\text { caught my attention. And then I'd } \\
\text { say in high school that spawned } \\
\text { into being really interested in } \\
\text { science and finding out I had a } \\
\text { gift in figuring stuff out and } \\
\text { problem-solving. - Garrett } \\
\text { Tresler }\end{array}$ \\
\hline Display & 38 & 15 & $\begin{array}{l}\text { Outwardly displaying } \\
\text { oneself as a 'science } \\
\text { person' through words, } \\
\text { actions, appearance, } \\
\text { etc. }\end{array}$ & \\
\hline $\begin{array}{l}\text { Display - } \\
\text { Science Person }\end{array}$ & 35 & 14 & $\begin{array}{l}\text { Demonstrating 'I am a } \\
\text { science person' }\end{array}$ & $\begin{array}{l}\text { And I mean I wear a lab coat } \\
80 \% \text { of the time not because I } \\
\text { necessarily have to, but because } \\
\text { A, I can get away with it, and B, } \\
\text { really it sparks the interest of the } \\
\text { kids. They're like, you know, } \\
\text { he's wearing a lab coat. And the } \\
\text { reason why I put it on to begin } \\
\text { with was because I found it in a } \\
\text { drawer that I was cleaning out in } \\
\text { my new classroom that I thought, } \\
\text { oh, let me check this out, it was }\end{array}$ \\
\hline
\end{tabular}




\begin{tabular}{|c|c|c|c|c|}
\hline & & & & $\begin{array}{l}\text { my size, and so I went, okay, } \\
\text { there's a reason why this thing is } \\
\text { my size. I have to wear it. And } \\
\text { then it stuck. The kids wouldn't } \\
\text { let me take it off. They're like, } \\
\text { no you got to have your lab coat } \\
\text { on. It's who you are. And since } \\
\text { then, I just, you know, I think } \\
\text { science just by itself is a little bit } \\
\text { more exciting because it can be, } \\
\text { and I embrace that as well. And I } \\
\text { sort of wear it, I flaunt it, you } \\
\text { know, why not? Science is fun. It } \\
\text { can be fun. You can do neat } \\
\text { things with science, so why not? } \\
\text { - Fred Robbins }\end{array}$ \\
\hline $\begin{array}{l}\text { Display - } \\
\text { Not/Conflicted }\end{array}$ & 3 & 3 & $\begin{array}{l}\text { Conflicted displays or } \\
\text { believing one is not a } \\
\text { science person }\end{array}$ & $\begin{array}{l}\text { So, I mean I didn't dislike } \\
\text { science. It was I just didn't have } \\
\text { any real strong affinity towards } \\
\text { it, I mean I hated science fair } \\
\text { projects. - Amanda Kerry }\end{array}$ \\
\hline Learn & 56 & 12 & $\begin{array}{l}\text { Motivation to learn } \\
\text { more about science } \\
\text { and/or teaching }\end{array}$ & \\
\hline Learn - PD & 20 & 9 & $\begin{array}{l}\text { Participation in science } \\
\text { PD and/or courses }\end{array}$ & $\begin{array}{l}\text { Really positive work experiences } \\
\text { along the years. I've really } \\
\text { taught with some outstanding } \\
\text { teachers, great mentors. And I've } \\
\text { also been fortunate to have lots } \\
\text { of great opportunities for quality } \\
\text { professional development. So, } \\
\text { when you go off and do } \\
\text { professional development } \\
\text { activities that actually expand } \\
\text { your thinking and expand your } \\
\text { mind and you come back, with } \\
\text { new things to bring to the } \\
\text { classroom. I've been really } \\
\text { fortunate to have lots of those } \\
\text { opportunities. And I think that } \\
\text { really helps to add to my } \\
\text { teaching. - Connie Stevens }\end{array}$ \\
\hline $\begin{array}{l}\text { Learn - } \\
\text { Personally }\end{array}$ & 20 & 8 & $\begin{array}{l}\text { Personal endeavor to } \\
\text { learn more science on } \\
\text { own usually }\end{array}$ & $\begin{array}{l}\text { The words that reverberate in my } \\
\text { head are the more I learn, the } \\
\text { more I know there is to learn. I } \\
\text { mean that's the cool thing about }\end{array}$ \\
\hline
\end{tabular}




\begin{tabular}{|c|c|c|c|c|}
\hline & & & & $\begin{array}{l}\text { science. It's not static, it's } \\
\text { amazing. There's always } \\
\text { something out there and it's } \\
\text { relevant and it's authentic too. - } \\
\text { Barbara Pender }\end{array}$ \\
\hline $\begin{array}{l}\text { Learn - } \\
\text { Pedagogy }\end{array}$ & 16 & 8 & $\begin{array}{l}\text { Want to improve own } \\
\text { pedagogical practice }\end{array}$ & $\begin{array}{l}\text { I mean there was a lot of trial } \\
\text { and error, there's no question } \\
\text { about that. Without having that } \\
\text { pedagogy, I feel like I was able } \\
\text { to kind of choose to do } \\
\text { something and go with it and } \\
\text { then figure out whether it worked } \\
\text { or not. Even without the } \\
\text { pedagogy, I have always } \\
\text { prescribed to the concept that if } \\
\text { you teach something, you can't } \\
\text { just keep teaching it the same } \\
\text { way. You have to reflect upon it } \\
\text { and make the changes. And so, } \\
\text { in that respect, I felt like I was } \\
\text { learning from my mistakes and } \\
\text { tweaking what went well. I feel } \\
\text { like I've kind of done that all } \\
\text { through my teaching career. - } \\
\text { Emily Skand }\end{array}$ \\
\hline Research & 18 & 8 & $\begin{array}{l}\text { Participated in } \\
\text { scientific research }\end{array}$ & $\begin{array}{l}\text { So, this year I made them do } \\
\text { semester long experiment } \\
\text { where we put out cover boards } \\
\text { and we're going out once a } \\
\text { week to see what kind of } \\
\text { critters were living under } \\
\text { there, counting them, trying to } \\
\text { identify them to the species } \\
\text { level and doing a lab report. } \\
\text { I'm trying to get them into } \\
\text { research experiences like I had } \\
\text { but obviously, not as rigorous } \\
\text { because they're high school } \\
\text { kids. - Krista Czapkas }\end{array}$ \\
\hline Activ & 63 & 15 & $\begin{array}{l}\text { Activism or advocacy } \\
\text { on climate change issue }\end{array}$ & \\
\hline $\begin{array}{l}\text { Activ- } \\
\text { Community }\end{array}$ & 9 & 6 & $\begin{array}{l}\text { Action into the } \\
\text { community }\end{array}$ & $\begin{array}{l}\text { That way they can see right in } \\
\text { their neighborhood something } \\
\text { they could do, and talking about }\end{array}$ \\
\hline
\end{tabular}




\begin{tabular}{|c|c|c|c|c|}
\hline & & & & $\begin{array}{l}\text { the shade it's provided, and } \\
\text { talking about urban heat island } \\
\text { effect, and talking about air } \\
\text { conditioning and using energy. } \\
\text { All those little threads that go out } \\
\text { of this spider web of } \\
\text { connections. Something as } \\
\text { simple as tree planting affects } \\
\text { multiple things that in turn affect } \\
\text { climate change. - Wanda Katz }\end{array}$ \\
\hline $\begin{array}{l}\text { Activ - } \\
\text { Students Now }\end{array}$ & 8 & 5 & $\begin{array}{l}\text { Action now and with } \\
\text { students }\end{array}$ & $\begin{array}{l}\text { I would say out of everything } \\
\text { that I've taught this year this has } \\
\text { been the topic that they've } \\
\text { grabbed onto the most because } \\
\text { they feel that they can do } \\
\text { something about it and working } \\
\text { with gifted kids a lot of them } \\
\text { really want to do something and } \\
\text { help the world in some way like } \\
\text { they feel it is personal justice to } \\
\text { fix and solve problems and this } \\
\text { ties in with that greatly. - Tara } \\
\text { Thorpe }\end{array}$ \\
\hline Activ - Avoid & 3 & 3 & $\begin{array}{l}\text { Avoid pushing student } \\
\text { activism }\end{array}$ & $\begin{array}{l}\text { I guess I see myself more as the } \\
\text { teaching and educating part. But } \\
\text { in the hopes that it would lead to } \\
\text { inspiring action. I don't think I } \\
\text { ever want to be a teacher } \\
\text { twisting a kid's arm to make an } \\
\text { action. One of the things we } \\
\text { discussed in our group at school } \\
\text { was whether we wanted to have } \\
\text { them do a final project where } \\
\text { they wrote a letter to a political } \\
\text { person of some kind. I kind of } \\
\text { shy away from that a little bit, } \\
\text { just because I don't feel like } \\
\text { that's my job. I mean, some of } \\
\text { them are very, very intense about } \\
\text { the issues and they feel like they } \\
\text { need to call for action. I still feel } \\
\text { like they're still kids. I guess } \\
\text { having them write it is one thing, } \\
\text { having them send it is another, } \\
\text { too. I don't know. I guess I worry } \\
\text { about and I almost feel like that } \\
\text { is, and I know it's not because it's }\end{array}$ \\
\hline
\end{tabular}




\begin{tabular}{|c|c|c|c|c|}
\hline & & & & $\begin{array}{l}\text { science-based, but I feel like } \\
\text { that's almost asserting your } \\
\text { religion. You know what I } \\
\text { mean? It's little too pushy for me, } \\
\text { personally. - Beverley Sanders }\end{array}$ \\
\hline $\begin{array}{l}\text { Activ - } \\
\text { Example }\end{array}$ & 8 & 3 & Lead by example & $\begin{array}{l}\text { Another thing that I want to } \\
\text { change, which kind of goes into } \\
\text { the action portion is I'd like to } \\
\text { lead a little bit more by example. } \\
\text { Yeah, I'm still starting out, I'm a } \\
\text { second year teacher, I just moved } \\
\text { down here two years ago, but } \\
\text { eventually when I buy a house, I } \\
\text { would like it to be more energy } \\
\text { efficient. I would like to use } \\
\text { some kind of renewable, I'd like } \\
\text { to buy a more efficient vehicle. I } \\
\text { still drive a pretty efficient one, } \\
\text { but maybe one that is electric. I'd } \\
\text { like to lead more by example to } \\
\text { kind of help with that action } \\
\text { piece, too. - Krista Czapkas }\end{array}$ \\
\hline $\begin{array}{l}\text { Activ - Non- } \\
\text { committal }\end{array}$ & 2 & 2 & $\begin{array}{l}\text { Non-committal action } \\
\text { personally }\end{array}$ & $\begin{array}{l}\text { We certainly talk about reducing } \\
\text { energy, how we can reduce our } \\
\text { CO2 emissions, and when push } \\
\text { comes to shove I really probably } \\
\text { don't put as much stake in the } \\
\text { gain as I would say that I want } \\
\text { to. I think it's important to me. I } \\
\text { think it is important particularly } \\
\text { for where I live in [midAtlantic } \\
\text { state], we're really going to see } \\
\text { the effects of climate change if } \\
\text { the models hold true. But I think } \\
\text { on the same tune I've got to be } \\
\text { honest and say, "Yeah, it's } \\
\text { important but probably not as } \\
\text { important as I hope it to be." I'm } \\
\text { not looking to bike to work. I } \\
\text { guess I could bike to the grocery } \\
\text { store or carpool but that's way } \\
\text { more inconvenient than it is to } \\
\text { do that. - Garrett Tresler }\end{array}$ \\
\hline
\end{tabular}




\begin{tabular}{|c|c|c|c|c|}
\hline $\begin{array}{l}\text { Activ - Small } \\
\text { Steps }\end{array}$ & 17 & 10 & $\begin{array}{l}\text { Start now with small } \\
\text { steps }\end{array}$ & $\begin{array}{l}\text { So, I mean that will mean we } \\
\text { didn't get to some of it, but then } \\
\text { I'd to get to my last unit in } \\
\text { environmental which was, } \\
\text { population growth and waste and } \\
\text { how it impacts the world and that } \\
\text { is a really good one to leave the } \\
\text { kids with. And they were really } \\
\text { into it because we're talking } \\
\text { about solutions that they could } \\
\text { actually do really easily like } \\
\text { composting or recycling, things } \\
\text { like that. And that's a good way } \\
\text { to end the year because they're } \\
\text { not worried as much about, not } \\
\text { worry that's not the right word, } \\
\text { but they're not in fear of, like oh } \\
\text { man, fossil fuels, how am I going } \\
\text { to get away from that? I'm just } \\
\text { like all right, let's just take some } \\
\text { small steps and maybe when they } \\
\text { get to a little bit older age they } \\
\text { will remember, well, fossil fuels } \\
\text { are bad, and they are there other } \\
\text { things that I can support with my } \\
\text { money like I can get solar panels, } \\
\text { or things like that, you know? - } \\
\text { Krista Czapkas }\end{array}$ \\
\hline $\begin{array}{l}\text { Activ-Future } \\
\text { Action }\end{array}$ & 16 & 10 & Teach for future action & $\begin{array}{l}\text { What are some of your main } \\
\text { goals that you want students to } \\
\text { learn about climate change? } \\
\text { KARMEN: How they are } \\
\text { involved with it. Things that they } \\
\text { could at least try to do just within } \\
\text { their household, try to recycle a } \\
\text { little more, try to stop using so } \\
\text { much water. Being aware of the } \\
\text { food that they eat, so they like } \\
\text { seafood. Well, I teach a whole } \\
\text { thing about the oceans and the } \\
\text { animals that are dying off in the } \\
\text { ocean, and the nets that they use, } \\
\text { and things like that. Live catch, } \\
\text { and how does it affect your } \\
\text { eating. And genetically modified } \\
\text { organisms. Students have said to } \\
\text { me, "Well, I can't do that a lot }\end{array}$ \\
\hline
\end{tabular}




\begin{tabular}{|c|c|c|c|c|}
\hline & & & & $\begin{array}{l}\text { now because I don't buy my own } \\
\text { food. But when I start buying my } \\
\text { own food I'm gonna really think } \\
\text { about it." Right, and so that's } \\
\text { kind of the hope, that you're } \\
\text { giving them a platform of } \\
\text { knowledge so that they have a } \\
\text { better understanding of it. - } \\
\text { Karmen Losa }\end{array}$ \\
\hline Need & 101 & 15 & $\begin{array}{l}\text { Needs to better } \\
\text { promote, support, or } \\
\text { include climate change } \\
\text { in their instruction }\end{array}$ & \\
\hline $\begin{array}{l}\text { Need - } \\
\text { Complex }\end{array}$ & 12 & 8 & $\begin{array}{l}\text { Complex, complicated } \\
\text { and ever-changing nature } \\
\text { of CC }\end{array}$ & $\begin{array}{l}\text { When they look into the future, } \\
\text { they want an answer of when. } \\
\text { They want a set number, so that's } \\
\text { something that I've struggled } \\
\text { with, how to explain to them that } \\
\text { we don't know for sure and it } \\
\text { depends on what decisions we } \\
\text { make in the future. - Connie } \\
\text { Stevens }\end{array}$ \\
\hline Need - PD & 11 & 8 & $\begin{array}{l}\text { Need CC specific PD to } \\
\text { model effective } \\
\text { pedagogy }\end{array}$ & $\begin{array}{l}\text { I'm disappointed because I think } \\
\text { that until you have [professional } \\
\text { development], there's going to be } \\
\text { very limited instruction. I think } \\
\text { that that's needed. I'm a pretty } \\
\text { fearless teacher, but I saw those } \\
\text { teachers in [Climate Academy], } \\
\text { and I was just astonished that } \\
\text { they were shutting down so } \\
\text { quickly. It tells you the level of } \\
\text { your challenge. - Wanda Katz }\end{array}$ \\
\hline $\begin{array}{l}\text { Need - } \\
\text { Curriculum }\end{array}$ & 15 & 7 & $\begin{array}{l}\text { Need curriculum with } \\
\text { CC topics explicitly } \\
\text { included }\end{array}$ & $\begin{array}{l}\text { One of the best things we ever } \\
\text { did was adopt the NGSS, } \\
\text { because it makes it explicit. But, } \\
\text { it didn't fully weave } \\
\text { sustainability through life } \\
\text { science, and it certainly didn't do } \\
\text { much for chemistry. So, I don't } \\
\text { know. I don't know. It may be } \\
\text { that the NGSS becomes a thing } \\
\text { that helps us move forward. } \\
\text { Because, to teach that way really }\end{array}$ \\
\hline
\end{tabular}




\begin{tabular}{|c|c|c|c|c|}
\hline & & & & $\begin{array}{l}\text { does require inquiry, and that } \\
\text { means real world, and that } \\
\text { naturally goes to sustainability. } \\
\text { But, I don't know. - Mary } \\
\text { Jenkins }\end{array}$ \\
\hline Need - Time & 8 & 6 & $\begin{array}{l}\text { Need more time and } \\
\text { space in curriculum for } \\
\text { CC }\end{array}$ & $\begin{array}{l}\text { I think it's been mostly positive. } \\
\text { The kids tend to listen to what I } \\
\text { say, so I tend to go that route of } \\
\text { what we can do to help maybe } \\
\text { prevent the progression of } \\
\text { climate change. For the most } \\
\text { part, the only kind of push back } \\
\text { has really just been time, and just } \\
\text { fighting the battle of what I have } \\
\text { to teach and then climate change } \\
\text { has kind of not been one of the } \\
\text { things that I have to teach, and so } \\
\text { it kind of just gets put on the } \\
\text { back burner. That's basically } \\
\text { only been the real negative.- } \\
\text { Fiona Henry }\end{array}$ \\
\hline $\begin{array}{l}\text { Need - } \\
\text { Urgency }\end{array}$ & 22 & 8 & $\begin{array}{l}\text { Need more widespread } \\
\text { sense of } \\
\text { urgency/importance of } \\
\text { CC }\end{array}$ & $\begin{array}{l}\text { I think it's just that we are still } \\
\text { tied to the numbers on the test } \\
\text { until the right curriculum and } \\
\text { assessment and materials are } \\
\text { acquired, it's frustrating. You } \\
\text { have the verbal support of people } \\
\text { to do stuff, but you are on your } \\
\text { own when it comes to actually } \\
\text { implementing it due to materials } \\
\text { and resources. - Melissa Eckerds }\end{array}$ \\
\hline $\begin{array}{l}\text { Need - } \\
\text { Engagement }\end{array}$ & 2 & 2 & $\begin{array}{l}\text { Need parental } \\
\text { engagement - pros and } \\
\text { cons }\end{array}$ & $\begin{array}{l}\text { Also, kind of with my kids, my } \\
\text { clientele because - and this is a } \\
\text { blanket statement, but it } \\
\text { shouldn't be - but because my } \\
\text { kids are kind of the non-high } \\
\text { flyers, I don't hear a lot from } \\
\text { parents. I don't really ever get } \\
\text { that call of why are you teaching } \\
\text { climate change or why did you } \\
\text { talk about evolution? Because } \\
\text { they don't go home and tell their } \\
\text { parents or maybe their parents } \\
\text { just don't care. So, maybe that's } \\
\text { lucky too though that I don't } \\
\text { have uptight parents who don't } \\
\text { know about science. - Krista }\end{array}$ \\
\hline
\end{tabular}




\begin{tabular}{|c|c|c|c|c|}
\hline & & & & Czapkas \\
\hline Need - Interest & 13 & 8 & $\begin{array}{l}\text { Need to build authentic } \\
\text { interest in } C C\end{array}$ & $\begin{array}{l}\text { I would recommend spending a } \\
\text { lot of time on conversational talk } \\
\text { and discourse with the students } \\
\text { about what they think after } \\
\text { reading articles after looking at } \\
\text { videos after playing with } \\
\text { evidence and doing experiments } \\
\text { what they're thinking - not just } \\
\text { telling them the content but } \\
\text { really having an open discussion. } \\
\text { And sometimes debates happen } \\
\text { like there will be students that } \\
\text { think about this way about this } \\
\text { and that way about it and really } \\
\text { encouraging those appropriate } \\
\text { debates in the class. And making } \\
\text { the students feel like they are } \\
\text { owning what they're learning } \\
\text { and that they have a say in what } \\
\text { they are learning and that they } \\
\text { are driving that I would think } \\
\text { that that's really important } \\
\text { because you want them to get } \\
\text { excited about what they're doing } \\
\text { here with climate and especially } \\
\text { if you're doing a project by the } \\
\text { end then they are going to be } \\
\text { presenting or coming up with a } \\
\text { problem and solution and that's } \\
\text { pretty important. - Tara Thorpe }\end{array}$ \\
\hline Need - CK & 16 & 11 & $\begin{array}{l}\text { Need to deepen CC } \\
\text { content knowledge }\end{array}$ & $\begin{array}{l}\text { You can think of a colleague, a } \\
\text { past or former colleague, and } \\
\text { think, "Do they have the } \\
\text { knowledge?" I guess that's a } \\
\text { good first question. Do you feel } \\
\text { that your colleagues have the } \\
\text { knowledge that you have now on } \\
\text { even being able to teach climate } \\
\text { change? Or is that something that } \\
\text { they would need to do first? } \\
\text { EMILY: I think, for } \\
\text { anybody, they're going to need to } \\
\text { sit down and be able to } \\
\text { understand the science. Even if } \\
\text { it's not every little gory detail, } \\
\text { they still need to be able to know }\end{array}$ \\
\hline
\end{tabular}




\begin{tabular}{|c|c|c|c|c|}
\hline & & & & $\begin{array}{l}\text { the basics. The difference } \\
\text { between land ice and sea ice and, } \\
\text { which one's contributing to rising } \\
\text { sea levels. There, again, kids } \\
\text { coming in and saying, "Oh wait a } \\
\text { minute, land ice versus sea ice. } \\
\text { And the sea ice it will melt and } \\
\text { let it melt, it's going to make the } \\
\text { water rise." No. Again, } \\
\text { understanding the basics, I think, } \\
\text { is really important. - Emily } \\
\text { Skand }\end{array}$ \\
\hline $\begin{array}{l}\text { Need - } \\
\text { Integrate }\end{array}$ & 2 & 2 & $\begin{array}{l}\text { Need to slowly } \\
\text { infuse/integrate CC over } \\
\text { time }\end{array}$ & $\begin{array}{l}\text { I'd tell them to start slow and do } \\
\text { baby steps. Yeah, because if they } \\
\text { try to do too many, too high } \\
\text { level, because it is high level } \\
\text { thinking and information, you } \\
\text { know? But if you go that route, } \\
\text { students are gonna be lost right } \\
\text { away. And unfortunately, most } \\
\text { of the level of student in our } \\
\text { school, they're just, you know, } \\
\text { they're just not there. So that's } \\
\text { why I try to do the baby steps } \\
\text { and get them started, and then try } \\
\text { and pull some of the more } \\
\text { higher-level thinking, like the } \\
\text { chemistry of it, how does one } \\
\text { thing come apart, and then it } \\
\text { becomes something else, you } \\
\text { know? So those kinds of things, I } \\
\text { would recommend that, and pick } \\
\text { a couple topics to maybe follow } \\
\text { through and become more in- } \\
\text { depth with. - Karmen Losa }\end{array}$ \\
\hline Geo & 48 & 14 & $\begin{array}{l}\text { Local geographic } \\
\text { connections to CC }\end{array}$ & \\
\hline $\begin{array}{l}\text { Geo - } \\
\text { Community }\end{array}$ & 26 & 11 & $\begin{array}{l}\text { Identify how CC affects } \\
\text { local area and } \\
\text { community }\end{array}$ & $\begin{array}{l}\text { Do you think it's, when you're } \\
\text { saying educate yourself, is it } \\
\text { mostly on the content } \\
\text { knowledge, like increasing your } \\
\text { own content knowledge about } \\
\text { climate change or things like } \\
\text { how to address it because some } \\
\text { people view it as like a } \\
\text { controversial topic? }\end{array}$ \\
\hline
\end{tabular}




\begin{tabular}{|c|c|c|c|c|}
\hline & & & & $\begin{array}{l}\text { MELISSA: I guess all } \\
\text { encompassing, be educated about } \\
\text { what is going on in your } \\
\text { community. Is it affecting your } \\
\text { local community? Is it affecting } \\
\text { your life? Be ready to answer } \\
\text { questions. Be ready to make your } \\
\text { own connections, like if you } \\
\text { have stories that you can make } \\
\text { up or you can include that } \\
\text { connect what you currently do } \\
\text { with what you're teaching, then } \\
\text { that's a good thing. Know current } \\
\text { laws out there that, not like a } \\
\text { lawyer, but the general idea of } \\
\text { where our United States } \\
\text { legislature is headed in terms of } \\
\text { environmental legislation and } \\
\text { law. Be aware of your } \\
\text { community resources. - Melissa } \\
\text { Eckerds }\end{array}$ \\
\hline $\begin{array}{l}\text { Geo - } \\
\text { Personally }\end{array}$ & 22 & 13 & $\begin{array}{l}\text { Identify how CC affects } \\
\text { you personally }\end{array}$ & $\begin{array}{l}\text { I also wanted them to understand } \\
\text { how they themselves would be } \\
\text { impacted locally. Most of the } \\
\text { kids that attend my school live in } \\
\text { [coastal midAtlantic] County, } \\
\text { which has a lot of shore line. A } \\
\text { lot of my students go home on } \\
\text { the weekends and then go } \\
\text { boating or some of them even } \\
\text { have waterfront property. } \\
\text { They're going to see this happen } \\
\text { if they haven't already started } \\
\text { seeing changes. For them, again, } \\
\text { I wanted to show them how they } \\
\text { would be impacted locally. - } \\
\text { Emily Skand }\end{array}$ \\
\hline Curr_Conn & 95 & 15 & $\begin{array}{l}\text { Curricular connections } \\
\text { to } \mathrm{CC}\end{array}$ & \\
\hline $\begin{array}{l}\text { Curr_Conn - } \\
\text { Add }\end{array}$ & 8 & 6 & $\begin{array}{l}\text { Able to add a CC unit to } \\
\text { curriculum }\end{array}$ & $\begin{array}{l}\text { It fits quite well because climate } \\
\text { change is part of our human } \\
\text { interactions with the earth unit. - } \\
\text { Beverley Sanders }\end{array}$ \\
\hline $\begin{array}{l}\text { Curr_Conn - } \\
\text { Direct }\end{array}$ & 15 & 10 & $\begin{array}{l}\text { Highlight direct personal } \\
\text { impacts from CC }\end{array}$ & $\begin{array}{l}\text { So, I try to bring those kinds of } \\
\text { things out there, so they can } \\
\text { make the connection from what }\end{array}$ \\
\hline
\end{tabular}




\begin{tabular}{|c|c|c|c|c|}
\hline & & & & $\begin{array}{l}\text { they are learning to the real } \\
\text { world. Because they are middle } \\
\text { school and that all seems really } \\
\text { far away, even when it is not. So, } \\
\text { I try to bring in those things and } \\
\text { show little video clips. - } \\
\text { Veronica Acker }\end{array}$ \\
\hline $\begin{array}{l}\text { Curr_Conn - } \\
\text { Infuse }\end{array}$ & 50 & 14 & $\begin{array}{l}\text { Infuse CC concepts } \\
\text { throughout the } \\
\text { curriculum }\end{array}$ & $\begin{array}{l}\text { And, again, I think the topic also } \\
\text { lends itself to every discipline } \\
\text { and science because it deals with } \\
\text { so much, there's something for } \\
\text { everyone when it comes to } \\
\text { climate change here. There's } \\
\text { chemistry involved, there's } \\
\text { physics involved, there's } \\
\text { meteorology involved, you can } \\
\text { really infuse it wherever you } \\
\text { want to. - Emily Skand }\end{array}$ \\
\hline $\begin{array}{l}\text { Curr_Conn - } \\
\text { Missed }\end{array}$ & 11 & 7 & $\begin{array}{l}\text { Missed opportunities to } \\
\text { include CC }\end{array}$ & $\begin{array}{l}\text { Well, like one engineering } \\
\text { teacher was doing something } \\
\text { with igloos. Making igloos. And } \\
\text { I didn't have a chance to really } \\
\text { check out everything she did } \\
\text { with her lesson because she sent } \\
\text { me a copy of it, and we talked } \\
\text { about it. And I do believe that } \\
\text { she was trying to say something } \\
\text { about how the ice is melting and } \\
\text { the cultures are changing. } \\
\text { Something I don't remember. But } \\
\text { I remember saying, "Wow, that's } \\
\text { a great lesson for climate } \\
\text { change." And I think she was } \\
\text { kind of was like, "Oh, I didn't } \\
\text { even think of it in that respect." } \\
\text { So, she's looking at the } \\
\text { engineering aspect of developing } \\
\text { and building an igloo. - Karmen } \\
\text { Losa }\end{array}$ \\
\hline $\begin{array}{l}\text { Curr_Conn - } \\
\text { NGSS }\end{array}$ & 4 & 4 & Presence of CC in NGSS & $\begin{array}{l}\text { Sustainability has now become } \\
\text { the theme under which our } \\
\text { textbook, which is NGSS } \\
\text { aligned, it has put all of the } \\
\text { topics under sustainability. So, } \\
\text { it's a much more natural segue } \\
\text { for me. -Mary Jenkins }\end{array}$ \\
\hline & & & & \\
\hline
\end{tabular}




\begin{tabular}{|c|c|c|c|c|}
\hline $\begin{array}{l}\text { Curr_Conn - } \\
\text { Slowly }\end{array}$ & 7 & 5 & $\begin{array}{l}\text { Slowly increase } \mathrm{CC} \\
\text { instruction/connections } \\
\text { over time }\end{array}$ & $\begin{array}{l}\text { I think I would [recommend to] } \\
\text { start small and choose lessons } \\
\text { that make sense to you, and then } \\
\text { add to it over time so that as you } \\
\text { have a better understanding over } \\
\text { time, you can bring more of that } \\
\text { to the classroom. And don't give } \\
\text { up. If it seems complicated, just } \\
\text { like you tell your students, if it } \\
\text { seems complicated, you still } \\
\text { need to stick with it and figure it } \\
\text { out. - Wanda Katz }\end{array}$ \\
\hline Confid & 35 & 12 & Confidence to teach CC & \\
\hline $\begin{array}{l}\text { Confid - } \\
\text { Support }\end{array}$ & 4 & 3 & $\begin{array}{l}\text { Confident because of } \\
\text { social support of other } \\
\text { CC educators }\end{array}$ & $\begin{array}{l}\text { but maybe other science teachers } \\
\text { in your county or in your area, or } \\
\text { do you feel like you're one of the } \\
\text { few people working to teach this } \\
\text { topic? } \\
\text { BEVERLEY: At least in my } \\
\text { county, I feel like it's the norm. } \\
\text { In my county because we all } \\
\text { know it's part of that curriculum, } \\
\text { and when we offered that } \\
\text { workshop during the curriculum } \\
\text { day in February, we had tons of } \\
\text { people. Pretty much everybody } \\
\text { in the county that taught that } \\
\text { course was there. And they were } \\
\text { like, "Share with me. What do } \\
\text { you got?" So, I feel like it's } \\
\text { probably the norm, but I think } \\
\text { that there are also a couple of us } \\
\text { in the county that have a lot more } \\
\text { of a knowledge base that did } \\
\text { some other things on their own } \\
\text { or at least could ad lib better, } \\
\text { maybe both. I was wondering } \\
\text { that, I'm like, "Yeah, I can't ad } \\
\text { lib much on this, so here's a } \\
\text { script I get." - Beverley Sanders }\end{array}$ \\
\hline Confid - PD & 8 & 6 & $\begin{array}{l}\text { Confident because of } \\
\text { participation in PD }\end{array}$ & $\begin{array}{l}\text { I think this past year it was really } \\
\text { beneficial and helped me grow as } \\
\text { a teacher because I was } \\
\text { comfortable with teaching it. } \\
\text { Honestly, I don't know if I was } \\
\text { another teacher in a different }\end{array}$ \\
\hline
\end{tabular}




\begin{tabular}{|c|c|c|c|c|}
\hline & & & & $\begin{array}{l}\text { school having to teach climate } \\
\text { change without going through } \\
\text { the training, I don't know that I } \\
\text { would be that comfortable. - } \\
\text { Veronica Acker }\end{array}$ \\
\hline Confid - Data & 3 & 3 & $\begin{array}{l}\text { Confident to teach } \\
\text { because of strength of } \\
\text { CC data and evidence }\end{array}$ & $\begin{array}{l}\text { I think the things that have } \\
\text { helped me feel prepared is } \\
\text { having access to reliable data. } \\
\text { When I can point to specific data } \\
\text { about CO2 levels in the oceans } \\
\text { and in the atmosphere, then I feel } \\
\text { that what I'm telling my students, } \\
\text { the information that I'm } \\
\text { presenting to my students and the } \\
\text { conclusions that they are able to } \\
\text { draw on their own is based in } \\
\text { fact, and I think that's very } \\
\text { important. I think that's helped } \\
\text { me feel prepared to discuss the } \\
\text { topic with my students. - Connie } \\
\text { Stevens }\end{array}$ \\
\hline $\begin{array}{l}\text { Confid - } \\
\text { General }\end{array}$ & 20 & 11 & $\begin{array}{l}\text { Having confidence in } \\
\text { general to teach } \mathrm{CC}\end{array}$ & $\begin{array}{l}\text { The more I am exposed to the } \\
\text { science behind climate change, } \\
\text { the more confident I become in } \\
\text { teaching it or discussing it with } \\
\text { my peers as well as my students. } \\
\text { If it takes me more than one time } \\
\text { learning or hearing the content } \\
\text { and information, that reinforces } \\
\text { how I teach it as well. - Karmen } \\
\text { Losa }\end{array}$ \\
\hline Support & 112 & 15 & $\begin{array}{l}\text { Supports in place, or } \\
\text { desired, to teach CC }\end{array}$ & \\
\hline Support - Self & 3 & 2 & $\begin{array}{l}\text { Personally motivated } \\
\text { (self-support) }\end{array}$ & $\begin{array}{l}\text { Have you received any positive } \\
\text { recognition for including climate } \\
\text { change in your teaching? } \\
\text { KRISTA: I don't think so, } \\
\text { no. I mean I always pat myself } \\
\text { on the back of afterwards } \\
\text { (laughs) - Krista Czapkas }\end{array}$ \\
\hline $\begin{array}{l}\text { Support - } \\
\text { Parents }\end{array}$ & 2 & 2 & $\begin{array}{l}\text { Positive recognition } \\
\text { from parents in support } \\
\text { of teaching } \mathrm{CC}\end{array}$ & $\begin{array}{l}\text { No surprisingly and even back in } \\
\text { [former school] I didn't, and I } \\
\text { took that to be because I was in a } \\
\text { smaller school and was with very } \\
\text { supportive parents and staff in a }\end{array}$ \\
\hline
\end{tabular}




\begin{tabular}{|c|c|c|c|c|}
\hline & & & & $\begin{array}{l}\text { smaller community - it was } \\
\text { great. - Tara Thorpe }\end{array}$ \\
\hline $\begin{array}{l}\text { Support - } \\
\text { NGSS }\end{array}$ & 3 & 3 & $\begin{array}{l}\text { Perceived/Overt support } \\
\text { for teaching CC because } \\
\text { of its inclusion in the } \\
\text { NGSS }\end{array}$ & $\begin{array}{l}\text { But I have been encouraged this } \\
\text { past year, because climate } \\
\text { change is now becoming a part } \\
\text { of NGSS and it's starting to get } \\
\text { attention and part of that whole } \\
\text { NGSS with that engineering } \\
\text { piece in there. - Garrett Tresler }\end{array}$ \\
\hline $\begin{array}{l}\text { Support - } \\
\text { Admin }\end{array}$ & 12 & 9 & $\begin{array}{l}\text { Support from } \\
\text { administrators - } \\
\text { principals, science } \\
\text { supervisors, etc. - for } \\
\text { CC instruction }\end{array}$ & $\begin{array}{l}\text { Overall, in general, I think seven } \\
\text { or eight years ago, in the } \\
\text { community where I taught, there } \\
\text { was a lot of pushback. And we } \\
\text { were lucky that the } \\
\text { administration and the school } \\
\text { board were very science- } \\
\text { oriented, and they didn't sweep it } \\
\text { under the rug and they would } \\
\text { support you. I've seen that } \\
\text { change, I used to tell the kids, } \\
\text { God and science are not mutually } \\
\text { exclusive and it's not a belief, it's } \\
\text { not something you feel in your } \\
\text { heart, although it could. But it's } \\
\text { something that you recognize is } \\
\text { actual in your head. - Barbara } \\
\text { Pender }\end{array}$ \\
\hline $\begin{array}{l}\text { Support - } \\
\text { Colleagues }\end{array}$ & 12 & 7 & $\begin{array}{l}\text { Support from colleagues } \\
\text { or co-teachers in same } \\
\text { school for CC education } \\
\text { efforts }\end{array}$ & $\begin{array}{l}\text { And even this year as I bring that } \\
\text { personal experience in, there are } \\
\text { a few I think the fourth-grade } \\
\text { unit in the district requires } \\
\text { environmental ecosystems and } \\
\text { habitats topics and they were } \\
\text { asking me to go in and share } \\
\text { about my experiences up there. } \\
\text { So, reaching out to the school } \\
\text { community and kind of } \\
\text { extending on that and bring that } \\
\text { back in has been really awesome. } \\
\text { - Tara Thorpe }\end{array}$ \\
\hline $\begin{array}{l}\text { Support - CC } \\
\text { Educators }\end{array}$ & 8 & 5 & $\begin{array}{l}\text { Support from the } \\
\text { community of other CC } \\
\text { educators, typically } \\
\text { outside of one own's } \\
\text { school }\end{array}$ & $\begin{array}{l}\text { Ultimately, we know the } \\
\text { information but just help with } \\
\text { piecing it together to help make } \\
\text { it make sense and I don't know if } \\
\text { I would be in the same place } \\
\text { with being ready. Like that first } \\
\text { year of [Climate Academy], just }\end{array}$ \\
\hline
\end{tabular}




\begin{tabular}{|c|c|c|c|c|}
\hline & & & & $\begin{array}{l}\text { knowing there were so many } \\
\text { teachers in the same boat and we } \\
\text { were all trying to figure out what } \\
\text { to do with all this information. } \\
\text { And we all understood it to a } \\
\text { certain degree, with some people } \\
\text { knowing the science a bit better } \\
\text { on the chemistry side or the } \\
\text { biology side, but I think just } \\
\text { allowing myself to be okay with } \\
\text { not knowing and just figuring it } \\
\text { out and just growing along the } \\
\text { way, I think that that has been } \\
\text { really beneficial. - Veronica } \\
\text { Acker }\end{array}$ \\
\hline Support - PD & 53 & 15 & $\begin{array}{l}\text { Specific support received } \\
\text { via professional } \\
\text { development } \\
\text { workshops/courses to } \\
\text { teach/improve } \\
\text { instruction related to CC }\end{array}$ & $\begin{array}{l}\text { I've very thankful for programs } \\
\text { like the Climate Academy that } \\
\text { have helped teachers like me } \\
\text { who often feel overwhelmed } \\
\text { with the task of teaching these } \\
\text { enormous concepts while also } \\
\text { feeling overwhelmed with just } \\
\text { teaching, in general. This } \\
\text { program helped at least alleviate } \\
\text { the stress of content and science } \\
\text { pedagogy allowing me to focus } \\
\text { on students and teaching. For } \\
\text { that I'm truly grateful. - Garrett } \\
\text { Tresler }\end{array}$ \\
\hline Evid & 47 & 13 & $\begin{array}{l}\text { Utilizing an evidence or } \\
\text { data focused approach } \\
\text { to teaching CC }\end{array}$ & \\
\hline $\begin{array}{l}\text { Evid - Critical } \\
\text { Thinking }\end{array}$ & 4 & 3 & $\begin{array}{l}\text { Focus on building } \\
\text { critical thinking skills in } \\
\text { students }\end{array}$ & $\begin{array}{l}\text { It's kind of just being open- } \\
\text { minded and being willing to } \\
\text { change your opinion and not just } \\
\text { taking social media verbatim but } \\
\text { really thinking about it so like if } \\
\text { you see something on social } \\
\text { media and it says something } \\
\text { about it, don't just share it right } \\
\text { away, actually open it up and } \\
\text { read it and where do they get the } \\
\text { information from, what's in their } \\
\text { reference page. - Tara Thorpe }\end{array}$ \\
\hline Evid - Data & 43 & 13 & $\begin{array}{l}\text { Educative power of } \\
\text { evidence and data for }\end{array}$ & $\begin{array}{l}\text { And I have seen attitudes shift } \\
\text { with the kids, year after year. We }\end{array}$ \\
\hline
\end{tabular}




\begin{tabular}{|c|c|c|c|c|}
\hline & & & teaching $\mathrm{CC}$ & $\begin{array}{l}\text { don't just *believe* in climate } \\
\text { change, we understand the data } \\
\text { and there's less of a pushback. - } \\
\text { Barbara Pender }\end{array}$ \\
\hline Poli & 107 & 15 & $\begin{array}{l}\text { Political landscape and } \\
\text { its influences on CC } \\
\text { education efforts }\end{array}$ & \\
\hline Poli - Avoid & 8 & 7 & $\begin{array}{l}\text { Avoid all discussion of } \\
\text { politics }\end{array}$ & $\begin{array}{l}\text { You can't say it's not true if you } \\
\text { have an actual data source. That's } \\
\text { fine, and nobody has really been } \\
\text { argumentative. You know, } \\
\text { nobody's really cared. People } \\
\text { have come in and mumbled and } \\
\text { been like "Grumble, grumble, } \\
\text { blah, blah, blah, Trump didn't } \\
\text { sign the such and such." You } \\
\text { know, and I was like "Well, it is } \\
\text { what it is, but-" ... Because the } \\
\text { administration told us that they } \\
\text { don't want us talking about } \\
\text { politics in class. I tell my } \\
\text { students I understand, however, } \\
\text { they asked us not to talk about } \\
\text { politics in class, so regardless of } \\
\text { what your belief is, please don't, } \\
\text { because you don't know what } \\
\text { everybody else believes, you } \\
\text { might be making someone else } \\
\text { uncomfortable. We just don't talk } \\
\text { about that, you know what I } \\
\text { mean? - Amanda Kerry }\end{array}$ \\
\hline Poli - Evaluate & 13 & 8 & $\begin{array}{l}\text { Encourage students to } \\
\text { evaluate and decide for } \\
\text { themselves }\end{array}$ & $\begin{array}{l}\text { Either way I just want them to be } \\
\text { able to be fearless about thinking } \\
\text { differently than their parents. } \\
\text { And they even said that to me, I } \\
\text { asked them near the end of the } \\
\text { year I said, is climate change } \\
\text { something that your generation is } \\
\text { going to need to be creative with, } \\
\text { to tackle, and to try and change? } \\
\text { And every kid in both of my } \\
\text { classes, except for one who was } \\
\text { kind of bump on a log anyway } \\
\text { and didn't do anything and failed } \\
\text { for the year, but every kid was } \\
\text { yeah, we need to do something. }\end{array}$ \\
\hline
\end{tabular}




\begin{tabular}{|c|c|c|c|c|}
\hline & & & & $\begin{array}{l}\text { And one kid said, it's hard } \\
\text { though because a lot of us come } \\
\text { from somewhere where they } \\
\text { don't believe in climate change } \\
\text { and our parents don't believe in } \\
\text { that. But, that's all right, you } \\
\text { guys are younger, and you are } \\
\text { learning new stuff and they } \\
\text { didn't learn about this probably } \\
\text { back when they were in high } \\
\text { school. So, just kind of I want } \\
\text { them to be able to break those } \\
\text { boundaries. - Krista Czapkas }\end{array}$ \\
\hline Poli-General & 34 & 9 & $\begin{array}{l}\text { Influence of general } \\
\text { political landscape }\end{array}$ & $\begin{array}{l}\text { I will say probably one of the } \\
\text { biggest driving factors this year } \\
\text { was the current political climate. } \\
\text { The resources that were available } \\
\text { online through the } \\
\text { Environmental Protection } \\
\text { Agency started disappearing } \\
\text { when I was in the middle of my } \\
\text { unit. And while that was slightly } \\
\text { an inconvenient, to say the least, } \\
\text { it also did provide conversation } \\
\text { and also the concept that here we } \\
\text { are learning about science as a } \\
\text { process, but it can't be taken in a } \\
\text { vacuum. Because if you look at } \\
\text { the history of science, so many } \\
\text { scientists and so many new ideas } \\
\text { were suppressed and were } \\
\text { counter to what the people in } \\
\text { power wanted you to think. It } \\
\text { was a challenge to what people } \\
\text { believed. And so, this year for } \\
\text { me, and I have to say and } \\
\text { speaking to my other fellow } \\
\text { faculty members who do teach } \\
\text { science, that was a huge } \\
\text { motivating factor because we } \\
\text { really felt like that information } \\
\text { was going to disappear and that } \\
\text { we needed to address it because } \\
\text { the kids, especially in their } \\
\text { position of being the next } \\
\text { generation coming up and having } \\
\text { to deal with what we choose to }\end{array}$ \\
\hline
\end{tabular}




\begin{tabular}{|c|c|c|c|c|}
\hline & & & & $\begin{array}{l}\text { or choose not to deal with, } \\
\text { they're the next ones to do it. So } \\
\text { that was a huge influence in how } \\
\text { much depth I chose to get into it } \\
\text { this year and, yes, that was a } \\
\text { huge influence. - Emily Skand }\end{array}$ \\
\hline Poli-Limited & 11 & 7 & $\begin{array}{l}\text { Experience of limited } \\
\text { pushback from others for } \\
\text { teaching CC }\end{array}$ & $\begin{array}{l}\text { The kids, I think bought in a lot } \\
\text { more. I only actually really had } \\
\text { one kid give me pushback and } \\
\text { he's a kid who doesn't do any } \\
\text { work in school and didn't even } \\
\text { pass the class, so yeah. I think } \\
\text { my approach changed a lot } \\
\text { between year one and year two. } \\
\text { That's because literally, year one, } \\
\text { kids would try and get under my } \\
\text { skin and just say silly things like, } \\
\text { "Well it snowed this year, so the } \\
\text { climate can't be changing." I'm } \\
\text { like, "That argument is so } \\
\text { annoying to me.". I've kind of } \\
\text { seen both experiences with } \\
\text { teaching it. - Krista Czapkas }\end{array}$ \\
\hline $\begin{array}{l}\text { Poli-No } \\
\text { pushback }\end{array}$ & 17 & 10 & $\begin{array}{l}\text { Experience of no } \\
\text { pushback from others for } \\
\text { teaching CC }\end{array}$ & $\begin{array}{l}\text { I think it went really well. I was } \\
\text { totally expecting a lot of } \\
\text { resistance, especially in the } \\
\text { community I live in. Strongly } \\
\text { Republican community, } \\
\text { somewhat anti-government, } \\
\text { even. So, I was expecting a lot of } \\
\text { resistance, and I did not } \\
\text { experience any. I had no parent } \\
\text { complaints, I had no student } \\
\text { arguments or complaints, and } \\
\text { they kind of just went with the } \\
\text { flow, they respected it as science, } \\
\text { and like I said, it really wasn't an } \\
\text { issue. It really went very } \\
\text { smoothly. - Beverley Sanders }\end{array}$ \\
\hline Poli-CC term & 6 & 2 & $\begin{array}{l}\text { Shy away from using the } \\
\text { term ' } \mathrm{CC} \text { ' }\end{array}$ & $\begin{array}{l}\text { But I think because I didn't say, } \\
\text { "We're having climate change } \\
\text { test today," I laid it out there, but } \\
\text { I didn't put a big brand name on } \\
\text { it and push it, you know what I } \\
\text { mean? - Barbara Pender }\end{array}$ \\
\hline $\begin{array}{l}\text { Poli - Students } \\
\text { Need }\end{array}$ & 12 & 7 & $\begin{array}{l}\text { Students need and want } \\
\text { to learn about CC due to }\end{array}$ & $\begin{array}{l}\text { I just really thought, again, in } \\
\text { light of the election, and in light }\end{array}$ \\
\hline
\end{tabular}




\begin{tabular}{|c|c|c|c|c|}
\hline & & & its current relevance & $\begin{array}{l}\text { of how visible the topic was } \\
\text { between that and also the Paris } \\
\text { Climate accord. The kids are } \\
\text { getting the news on their phone, } \\
\text { the kids are hearing their parents } \\
\text { talk about stuff, so I want them } \\
\text { to be able to be part of the } \\
\text { conversation, because who is } \\
\text { going to be affected? They are. - } \\
\text { Emily Skand }\end{array}$ \\
\hline $\begin{array}{l}\text { Poli - Diff } \\
\text { Location }\end{array}$ & 6 & 5 & $\begin{array}{l}\text { Would anticipate } \\
\text { pushback if in a different } \\
\text { location, but none } \\
\text { experienced in current } \\
\text { situation }\end{array}$ & $\begin{array}{l}\text { I'm sure if I was teaching in a } \\
\text { Trump land, I would. No, I have } \\
\text { not gotten any pushback at all } \\
\text { from that. That would be } \\
\text { political pushback, and that } \\
\text { would come from areas where } \\
\text { there's more people who seem to } \\
\text { buy into the hoax statement, I } \\
\text { guess. - Wanda Katz }\end{array}$ \\
\hline Role & 79 & 15 & $\begin{array}{l}\text { Perceptions of } \\
\text { Role/Responsibility } \\
\text { towards teaching CC }\end{array}$ & \\
\hline Role - Could & 4 & 1 & $\begin{array}{l}\text { Could have done more to } \\
\text { teach about } \mathrm{CC}\end{array}$ & $\begin{array}{l}\text { If I had really tried, I could've } \\
\text { gotten more in, you know what I } \\
\text { mean? I think that you can even } \\
\text { get it in, if you really wanted to. } \\
- \text { Amanda Kerry }\end{array}$ \\
\hline $\begin{array}{l}\text { Role - Don't } \\
\text { Engage }\end{array}$ & 1 & 1 & $\begin{array}{l}\text { Don't engage in the } \mathrm{CC} \\
\text { denial debate }\end{array}$ & $\begin{array}{l}\text { I don't take a stand. I don't argue } \\
\text { personally. I handle the class as } \\
\text { using scientific thinking. What is } \\
\text { the claim? What is the evidence? } \\
\text { What is the reasoning? It's that } \\
\text { simple. - Wanda Katz }\end{array}$ \\
\hline $\begin{array}{l}\text { Role - Protect } \\
\text { Environ }\end{array}$ & 7 & 7 & $\begin{array}{l}\text { Have a duty to protect } \\
\text { the environment }\end{array}$ & $\begin{array}{l}\text { It's a combination of a } \\
\text { stewardship mission that I think } \\
\text { is important for teachers when } \\
\text { they're working with students to } \\
\text { inculcate students in their } \\
\text { responsibilities as stewards of } \\
\text { the planet, and then having the } \\
\text { tools and the knowledge now } \\
\text { from my training to be able to } \\
\text { [teach climate change] } \\
\text { effectively. - Wanda Katz }\end{array}$ \\
\hline Role-Future & 15 & 8 & Need to educate and & My goals are to inform them of \\
\hline
\end{tabular}




\begin{tabular}{|c|c|c|c|c|}
\hline Citizens & & & $\begin{array}{l}\text { inform students because } \\
\text { they are future citizens }\end{array}$ & $\begin{array}{l}\text { these changes and give them } \\
\text { some tools that will help them } \\
\text { approach the issues calmly and } \\
\text { with purpose. - Karmen Losa }\end{array}$ \\
\hline $\begin{array}{l}\text { Role - Student } \\
\text { Interest }\end{array}$ & 11 & 6 & $\begin{array}{l}\text { Engage in conversations } \\
\text { related to CC around } \\
\text { students' interests }\end{array}$ & $\begin{array}{l}\text { But that was my main goal too - } \\
\text { I don't want to preach the kids I } \\
\text { don't want to share my own } \\
\text { personal opinions. I want to have } \\
\text { an open discussion about it and } \\
\text { have them draw their own } \\
\text { conclusions by the end. So that's } \\
\text { kind of how we've been } \\
\text { approaching it and that's maybe } \\
\text { why we've gotten the positive } \\
\text { feedback that we've gotten } \\
\text { because it's very much just a } \\
\text { discussion - Tara Thorpe }\end{array}$ \\
\hline $\begin{array}{l}\text { Role - Less } \\
\text { Action }\end{array}$ & 9 & 7 & $\begin{array}{l}\text { Focus on CC education, } \\
\text { less on CC action }\end{array}$ & $\begin{array}{l}\text { I guess I see myself more as the } \\
\text { teaching and educating part. But } \\
\text { in the hopes that it would lead to } \\
\text { inspiring action. I don't think I } \\
\text { ever want to be a teacher } \\
\text { twisting a kid's arm to make an } \\
\text { action. One of the things we } \\
\text { discussed in our group at school } \\
\text { was whether we wanted to have } \\
\text { them do a final project where } \\
\text { they wrote a letter to a political } \\
\text { person of some kind. I kind of } \\
\text { shy away from that a little bit, } \\
\text { just because I don't feel like } \\
\text { that's my job. I mean, some of } \\
\text { them are very, very intense about } \\
\text { the issues and they feel like they } \\
\text { need to call for action. I still feel } \\
\text { like they're still kids. I guess } \\
\text { having them write it is one thing, } \\
\text { having them send it is another, } \\
\text { too. I don't know. I guess I worry } \\
\text { about and I almost feel like that } \\
\text { is, and I know it's not because it's } \\
\text { science-based, but I feel like } \\
\text { that's almost asserting your } \\
\text { religion. You know what I } \\
\text { mean? It's little too pushy for me, } \\
\text { personally. - Beverley Sanders }\end{array}$ \\
\hline
\end{tabular}




\begin{tabular}{|c|c|c|c|c|}
\hline $\begin{array}{l}\text { Role - Only } \\
\text { One }\end{array}$ & 3 & 3 & $\begin{array}{l}\text { Feel like 'I'm the only } \\
\text { one' teaching CC }\end{array}$ & $\begin{array}{l}\text { They're not the norm. I'm } \\
\text { definitely one of the few. - Fred } \\
\text { Robbins }\end{array}$ \\
\hline Role - Fun & 3 & 1 & $\begin{array}{l}\text { Make learning about CC } \\
\text { fun and engaging }\end{array}$ & $\begin{array}{l}\text { We will definitely do it again } \\
\text { next year. I know I'm going to be } \\
\text { co-teaching with the same co- } \\
\text { teacher for at least one section, } \\
\text { and so we'll definitely do it again } \\
\text { next year. Because we prepped it } \\
\text { and it was fun, they enjoyed it, } \\
\text { the kids enjoyed it, and they } \\
\text { learned, and that's the whole } \\
\text { goal. If they learned the content, } \\
\text { and they had fun doing it and it } \\
\text { was fun, we're definitely doing it } \\
\text { again. If we could add some stuff } \\
\text { to make it more engaging and } \\
\text { more informational, all the } \\
\text { better. - Amanda Kerry }\end{array}$ \\
\hline Role - Model & 10 & 6 & $\begin{array}{l}\text { Model to students how to } \\
\text { act on CC }\end{array}$ & $\begin{array}{l}\text { You know what I think is the } \\
\text { most effective is the fact that I } \\
\text { was their favorite teacher, and } \\
\text { that it's important to me. And } \\
\text { that seemed to be the biggest } \\
\text { impact. You know, I had kids } \\
\text { like, "You're my hero." I'm like, } \\
\text { "What?" And they're like, "Yeah, } \\
\text { you go, and you fight for what } \\
\text { you believe." - Mary Jenkins }\end{array}$ \\
\hline $\begin{array}{l}\text { Role - Share } \\
\text { Passion }\end{array}$ & 10 & 7 & $\begin{array}{l}\text { Share my passion for the } \\
\text { environment }\end{array}$ & $\begin{array}{l}\text { I really like these experiences, I } \\
\text { mainly love just talking with kids } \\
\text { about it and sharing my passion } \\
\text { and I think that comes across a } \\
\text { lot when I teach it not that other } \\
\text { things I'm not passionate about } \\
\text { but when I see the students perk } \\
\text { up and ask questions that has } \\
\text { been really cool - Tara Thorpe }\end{array}$ \\
\hline $\begin{array}{l}\text { Role - Not } \\
\text { Required }\end{array}$ & 6 & 5 & $\begin{array}{l}\text { Teach CC even though it } \\
\text { is not a required part of } \\
\text { my curriculum }\end{array}$ & $\begin{array}{l}\text { I think where I struggled when } \\
\text { it's not in the curriculum, it's not } \\
\text { on the final exam, but it's } \\
\text { something I feel like that this is } \\
\text { something that kids should } \\
\text { know. It's a relevant topic in } \\
\text { science. It gives some excitement }\end{array}$ \\
\hline
\end{tabular}




\begin{tabular}{|l|l|l|l|}
\hline & & $\begin{array}{l}\text { and meaning to physics more } \\
\text { than just Newton's Laws and } \\
\text { forces, but it was a hard balance. } \\
\text { - Garrett Tresler }\end{array}$ \\
\hline
\end{tabular}




\section{Appendix E}

\section{CODE-WEAVING EXAMPLE}

Example of the personal elements theoretical code-weaving. From the descriptive codes presented above in Table 12 of Chapter 4, the two codes for “Display Oneself as a Science Person” (“Display”) and "Deep Personal Interest in Nature" ("DPI") both had been coded with the theoretical code category of personal and presented very similar accounts from teacher interviews. This grouping was labeled "Personal Interest in Environment" to identify similar occurrences from the various teacher narratives, shown in Figure 10 below. The original codes of "DPI" and "Display" are retained in this visual as a subscript outside of the box.

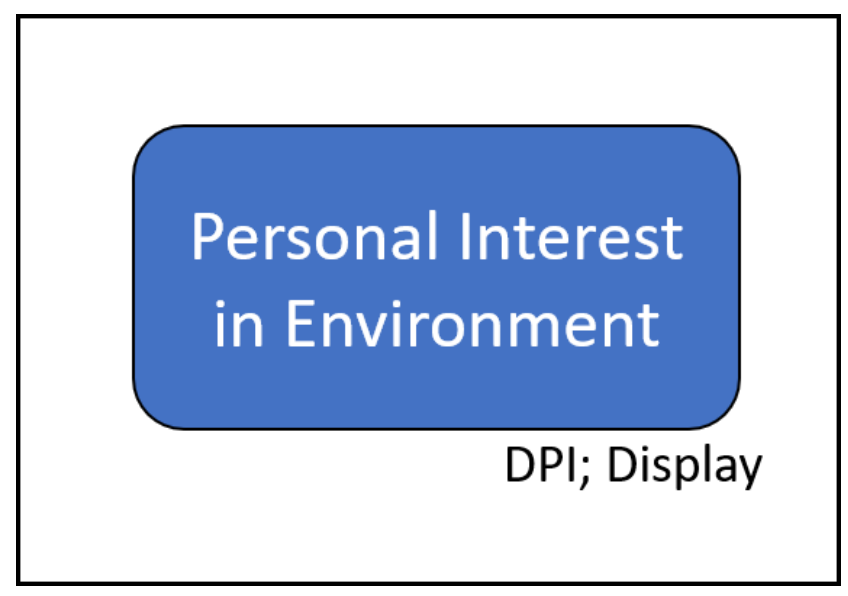

Figure 10 Initial Step of Code-Weaving 
This process was repeated with other descriptive codes with personal elements, such as the "Role for Teaching Climate Change" and were labeled "Responsibility to Teach Climate Change to Protect Environment" as seen on the right side of Figure 11. These two boxes were also situated temporally depending if the influences were predominantly retrospective or prospective. For example, the first box, "Personal Interest in Environment" was placed to sit between past and present time periods while "Responsibility to Teach Climate Change to Protect Environment" was situated to reflect the current and desired future goals, as seen in Figure 11. These two boxes were also connected via an arrow to demonstrate the likely relationship between having a personal interest in the environment and the outcome of holding a sense of responsibility to protect that environment to create a "thinking display" (Miles \& Huberman, 1994) as the first strand of the conceptual model as shown in Figure 11. 


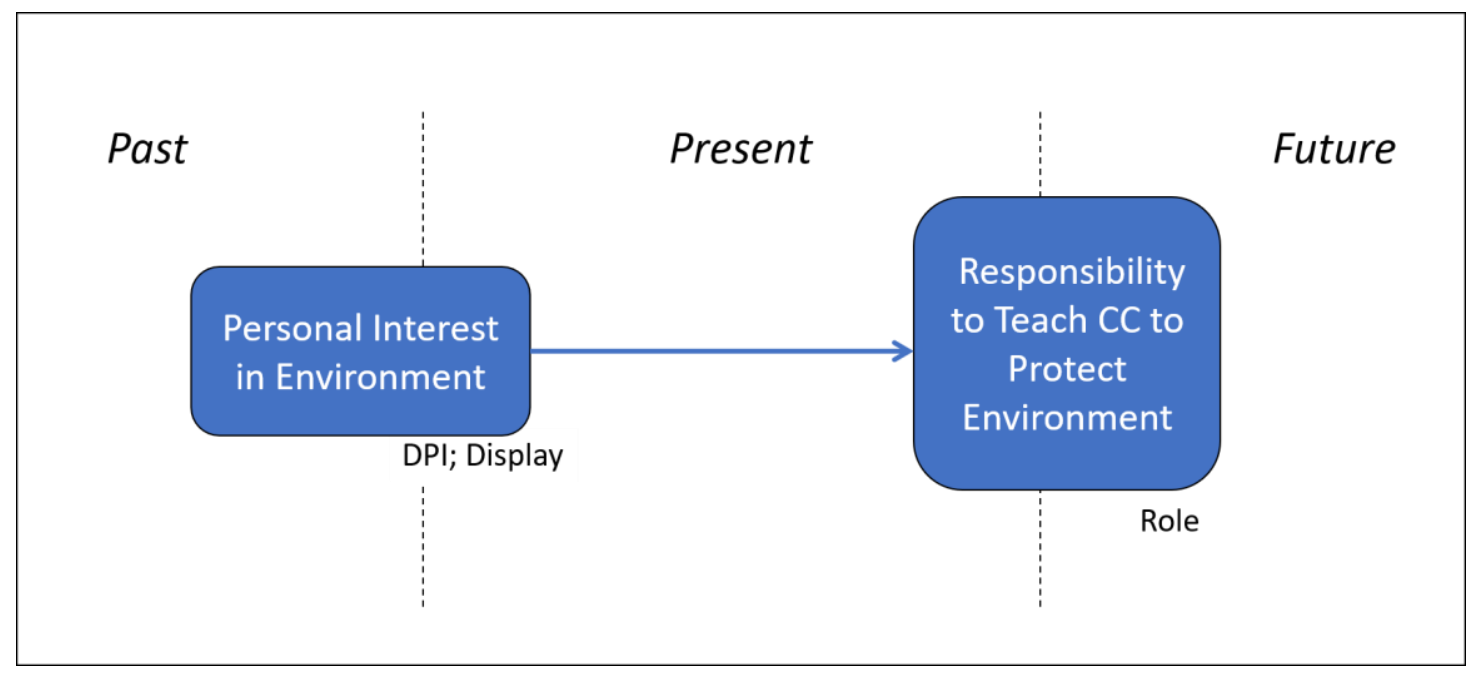

Figure 11 Final Step of Code-Weaving for Personal Elements

This process was repeated with all 18 codes to create three primary thinking displays related to the personal, professional, and political elements comprising the overall conceptual model, as shown in Figure 1 in Chapter 4. 